
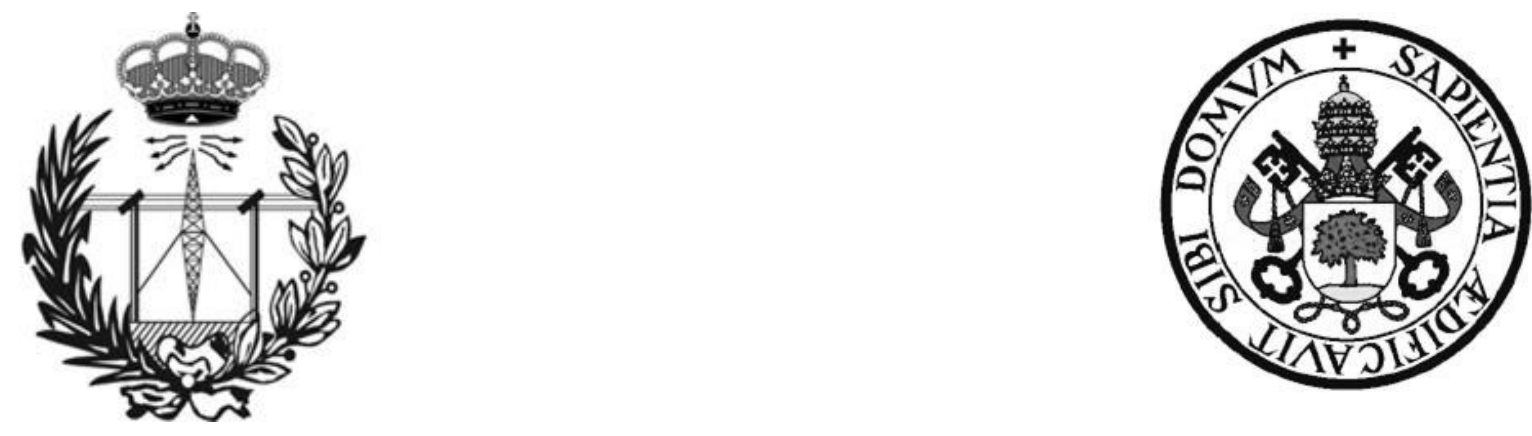

\author{
Universidad de Valladolid \\ Dpto. de Teoría de la Señal y Comunicaciones e \\ Ingeniería Telemática
}

Tesis Doctoral

\title{
Evaluación de la Influencia del \\ Cuerpo Humano en las Medidas de \\ Exposición a Radiaciones No Ionizantes en \\ Recintos Interiores
}

Silvia María de Miguel Bilbao

Enero de 2015

Director: Dr. Juan Blas Prieto

Codirectora: Dra. María Victoria Ramos González 





\section{Resumen}

Los dosímetros personales se emplean para medir los niveles de exposición a los campos electromagnéticos (CEM). Estos dispositivos introducen una perturbación debido a la presencia del cuerpo humano. Es posible modelar esta alteración de los niveles de exposición detectados en medidas experimentales mediante técnicas de simulación. Se propone la implementación de un modelo teórico que permita caracterizar y modelar este fenómeno en entornos interiores y en condiciones de movimiento. Se ha comprobado que la subestimación ocasionada por el efecto del cuerpo humano depende de las dimensiones del recinto.

Los resultados teóricos han sido verificados mediante la realización de varias campañas de medidas. Se han comparado los valores obtenidos y las funciones de distribución acumulada (FDA) de los resultados experimentales y teóricos, con el fin de aportar fiabilidad al modelo propuesto. Se ha comprobado el ajuste de las FDAs obtenidas con las funciones de distribución características de los niveles de exposición a radiaciones no ionizantes en recintos interiores.

Con el fin de compensar los efectos de este fenómeno, y eliminar la incertidumbre en los datos de exposición a los CEM proporcionados por los dosímetros personales, se ha discutido el uso de los factores de corrección como posible alternativa. 



\begin{abstract}
Personal dosimeters are used to measure the levels of exposure to electromagnetic fields (EMF). These devices introduce a perturbation due to the presence of the human body. It is possible to model this disturbance in exposure levels detected in experimental measurements using simulation techniques. It is proposed the implementation of a theoretical model to characterize and model this phenomenon in indoor environments and motion conditions. It has been checked that the underestimation caused by the effect of the human body depends on the dimensions of the enclosure.

The theoretical results have been verified by performing several campaigns of measurements. The obtained values and the cumulative distribution function $(\mathrm{CDF})$ of the experimental and theoretical results have been compared in order to provide reliability to the proposed model. It has been checked that the CDFs follow one of the most typical statistical distributions that model the level of exposure to non-ionizing radiation in indoor enclosures.

In order to make up for the effects of this phenomenon, and eliminate the uncertainty in the data of EMF exposure provided by personal dosimeters, it has been discussed about the use of correction factors as a possible alternative.
\end{abstract}





\section{Agradecimientos}

Este trabajo no habría sido posible sin la contribución de muchas personas que de forma directa e indirecta ofrecieron su apoyo.

De forma especial, agradezco la excelente labor de dirección realizada por parte de Dr. Juan Blas.

Agradezco enormemente a mi codirectora, Dra. Victoria Ramos, por la oportunidad de introducirme en esta área de conocimiento. Y también agradezco a toda la unidad de Telemedicina y e-Salud del instituto de Salud Carlos III por su ánimo, y en especial a Jorge García por su valiosa ayuda en la parte experimental de este trabajo.

Y por último, y no menos importante, gracias a mi familia por apoyarme. 

Índice

\section{Índice}

CAPITULO 1.......................................................................................................................1

INTRODUCCIÓN ........................................................................................1

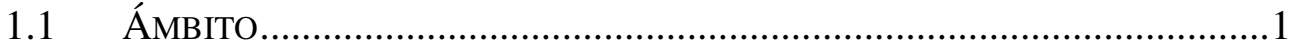

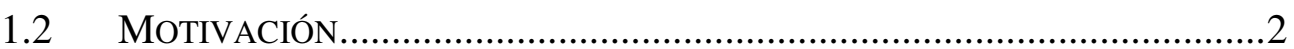

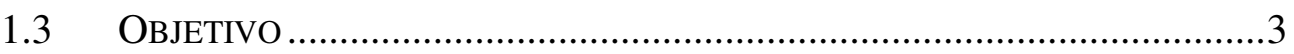

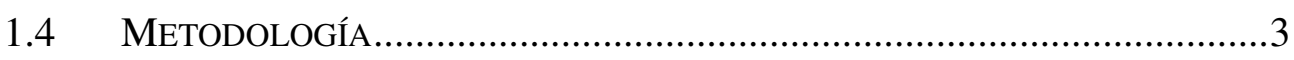

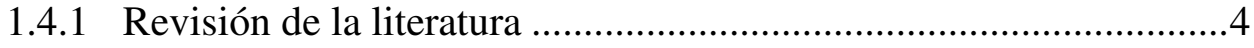

1.4.2 Implementación del modelo teórico......................................................

1.4.3 Diseño del protocolo experimental ................................................5

1.4.4 Implementación de las medidas experimentales .................................6

1.4.5 Tratamiento estadístico de los datos obtenidos .................................6

1.4.6 Estudio de la aplicabilidad de factores de corrección .........................7

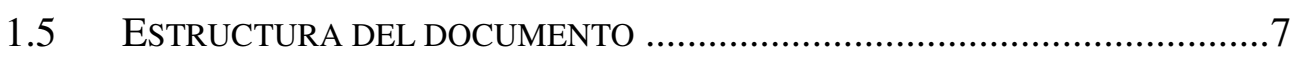

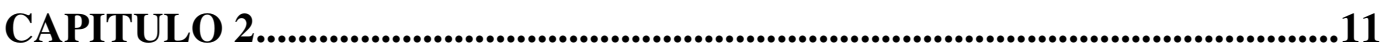

REVISIÓN DE LA INFLUENCIA DEL CUERPO HUMANO EN LAS MEDIDAS DOSIMÉTRICAS ........................................................................11

$2.1 \quad$ TIPOS DE MEDIDAS DOSIMÉTRICAS ...................................................11

2.2 FUENTES DE INCERTIDUMBRE EN LA MEDICIÓN DE LOS NIVELES DE

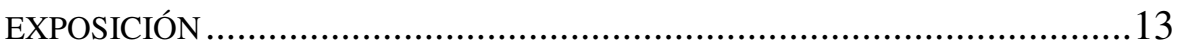

2.3 INFLUENCIA DEL CUERPO HUMANO EN LAS MEDIDAS DOSIMÉTRICAS ..14

2.3.1 Caracterización y cuantificación ......................................................16 
Índice

2.3.2 Escenarios de influencia del efecto sombra en recintos interiores 18

2.3.2.1 Cuerpo humano: obstáculo de radioenlaces inalámbricos.....20

2.3.2.2 Cuerpo humano: portador del dispositivo receptor .............. 21

2.3.2.3 Análisis estadístico mediante FDAs ...................................... 24

2.3.3 Necesidad de modelado del efecto sombra................................... 25

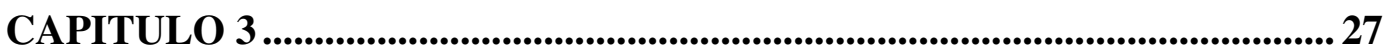

NORMATIVA DE PROTECCIÓN FRENTE A RADIACIONES NO

IONIZANTES ............................................................................................ 27

3.1 ESTÁNDARES INTERNACIONALES SOBRE EXPOSICIÓN A LOS CEM......27

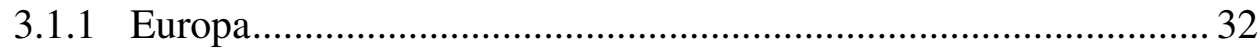

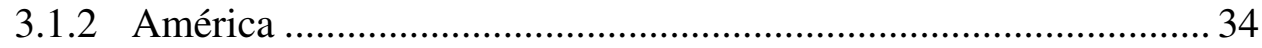

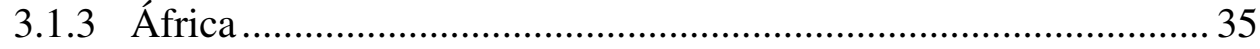

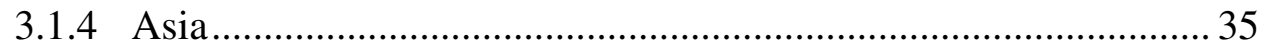

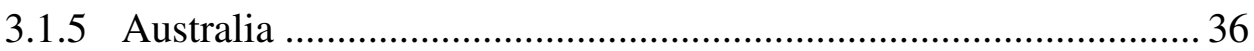

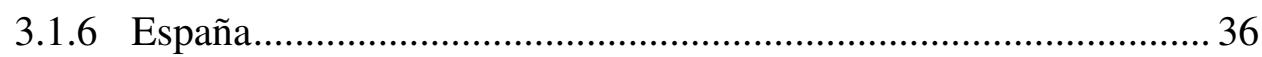

3.1.7 Normativa referente a la exposición de trabajadores..................... 36

3.2 ANÁLISIS DE LA EXPOSICIÓN A LAS REDES WI-FI................................ 39

3.2.1 Tipología de límites de exposición y sus características ............... 41

3.2.2 Exposición en ambientes sensibles.............................................. 42

3.2.3 Efectos biológicos .................................................................... 43

3.3 NORMATIVA SOBRE COMPATIBILIDAD ELECTROMAGNÉTICA ............... 44

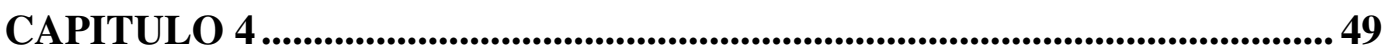

MODELOS DE PROPAGACIÓN DE SISTEMAS DE COMUNICACIONES

INALÁMBRICOS .................................................................................................... 49

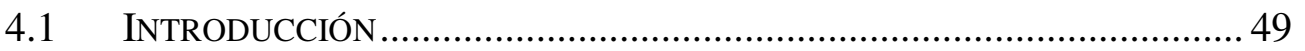


4.1.1 Propagación en entornos exteriores vs. interiores .........................50

4.2 TÉCNICAS DE CONSTRUCCIÓN DE MODELOS ......................................51

4.3 IMPORTANCIA DE LOS MODELOS DE PROPAGACIÓN .............................53

4.3.1 Modelos específicos, empíricos, y teóricos..................................54

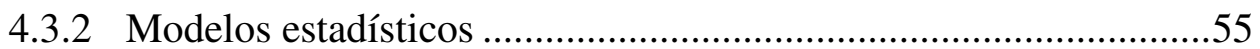

4.3.3 Retos de los modelos de propagación ...........................................55

4.4 MODELOS DE PÉRDIDAS DE TRAYECTORIAS ......................................57

4.4.1 Modelos empíricos y teóricos ……………..................................57

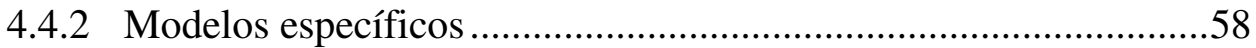

4.4.2.1 Modelos de trazado de rayos (ray tracing) .............................59

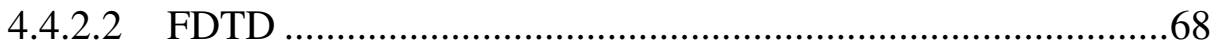

4.4.2.3 Método de los momentos ...................................................69

4.4.2.4 Modelos de redes neuronales artificiales ..............................70

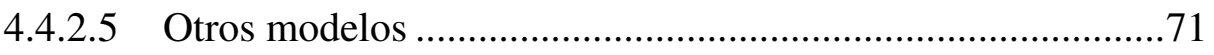

4.5 MODELOS DE DESVANECIMIENTO A PEQUEÑA ESCALA …......................73

4.5.1 Modelos estadísticos ..............................................................73

4.6 RESUMEN DE LOS MODELOS DE PÉRDIDAS DE PROPAGACIÓN................74

4.7 INTRODUCCIÓN DEL EFECTO SOMBRA EN LOS MODELOS DE

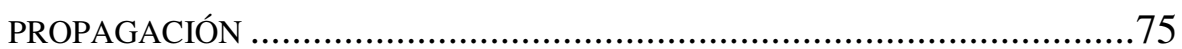

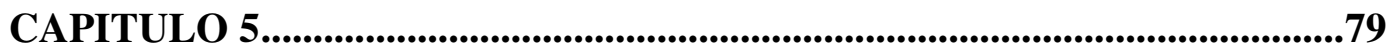

IMPLEMENTACIÓN DEL MÉTODO DE TRAZADO DE RAYOS EN

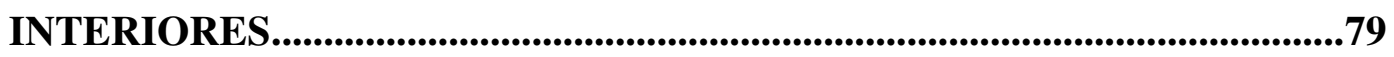

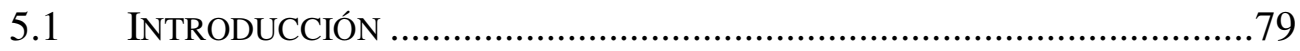

5.2 JUSTIFICACIÓN DE LA APLICACIÓN DEL MÉTODO DE TRAZADO DE RAYOS

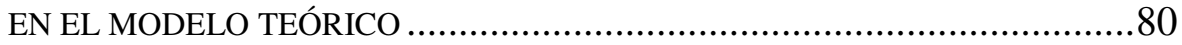

5.3 CÁLCULO TEÓRICO DE LOS NIVELES DE CAMPO-E EN INTERIORES .......83 


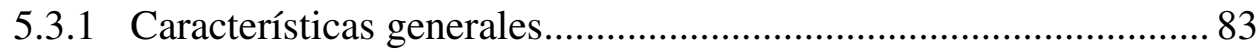

5.3.2 Descripción detallada del desarrollo del modelo........................... 86

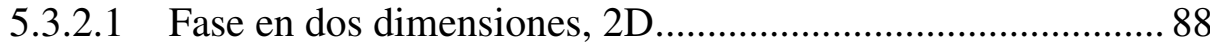

5.3.2.2 Fase en tres dimensiones, 3D .......................................... 91

5.3.2.3 Característica de recursividad............................................... 96

5.3.3 Desarrollo del modelo en una fase en 3D ................................... 97

5.3.3.1 Concepto de matriz de imágenes ........................................... 97

5.3.4 Aplicación de las áreas de visibilidad ......................................... 104

5.3.5 Calculo de los rayos difractados .............................................. 108

5.3.6 Concepto de ángulo de sombra................................................... 111

5.3.6.1 Simulación teórica del concepto de ángulo de sombra........ 112

5.3.7 Simulación de las condiciones de medida del dosímetro ............ 115

5.3.8 Simulación de la fuente emisora................................................. 115

5.3.8.1 Simulación de las condiciones de radiación de la antena.... 116

CAPITULO 6 121

PROTOCOLO DE REALIZACIÓN DE LAS MEDIDAS

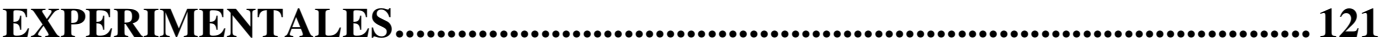

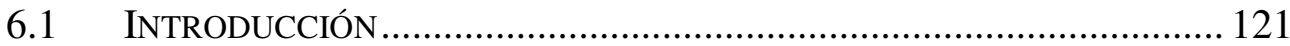

6.2 REALIZACIÓN DEL PRIMER EXPERIMENTO........................................ 122

6.2.1 Protocolo experimental............................................................ 122

6.2.2 Descripción del material............................................................ 124

6.2.2.1 Dispositivos de medida..................................................... 124

6.2.2.2 Fuente de radiación......................................................... 124

6.2.3 Descripción del entorno experimental electromagnético ............ 126

6.3 REALIZACIÓN DEL SEGUNDO EXPERIMENTO .................................... 127

6.4 REALIZACIÓN DE LOS EXPERIMENTOS DE CONTRASTE ...................... 129 
Índice

6.5 ANÁLISIS DE LA POSICIÓN DEL DOSÍMETRO EN LA ZONA DE SOMBRA 130

CAPITULO 7.........................................................................................................................135

ANÁLISIS DE LOS RESULTADOS .................................................................135

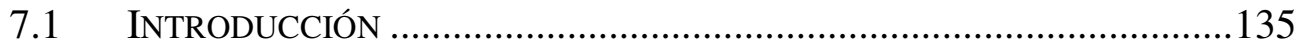

7.2 RESULTADOS DEL PRIMER EXPERIMENTO ..........................................136

7.2.1 Niveles de exposición del campo-E ................................................136

7.2.2 Función de distribución acumulada ............................................138

7.2.3 Ángulo de sombra .........................................................................

7.3 RESULTADOS DEL SEGUNDO EXPERIMENTO......................................141

7.3.1 Niveles de exposición del campo-E .............................................142

7.3.2 Función de distribución acumulada ..................................................144

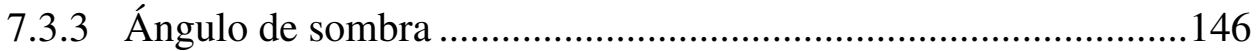

7.4 RESULTADOS DE LOS EXPERIMENTOS DE CONTRASTE .........................147

7.4.1 Niveles de exposición del campo-E ..............................................148

7.4.2 Función de distribución acumulada ............................................149

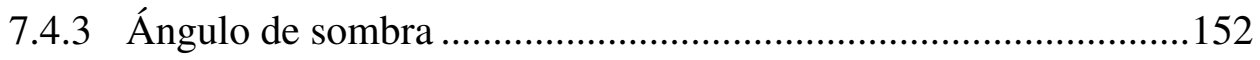

7.5 DISCUSIÓN DE LOS RESULTADOS ....................................................152

7.5.1 Influencia de la polarización del transmisor en el efecto sombra 152

7.5.2 Efecto de dispersión ...................................................................154

7.5.3 Relación entre el ángulo de sombra y el tamaño del recinto.........157

7.5.4 Concepto de variabilidad del diagrama de radiación .....................159

7.6 ERROR CUADRÁTICO MEDIO ...........................................................161

7.7 ANÁLISIS ESTADÍSTICO DE LOS RESULTADOS …………………….......164

7.8 FACTORES DE CORRECCIÓN ..............................................................169

CAPITULO 8.....................................................................................................................175

CONCLUSIONES.................................................................................................175 
Índice

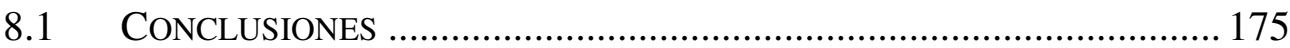

8.1.1 Mejora de los procedimientos de medición de dosímetros personales 176

8.1.2 Modelado del efecto sombra del cuerpo humano y sus implicaciones estadísticas. 177

8.2 LISTADO DE PUBLICACIONES ....................................................... 180

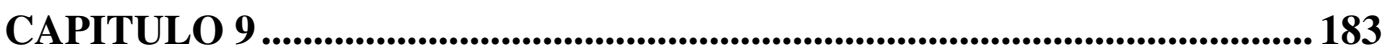

NUEVAS PROPUESTAS DE INVESTIGACIÓN.............................................. 183

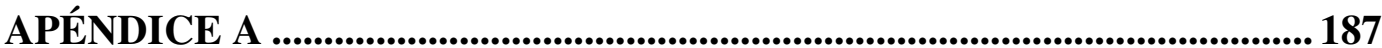

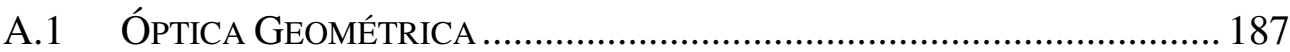

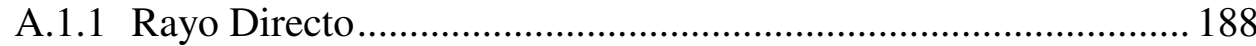

A.1.2 Rayo Reflejado .................................................................... 189

A.1.2.1 Polarización Soft .............................................................. 190

A.1.2.2 Polarización Hard ..................................................................... 191

A.1.2.3 Campo eléctrico definido por un rayo reflejado ................... 192

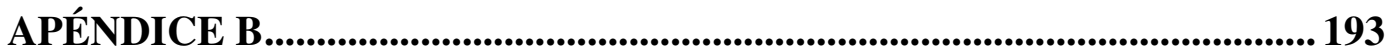

B.1 TEORÍA GEOMÉTRICA DE LA DIFRACCIÓN (GTD)............................. 193

B.2 CAMPo ElÉCTRICO DEFINIDO POR UN RAYO DifRACTADO.............. 195

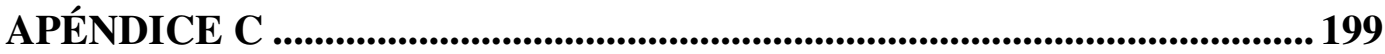

C.1 DIAGRAMA DE RADIACIÓN DE LAS ANTENAS …................................ 199

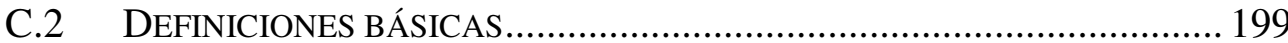

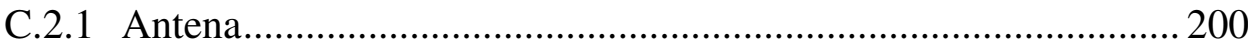

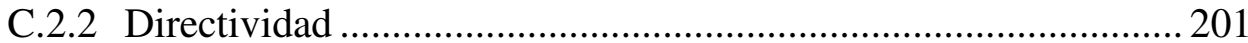

C.2.3 Diagrama de radiación............................................................. 202

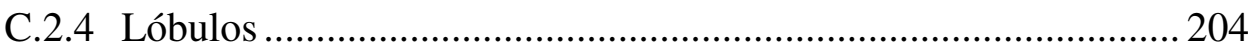


Índice

C.2.5 Nivel de lóbulos secundarios ......................................................205

C.2.6 Ancho del haz principal a $-3 \mathrm{~dB}$.............................................205

C.2.7 Ancho del haz principal entre nulos ...........................................206

C.2.8 Relación delante-atrás ............................................................206

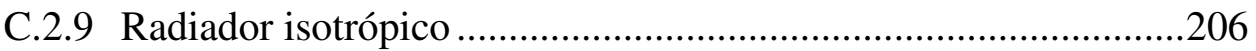

C.2.10 Ganancia............................................................................207

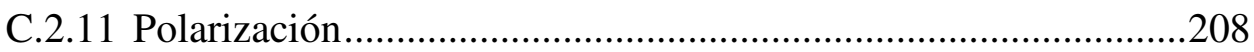

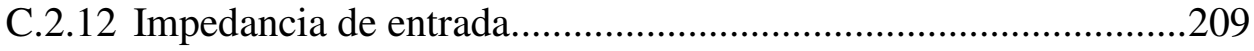

C.2.13 Resistencia de radiación ..........................................................209

C.2.14 Relación de onda estacionaria...................................................210

C.2.15 Ancho de banda de la antena.....................................................210

C.2.16 Intensidad de Campo..............................................................210

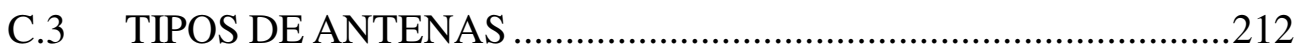

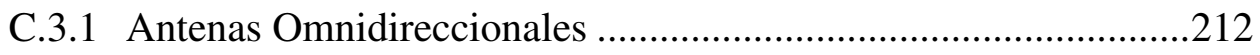

C.3.2 Antenas Direccionales.........................................................213

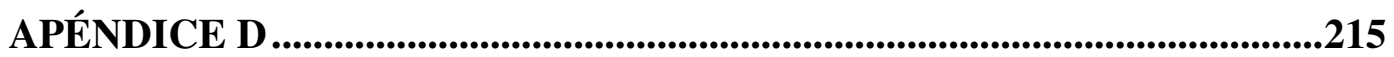

D.1 VALORES DEL DIAGRAMA DE RADIACIÓN …....................................215

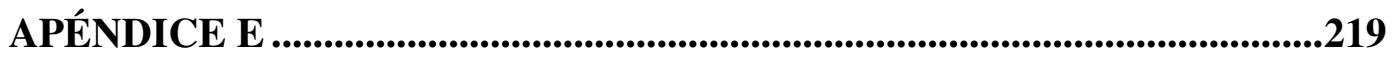

E.1 VALORES DE CALIBRACIÓN DEL CABLE ROHDE \& SCHWARZ LA-RG$214 / \mathrm{U}$

APÉNDICE F

F.1 Resultados DE CALIBRACIÓN DE LA ANTENA BICÓNICA PCD 8250221

APÉNDICE G.

G.1 SISTEMA DE COORDENADAS ESFÉRICAS, CONVENIO 225 
Índice

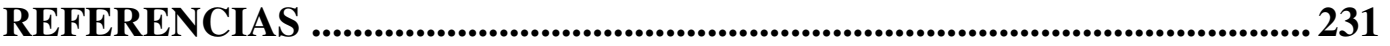




\section{CAPITULO 1}

\section{Introducción}

\section{1 Ámbito}

Hoy en día existe una exposición muy notable a radiaciones no ionizantes, tanto en entornos interiores como en exteriores debido al espectacular auge de los sistemas de comunicaciones inalámbricos. En particular, en entornos interiores, ha aumentado el uso de las tecnologías inalámbricas de corto alcance, siendo la banda de frecuencia de $2.4 \mathrm{GHz}$ la más empleada por los dispositivos de comunicaciones personales.

Los dosímetros personales llevables miden los niveles de intensidad de los campos electromagnéticos (CEM) en localizaciones próximas a la superficie del cuerpo humano y son utilizados para cuantificar los niveles de radiación a los que está expuesto el usuario en un instante concreto. Se ha comprobado que la 
Introducción

presencia del cuerpo humano es causa de una subestimación de los resultados obtenidos en comparación con los valores que se obtendrían en ausencia de dicha influencia.

\subsection{Motivación}

Los dosímetros se utilizan normalmente para la evaluación de la exposición a las radiaciones no ionizantes en la investigación epidemiológica. Sin embargo, los datos registrados por este tipo de dispositivos no se pueden considerar lo suficientemente fiables [Lau12]. Son muchos los casos en los que se han detectado fallos en los valores de exposición a los CEM medidos por los dosímetros.

Existen numerosos estudios que tratan sobre los inconvenientes de las medidas realizadas por los dosímetros, entre los que se incluyen la subestimación debida a la presencia del cuerpo humano [Kna08]. Algunos de estos estudios cuantifican numéricamente dicha atenuación para cada una de las frecuencias más comunes de los sistemas de comunicaciones, pero siempre para casos estáticos en los que el usuario se sitúa en una posición fija respecto de la fuente de radiación [Bol11]. Existen estudios que se han enfocado en la simulación de la influencia del cuerpo humano en las medidas registradas por dosímetros basándose en el trazado de rayos [Gha07]. En otros casos se ha tratado de simplificar el problema considerando el cuerpo humano como una forma geométrica uniforme [Gha04], [Gha07]. Mientras, otros trabajos tienen por objetivo cuantificar la atenuación ocasionada por el cuerpo humano en entornos exteriores [Bol11], y en entornos interiores [Neu10], pero ningún estudio previo se ha centrado en el modelado del bloqueo de los rayos debido a la presencia del cuerpo humano, en condiciones de movimiento y en recintos interiores. 
Para caracterizar la atenuación o subestimación en las medidas de exposición al campo eléctrico, se han comparado los valores obtenidos sin considerar la presencia del cuerpo humano, con los valores registrados en el caso que el cuerpo humano se encuentre situado entre la fuente de radiación y el dispositivo de medida. En este caso el dosímetro se encuentra completamente fuera de la línea de visión con respecto a la fuente de radiación.

Mediante la comparación de ambos tipos de resultados es posible caracterizar la atenuación de los rayos debido a la influencia del cuerpo humano. Se puede considerar que los rayos incidentes pertenecientes a un determinado sector angular son bloqueados por el cuerpo humano experimentando una pérdida de intensidad que se traduce en una subestimación de los niveles de exposición reales a los CEM.

\subsection{Objetivo}

El objetivo de la Tesis Doctoral es el modelado y validación experimental de la perturbación de las medidas registradas por dosímetros personales llevables, debido al efecto sombra del cuerpo del usuario, en recintos interiores, y en condiciones de movimiento.

\subsection{Metodología}

A continuación se propone la metodología que se ha llevado a cabo para alcanzar el objetivo propuesto. 


\subsubsection{Revisión de la literatura}

Se ha realizado una revisión de la literatura científica disponible sobre la influencia del cuerpo en los datos medidos por dosímetros personales.

\subsubsection{Implementación del modelo teórico}

Se ha implementado un programa de simulación del cálculo de la exposición al campo eléctrico (campo-E) basado en la óptica geométrica del trazado de rayos en recintos cerrados, en el que se ha introducido el modelado del bloqueo de rayos ocasionado por el cuerpo humano. Las simulaciones de la evaluación del campo-E se realizaron en presencia y en ausencia de la influencia del cuerpo humano.

El modelo se ha desarrollado siguiendo la técnica híbrida de la teoría de las imágenes según la cual la generación de imágenes en dos dimensiones (2D), en los planos vertical y horizontal, se combina para obtener los caminos que siguen los rayos en tres dimensiones (3D) [Zho01]. En el desarrollo del modelo teórico es relevante considerar la influencia de varios parámetros topológicos y electromagnéticos, como son las dimensiones del recinto y la posición del transmisor y del receptor, así como se han de tener en cuenta las características electromagnéticas de los materiales del recinto [Sei94], [Ath00].

Los ambientes interiores están caracterizados por reflexiones y difracciones que generan fuentes de radiación secundarias, y como consecuencia se obtienen mediciones de los niveles de campo-E de diferentes intensidades. En un escenario multitrayecto la exposición humana se caracteriza por un número de rayos de diferentes intensidades que inciden sobre el cuerpo humano con diferentes ángulos de llegada. 
Es obvio que existe una región de sombra en el plano azimut respecto a la posición vertical del cuerpo humano. El tamaño de este sector angular cambia con el ángulo de llegada (angle of arrival, AoA) de la principal contribución de radiofrecuencia $(\mathrm{RF})$, y depende de la posición relativa del dosímetro con respecto a la fuente principal de radiación y del cuerpo humano.

En lugar de calcular todas las posibles regiones de sombra al detalle, existen estudios que simplifican el problema asumiendo que los rayos pertenecientes a un cierto ángulo de llegada alrededor del cuerpo son bloqueados, y por lo tanto alcanzan el dosímetro más atenuados que el resto de los rayos [Rod10]. En este estudio se considera que los rayos que son bloqueados se atenúan $30 \mathrm{~dB}$ [Bla07]. Esta propuesta tiene la ventaja de proporcionar una regla simple de aceptar o descartar los rayos, independientemente de la posición de la fuente.

\subsubsection{Diseño del protocolo experimental}

Se ha llevado a cabo el diseño (y posterior implementación) de un protocolo de realización de medidas de exposición al campo-E. Con el fin de profundizar en aquellos casos en los que la exposición del usuario sea máxima se han comparado los niveles de campo-E obtenidos con un dosímetro en línea de visión con la fuente de radiación, con los valores medidos por un segundo dosímetro fuera completamente de la línea de visión, donde el cuerpo humano se encuentra situado entre la fuente de radiación y el dosímetro. Los dosímetros que se han empleado en la realización de las medidas son Antennessa EME SPY 120 y Satimo EME SPY 121/100. Ambos se configuraron con los mismos parámetros de operación.

Es relevante la correcta elección de los recintos interiores para llevar a cabo la validación experimental del modelo. Los escenarios seleccionados deben cumplir determinadas condiciones para asegurar que los niveles de exposición medidos 
Introducción

proceden únicamente de la fuente de radiación y garantizar así un ambiente electromagnético fiable. Se ha de comprobar la no existencia de otras fuentes de radiación y/o dispositivos que estén emitiendo en la frecuencia de trabajo. Para tener un máximo control sobre los parámetros de emisión, como son: potencia emitida, frecuencia, modulación, y polarización, los instrumentos que se han empleado como fuente de radiación han sido un generador de señal analógico Agilent N5181A MXG, y una antena bicónica Seibersdorf Precision Conical Dipole (PCD) 8250, ambos conectados con un cable calibrado Rohde \& Schwarz LA-RG-214/U.

\subsubsection{Implementación de las medidas experimentales}

Se ha llevado a cabo la realización de la campaña de medidas en entornos simples para la posterior comparación con el modelo teórico. El objetivo del estudio experimental es medir la intensidad del campo-E a la frecuencia Wi-Fi, (que se corresponde con la banda de $2400-2500 \mathrm{MHz}$ ) en los puntos de una trayectoria predefinida en presencia y en ausencia del cuerpo humano.

Ha sido de interés realizar las pruebas experimentales en más de un recinto para aportar una mayor validez y fiabilidad al modelo propuesto.

\subsubsection{Tratamiento estadístico de los datos obtenidos}

Mediante el análisis estadístico se ha realizado una valoración de la fiabilidad de los resultados teóricos (simulados) mediante la comparación de la función de distribución acumulada (FDA) de las series de datos obtenidas en los casos simulado y experimental. 
También se ha verificado el ajuste de las FDAs obtenidas con las funciones de distribución características de los niveles de exposición a radiaciones no ionizantes en recintos interiores [Bab00], [Wyn09], [San10].

\subsubsection{Estudio de la aplicabilidad de factores de corrección}

Mediante el estudio del ajuste de las funciones de distribución se ha analizado la efectividad del empleo de factores de corrección para compensar la atenuación ocasionada por el bloqueo de los rayos. De esta forma se pretenden detectar errores sistemáticos que no son detectables mediante la comparación de los valores medios o mediante el cálculo del error cuadrático medio.

\subsection{Estructura del documento}

Los contenidos de esta tesis se organizan según la estructura descrita anteriormente. Inicialmente se presenta un estudio del estado del arte sobre los diferentes modelos teóricos de propagación de ondas electromagnéticas, y sobre los escenarios de influencia de la presencia del cuerpo humano en la zona de cobertura de los enlaces inalámbricos. Este planteamiento pretende servir de base para abordar la solución del modelado del cuerpo humano como parte del modelo teórico del trazado de rayos basado en el método de las imágenes. A continuación se expone la parte experimental del trabajo donde se presenta el entorno de realización de las pruebas, el material empleado, y el protocolo utilizado en la realización de las medidas del campo-E. Finalmente se comparan los resultados de la simulación y los resultados de la fase experimental para comprobar la adecuación del modelado del efecto sombra propuesto con los resultados de la parte experimental del estudio. 
El capítulo 2, Revisión de la influencia del cuerpo humano en las medidas dosimétricas, está dedicado a la revisión de la literatura sobre la influencia del cuerpo humano en las medidas registradas por los dosímetros. También se describen los diferentes escenarios de influencia del efecto sombra en los enlaces radioeléctricos.

El capítulo 3, Normativa de protección frente a radiaciones no ionizantes, se centra en la normativa actual vigente sobre la exposición a los CEM y sus implicaciones en el ámbito de la salud.

El capítulo 4, Modelos de propagación de sistemas de comunicaciones inalámbricos, presenta una visión general del estado del arte de los modelos existentes destinados al cálculo de la propagación de señales. De cada uno de las técnicas presentadas se lleva a cabo una pequeña descripción de sus características. Se presentan los modelos empíricos, pero la atención se ha centrado principalmente en la aplicación de las técnicas de trazado de rayos para el desarrollo de modelos de propagación deterministas.

El capítulo 5, Implementación del método de trazado de rayos en interiores, está dedicado a la descripción del modelo teórico que se ha implementado para caracterizar la propagación de ondas electromagnéticas en entornos interiores bajo la influencia del efecto sombra del cuerpo humano. El objetivo es predecir la subestimación ocasionada por la presencia del usuario portador del dosímetro en las medidas de los CEM que son registradas por este dispositivo de medida.

El capítulo 6, Protocolo de realización de las medidas experimentales, presenta la realización de las pruebas experimentales. En este capítulo se describe el entorno experimental, las características del ambiente electromagnético, el material empleado, y el protocolo que se ha de seguir durante el proceso de registro de los valores de los CEM. Todos los requisitos y condiciones que se han 
descrito en este capítulo son requeridos para la ejecución correcta de la parte experimental del estudio.

En el capítulo 7, Análisis de los resultados, se comparan los resultados teóricos y experimentales obtenidos en los diferentes entornos con el fin de aportar conclusiones sólidas. Además se lleva a cabo un análisis estadístico para la verificación del modelo teórico propuesto. También se expone la discusión sobre la validez del uso de los factores de corrección para solucionar la subestimación producida por la presencia del cuerpo humano.

En el capítulo 8, Conclusiones, se valora el modelado del efecto sombra del cuerpo humano mediante el modelo teórico propuesto comparando los resultados obtenidos con los niveles de los CEM medidos en la parte experimental. También se resumen las principales conclusiones extraídas como consecuencia de la elaboración de este trabajo.

Y por último en el capítulo 9, Nuevas propuestas de investigación, se muestran las líneas de investigación futuras que son posibles de desarrollar a partir del trabajo realizado en esta tesis. 



\section{CAPITULO 2}

\section{Revisión de la influencia del}

cuerpo humano en las medidas

dosimétricas

\subsection{Tipos de medidas dosimétricas}

Los dosímetros personales llevables se emplean generalmente para el análisis de las medidas de exposición en los estudios epidemiológicos. Existen diferentes estrategias y metodologías para monitorizar la exposición a los CEM. Se emplean dos tipos de procedimientos, estáticos y dinámicos [Urb14]. Los métodos estáticos generalmente se llevan a cabo con un analizador de espectro para determinar el nivel de señal concreto en una determinada posición. Este método consume 
Revisión de la influencia del cuerpo humano en las medidas dosimétricas

bastantes recursos en términos de equipamiento, costes y entrenamiento del personal. Como consecuencia, la representación de los datos recogidos a lo largo del tiempo en una zona geográfica amplia conlleva cierta complicación. En estos casos otra posibilidad es el uso de dosímetros, que son dispositivos que permiten obtener numerosas medidas en diferentes localizaciones y con poco esfuerzo.

Aunque los datos obtenidos con los dosímetros no son tan exactos como las medidas proporcionadas por el analizador de espectro, numerosos estudios epidemiológicos emplean dosímetros debido a su fácil manejo así como a la elevada frecuencia de obtención de medidas [Aer13], siendo la mínima tasa de adquisición una muestra cada $4 \mathrm{~s}$.

Por otra parte también se pueden considerar dos tipos de medidas: de banda ancha, y de banda estrecha o espectrales. Las medidas de banda ancha generalmente se llevan a cabo mediante un medidor de campo y una sonda de banda ancha, obteniéndose datos en un rango de span de varios GHz. Las medidas espectrales son medidas que se realizan en una banda específica y se llevan a cabo con uno de estos dos instrumentos: un analizador de espectro o un dosímetro [Aer13], [Est14].

En este estudio se pretende analizar los niveles de exposición en ambientes interiores y en condiciones dinámicas. El instrumento de medida seleccionado para realizar la parte experimental es el dosímetro, que se ha empleado en numerosos estudios para el análisis de la exposición a CEM en entornos exteriores, de forma dinámica, y en zonas geográficas amplias [Bee13], [Aer13], [Urb14]. Es importante considerar que el análisis de los niveles de intensidad promedio del campo-E en diferentes ubicaciones de una zona reducida, se corresponde con un escenario de exposición más realista que las medidas realizadas en una localización específica y de forma continuada. 


\subsection{Fuentes de incertidumbre en la medición de los niveles de exposición}

A pesar de las ventajas que se han descrito sobre el uso de los dosímetros en la medición de los CEM, en función de la localización y de forma continuada en el tiempo, las medidas registradas por estos dispositivos no son del todo fiables [Lau12]. Existen varios estudios que afirman la existencia de fallos en las medidas de los CEM registradas por este tipo de dispositivos.

En [Kna08] se enumeran varios factores que pueden ser considerados como fuente de incertidumbre debido al empleo de dosímetros para la obtención de los niveles de los CEM en los estudios de ámbito epidemiológico. Uno de estos factores es el efecto sombra del cuerpo humano. El lugar donde el usuario lleva el dosímetro, y el ángulo de incidencia de los rayos procedentes de la fuente transmisora, son factores a tener en cuenta en la incertidumbre de las medidas proporcionadas por estos dispositivos como consecuencia de la presencia del cuerpo humano [Bah08], [Isk10].

La polarización de la onda que incide sobre el dosímetro puede afectar a la intensidad de los niveles de los CEM que son medidos. La sensibilidad (entendida como el rango de medida) es una característica intrínseca de los dosímetros que introduce una subestimación, o sobrestimación, de los datos medidos: si el valor medido es mayor o menor que el rango de medida, el valor que se registra en la memoria del dosímetro es el valor del límite superior, o inferior, del rango de la sensibilidad. Los dosímetros permiten medir los niveles de exposición dependientes de la frecuencia, pero no permiten la identificación de la fuente específica de radiación dentro de la misma banda. Además, no son capaces de 
Revisión de la influencia del cuerpo humano en las medidas dosimétricas

diferenciar los niveles de exposición procedentes de diferentes fuentes de transmisión [Kna08], [Röö10].

Otro factor de incertidumbre es la variación de la potencia de emisión de las fuentes de radiación debido a las características del enlace de radiocomunicación. La intensidad de los CEM depende de varios factores como son la potencia de emisión de los dispositivos, la velocidad de la información transmitida, el número de receptores, los requisitos de calidad de servicio, etc [Bec12]. Todos estos factores son parámetros que no pueden ser registrados y controlados por los dosímetros. Cabe señalar que los niveles de exposición a las radiaciones radioeléctricas dependen de la potencia de emisión de la fuente transmisora, que a su vez dependen del uso, del número de usuarios, de las características del entorno y del ambiente electromagnético [And10], [DeM13].

\subsection{Influencia del cuerpo humano en las medidas dosimétricas}

Este trabajo analiza la influencia de lo que se ha denominado "efecto sombra del cuerpo humano" en las medidas registradas por los dosímetros.

Muchos autores exponen como el cuerpo del usuario que es portador de un dispositivo de medida, o de un dispositivo receptor de comunicaciones, ocasiona una subestimación nada despreciable del nivel de señal que es detectado [Tof93], [Che98], [Zir04], [Bla07], [Cot07], [Bah08], [Kna08], [Cot09], [Röö10], [Isk10], [Neu10], [Rod10], [Bol11], [Thi14]. Como toda radiación electromagnética, los campos electromagnéticos de alta frecuencia llevan energía, cuando el cuerpo humano se encuentra expuesto a las ondas de radio, parte de esta energía es dispersada causando la subestimación de los datos registrados por los dosímetros 
[Tof93], [Cot09], [Thi13]. Por otra parte, cuando un usuario está expuesto a radiación electromagnética parte de la energía incidente también es absorbida por su propio cuerpo [AGN12]. La tasa de absorción específica (specific absorption rate, SAR) de cualquier tejido vivo es una medida de potencia por unidad masa y se expresa en unidades de $\mathrm{W} \mathrm{kg}^{-1}$. Como se verá más adelante existen límites de SAR impuestos por los gobiernos y los organismos internacionales para garantizar la seguridad en la exposición a radiaciones de RF.

El efecto sombra del cuerpo humano provoca que la intensidad del campo-E registrada por los dosímetros llevables, portados por el usuario, sea diferente de la intensidad de campo-E que realmente incide sobre él.

A su vez, la mayor o menor incertidumbre de los datos registrados por un dosímetro que es portado por un usuario depende de características fisiológicas de éste, como son: la morfología, peso e índice de masa corporal del sujeto, y las características eléctricas de los tejidos [Küh09], [Neu09], [Bak10], [ElH10], [Isk10]. Otros factores intrínsecos del sujeto que influyen en la variabilidad de las medidas son: la posición cuerpo (sentado o levantado), la posición de los brazos, o si se encuentra en estado dinámico o estacionario [Cot09], [Fin10].

Los dosímetros personales generalmente son calibrados en condiciones de espacio libre, y teniendo en cuenta que existen claras evidencias sobre la existencia de determinados factores que causan incertidumbre en los datos registrados, será necesario interpretar cuidadosamente los resultados obtenidos y analizar la influencia de todos los factores para realizar un análisis fiable de la exposición de los seres humanos a las radiaciones de RF. En consecuencia, un dosímetro llevado por un usuario medirá, además del campo incidente, todas las contribuciones del campo eléctrico, (incluyendo las ocasionadas por las reflexiones y las dispersiones del cuerpo humano), que serán necesarias para la 
Revisión de la influencia del cuerpo humano en las medidas dosimétricas

cuantificación de la exposición a radiaciones no ionizantes, y para su posterior comparación con los niveles de exposición [ICN98].

Para abordar todos estos factores de incertidumbre, es importante tenerlos en cuenta a la hora de analizar los datos medidos, así como en el desarrollo de los modelos de simulación de las condiciones de exposición a los CEM. Se recomienda la comparación entre los datos medidos y los resultados de la simulación, con el fin de mejorar la calidad de los estudios epidemiológicos sobre la exposición a las radiaciones de RF [Kna08].

\subsubsection{Caracterización y cuantificación}

En [Bol11] se propone el empleo de factores de corrección con el fin de compensar los errores en las medidas debido a la influencia del cuerpo, al ángulo de elevación, y a la calibración. Con respecto a la influencia del cuerpo humano, los factores de corrección se calculan en función de la frecuencia y la polarización de la onda incidente. En este estudio los datos de incertidumbre se expresan en decibelios $(\mathrm{dB})$, y se definen mediante $20 \log _{10}\left(\mathrm{E}_{\text {resp }} / \mathrm{E}_{\text {inc }}\right)$, donde $\mathrm{E}_{\text {resp }}$ es la intensidad de campo-E de respuesta y $\mathrm{E}_{\mathrm{inc}}$ es el campo incidente en la localización del dosímetro en ausencia del cuerpo humano.

En el trabajo de [Neu10] también se propone calcular un factor de corrección para evitar la subestimación de las medidas de los dosímetros en presencia del cuerpo humano. En este caso se eligen dos tipos diferentes de escenarios: para GSM, FM, y UMTS un entorno urbano, y para WLAN un recinto interior. El trabajo propone la comparación entre el campo-E medido por un dosímetro en la posición del cuerpo humano sin que el cuerpo esté presente en entornos interiores y exteriores. En este estudio la subestimación de las medidas se define como la relación entre el promedio de los niveles de campo en la localización del 
dosímetro, y el nivel de campo promediado sobre el volumen del cuerpo humano sin que éste esté presente.

Algunos de estos estudios, y muchos otros, han tratado de cuantificar el efecto del cuerpo humano en las medidas registradas por los dosímetros. Cabe mencionar que la influencia del efecto sombra en las medidas registradas por los dosímetros es diferente en entornos interiores [Neu10] y en exteriores [Kna08] [Rod10], [Bol11]. Es predecible que la influencia del cuerpo humano será mayor en espacios abiertos que en recintos cerrados, y como ya se ha indicado, no es un efecto despreciable y debería ser tenido en cuenta en el análisis de la exposición de los seres humanos a las radiaciones no ionizantes.

Trabajos anteriores estudian el efecto sombra mediante las simulaciones empleando el método de las diferencias finitas en el dominio del tiempo (finitedifference time-domain, FDTD) y la verificación experimental, indicando que en la región de sombra, este error puede llegar a alcanzar 30 dB (sólo el $0.1 \%$ de la potencia de la onda incidente sería detectada) en la banda de frecuencia de GSM, y en un escenario poco favorable, en el que el dosímetro se encuentra fuera de la línea de visión con respecto a la fuente de radiación [Bla07]. Otros trabajos concluyen que en los entornos interiores la presencia del cuerpo humano supone un error de $25 \mathrm{~dB}$ en la banda de frecuencias de $10 \mathrm{GHz}$ (en cuyo caso sólo el $0.3 \%$ de la potencia de la onda incidente sería detectada) [Gha04]. En [Bol11] se distingue entre la polarización horizontal y la polarización vertical de la fuente de radiación para fijar la atenuación debida a la presencia del cuerpo humano, siendo $30 \mathrm{~dB}$ la mayor atenuación en el caso de la frecuencia Wi-Fi y en polarización vertical.

Los efectos del cuerpo humano en entornos interiores se han analizado a altas frecuencias, especialmente a la frecuencia UWB [Ghad04], [Hua06], [Gha07], 
Revisión de la influencia del cuerpo humano en las medidas dosimétricas

[Zha09]. Otros trabajos ajustan la atenuación debida al efecto sombra dependiendo de la posición de la fuente de radiación y de la frecuencia de la señal, incluyendo la frecuencia de $2.4 \mathrm{GHz}$, en un espacio abierto de prueba [Bol11]. En [Neu10] se propone el empleo de factores de corrección en entornos interiores a la frecuencia Wi-Fi, en la banda de $2.4 \mathrm{GHz}$. En [Cot09] se estudia la atenuación introducida por el cuerpo humano concretamente en redes de área personal, WPAN, a la frecuencia $2.45 \mathrm{GHz}$, dependiendo de las condiciones del usuario (parado o en movimiento) y del tipo de entorno (interior y exterior). No existen estudios previos que modelen la atenuación del campo-E debido a los efectos del cuerpo humano en recintos interiores, y en condiciones de movimiento, siendo la frecuencia de trabajo la banda de $2.4 \mathrm{GHz}$ que es una de las más empleadas en las comunicaciones Wi-Fi.

\subsubsection{Escenarios de influencia del efecto sombra en recintos interiores}

Muchos de los trabajos que se han indicado se centran en la atenuación detectada por la presencia del cuerpo humano en los niveles de señal que son registrados por los dosímetros personales.

El efecto sombra del cuerpo humano no sólo es un factor de incertidumbre en las medidas de los niveles de señal que son detectados por los dosímetros, si no que el cuerpo humano también puede afectar a las comunicaciones personales en las que se emplean terminales portados por los usuarios, así como también puede ser considerado como un obstáculo en función de su ubicación si distorsiona el establecimiento de un radioenlace inalámbrico.

La subestimación en los niveles de señal ocasionada por la presencia del cuerpo humano se da en tres escenarios posibles: 
1.- El cuerpo humano es un obstáculo si se encuentra dentro de la zona de cobertura de un radioenlace, siendo causa de desvanecimiento de la señal.

2.- El cuerpo humano es causa de variación de determinadas características de operación de los dispositivos receptores de radiocomunicaciones debido a la extrema proximidad de éstos con el usuario durante su funcionamiento.

3.- El cuerpo humano es un factor de incertidumbre en las campañas de medición de los niveles de exposición a los CEM debido a la proximidad existente entre el dispositivo de medida y el usuario portador de dicho dispositivo.

Dado que este trabajo se basa en el punto 3, y ya se ha presentado el estado del arte referente a los factores de incertidumbre en las medidas dosimétricas, a continuación se indican una serie de estudios reales centrados en los puntos 1 y 2 en los que se describen escenarios experimentales donde el cuerpo humano es causa de perturbación de la señal recibida, tanto en terminales de comunicaciones llevables como en receptores fijos de radioenlaces.

A continuación se indicarán diferentes estudios sobre la influencia de la presencia del cuerpo humano, donde la localización del usuario con respecto a la posición del transmisor y del receptor es un factor a tener en cuenta. Se distinguen los dos escenarios indicados: puede que el receptor se encuentre en posición estática y el usuario en estado de movimiento, en cuyo caso se define la variación de la potencia recibida en el receptor en función de la posición de usuario, mientras, en otros casos, se considera un receptor móvil que es llevado por el usuario [Zir04], [Cot07]. Este último caso es el escenario de uso del teléfono móvil que típicamente está provisto de varias interfaces de red, como son Bluetooth, WLAN y la red de telefonía móvil, por lo que hay que tener en cuenta la influencia del cuerpo en los diferentes tipos de redes, considerando las posibles diferencias. 
Revisión de la influencia del cuerpo humano en las medidas dosimétricas

Se expondrá la influencia de la presencia del cuerpo humano como usuario de comunicaciones móviles inalámbricas distinguiendo tres tipos de redes: redes de área local inalámbricas WLAN, redes de área personal inalámbricas WPAN, y redes de telefonía móvil. Cabe destacar la dependencia de la influencia del efecto sombra con las dimensiones del recinto empleado como escenario experimental. En concreto, en los estudios que se presentan se distinguen tres tipos de recintos interiores: cámaras anecoicas, pasillos estrechos y recintos espaciosos cuyas características afectan a los resultados obtenidos.

\subsubsection{Cuerpo humano: obstáculo de radioenlaces inalámbricos}

De forma general la presencia del cuerpo humano ocasiona un desvanecimiento notable del nivel de señal en recintos interiores en los que existe un radio enlace entre un transmisor y un receptor. Se han realizado pruebas experimentales y simulaciones en las que el cuerpo humano es considerado como un obstáculo de la propagación en el interior de un recinto [Wat08], demostrándose de forma teórica que el cuerpo humano se puede modelar como un cilindro metálico [Gha04], [Hua06], [Gha07].

En [Zha09], además de introducir el concepto de "efecto sombra del cuerpo humano", también se propone modelar la presencia del usuario como una región de sombra en la que los rayos son atenuados. Al igual que en los estudios anteriormente citados, el transmisor y el receptor son estáticos, y se analiza la atenuación de la intensidad de la señal en función de la posición del cuerpo humano al ser un obstáculo móvil en el recinto de estudio. La frecuencia de trabajo empleada ha sido la frecuencia de UWB en la banda de $10 \mathrm{GHz}$, que también se ha considerado en estudios previos [Gha04], [Hua06], [Gha07], [Wat08]. 


\subsubsection{Cuerpo humano: portador del dispositivo receptor}

En el ámbito de las comunicaciones personales, las redes de área local inalámbricas han adquirido una gran presencia en entornos interiores ya que proporcionan una gran variedad de servicios de telecomunicaciones en diversos ámbitos (doméstico, salud, laboral) de la vida diaria [Tof93]. La característica de ubicuidad de las comunicaciones móviles es posible a través de una gran variedad de terminales inalámbricos: teléfonos, tabletas, portátiles, etc., que operan siempre en condiciones de proximidad respecto del usuario, siendo generalmente la distancia de separación no superior a 1 metro.

Aunque la mayoría de los terminales han sido diseñados para ser usados de forma estacionaria y aislada, en la mayoría de las aplicaciones el terminal de comunicación es un dispositivo que se encuentra en contacto directo con el usuario. Bajo estas condiciones de proximidad se ha comprobado que el diagrama de radiación del terminal móvil se distorsiona considerablemente debido al acoplamiento del cuerpo humano, lo que ocasiona una atenuación considerable de la señal recibida. Estos efectos generalmente no son sólo dependientes de la frecuencia sino que también dependen del diseño del terminal, de su antena y de su localización exacta respecto a la posición del cuerpo [Sca01].

Ante las condiciones multitrayecto presentes en entornos interiores, la distorsión del diagrama de radiación del terminal que está siendo portado se puede considerar como una forma de filtrado espacial, al considerar que los rayos incidentes que pertenecen a un determinado sector angular son atenuados. Dependiendo de la frecuencia de operación, y de la proximidad al cuerpo humano, se produce una pérdida de la potencia de la señal debido a la SAR del usuario. La presencia de todos estos factores trae como consecuencia una pérdida del nivel de señal que se recibe, y como consecuencia se pueden dar errores significativos en 
Revisión de la influencia del cuerpo humano en las medidas dosimétricas

la transmisión, que pueden ser más notables cuando el dispositivo es llevado que cuando este dispositivo se encuentra colgado.

[Zir04] estudia el efecto del cuerpo humano en los dispositivos de comunicaciones personales llevables. En este trabajo las condiciones experimentales son las siguientes: se considera un transmisor fijo y un receptor que es portado por el usuario colocado a la altura de la cadera. Se estudian los dos casos: en línea de visión (line of sight, LoS), y fuera de la línea de visión (non-line of sight, NLoS) respecto de la posición de la fuente transmisora. Las medidas experimentales se realizan en dos entornos: uno es un pasillo largo y estrecho, y el otro es una habitación. Los resultados de este estudio demuestran que el efecto sombra del cuerpo humano es más significativo en recintos espaciosos que en recintos de menor volumen.

Con el fin de evitar que las comunicaciones personales inalámbricas no ofrezcan las prestaciones deseadas es necesario que los fabricantes tengan en cuenta todos los factores descritos. Los dispositivos de comunicaciones móviles generalmente están provistos de una antena integrada, que es un componente de coste relativamente bajo, pero su diseño no es sencillo si se pretende evitar las limitaciones que conlleva su uso. En el diseño de antenas destinadas a los terminales móviles, es necesario tener en cuenta que la antena durante su funcionamiento se encuentra en contacto directo con el usuario, lo cual afectará a la impedancia de entrada, al diagrama de radiación, a la eficiencia de radiación, y a los niveles de emisión [Tof93]. Existen dos aspectos importantes como consecuencia de la proximidad de las antenas con el cuerpo humano, uno de ellos es el posible riesgo para la salud debido al aumento de los niveles de exposición a los que está sometido el usuario, mientras que el otro aspecto es referente a la 
influencia de la presencia del usuario en el correcto o no correcto funcionamiento de la antena.

En la práctica, los sistemas provistos de una antena en contacto con el cuerpo requerirán de la verificación a través de mediciones de una serie de características. Estas comprobaciones pueden incluir el cálculo de los diagramas de radiación cuando estos dispositivos se encuentran en el espacio libre y en contacto con el cuerpo del usuario. Aun así, en estos ensayos también pueden darse factores de incertidumbre en escenarios reales, por ejemplo, la constitución del usuario puede determinar la mayor o menor distorsión del diagrama de radiación. Por otra parte también se observan ciertas variaciones de estos factores en función de la frecuencia: a frecuencias inferiores a $1 \mathrm{GHz}$, el diagrama de radiación no sufre un deterioro significativo, pero las pérdidas debido a la absorción son altas. A frecuencias más altas las pérdidas debido a la SAR no son tan significativas, y además, cuanto mayor sea la distancia entre la antena y el cuerpo el fenómeno de la absorción disminuye de manera más considerable [Sca01].

Por otra parte, la alteración del diagrama de radiación puede ser bastante notable en ambientes interiores donde existe una fuerte componente de trayectos múltiples [Sca01]. Hasta ahora se ha presentado la influencia del cuerpo humano en escenarios interiores de utilización de comunicaciones personales como son las redes de telefonía móvil y las redes de la área local, WLAN, pero el cuerpo humano también influye en las redes personales inalámbricas, WPAN, en las que el transmisor y el receptor son llevados por el usuario. [Cot09] propone un escenario experimental en donde un voluntario portaba simultáneamente un transmisor y siete receptores en diferentes ubicaciones: en la cabeza, parte delantera del torso, parte trasera del torso, y en las extremidades. Se estudió el efecto del usuario como parte del canal de comunicación considerando los estados 
Revisión de la influencia del cuerpo humano en las medidas dosimétricas

de movimiento y estático, y además en tres entornos interiores diferentes: una cámara anecoica, un pasillo estrecho y una zona amplia. Además este trabajo incluye la caracterización estadística de los resultados, que se indicará con más detalle en el siguiente apartado.

\subsubsection{Análisis estadístico mediante FDAs}

Un aspecto importante es el estudio del comportamiento estadístico de los datos obtenidos. En concreto [Cot09] propone tres distribuciones candidatas, Nakagami, Lognormal, y Rice, verificándose que la distribución de Nakagami es la que mejor se ajusta en los casos en los que el usuario se encuentra en posición estacionaria, mientras que en estado de movimiento los casos en los que las FDAs se ajustan con la distribución de Nakagami son mucho menores. Es importante este resultado a la hora de analizar los resultados obtenidos en este estudio, pero teniendo en cuenta que en [Cot09] se estudia la influencia del cuerpo humano como parte del canal de comunicación donde el transmisor y el receptor son portados por un mismo individuo, no siendo éstas las mismas condiciones experimentales que se presentan en este trabajo.

En [Cot07] se analiza la influencia del cuerpo humano en recintos interiores multitrayecto donde el transmisor se encuentra en una posición fija y el receptor es portado por el usuario en diferentes localizaciones del cuerpo: ambas muñecas, parte alta de la espalda a la izquierda y a la derecha, cadera izquierda, y el lado izquierdo del pecho. La frecuencia de estudio es $868 \mathrm{MHz}$. Las pruebas experimentales se han realizado tanto en línea de visión, como fuera de la misma, y en los tres mismos entornos: cámara anecoica, pasillo estrecho y recinto espacioso. Igualmente se han analizado las FDAs de los niveles de señal obtenidos en función de las diferentes posiciones de receptor. Se comprueba que la distribución que mejor se ajusta es Nakagami en todos los escenarios, salvo en el 
pasillo más estrecho donde la característica de propagación multitrayecto es más notable. En este último caso la distribución que presenta mejores resultados es Ricean.

\subsubsection{Necesidad de modelado del efecto sombra}

La interacción entre los dispositivos de comunicaciones personales y el propio cuerpo humano es un factor importante en el rendimiento de los sistemas de comunicación inalámbrica. Todos los contextos en los que se ha enmarcado la influencia del cuerpo humano exponen que la presencia del usuario en recintos interiores donde se ha establecido un radio enlace es causa de una atenuación de la señal debido a la energía absorbida por los tejidos vivos así como al efecto de dispersión, o scattering, del propio cuerpo.

No obstante hasta ahora no se ha tenido en cuenta el modelado del cuerpo mediante la atenuación de los rayos con un determinado ángulo de llegada desde el punto de vista de la importancia que ello conlleva en la correcta interpretación de los niveles de exposición de las personas y de sus posibles implicaciones para la salud. 



\section{CAPITULO 3}

\section{Normativa de protección frente a radiaciones no ionizantes}

\subsection{Estándares internacionales sobre exposición a los CEM}

Hoy en día los gobiernos y las autoridades competentes en salud han adoptado medidas preventivas con el fin de minimizar el riesgo asociado con la exposición a los CEM. Desde hace varias décadas, diferentes organismos nacionales e internacionales han elaborado, y también actualizado, normas referentes a la protección contra los efectos de la exposición a los CEM en la salud de las personas. Estos estándares han sido elaborados para alcanzar los niveles de potencia y exposición compatibles con la salud humana. 
Normativa de protección frente a radiaciones no ionizantes

Con los años, estas normas han evolucionado desde simples recomendaciones sobre límites de exposición en un rango limitado de frecuencia, a un sistema amplio y complejo sobre protección a los CEM, que cubre una gran parte del espectro desde $0 \mathrm{~Hz}$ a $300 \mathrm{GHz}$ [Gra09].

Hay muchos socios que contribuyen a este proceso, incluyendo la Organización Mundial de la Salud (OMS), que en 1996 estableció el proyecto internacional "EMF Project" con el fin de evaluar la evidencia científica de los posibles efectos sobre la salud y el medio ambiente de la exposición a los campos electromagnéticos en el rango de frecuencia de 0 a $300 \mathrm{GHz}$. A nivel internacional, la Comisión Internacional sobre Protección Radiológica a Radiaciones no Ionizantes (International Commission on Non Ionizing Radiation Protection, ICNIRP) ha establecido la normativa más extendida referente a los niveles de exposición. Así en respuesta a ese interés, en 1998 el ICNIRP, y un panel de expertos convocado por la OMS, publicó un conjunto de directrices destinadas a limitar la exposición humana a los CEM no ionizantes, con efectos potencialmente dañinos de salud a corto plazo [ICN98]. Existe un amplio consenso sobre estas directrices, que han llegado a formar la base de los reglamentos nacionales en numerosos países.

Las restricciones contempladas en estas directrices se basan en datos científicos, sin embargo, acorde al conocimiento disponible en la actualidad, estas restricciones proporcionan un nivel adecuado de protección contra la exposición a los CEM variables en el tiempo. Se presentan dos clases de orientaciones:

- Restricciones básicas: son restricciones de la exposición a campos eléctricos, magnéticos y electromagnéticos variables en el tiempo, que se han establecido basándose directamente en los efectos sobre la salud. Dependiendo de la frecuencia del campo, las cantidades físicas usadas para 
Normativa de protección frente a radiaciones no ionizantes

especificar estas restricciones son la densidad de corriente (J), la tasa de absorción específica, SAR, y la densidad de potencia (S).

- Los niveles de referencia: estos niveles se han establecido a efectos prácticos de evaluación de la exposición para determinar si las restricciones básicas son susceptibles de ser superadas. Algunos niveles de referencia son derivados de restricciones básicas relevantes usando técnicas de medición y/o computacionales, y algunas están basadas en percepciones y efectos indirectos adversos por la exposición a los CEM. Las cantidades derivadas son, entre otras, la intensidad de campo-E (E), la intensidad de campo magnético $(\mathrm{H})$, la densidad de flujo magnético (B), la densidad de potencia (S) y las corrientes que fluyen a través de las extremidades $\left(\mathrm{I}_{\mathrm{L}}\right)$.

Si el valor medido o calculado supera el nivel de referencia, no implica necesariamente que se haya rebasado la restricción básica. Sin embargo, cada vez que un nivel de referencia se sobrepase es necesario comprobar el cumplimiento de la restricción básica pertinente, para decidir si las medidas de protección adicionales son necesarias.

En 1999, el Consejo de la Unión Europea adoptó los criterios y directrices de la OMS-ICNIRP y les dio la forma jurídica de Recomendación [CE99]. Los países europeos que respaldaron la recomendación se comprometieron a adoptar las estrategias jurídicas y técnicas necesarias para hacer cumplir los límites establecidos en su territorio. Las objeciones que fueron planteadas por varios expertos en contra de algunos de los límites establecidos fueron causa de controversia. Como consecuencia de este desacuerdo, algunos países europeos, Suiza (en 1999), Italia (en 2003), Austria (en 2007), Liechtenstein (en 2008), 
Normativa de protección frente a radiaciones no ionizantes

adoptaron límites de exposición que, en algunos aspectos, son más restrictivos que los recomendados por el ICNIRP y el Consejo Europeo.

Los límites de exposición en los diferentes países pueden variar en factores de 10 o más, dependiendo del rango de frecuencias y del tipo de público expuesto, según se trate de trabajadores o público en general. Las diferencias entre la normativa existente en diferentes países se basan sobre todo en la interpretación de los datos existentes, así como en las razones que han llevado a establecer ese tipo de normativa, incluyendo el contexto socio-político.

Para explicar las diferencias entre las diferentes normas es necesario comprender cómo los diferentes estándares han evolucionado hasta su forma actual. La discrepancia entre las normas se puede atribuir a muchos factores incluyendo el país de origen, el organismo responsable, el proceso de desarrollo, la filosofía de la protección, el concepto de efecto, el año de desarrollo, la base de datos científicos utilizados, la elección de las restricciones básicas, y el enfoque de la derivación de los niveles de referencia [Roy07]. Además, si el estándar está regulado o no, varía de un país a otro. Se pueden establecer claras diferencias entre las normas vigentes en los países de Europa del este (Rusia, Hungría, Bulgaria, Polonia, República Checa, entre otros) y los países occidentales, refiriéndose a los más de los 50 países que han adoptado la normativa del ICNIRP y del IEEE [IEE99].

Figura 1, Figura 2 y Figura 3 muestran los niveles de referencia de exposición del campo-E recomendados por el ICNIRP para el público general y ocupacional, y por el IEEE para ambientes controlados y no controlados. 


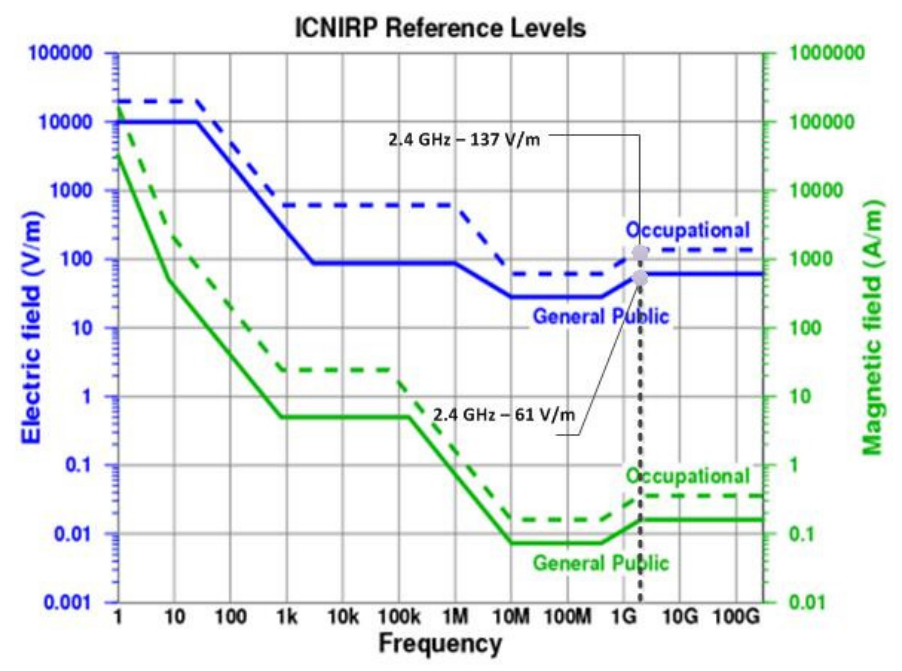

Figura 1.- Niveles de referencia del ICNIRP para la exposición del público general y ocupacional. Se han indicado los niveles de referencia para la frecuencia particular de estudio: $2.4 \mathrm{GHz}$.

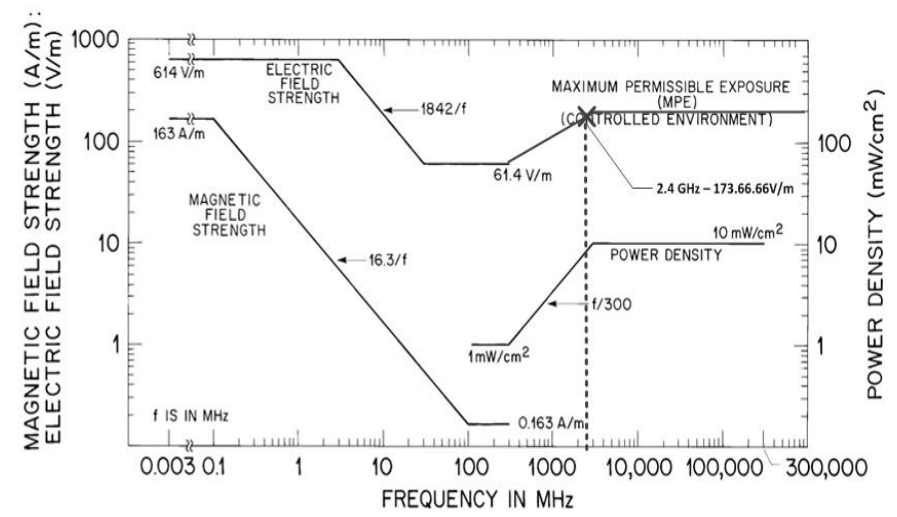

Figura 2.- Umbral de campo-E establecidos por el IEEE para ambientes controlados. Se han indicado los niveles de referencia para la frecuencia particular de estudio: $2.4 \mathrm{GHz}$. 
Normativa de protección frente a radiaciones no ionizantes

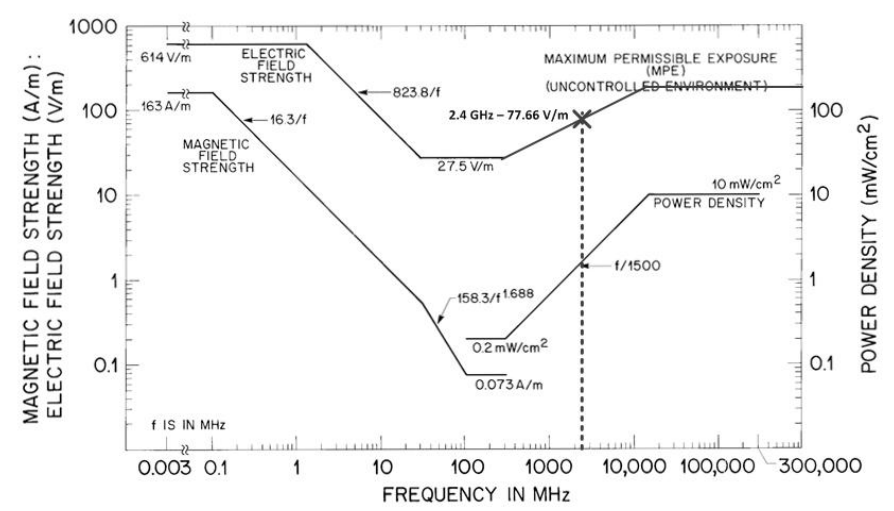

Figura 3.- Umbral de campo-E establecidos por el IEEE para ambientes no controlados. Se han indicado los niveles de referencia para la frecuencia particular de estudio: $2.4 \mathrm{GHz}$.

La Tabla 1 resume los límites de exposición al campo-E que se establecen en los estándares más extendidos (ICNIRP e IEEE). Los límites de exposición se han indicado para la banda de frecuencia Wi-Fi de $2.4 \mathrm{GHz}$.

Tabla 1. Límites de exposición establecidos por el ICNIRP y el IEEE para la frecuencia Wi-Fi de $2.4 \mathrm{GHz}$

\begin{tabular}{lccc}
\hline ICNIRP & ICNIRP & IEEE 95.1 & IEEE 95.1 \\
Público general & Ocupacional & Ambientes controlados & Ambientes no controlados \\
\hline $61 \mathrm{~V} / \mathrm{m}$ & $137 \mathrm{~V} / \mathrm{m}$ & $173.66 \mathrm{~V} / \mathrm{m}$ & $77.66 \mathrm{~V} / \mathrm{m}$ \\
\hline
\end{tabular}

\subsubsection{Europa}

En general los estándares de seguridad vigentes en los países occidentales pretenden proteger contra los efectos biológicos agudos que podrían ser potenciales indicadores de efectos adversos para la salud. En el enfoque occidental se establece como restricción básica los límites de SAR en función de la frecuencia. En contraste las normas denominadas "normas de higiene" 
Normativa de protección frente a radiaciones no ionizantes

(hygienic standards) en los países de Europa del Este (EE) no sólo se basan en los efectos térmicos, si no que pretenden proteger frente a los efectos no térmicos que pudieran ser causados por la exposición crónica y continuada en el tiempo a niveles bajos de exposición, estableciéndose como restricción básica el parámetro denominado carga de energía que se define como el producto de la intensidad de campo y la duración de la exposición [Gaj02], [Roy07]. En general los estándares de exposición a los CEM en los países de EE (Bulgaria, Polonia, Rumanía y Eslovaquia) establecen umbrales de exposición mucho más bajos que los países de Europa Occidental.

Otra característica de los países EE es el concepto se dosis, que se define como la limitación de la duración de la exposición a los CEM de forma acumulada. Se calcula multiplicando la duración de la exposición por $2 \mathrm{~W} \mathrm{~m}^{-2}$, con un límite de hasta 8 horas para el caso del público ocupacional. En el caso del público general se aplica una fórmula parecida pero con límite de tiempo de exposición de 24 horas [Ose03]. En general, el enfoque de la protección, y en particular, los parámetros empleados a la hora de establecer los límites de exposición son diferentes a los utilizados en otras normas internacionales vigentes en los países occidentales [Rep12]. También podrían atribuirse diferencias en las etapas del proceso de elaboración de las normas y estándares, como son, la metodología empleada en los estudios experimentales, las diferentes filosofías para el desarrollo de estándares, los datos científicos utilizados como base para las normas, incluyéndose además diferencias en la percepción del riesgo.

Acerca de la normativa vigente en el resto del mundo, las normas de seguridad más utilizadas en la actualidad son ICNIRP [ICN98] y ANSI/IEEE C95.1 [IEE99]. 
Normativa de protección frente a radiaciones no ionizantes

\subsubsection{América}

Fuera de Europa existen normas internacionalmente reconocidas y desarrolladas por otros órganos, en particular cabe señalar el Instituto de Ingenieros Eléctricos y Electrónicos (Institute of Electrical and Electronics Engineers, IEEE), y la Comisión Federal de Comunicaciones (Federal Communications Commission, FCC) de Estados Unidos (EEUU). A pesar de algunas diferencias de relevancia, tales como la clasificación de los entornos de exposición en entornos controlados y no controladas, en lugar de distinguir distintos tipos de personal expuesto (trabajadores vs. público en general), estas normas muestran una estrecha similitud con el ICNIRP, y presentan el mismo enfoque.

El estándar IEEE C95.1 se emplea en entornos controlados (ocupacional) y no controlados (público en general) en el rango de frecuencia de 300 kHz-100 GHz. La ley correspondiente ha sido emitida por la FCC de EEUU.

En Norte América cabe destacar la situación de Canadá, donde está vigente el Código de Seguridad 6 que proporciona la protección de la población y los trabajadores contra la exposición a los campos electromagnéticos de RF en el rango de frecuencias de $3 \mathrm{kHz}-300 \mathrm{GHz}$. El contenido es una versión ligeramente modificada de la norma IEEE C95.1

En América del Sur, la Organización Panamericana de la Salud promueve estudios epidemiológicos, con el fin de proponer guías y estándares armonizados. Algunos países de América Latina, entre ellos Argentina, Brasil, Chile, Colombia, Costa Rica, Ecuador, México, Perú y Venezuela ya han promulgado una legislación parcial basada en las recomendaciones internacionales. 


\subsection{3 África}

En el continente africano, Sudáfrica es el único país en el que se conoce que se haya establecido una normativa acerca de la exposición a los CEM, que está basada en la norma del ICNIRP, tanto para la población en general como para los trabajadores.

\subsubsection{Asia}

En Asia, la mayoría de los países no han adoptado estándares conocidos, pero existe alguna excepción. En Israel, los límites actuales se basan en las directrices del ICNIRP, aunque se han realizado algunas revisiones: se agrega un factor de seguridad en las directrices medioambientales solo para la exposición del público general. En 2001, Turquía implementó una regulación de la exposición a los CEM para el público general en el rango de frecuencia de $10 \mathrm{kHz}-60 \mathrm{GHz}$. Se establecen niveles de referencia para las magnitudes de campo-E, campo magnético y la densidad de potencia, y las correspondientes distancias de seguridad, sin hacer referencia a las cantidades dosimétricas. Sólo en el caso de la exposición a múltiples frecuencias, se aplican las normas del ICNIRP.

En Japón, las directrices en vigor en el rango de $10 \mathrm{kHz}-300 \mathrm{GHz}$ son coherentes con el ICNIRP, pero existen algunas diferencias. En cuanto al resto de los países asiáticos, sólo los siguientes cuentan con normas específicas conocidas: Singapur, China, Corea del Sur, Taiwán y Filipinas. Singapur ha adoptado directrices de seguridad sobre la base del ICNIRP de cumplimiento voluntario tanto para los trabajadores como para el público general. En China, el Ministerio de Salud ha emitido un estándar referente al establecimiento de límites de exposición de obligado cumplimiento en los ambientes públicos y laborales. En la República de Corea las reglas actuales consisten en pautas de cumplimiento en el 
Normativa de protección frente a radiaciones no ionizantes

ámbito público y ocupacional para la protección de la exposición, así como también existe una normativa en vigor en cuanto a los dispositivos y métodos que se han de emplear para medir los CEM, incluyendo las directrices para la medición de SAR. Filipinas ha adoptado normas de protección radiológica de RF basada en la norma australiana.

\subsubsection{Australia}

En 2002, la Agencia Australiana de Radioprotección y Seguridad Nuclear (Australian Radiation Protection and Nuclear Safety Agency, ARPANSA) publicó un estándar de protección de la exposición a campos de RF de $3 \mathrm{kHz}$ a $300 \mathrm{GHz}$, donde los límites indicados, se basan en las directrices del ICNIRP. La norma también establece requisitos relativos a la protección del público en general y a la gestión de riesgos en la exposición ocupacional, junto con información adicional sobre la medición y la evaluación del cumplimiento.

\subsubsection{España}

En España, el Real Decreto 1066/2001 regula los límites de exposición a los CEM basándose en las directrices establecidas por el ICNIRP para el público en general [RD01].

\subsubsection{Normativa referente a la exposición de trabajadores}

Para completar la descripción de la normativa vigente referente a la exposición de los trabajadores en Europa, cabe describir el proceso de emisión de Directivas por la Unión Europea sobre esta materia. 
Normativa de protección frente a radiaciones no ionizantes

En 2004, el Parlamento Europeo y el Consejo de la Unión Europea emitió la Directiva 2004/40/CE [Dir04], sobre requisitos mínimos de seguridad y salud relativos a la exposición de los trabajadores a los riesgos derivados de los agentes físicos, como los CEM. Esta Directiva en principio previó valores de acción y valores límite basados en el ICNIRP, pero después de la adopción de la Directiva se hicieron públicos varios estudios sobre los efectos en la salud debidos a la exposición a los CEM realizados con posterioridad. Estas publicaciones posteriores justifican el aplazamiento de la fecha límite para la transposición de la Directiva 2004/40/CE, siendo la nueva fecha el 30 de abril de 2012 [Dir08].

Sin embargo, dada la complejidad técnica de la materia, el plazo de la transposición se amplió: la fecha límite de 30 de abril de 2012 se vio reemplazada por el 31 de octubre de 2013 [Dir12].

La comunidad médica manifestó serias preocupaciones sobre el impacto potencial de la aplicación de dicha Directiva en los entornos de uso de equipos de obtención de imágenes médicas y en entornos industriales. Después de examinar atentamente los argumentos expuestos por las partes interesadas y, después de varias consultas, la Comisión decidió volver a examinar a fondo algunas de las disposiciones de la Directiva 2004/40/CE, a partir de la nueva información científica proporcionada por expertos reconocidos internacionalmente. Con el fin de establecer nuevas medidas más apropiadas y proporcionadas para proteger a los trabajadores contra los riesgos asociados a los CEM, se derogó la Directiva 2004/40/CE. La nueva Directiva tiene por objeto abordar todos los efectos biofísicos directos e indirectos causados por los CEM, con el fin no sólo de garantizar la salud y la seguridad de cada trabajador por separado, sino también de crear una base mínima de protección para todos los trabajadores en la Unión. 
Normativa de protección frente a radiaciones no ionizantes

La nueva Directiva 2013/35/EU del Parlamento Europeo y del Consejo, de 26 de junio de 2013, sobre los requisitos mínimos de seguridad y salud relativos a la exposición de los trabajadores a los riesgos derivados de los agentes físicos, deroga la Directiva 2004/40/CE [Dir13]. Se incorporan nuevos límites de exposición internacionales, dejando cierta flexibilidad en los sectores militar y en los ámbitos de uso de los equipos de obtención de imágenes por resonancia, y obligando a los empresarios a establecer medidas de evaluación y reducción del riesgo.

La legislación abarca todos los sectores, pero especialmente aquellos en los que los trabajadores están expuestos a un cierto nivel de riesgo, por ejemplo, la industria del acero o las personas que trabajan largas horas cerca de las estaciones de radiodifusión de televisión y de radio e instalaciones de radar.

En los estudios epidemiológicos se estudian los efectos a largo plazo de la exposición continua, pero no hay consenso sobre las métricas de dicha exposición. La evaluación se realiza en función del tiempo de exposición y de la naturaleza de los CEM en cada caso. La nueva Directiva aborda los efectos biológicos directos a corto plazo, por ejemplo: el calentamiento de los tejidos, la estimulación de los músculos, nervios u órganos sensoriales, y los efectos biológicos indirectos que son aquellos que son debidos a las interferencias con equipos electromédicos como son los marcapasos.

Sin embargo, ante la insistencia del Parlamento, la Comisión tiene la tarea de supervisar el progreso científico, y de establecer nuevas propuestas, si es necesario, para hacer frente a los posibles efectos a largo plazo. Teniendo en cuenta los valores límites se podría restringir el uso de ciertas tecnologías médicas o aplicaciones militares, pero la legislación incluye excepciones en estos sectores 
Normativa de protección frente a radiaciones no ionizantes

siempre que se tomen medidas para evitar los efectos adversos sobre la salud y los riesgos de seguridad.

Bajo las nuevas reglas, se han de evaluar los riesgos de la exposición a los CEM y adoptar las medidas necesarias para reducirlos, por ejemplo, mediante la sustitución de equipos o el uso de mecanismos de blindaje. Los valores límite de exposición a los CEM, y los umbrales a partir de los cuales se han de tomar medidas, ahora están basadas en las nuevas recomendaciones más estrictas del ICNIRP. Los Estados miembros han de poner en vigor las disposiciones legales, reglamentarias, y administrativas para cumplir la presente Directiva antes del $1 \mathrm{de}$ julio de 2016.

\subsection{Análisis de la exposición a las redes Wi-Fi}

La proliferación de puntos de acceso y dispositivos de comunicaciones personales con interfaces inalámbricas, y consecuentemente la aparición de redes de área local inalámbricas, WLAN, ha supuesto un aumento de los niveles de exposición a la frecuencia Wi-Fi $(2.4 \mathrm{GHz})$. No obstante estos niveles se mantienen por debajo de la mayoría de los umbrales de exposición internacionales, en particular los propuestos por el IEEE y el ICNIRP. Aunque hasta el día de hoy ninguna agencia internacional ha expresado su preocupación por los posibles riesgos contra la salud, persiste cierta controversia sobre los posibles riesgos ocasionados por las redes $\mathrm{Wi}-\mathrm{Fi}$ en espacios especialmente sensibles [Sag09], [Pey11]. Ante esta preocupación pública, algunas agencias han exigido que se investigue sobre los posibles efectos peligrosos que conlleva el uso de esta tecnología.

La mayoría de los dispositivos Wi-Fi operan en la banda de 2.400-2.485 GHZ (2.412 GHz-2.462 GHz en EEUU). Este intervalo de frecuencias se corresponde 
Normativa de protección frente a radiaciones no ionizantes

con parte de la banda destinada a aplicaciones médicas, científicas e industriales (industrial-scientific-medical, ISM) de 2.4-2.5 GHz que se emplea para muchos fines, incluyendo su utilización por una gran variedad de dispositivos de comunicaciones digitales que generalmente se encuentran en entornos domésticos: dispositivos Bluetooth y ZigBee, interfaces inalámbricas, teléfonos móviles, medidores del consumo de gas, agua o electricidad, etc., así como otros dispositivos que no son de comunicaciones, como son los hornos microondas [Fos13-1]. La banda ISM también se emplea para otros usos como son los sistemas de calentamiento industrial y las aplicaciones médicas. Se trata de una banda de "uso común" que no requiere de título habilitante para su utilización.

En los últimos años, han aparecido dispositivos Wi-Fi que operan cerca de la banda de $5 \mathrm{GHz}$, o en la banda ISM de 5.725-5.850 GHz, o en otra banda diferente como puede ser 5.15-5.35 GHz. La mayoría de los dispositivos Wi-Fi (independientemente del tipo de protocolo) transmiten en canales que tienen un ancho de banda de $20 \mathrm{MHz}$, aunque 802.11n proporciona la transmisión en dos canales de $40 \mathrm{MHz}$ para aumentar la velocidad de transmisión de datos. La transmisión consiste en trenes de pulsos cuya duración va desde unas pocas décimas de ms, a $10 \mathrm{~ms}$ o menos, dependiendo de la cantidad de datos que estén siendo llevados por el burst (ráfaga). Los pulsos son modulados usando técnicas digitales dependiendo de la variante de 802.11 que esté siendo usada, como son: espectro ensanchado por secuencia directa (Direct-Sequence Spread Spectrum, DSSS), espectro ensanchado por salto de frecuencia (Frequency Hopping Spread Spectrum, FHSS), y multiplexación por división de frecuencias ortogonales (Orthogonal Frequency Division Multiplexing, OFDM). Debido a estas diferentes técnicas de modulación las características espectrales dentro del canal que está siendo utilizado por el dispositivo son diferentes en cada momento. 
Normativa de protección frente a radiaciones no ionizantes

La velocidad a la que se transmiten los datos depende del protocolo empleado, la calidad de la señal, la congestión de la red y otros factores. La velocidad de transmisión en parte determina el número de pulsos, y por lo tanto la cantidad de energía de RF requerida para transmitir un número dado de bytes de datos. A diferencia de los teléfonos móviles, Wi-Fi no emplea control de potencia adaptativo (ajuste de la potencia transmitida desde el cliente según la señal de la estación base).

\subsubsection{Tipología de límites de exposición y sus características}

En lo referente a la máxima potencia permitida para los dispositivos Wi-Fi, varía de unos países a otros. En norte América la máxima potencia permitida es de 1W. En el caso de la Unión Europea, la máxima potencia isótropa radiada equivalente (PIRE) que se permite es $0.1 \mathrm{~W}$ para la banda de $2400-2483.5 \mathrm{MHz}$ [EU13]. Por lo que en Europa se exigen niveles de exposición mucho más bajos que los permitidos en EEUU y Canadá.

Los hornos microondas constituyen una fuente de radiación a la frecuencia WiFi de $2.4 \mathrm{GHz}$. Los hornos están diseñados para mantener la energía dentro del horno, pero existen fugas de pequeñas cantidades de energía a través de las puertas. En Estados Unidos, la máxima densidad de potencia permitida de RF fuera de un horno microondas es comparable con la potencia emitida por un dipolo radiando aproximadamente a $1 \mathrm{~W}$. Sin embargo, los hornos operan con un factor del $100 \%$ siempre que el horno esté encendido, lo que contrasta con el bajo factor de ocupación de los dispositivos Wi-Fi y de la mayoría de los equipos de comunicaciones. 
Normativa de protección frente a radiaciones no ionizantes

En resumen, Wi-Fi funciona bajo limitaciones de potencia y en bandas de frecuencia similares que muchos otros dispositivos de comunicaciones y electrodomésticos del mercado de consumo. Estos dispositivos presentan características muy diversas en lo que respecta al tipo de modulación, ancho de los pulsos y factor de ocupación de la transmisión. Todos son fuentes de energía localizadas cuya intensidad decae muy rápidamente con el aumento de la distancia, lo que complica bastante las comparaciones de los niveles de exposición. Aunque en los hogares existe una gran diversidad de dispositivos de comunicaciones inalámbricos cuyos niveles de emisión de RF varían considerablemente, por lo general, se encuentran siempre muy por debajo de los niveles de exposición recomendados [Fos13-1].

La mayoría de las recomendaciones nacionales e internacionales proporcionan los límites de exposición en términos de potencia absorbida por el cuerpo humano, SAR, (restricción básica), o mediante la densidad de potencia incidente sobre el cuerpo de una persona (nivel de referencia) [ICN98].

\subsubsection{Exposición en ambientes sensibles}

Las WLANs, los dispositivos, y puntos de acceso Wi-Fi ocasionan niveles de exposición que han sido analizados mediante la realización de medidas experimentales y simulaciones [Bar11].

Es sabido que las condiciones de exposición en las redes WLAN dependen de varios factores como son la velocidad de transmisión de los datos y el factor de ocupación. En las conexiones Wi-Fi no hay transmisión de datos continua durante todo el intervalo de la transmisión lo que ocasiona que los niveles de exposición no sean tan elevados. 
Normativa de protección frente a radiaciones no ionizantes

Estudios de ingeniería muestran que la densidad de potencia de pico procedente de los dispositivos Wi-Fi, y la densidad de potencia de pico promediada en el tiempo son altamente variables, pero debido al bajo ciclo de ocupación, el resultado es siempre una pequeña fracción de la densidad de potencia de pico permitida. Como consecuencia, la exposición de RF a las redes WLAN, en condiciones realistas, es siempre una muy pequeña fracción de los límites indicados por el ICNIRP y el IEEE/FCC. En resumen, la baja potencia de operación y el bajo factor de ocupación garantizan el cumplimiento de los límites de la SAR para la exposición localizada [Fin10].

En concreto, en entornos sanitarios se ha mostrado cierta preocupación por las posibles interferencias entre las emisiones procedentes de los dispositivos Wi-Fi y los dispositivos electromédicos [Urd07], [Car11]. Existen estudios donde se ha alertado sobre el riesgo de interferencias en el caso del uso de teléfonos móviles [Tan09], pero sólo hay peligro en los casos en los que el terminal se encuentre demasiado cerca de los dispositivos electromédicos, situación poco probable teniendo en cuenta la forma de uso de estos dispositivos. Con el fin de evitar estas posibles situaciones de riesgo, los fabricantes de dispositivos médicos especifican la distancia de separación mínima que se ha de mantener entre los transmisores de $\mathrm{RF}$ (incluyendo los dispositivos $\mathrm{Wi}-\mathrm{Fi}$ ), y los dispositivos vulnerables como son los desfibriladores implantables o los implantes cocleares [Tri04].

\subsubsection{Efectos biológicos}

Consecuentemente, existe una literatura científica masiva sobre los efectos biológicos de la energía de RF en la banda de frecuencia de $\mathrm{Wi}-\mathrm{Fi}$, aunque pocos estudios se han centrado en la forma de onda que caracteriza el protocolo 802.11. Estos estudios han sido analizados repetitivamente por las agencias de salud. 
Normativa de protección frente a radiaciones no ionizantes

Todos estos trabajos coinciden en la no existencia de peligros para la salud siempre y cuando los niveles de exposición se encuentren por debajo de los límites recomendados (ICNIRP o IEEE) [Fos13-1]. Sin embargo en 2011 la Agencia Internacional de Investigación del Cancer (International Agency for Research on Cancer, IARC) que es parte de la OMS (World Health Organization, WHO) confirma lo que muchos expertos habían advertido: el uso regular del teléfono móvil por los adultos puede aumentar significativamente el riesgo de glioma. Este posible riesgo abarca otros tipos de radiación dentro de la parte de RF del espectro electromagnético: radiación emitida por las antenas de estaciones base, torres de radio y televisión, radar, Wi-Fi, etc.

De acuerdo con la decisión adoptada por el IARC, el nivel de desconfianza no es del todo evidente, por lo que los campos de RF se incluyen como cancerígenos probables de "clase B". Se tomó esta decisión en el contexto particular del uso del móvil a largo plazo, pero no tiene ninguna implicación en los posibles efectos de la salud derivados del uso de los dispositivos Wi-Fi, debido a que las condiciones de exposición son bastantes diferentes [Fos13-2].

\subsection{Normativa sobre compatibilidad electromagnética}

El trabajo que se presenta surge ante el posible riesgo de subestimación de los niveles de exposición a radiaciones no ionizantes en los estudios epidemiológicos que emplean dosímetros como dispositivos de medida.

Numerosos estudios se centran en la obtención de los niveles de exposición a los CEM para verificar del cumplimiento de la normativa referente a la seguridad y salud de las personas [ICN98]. A partir de la normativa de la exposición humana 
Normativa de protección frente a radiaciones no ionizantes

a los CEM, existe un ámbito referente a la compatibilidad electromagnética de dispositivos electromédicos y de equipos de radiocomunicaciones que coexisten en entornos sanitarios.

La aplicación de tecnologías de comunicaciones inalámbricas en entornos sanitarios aporta flexibilidad y movilidad a la monitorización de los pacientes proporcionando una mejor calidad y una reducción del coste de la atención sanitaria. La utilización de sistemas inalámbricos integrados para las aplicaciones clínicas en todo el recinto hospitalario y para las aplicaciones no hospitalarias, supone un funcionamiento más eficiente, efectivo y competitivo del sistema sanitario.

La capacidad de los sistemas eléctricos y electrónicos de funcionar en un entorno electromagnético sin efectos adversos, se conoce como compatibilidad electromagnética (electromagnetic compatibility, EMC). El funcionamiento de cualquier sistema electrónico puede verse alterado si se somete a emisiones electromagnéticas de cierta potencia. Por esta razón, para garantizar la EMC es necesario restringir y controlar las emisiones electromagnéticas, así como asegurar que los sistemas electrónicos presentan la suficiente inmunidad frente a las interferencias electromagnéticas (electromagnetic interference, EMI).

El problema de la EMC en los entornos sanitarios aumenta la preocupación de la existencia de riesgos potenciales de EMI debidos a la diversidad de equipos electrónicos utilizados y las condiciones de seguridad implicadas.

Los esfuerzos realizados para asegurar la EMC entre dispositivos electromédicos y redes de comunicaciones inalámbricas están motivados por las siguientes situaciones:

- Degradación de prestaciones debidas a EMI asociadas a muertes, daños graves o administración errónea de tratamientos. 
Normativa de protección frente a radiaciones no ionizantes

- Utilización de dispositivos médicos en las proximidades de otros dispositivos, cuyas emisiones electromagnéticas pueden causar degradación de prestaciones entre sí.

- Entorno electromagnético cada vez más intenso (por ejemplo, teléfonos celulares y portátiles, sistemas inalámbricos, comunicaciones móviles, sistemas con pagging, telemetría, etc.).

- Dispositivos de telemetría médica que comparten frecuencias de comunicaciones con equipos comerciales y que han registrado incidentes durante tratamientos de soporte vital.

- Degradación de prestaciones en sistemas basados en microprocesador cuyo resultado es la pérdida de datos almacenados y la necesidad de intervención del operador del sistema.

- Aumento del número de hospitales ubicados en las proximidades de estaciones emisoras (y viceversa).

- Los usuarios de los dispositivos no suelen estar informados sobre su entorno electromagnético y sus características de intensidad de campo, distribución de frecuencias, o características temporales.

- Una vez experimentada la degradación de prestaciones del dispositivo médico, es frecuente que el usuario no la asocie con EMI como posible causa de fallo, por lo que el fallo quedará asociado a otra causa.

- Incidentes de interferencias aislados pueden ser imposibles de registrar o de repetir.

- Los usuarios y los fabricantes a menudo disienten sobre la responsabilidad de evitar los problemas de EMI.

- Muchos de los incidentes registrados se podían haber evitado aplicando técnicas de diseño adecuadas, cumpliendo la normativa existente y 
aplicando métodos de prueba para controlar las emisiones y asegurar la inmunidad adecuada.

A parte de las normas relativas a la exposición a los CEM y la salud [ICN98], existe una norma sobre EMC de dispositivos médicos y sistemas de radiocomunicaciones [AEN08].

Organismos reguladores nacionales e internacionales han establecido diferentes límites de niveles permitidos de radiación electromagnética. La Unión Europea ha reconocido la importancia del problema de la EMC, y todos los productos vendidos en Europa deben cumplir los requerimientos indicados. La norma que regula los dispositivos electromédicos, IEC 60601-1-2 [AEN08], establece las pruebas de inmunidad frente a radiaciones en las frecuencias entre $80 \mathrm{MHz}$ y 2.5 $\mathrm{GHz}$ para dispositivos sanitarios de soporte vital y de no soporte vital, y establece los límites de distancias consideradas de seguridad de separación entre los pacientes y los dispositivos acoplados.

La norma IEC 60601-1-2 establece un umbral de $3 \mathrm{~V} / \mathrm{m}$ de exposición a los CEM, por debajo del cual, se garantiza el correcto funcionamiento de los dispositivos electromédicos que se encuentran dentro del área de cobertura de las redes de comunicaciones inalámbricas. 



\section{CAPITULO 4}

\section{Modelos de propagación de sistemas de comunicaciones inalámbricos}

\subsection{Introducción}

Existen diferentes formas de modelar el fenómeno de la propagación de señales de RF en diferentes entornos. La señal emitida por un transmisor sufre una serie de fenómenos hasta llegar al receptor, siendo difícil de predecir la señal recibida en un determinado punto. Las señales transmitida y recibida son diferentes debido a las características del medio de transmisión y a la existencia de diferentes obstáculos. 
Modelos de propagación de sistemas de comunicaciones inalámbricos

Los diferentes modelos de propagación, desde el punto de vista teórico, tienen por objetivo calcular la potencia de la señal recibida.

El crecimiento de la capacidad de los sistemas de comunicaciones móviles, ha supuesto la expansión y la aparición de nuevas redes de comunicaciones inalámbricas de menor área de cobertura que ha permitido la clasificación de los modelos de propagación teóricos según el tipo de entorno, distinguiendo entre entornos interiores y entornos exteriores [Sar03].

\subsubsection{Propagación en entornos exteriores vs. interiores}

En lo referente a la propagación en entornos exteriores, hay que distinguir tres tipos de zonas: urbanas, suburbanas y áreas rurales. Un aspecto importante en los modelos de propagación en exteriores es el perfil del terreno, e incluso la presencia de elementos, como son árboles, edificios, coches, y otros obstáculos (entre los que se pueden incluir las personas) pueden ser tenidos en cuenta. En estos entornos las principales contribuciones al campo total que es detectado en el receptor son: el rayo directo, las reflexiones en el suelo y en las paredes de los edificios, y las difracciones que tienen lugar en las esquinas y en el tejado de los edificios.

Debido al notable crecimiento de los sistemas de comunicaciones de corto alcance, existe un gran interés en la caracterización de la radio propagación en entornos interiores. En cuanto a las diferencias que existen en la implementación de los modelos de propagación en entornos interiores respecto a los modelos de propagación en espacios abiertos merece la pena indicar dos aspectos: las distancias recorridas por los rayos son mucho más pequeñas, y en ocasiones la variabilidad del entorno es mucho mayor aun siendo más corta la distancia entre el transmisor y el receptor. La propagación en el interior de los edificios se basa en 
entornos multitrayecto mucho más complejos que en los espacios exteriores. Esto es debido principalmente a la naturaleza de las estructuras, la disposición de las habitaciones, y lo que es más importante, la variedad de los materiales de construcción que son utilizados.

Como consecuencia de la característica de multitrayecto, en las comunicaciones móviles inalámbricas, los rayos llegan al receptor a través de múltiples caminos, cada uno con su propio ángulo de llegada (angle of arrival, AoA), retardo y atenuación, siendo necesaria la definición de una metodología adaptativa en el modelado de la propagación en interiores, donde es importante tener en cuenta el AoA y el retraso de las señales.

\subsection{Técnicas de construcción de modelos}

Se denomina modelo científico a una representación abstracta, conceptual, gráfica o visual, física y matemática de fenómenos, sistemas o procesos a fin de analizar, describir, explicar, y simular (en general, explorar, controlar y predecir) esos fenómenos o procesos. Un modelo permite determinar un resultado final a partir de unos datos de entrada.

De la definición se puede considerar que la propagación de señales electromagnéticas en un entorno es predecible a través de un modelo. En la literatura existen diferentes clasificaciones, pero desde el punto de vista de la precisión, se diferencian los siguientes tipos de modelos científicos:

- Modelos matemáticos: en estos modelos el fenómeno de la propagación se describe mediante modelos matemáticos. La potencia computacional requerida puede llegar a ser un inconveniente importante debido a la aplicación de fórmulas matemáticas complejas y al elevado número de 
Modelos de propagación de sistemas de comunicaciones inalámbricos

parámetros de entrada.

- Modelos empíricos o estadísticos: este tipo de modelos consisten en la extrapolación estadística de los resultados obtenidos en las medidas experimentales. Su principal ventaja es que permiten integrar las características del entorno de forma global e implícita, sin que tengan que ser aportadas de forma aislada. Por otra parte como desventaja hay que indicar que las capacidades de exactitud y precisión de este modelo dependen de la similitud existente entre el entorno objeto de estudio y el entorno donde se llevaron a cabo las medidas.

- Modelos teóricos: los modelos teóricos de propagación se basan en los fenómenos físicos que existen en los entornos que se pretenden modelar. La principal ventaja es que pueden ser empleados en cualquier tipo de entorno independientemente de sus características sin que por ello se vea afectada su precisión. A la hora de implementar este tipo de modelos se encuentran dos desventajas importantes: son modelos especialmente complejos que requieren una carga computacional excesiva, y con frecuencia llegan a ser poco eficientes. Por otra parte estos modelos generan una gran cantidad de datos lo que requiere sistemas de almacenamiento no sólo eficientes, sino también de gran capacidad. Estos inconvenientes hacen que estos modelos sean más adecuados para el modelado de la propagación en recintos más pequeños. Como ventaja cabe considerar su elevada precisión frente a los modelos empíricos.

- Modelos deterministas: consisten en modelos matemáticos donde las mismas entradas producirán invariablemente las mismas salidas, no contemplándose la existencia del azar ni el principio de incertidumbre. Son modelos cuya solución para determinadas condiciones es única y siempre la misma. 
- Modelos estocásticos: los modelos estocásticos pueden ser considerados como los opuestos de los modelos anteriores, considerándose como intrínsecamente no deterministas. El azar interviene en el modelo, de modo que una misma entrada puede producir diversos estados y salidas de manera impredecible.

- Modelos de caja negra: literalmente se denomina caja negra a todo elemento que es estudiado desde el punto de vista de las entradas que recibe y las salidas o respuestas que produce, sin tener en cuenta su funcionamiento interno. Desde el punto de vista de los modelos de programación son modelos donde sólo se reproduce la entrada y salida del fenómeno, sin preocuparse de lo que pase en el interior.

\subsection{Importancia de los modelos de propagación}

Antes de la confirmación e implementación de los diseños de los sistemas de comunicaciones inalámbricas, deberían conocerse las características de propagación en el entorno mediante la utilización de modelos predictivos. Los modelos de propagación se pueden clasificar atendiendo a parámetros característicos de la propagación, como son las pérdidas de la trayectoria a gran escala, y las estadísticas de desvanecimiento a pequeña escala.

La información referente a las pérdidas de la trayectoria es importante para determinar cuál es el área de cobertura de las estaciones base según su ubicación. Los parámetros a pequeña escala generalmente proporcionan información estadística sobre variaciones de los CEM de forma local, lo que conlleva el cálculo de parámetros importantes que permiten la mejora del diseño del receptor 
Modelos de propagación de sistemas de comunicaciones inalámbricos

y evitan el desvanecimiento multitrayecto. $\mathrm{Si}$ no se realizan predicciones de propagación, las estimaciones de estos parámetros sólo pueden ser obtenidas mediante mediciones de campo que suponen una mayor inversión de tiempo y dinero.

\subsubsection{Modelos específicos, empíricos, y teóricos}

Los modelos predictivos de pérdidas a lo largo de la trayectoria se clasifican principalmente en tres tipos: específicos, empíricos, y teóricos [Isk02].

Como se señaló en la introducción, los modelos empíricos generalmente consisten en un conjunto de ecuaciones derivadas de mediciones exhaustivas, por lo que su aplicación resulta simple y eficiente [Oku68] [Hat80]. Proporcionan una gran precisión si se aplican en entornos con las mismas características que aquellos en los que se realizaron las mediciones. Los parámetros de entrada en este tipo de modelos son generalmente cualitativos y no específicos, por ejemplo, un área urbana densa, o un área rural, etc. Uno de los principales inconvenientes de los modelos empíricos es que no pueden ser usados en diferentes entornos sin que sean modificados, y en algunos entornos directamente no pueden ser utilizados. Por ejemplo, los modelos empíricos que caracterizan la propagación de sistemas de comunicaciones en grandes áreas de cobertura, no pueden ser empleados para predecir la propagación de sistemas diferentes caracterizados por zonas de cobertura menores.

Los métodos específicos están basados en métodos numéricos, tales como el trazado de rayos y el método de las diferencias finitas en el dominio del tiempo (FDTD) [Sei94], [Lia98]. Los parámetros de entrada en este caso son muy detallados y precisos. Las desventajas de estos métodos específicos es la excesiva carga computacional requerida en el caso de entornos complejos. 
En cuanto a los modelos teóricos se derivan de los fenómenos físicos asumiendo algunas condiciones ideales. Por ejemplo, los modelos que caracterizan la difracción sobre los tejados se obtienen a partir de la óptica física suponiendo alturas y espaciado uniforme entre los edificios. Los modelos teóricos son más eficientes que los modelos específicos, y a su vez los modelos específicos son más precisos que los modelos empíricos [Wal88].

\subsubsection{Modelos estadísticos}

Los modelos estadísticos permiten obtener parámetros de propagación, como son el error cuadrático medio referente al retardo, ancho de banda de coherencia, etc. Estos parámetros aportan información de utilidad para el diseño de los receptores así como permiten estimar la tasa de error de bit. También facilitan simulaciones del funcionamiento de los sistemas de comunicaciones y proporcionan procedimientos de medidas referentes a la calidad de servicio (quality of service, QoS).

\subsubsection{Retos de los modelos de propagación}

La rápida evolución de las comunicaciones inalámbricas ha supuesto el uso de la banda de alta frecuencia, y la implantación de redes de áreas de cobertura reducida y sistemas de antenas inteligentes, lo que hace que todo lo referente a las cuestiones de predicción de la propagación sea todo un reto.

En los casos de sistemas de comunicaciones que presentan zonas de cobertura amplias (macroceldas), los transmisores generalmente se encuentran localizados en torres altas, siendo los resultados de los modelos teóricos y empíricos bastante aceptables. En el caso de sistemas de comunicaciones caracterizados por áreas de cobertura mucho más reducidas (microceldas, e incluso picoceldas), la altura de la 
Modelos de propagación de sistemas de comunicaciones inalámbricos

antena transmisora puede que sea mucho más reducida que la altura promedio de los edificios que componen el entorno. En este caso la geometría de los edificios o las características del terreno afectarán enormemente a la propagación de las ondas de radio causando amplias zonas de sombra.

Las ondas de radio en entornos exteriores se propagan a través de los siguientes fenómenos: reflexiones que tienen lugar en las superficies de las paredes de los edificios y en el suelo, difracciones en los esquinas o vértices horizontales y verticales de los edificios, y dispersiones en las superficies rugosas (no lisas), o mediante una combinación de todos estos fenómenos. No existe un modelo estadístico y empírico general que pueda ser usado para la predicción de estos entornos complejos de propagación.

Los sistemas de antenas inteligentes, que aprovechan la diversidad espacial, requieren información sobre el AoA en entornos multitrayecto además de los parámetros habituales, como son las pérdidas de la trayectoria y la dispersión del retardo. Los sistemas de multiple-input multiple-output (MIMO) utilizan la característica de multitrayecto para proporcionar una mayor capacidad [Fos96], [Tar98], siendo completamente diferentes de los sistemas clásicos donde el multitrayecto se considera perjudicial. Todos estos nuevos sistemas implican modelos de canales espaciados en el tiempo y en la frecuencia.

Con el fin de abordar los entornos complejos se han desarrollado modelos de propagación específicos basados en las técnicas de trazado de rayos. El principal objetivo es determinar la trayectoria de un rayo que es lanzado desde una antena transmisora mediante un algoritmo básico de trazado de rayos. Este procedimiento implica el cálculo de la intersección de un rayo con una superficie (en tres dimensiones, 3D), o de un rayo con un segmento (dos dimensiones, 2D). Existe una limitación importante referente a la carga computacional sobre todo en 
entornos complejos y de grandes dimensiones. La eficiencia del cálculo computacional es el obstáculo más relevante en la aplicación de los métodos de trazado de rayos. Un procedimiento de trazado de rayos eficiente es importante para la mejora de la precisión en los procedimientos de predicción de la propagación ante los diferentes tipos de rayos (reflejados, transmitidos, difractados, dispersados y sus combinaciones) que son tenidos en cuenta.

El concepto de predicción implica diferentes aspectos entre los que se encuentran la precisión de las localizaciones del transmisor, receptor, y de los edificios, y un conocimiento preciso sobre los parámetros eléctricos de las paredes y de otros objetos presentes en el entorno. Árboles, postes, coches y peatones en entornos exteriores, y los muebles, en el caso de entornos interiores, pueden influenciar notablemente los resultados. Con el fin de alcanzar todos estos retos, los modelos existentes pueden ser mejorados mediante un conocimiento más preciso del entorno que se pretende caracterizar.

Este trabajo aporta el modelado de la presencia de personas en entornos interiores, comprobándose que su incorporación a los métodos existentes de trazado de rayos proporciona una mejora notable en la predicción de los niveles de señal en dichos entornos.

\subsection{Modelos de pérdidas de trayectorias}

\subsubsection{Modelos empíricos y teóricos}

Los modelos empíricos son bastante adecuados para ser empleados en escenarios exteriores, como son los ambientes urbanos caracterizados por áreas de coberturas extensas (macroceldas), o más reducidas (microceldas). 
Modelos de propagación de sistemas de comunicaciones inalámbricos

En cuanto a los ambientes exteriores el modelo de propagación en espacio libre es utilizado para predecir la potencia de la señal cuando el transmisor y el receptor se encuentran completamente en línea de visión sin que exista ningún obstáculo entre ellos. Los sistemas de comunicaciones por satélite y los enlaces de microondas se pueden modelar como propagación en el espacio libre. Otro método empleado en ambientes exteriores es el modelo de dos rayos donde se consideran dos contribuciones para el cálculo de la señal recibida: el rayo directo y el rayo reflejado en la tierra entre el entre el transmisor y el receptor.

Concretamente en entornos exteriores los modelos de propagación en ambientes urbanos han cobrado gran relevancia. El modelo de Okumura es uno de los más utilizados en zonas urbanas, mientras que el modelo de HATA es una formulación empírica de las gráficas de la información de las pérdidas de la trayectoria proporcionadas por el modelo de Okumura. El modelo COST-231Walfisch-Ikegami hace uso del modelo Walfisch-Bertoni [Har99], y el Dual-Slope es un método basado en el mecanismo de propagación de dos rayos: el rayo directo y el rayo reflejado en el suelo.

Todos estos modelos se traducen en procedimientos matemáticos simples de implementar, aunque su utilización es recomendable cuando no se requiere una precisión elevada.

\subsubsection{Modelos específicos}

Los modelos de propagación específicos, se denominan también modelos determinísticos, y están basados en la teoría de la propagación de ondas electromagnéticas. Al contrario que los modelos estadísticos, los modelos de propagación específicos no se basan en medidas exhaustivas, pero proporcionan 
predicciones precisas de la propagación de las señales a partir de un mayor conocimiento del entorno.

En teoría las características de propagación de las ondas electromagnéticas se podrían resolver de forma exacta resolviendo las ecuaciones de Maxwell. Desafortunadamente esta propuesta requiere operaciones matemáticas muy complejas, así como una considerable carga de computación

\subsubsection{Modelos de trazado de rayos (ray tracing)}

La teoría de rayos es un procedimiento que proporciona métodos específicos y precisos para obtener resultados útiles en las simulaciones. Debería destacarse que el método de trazado de rayos también sirve como punto de partida para el modelado estadístico. Estos modelos están basados en la óptica geométrica (geometrical optics, GO), ver Apéndice A, en la teoría uniforme de la difracción (uniform theory of difraction, UTD), ver Apéndice B, y en los diferentes mecanismos de propagación de rayos, que incluyen: rayo directo, difracción, reflexión, transmisión y dispersión. En algunos casos se consideran combinaciones de estos tipos de rayos, lo que complica y ralentiza el procedimiento de cálculo.

\section{Lanzado de rayos}

El procedimiento básico del trazado de rayos es el lanzado de rayos. Primeramente el rayo es lanzado desde una antena transmisora, a continuación se traza el rayo para comprobar si impacta contra un objeto o es recibido directamente por la antena receptora. En el que caso que un objeto sea alcanzado por el rayo antes de llegar al receptor, en función de la geometría y de las propiedades eléctricas del objeto tendrán lugar alguno o varios de estos fenómenos: reflexión, difracción, transmisión o dispersión. Cuando el rayo llega a 
Modelos de propagación de sistemas de comunicaciones inalámbricos

la antena receptora se calcula la intensidad del campo-E (o la potencia) asociada al rayo.

Este algoritmo presenta una serie de cuestiones fundamentales que necesitan ser consideradas: la primera es cómo lanzar un rayo, la segunda es cómo considerar si un rayo alcanza a un objeto, la tercera, en el caso que existan varios objetos susceptibles de ser alcanzados, cómo determinar cuál de ello es alcanzado y en qué orden, y por último, y en cuarto lugar, cómo determinar si un rayo es recibido.

1) Método de trazado de rayos y criterio de recepción: un rayo es en realidad un tubo de rayos y es por lo general un cono, como se muestra en la Figura 4 Cuando un cono de rayos es usado para cubrir el frente de ondas esférico en el punto de recepción, estos conos tienen que solaparse. En el caso de emplear tubos de rayos, Figura 4 (b), el frente de onda esférico puede ser cubierto sin que se superpongan los tubos de los rayos.

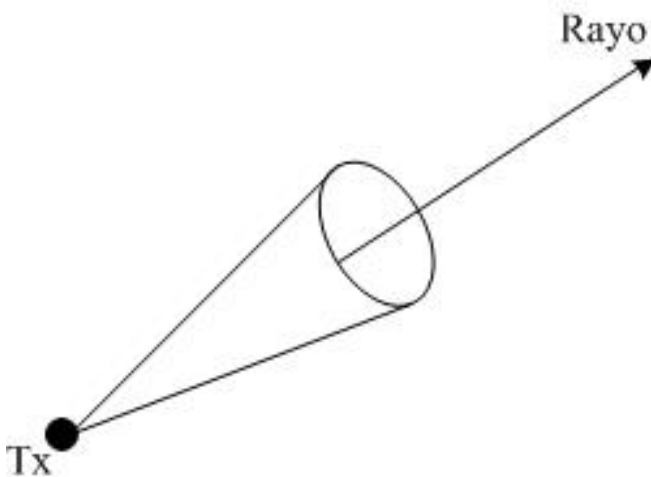

(a)

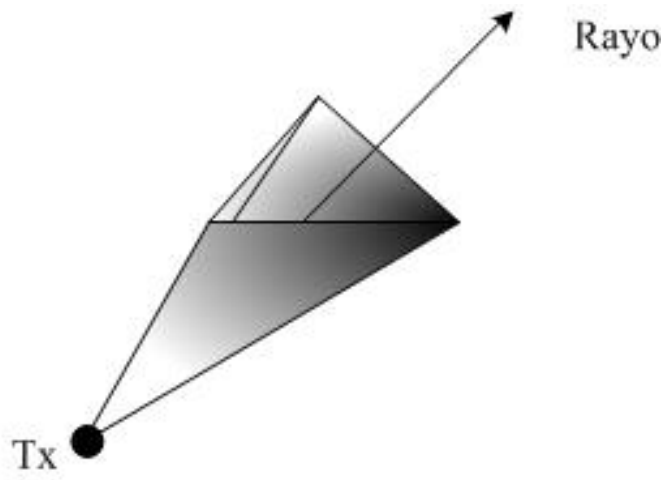

(b)

Figura 4.- Cono de rayos y tubo de rayos. (a) Cono de rayos. (b) Tubo de rayos. 
Para determinar si un rayo es recibido o no por una antena receptora, se ha de comprobar si el punto de recepción se encuentra dentro del tubo o del cono de rayos. Si es así el rayo será recibido, en caso contrario el rayo no será recibido.

Cuando el punto de recepción se encuentra localizado en un área donde hay solapamiento entre los conos de rayos, el receptor recibirá dos rayos, teniendo lugar un recuento doble de rayos.

2) Prueba de intersección de un rayo con un objeto: Para determinar si un rayo impacta contra un objeto, se tiene que comprobar la intersección del rayo con el objeto. Es un problema clásico de geometría. El método sencillo de lanzado de rayos comprueba todos los objetos para determinar si hay intersección, por lo que en el caso que exista un gran número de objetos esta comprobación puede llegar a ser bastante ineficiente.

\section{Método de las imágenes}

El método de las imágenes es un método simple y preciso para determinar la trayectoria de los rayos entre el transmisor (Tx) y el receptor (Rx). La Figura 5 muestra la idea básica del método de las imágenes. Para este caso simple, primeramente se determina la imagen del Tx por reflexión en la pared W1 (Tx1 en la Figura 5). A continuación se calcula la imagen de Tx1 debido a la pared W2 (Tx2). Uniendo Rx con el punto Tx2, se determina el punto de reflexión P2 en W2. El otro punto de reflexión (P1) es el punto de intersección entre la pared W1 y el segmento que une los puntos P2 y Tx1. 
Modelos de propagación de sistemas de comunicaciones inalámbricos

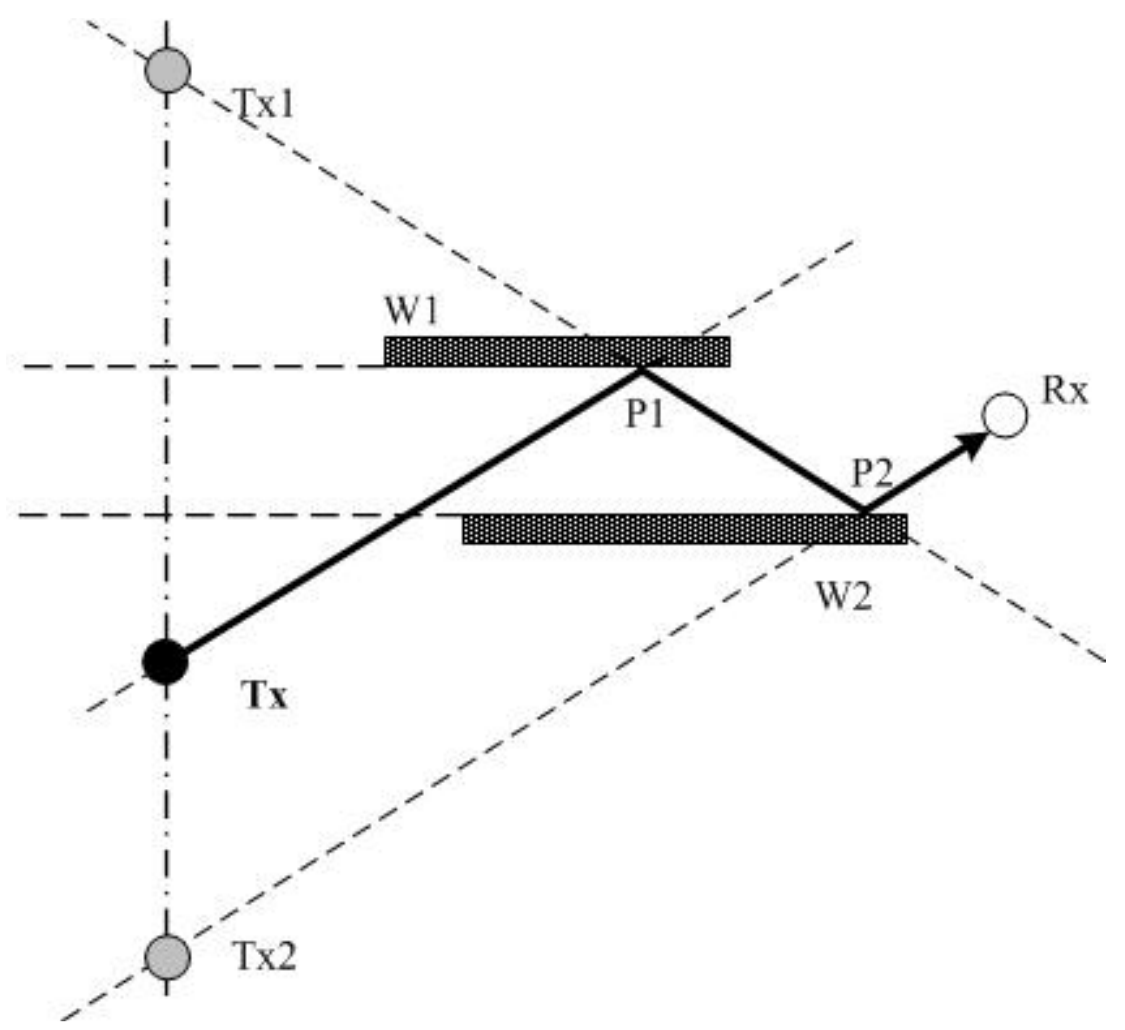

Figura 5.- Gráfico ilustrativo del método de las imágenes.

El método de las imágenes es preciso, pero resulta ineficiente cuando el número de paredes implicadas es elevado y cuando el número de reflexiones también es elevado. En el caso de aplicaciones reales, existen técnicas especiales como las técnicas híbridas y las técnicas de aceleración que son usadas para reducir el tiempo de computación.

\section{Método híbrido}

[Tan96] propone un método híbrido mediante la combinación de las técnicas del trazado de rayos y del método de las imágenes. El método del trazado de rayos se emplea para identificar rápidamente una posible trayectoria desde el transmisor al receptor. Cuando se determina la trayectoria, se identifican las paredes 
involucradas, y los puntos exactos de reflexión se pueden determinar de forma precisa mediante el método de las imágenes. Este método presenta las ventajas del empleo de ambos métodos, como son la eficiencia (técnica del lanzado de rayos) y la precisión (método de las imágenes).

\section{Algoritmos de aceleración de trazado de rayos}

El método de trazado de rayos es un método específico de predicción de la propagación que se caracteriza por ser simple y muy extendido, pero sin embargo, computacionalmente es poco eficiente. Con el fin de abordar esta importante desventaja se han propuesto varios métodos que se han denominado algoritmos de aceleración de trazado de rayos, los cuales proponen diversas técnicas que aportan más eficiencia al método convencional de trazado de rayos. Primeramente se reduce el número de objetos en los que el rayo puede incidir, para seguidamente acelerar el cálculo de los puntos de intersección. Todos los métodos de aceleración consisten en el preprocesamiento de los entornos de propagación y de las posiciones del transmisor y del receptor. A continuación se realizará un breve resumen de cada uno de estos métodos.

\section{1) Buffer angular}

La idea básica es dividir el espacio en regiones angulares acorde a un punto de origen, que puede ser el transmisor o una imagen del transmisor asociada a un plano de reflexión. Cuando un rayo es lanzado desde un punto de origen, sólo los objetos ubicados en la región angular que contiene el rayo son los que serán tenidos en cuenta para una posible intersección. Este método puede acelerar el algoritmo de trazado de rayos, pero cuando se dan múltiples reflexiones, el preprocesamiento llega a ser bastante complejo, debido a que se precisa un buffer angular por cada punto de origen, teniendo en cuenta que se entiende por punto de origen el transmisor y todas sus imágenes generadas. 
Modelos de propagación de sistemas de comunicaciones inalámbricos

\section{2) Algoritmo de búsqueda de trayectos de rayos}

Se basa en la idea de aplicar las rutinas de trazado de rayos sólo en aquellas áreas dónde sea probable que los rayos existan. Para ello se define el árbol de visibilidad para limitar la aplicación de las pruebas de intersección únicamente en aquellas zonas donde sea de interés. El árbol de visibilidad está formado por varias capas, la primera está formada por todos aquellos objetos que son visibles desde el transmisor, o que se encuentran en su línea de visión, LoS. La segunda capa contiene los objetos que son visibles desde la primera capa. Y las capas siguientes se constituyen estableciendo la misma relación de forma recursiva.

Cuando un rayo es lanzado desde un transmisor, sólo los objetos que se encuentran en la primera capa del árbol de visibilidad van a ser tenidos en cuenta para determinar el cálculo de los puntos de la reflexión en la primera intersección. Para determinar la n-ésima intersección del rayo, sólo se necesita comprobar los objetos en la capa n-ésima, lo que conduce a ahorrar tiempo de cálculo.

Este método presenta los mismos inconvenientes que el método del buffer angular, por ejemplo, cuando los niveles de intersección son altos, el establecimiento del árbol de visibilidad será más complejo y más lento.

Por otra parte, merece la pena mencionar la técnica de las "zonas de iluminación", que consiste en limitar cada una de las imágenes (y de la propia fuente principal) a una determinada área iluminada, tal que sólo se comprobará si hay intersección del rayo con los objetos que pertenecen a dicha área. La Figura 6 muestra el concepto de las áreas de iluminación, donde BS1 es la imagen de BS con respecto a la pared1 (W1), y BS2 (imagen de segundo orden) es la imagen de BS1 con respecto a la pared2 (W2). El receptor, que en la figura es MS, se encuentra en la zona iluminada por BS2. 


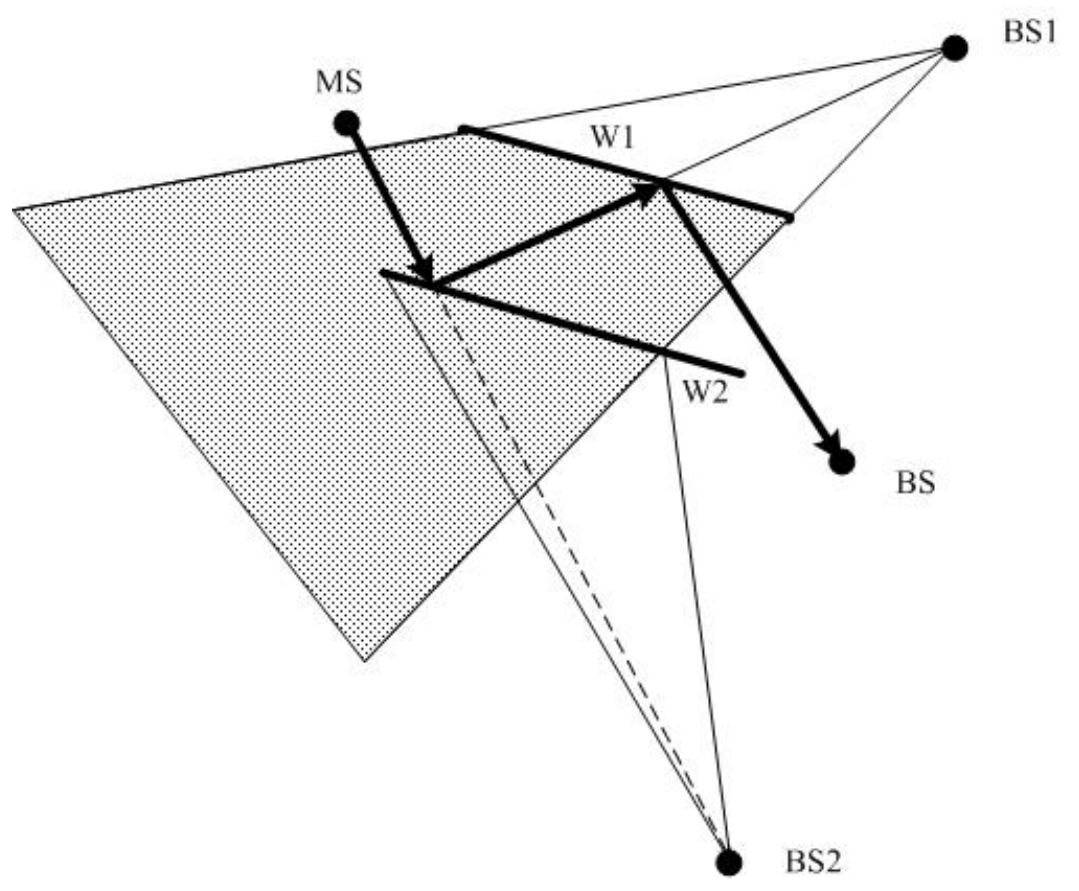

Figura 6.- Concepto básico de generación de imágenes y trazado de trayectos usando zonas de iluminación de las imágenes.

\section{3) Método de la reducción de las dimensiones 2D-2.5D}

Para alcanzar la eficiencia en los métodos de trazado de rayos y obtener una precisión aceptable, los algoritmos de trazado de rayos se pueden llevar a cabo en entornos que no son del todo 3D: $2.5 \mathrm{D}$.

Cuando en una región las alturas de los edificios son mucho mayores que la altura del transmisor, los rayos se propagan de forma lateral, es decir, la altura de los edificios se puede considerar infinita. En este caso el entorno complejo en 3D se puede considerar como un entorno mucho más simple de 2D lo que supone un gran ahorro en lo referente al tiempo de cálculo de los algoritmos implementados. Este método se basa en la teoría de las imágenes, y se ha empleado en trabajos 
Modelos de propagación de sistemas de comunicaciones inalámbricos

donde se han obtenido buenos resultados en comparación con las medidas realizadas $[\operatorname{Rod} 10]$.

4) Método de división en el espacio

Este método se emplea especialmente en la composición de gráficos del trazado de rayos. La idea básica es crear una cuadrícula (generalmente rectangular) en el entorno de propagación, y establecer una tabla para registrar los objetos ubicados en cada una de las celdas que componen la cuadrícula. Cuando se lanza un rayo, su trayecto se traza en la cuadrícula. Para cada celda que es atravesada por el rayo, la tabla de consulta proporciona los objetos que se encuentran en dicha celda. En caso afirmativo, se verifica si se produce una intersección entre el rayo y estos objetos, en cuyo caso se creará un nuevo rayo mediante las técnicas de la reflexión, difracción o transmisión, según corresponda. El trayecto de los nuevos rayos será trazado en la cuadrícula para repetirse de nuevo todo el proceso.

Este método proporciona rapidez y eficiencia, debido a que el algoritmo de trazado en la cuadrícula puede ser bastante rápido y la comprobación de la intersección se realiza con un número muy reducido de objetos. Existen dos tipos de métodos de división espacial que se resumen a continuación: división rectangular y división triangular.

- División rectangular: este método se caracteriza porque el trazado del rayo en la cuadrícula es muy rápido. La principal característica de este método es que las paredes han de estar colocadas en las líneas que componen la cuadrícula para ser lo suficientemente eficientes.

Cada una de las celdas de la cuadrícula se etiqueta con un número de identificación en función de la habitación o edificio en el que se 
encuentren, es decir, las celdas de una misma habitación cuentan con la misma identificación.

Cuando un rayo pasa de una celda a otra, y la etiqueta de la celda actual es diferente a la de la celda anterior, se considera que el rayo choca contra la pared que limita las dos celdas. De lo que se deduce que en este método se trata de evitar el algoritmo de comprobación de la intersección empleado en los métodos de división espacial habituales. Como resultado el tiempo empleado de la CPU se reduce notablemente.

- División triangular: este tipo de métodos presentan una gran mejora en cuanto al tiempo de CPU invertido. La principal característica de este tipo de métodos es que para encontrar el segmento sobre el que incide el rayo, sólo se precisa calcular dos productos vectoriales.

La Figura 7 describe el procedimiento básico: cuando un rayo, por ejemplo $\boldsymbol{u}$, que es trazado desde la fuente $\mathrm{P}_{0}$ abandona el primer segmento de corte, $A B$ en el triángulo $A B C$, se necesita determinar qué borde $A C$ o $B C$, será el siguiente. Se construye un vector unitario $v$, desde el punto de intersección en el segmento $A B$ y el punto $C$, que es el vértice opuesto al segmento $A B$. El signo del producto vectorial entre $\boldsymbol{u}$ y $\boldsymbol{v}$ determina el segmento sobre el que incidirá el rayo. Si el signo es positivo el rayo incide sobre $B C$ y si es negativo incide sobre $A C$. 


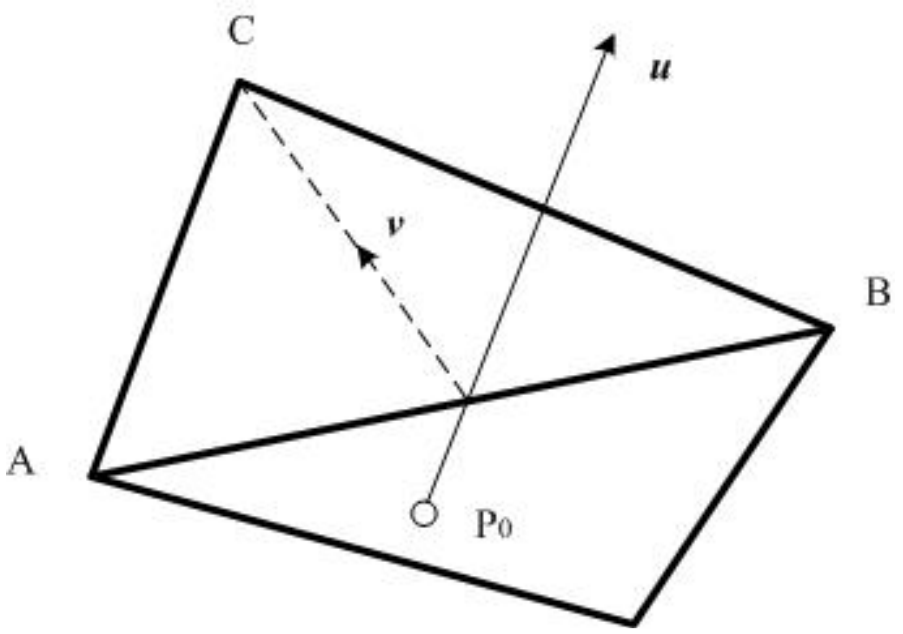

Figura 7.- Determinación del borde sobre el que incidirá el rayo en el método de división triangular

\subsubsection{FDTD}

Mediante la GO y UTD los algoritmos de trazado de rayos generalmente proporcionan una solución bastante simple para los problemas de predicción de radio propagación. Sin embargo, la GO proporciona buenos resultados para los objetos eléctricamente largos, y UTD proporciona el rigor suficiente únicamente en bordes perfectamente conductores. Por ejemplo, para el caso de estructuras que presenten pérdidas con dimensiones finitas, la técnica del trazado de rayos falla en la predicción del campo dispersado. En entornos de comunicaciones complicados las antenas transmisoras y receptoras están a menudo instaladas muy cerca de estructuras compuestas de materiales con propiedades complejas para las cuales no se obtienen soluciones del todo fiables.

Estos problemas se pueden resolver mediante las ecuaciones de Maxwell. En particular el método de las diferencias finitas en el dominio del tiempo, FDTD, es una alternativa. La ventaja del método de la FDTD es su precisión, y que 
simultáneamente proporciona una solución completa aportando información sobre la cobertura de la señal en un área dada.

En entornos exteriores simples, se aplica la FDTD en dos dimensiones. También se emplea para el estudio de áreas próximas a las estructuras compuestas de materiales complejos, donde las soluciones basadas en trazado de rayos no son lo suficientemente precisas.

Como cualquier procedimiento numérico, la FDTD requiere gran cantidad de memoria para llevar un registro de los resultados obtenidos en cada una de las localizaciones, y extender los cálculos a posibles actualizaciones en sucesivos instantes de tiempo. La aplicación de un método preciso de análisis numérico para modelar un área completa no es práctico, debido a la gran cantidad de recursos computacionales que son necesarios, y a su vez puede llegar a ser poco necesario en espacios abiertos donde no hay demasiados objetos.

\subsubsection{Método de los momentos}

Los modelos de trazado de rayos se pueden emplear con suficiente precisión para predecir la cobertura radio en edificios grandes que disponen de un gran número de paredes entre el transmisor y el receptor, mientras que el método de los momentos (Method of Moments, MoM) es mejor cuando se requiere una mayor precisión y cuando el tamaño del edificio es más pequeño. Una combinación de estos dos modelos también es posible, aprovechándose de las ventajas de cada uno de ellos. Para casos donde hay muchos obstáculos pequeños, o donde hay caminos que no pueden ser considerados en el trazado de rayos, MoM ofrece una buena solución.

Las soluciones que aporta este método son numéricamente exactas siempre y cuando la segmentación espacial usada para los objetos sea lo suficientemente 
Modelos de propagación de sistemas de comunicaciones inalámbricos

pequeña. Debido a las limitaciones computacionales de memoria y CPU, el MoM generalmente se emplea para el análisis de los objetos cuyo tamaño es del orden de decenas de la longitud de onda. Sin embargo, en el caso de estructuras cuyas dimensiones son de unas pocas longitudes de onda, el MoM puede ser usado para comprobar y verificar los resultados obtenidos tras la aplicación de la técnica de trazado de rayos.

\subsubsection{Modelos de redes neuronales artificiales}

El principal problema de los modelos estadísticos suele ser la precisión, mientras que los modelos específicos carecen de eficiencia computacional. Se puede alcanzar un compromiso entre ambos problemas mediante los modelos de redes neuronales artificiales (RNAs).

La implementación de los modelos RNAs requiere una base de datos en la que todas las zonas son clasificadas en diferentes categorías, por ejemplo, muros, pasillos, ventanas, etc.

El modelo recibe como entradas las categorías de objetos que existen en el entorno, la distancia normalizada entre emisor $\mathrm{y}$ receptor $\mathrm{y}$ finalmente información sobre el número y tipo de materiales que se van a encontrar dentro de los diferentes tipos de las categorías. La salida del modelo es el nivel de campo resultante. Para determinar los parámetros del modelo, hay que proporcionar datos de medidas tomadas sobre el terreno, que se denominan datos de entrenamiento.

El uso de RNAs ha mostrado muy buenos resultados en problemas con conjuntos de datos ruidosos, con una leve no linealidad en la predicción de niveles de campo. Otra característica clave de las RNAs es el paralelismo que presentan, permitiendo la rápida evaluación de la solución. 
Aunque los procesos de aprendizaje pueden tomar varias horas, el proceso posterior para la predicción de niveles es rápido. La precisión de cada modelo obtenido depende en gran medida de la complejidad de los nodos o neuronas de los que conste.

A pesar de todo lo comentado, las redes neuronales multicapa padecen inconvenientes relacionadas con la convergencia lenta e impredecible hacia la solución durante el aprendizaje. Para superar este inconveniente se hace uso de las funciones de base radial (Radial Base Functions, RBFs) que mejoran la capacidad y tiempo de aprendizaje.

\subsubsection{Otros modelos}

A parte de todos los mencionados anteriormente, se han introducido otros métodos para la predicción de la propagación en el diseño de sistemas de comunicaciones móviles. Algunos de estos modelos se describen a continuación.

\section{Modelo de la ecuación parabólica}

Este modelo ha sido aplicado en el modelado de la propagación de ondas de radio en un entorno urbano. La versión parabólica de las ecuaciones de Maxwell, permite un tratamiento completo de la dispersión electromagnética en tres dimensiones, que no es posible con las versiones escalares del algoritmo. Es especialmente útil para el modelado preciso de la dispersión ocasionada por un único edificio, o por un grupo de edificios, a la frecuencia de microondas. Entre los posibles ejemplos de su utilización cabe destacar la dispersión producida por un edificio cuyo techo tiene forma de semiesfera, y la dispersión de un grupo de edificios con tejados inclinados.

Modelo de la aproximación de campo lejano 
Modelos de propagación de sistemas de comunicaciones inalámbricos

Este método es substancialmente más rápido que las técnicas convencionales basadas en ecuaciones integrales. La técnica ha sido mejorada mediante la introducción de la función de Green. El método se ha aplicado a terrenos suavemente ondulados, y se ha comparado con resultados experimentales a la frecuencia de trabajo de $900 \mathrm{MHz}$. Se ha empleado esta técnica para abordar problemas complejos referentes a las dispersiones producidas por bordes, cortes y rugosidades presentes en el perfil del terreno. Los resultados numéricos obtenidos presentan buena conformidad con los resultados de las medidas experimentales realizadas.

\section{Modelo de guía de onda}

En zonas metropolitanas, donde existen edificios de gran tamaño, las alturas de las antenas de transmisión y recepción son inferiores a las alturas de los tejados. En términos de propagación de señales, las calles se pueden considerar como estructuras de guía de onda. En este caso, existe la necesidad de desarrollar un algoritmo eficiente para el cálculo y el mapeo de la distribución del campo en estas estructuras. Este método propone un análisis teórico de la propagación modelando las calles como guías de onda ranurada en tres dimensiones. Las características de propagación estadística en una guía de onda tal se expresan en términos de múltiples rayos aproximándose al observador. Estos algoritmos para la predicción de las pérdidas de propagación se han comparado con datos experimentales, obteniendo buenos resultados.

\section{Modelo de Boltzmann}

Este modelo fue inicialmente desarrollado para la simulación del flujo de fluidos. Describe un sistema físico en términos del movimiento de partículas microscópicas ficticias en una retícula. Es una técnica que puede tener en cuenta condiciones de contorno bastante complicadas. Se han llevado a cabo 
simulaciones en dos dimensiones, concretamente empleando mapas de entonos urbanos. Es un método simple y fácil de implementar que proporciona buenos resultados en comparación con mediciones realizadas in-situ.

\subsection{Modelos de desvanecimiento a pequeña escala}

El modelado a pequeña escala hace referencia al desvanecimiento multitrayecto que generalmente se analiza mediante los modelos estadísticos de propagación. El desvanecimiento a pequeña escala consiste en los cambios en la amplitud y fase, que experimenta la señal, como consecuencia de pequeños cambios en la distancia de separación entre el transmisor y el receptor. Estos cambios en la envolvente de la señal recibida se describen estadísticamente mediante procesos estocásticos.

Existen diferentes tipos de funciones estadísticas que permiten caracterizar las variaciones de la envolvente de la señal que es detectada como consecuencia del aumento, o disminución, de la distancia entre el transmisor y el receptor. Los principales modelos estadísticos se describen a continuación.

\subsubsection{Modelos estadísticos}

Existen diferentes modelos estadísticos que caracterizan la función de distribución de probabilidad de la señal recibida. Algunas de las distribuciones estadísticas son: Ricean, Rayleigh, LogNormal, Suzuki, Nakagami y Weibull. Como se indicará más adelante algunos de estos modelos son típicos de la propagación en exteriores, y otros en interiores. 
Modelos de propagación de sistemas de comunicaciones inalámbricos

Existen otros modelos estadísticos para los desvanecimientos que consisten en una combinación de dos de los indicados anteriormente y que han sido ampliamente utilizados [Sar03].

\subsection{Resumen de los modelos de pérdidas de propagación}

Se ha presentado un resumen de varios modelos empleados en la predicción de las pérdidas de propagación. La Tabla 2 recopila los modelos citados señalando cuáles son los empleados en entornos interiores y exteriores. Se presenta una comparación de los principales modelos que se han presentado [Sar03], distinguiendo dos enfoques diferentes. Uno de los enfoques consiste en los modelos empíricos o estadísticos, que se caracterizan por emplear parámetros obtenidos empíricamente mediante medidas experimentales. La segunda propuesta son los métodos específicos entre los que se encuentra el trazado de rayos.

Cada una de estas dos propuestas presenta diferentes tendencias en lo referente a precisión vs. complejidad. Los modelos empíricos son extremadamente simples, no emplean información del entorno, únicamente los parámetros necesarios, pero la predicción no es muy precisa. Por otra parte los modelos específicos son más precisos que los modelos empíricos, pero requieren un gran tratamiento de información específica sobre el área de interés, como es la localización de los objetos. 
Modelos de propagación de sistemas de comunicaciones inalámbricos

Tabla 2. Comparación de los principales modelos de pérdidas de propagación.

\begin{tabular}{|c|c|c|c|c|c|c|c|}
\hline Modelo & Entorno & Complejidad & $\begin{array}{l}\text { Datos } \\
\text { experimentales }\end{array}$ & $\begin{array}{l}\text { Detalles del } \\
\text { entorno }\end{array}$ & Precisión & Tiempo & Otros \\
\hline Okumura & $\begin{array}{l}\text { Macrocelda } \\
\text { (exteriores) }\end{array}$ & Simple & $\begin{array}{l}\text { Basado en } \\
\text { experimentos }\end{array}$ & No & Buena & Poco & $\begin{array}{l}\text { Gráfico de } \\
\text { pérdidas de } \\
\text { propagación }\end{array}$ \\
\hline Hata & $\begin{array}{l}\text { Macrocelda } \\
\text { (exteriores) }\end{array}$ & Simple & No & No & Buena & Poco & \\
\hline $\begin{array}{l}\text { COST- } \\
231 \\
\end{array}$ & $\begin{array}{l}\text { Microcelda } \\
\text { (exteriores) }\end{array}$ & Simple & No & No & Buena & Poco & \\
\hline $\begin{array}{l}\text { Dual } \\
\text { Slope }\end{array}$ & $\begin{array}{l}\text { Microcelda } \\
\text { y picocelda } \\
\text { (región } \\
\text { LoS) }\end{array}$ & Simple & No & No & Buena & Poco & \\
\hline $\begin{array}{l}\text { Trazado } \\
\text { de rayos }\end{array}$ & $\begin{array}{l}\text { Exteriores } \\
\text { e interiores }\end{array}$ & Complejo & No & $\mathrm{Si}$ & $\begin{array}{l}\text { Muy } \\
\text { buena }\end{array}$ & Mucho & \\
\hline FDTD & Interiores & Complejo & No & $\begin{array}{l}\text { Cada } \\
\text { detalle }\end{array}$ & La mejor & Mucho & $\begin{array}{lr}\text { Uso } & \text { con } \\
\text { trazado } & \text { de } \\
\text { rayos } & \\
\end{array}$ \\
\hline MoM & Interiores & Complejo & No & $\begin{array}{l}\text { Cada } \\
\text { detalle }\end{array}$ & La mejor & Mucho & \\
\hline RNA & $\begin{array}{l}\text { Exteriores } \\
\text { e interiores }\end{array}$ & Complejo & $\mathrm{Si}$ & Detalles & $\begin{array}{l}\text { Muy } \\
\text { buena }\end{array}$ & Poco & \begin{tabular}{lr}
\multicolumn{2}{l}{ Precisa tiempo } \\
para conocer \\
los r datos \\
experimentales
\end{tabular} \\
\hline
\end{tabular}

\subsection{Introducción del efecto sombra en los modelos de propagación}

Después de presentar los distintos modelos de predicción de la propagación de señales, es interesante exponer cómo diferentes trabajos de investigación han considerado el efecto sombra en la aplicación de estos modelos teóricos.

Hasta ahora, los métodos de predicción de propagación deterministas propuestos para los recintos interiores son útiles para la estimación de las pérdidas de propagación promediadas en entornos reales que generalmente suelen tener una 
Modelos de propagación de sistemas de comunicaciones inalámbricos

geometría complicada. Pero por otra parte, estos métodos generalmente fallan, o simplemente no consideran el efecto sombra del cuerpo humano en interiores.

Se han realizado trabajos empíricos basados en estudios experimentales en los que se describe el efecto sombra del cuerpo humano, pero no existe ningún modelo apropiado que puede ser usado conjuntamente en combinación con los métodos de propagación deterministas.

El efecto sombra del cuerpo humano es un fenómeno significativo y característico de la propagación en entornos interiores, y que también influye de manera notable en los espacios abiertos. En contraste con los entornos exteriores, la potencia de transmisión es menor en los recintos interiores, pero tal como se expondrá en los capítulos siguientes, la dispersión de propagación por el efecto sombra afecta a la intensidad de la señal recibida en entornos multitrayecto donde varios rayos contribuyen a la potencia recibida.

Existen trabajos que han introducido un nuevo modelo, que proporciona una forma de estimar el efecto sombra del cuerpo humano de forma determinista conjuntamente con los métodos de trazado de rayos existentes. En concreto, [Oba98] describe de forma detallada un procedimiento que consiste en la combinación del modelo de sombra del cuerpo humano con los modelos deterministas de trazado de rayos, prediciendo además la influencia de la posible presencia de individuos que obstaculizan el radioenlace. Se demuestra que el modelo propuesto puede estimar el peor caso en cuanto a las pérdidas de propagación debidas al efecto sombra del cuerpo humano, el cual está muy relacionado con la tasa de interrupción de un enlace de comunicación. Consiste en un modelo predictivo, para hacer frente a las posibles pérdidas de intensidad de los rayos como consecuencia del efecto sombra del cuerpo humano, planteando 
Modelos de propagación de sistemas de comunicaciones inalámbricos

una situación hipotética de presencia de usuarios en el recinto, pero en cualquier caso no resuelve una situación real. 



\section{CAPITULO 5}

\section{Implementación del método de trazado de rayos en interiores}

\subsection{Introducción}

En este capítulo se describe la implementación teórica del método de trazado de rayos para simular las condiciones de exposición a radiaciones no ionizantes en recintos interiores bajo la influencia del efecto sombra del usuario. Como ya se ha indicado el método de trazado de rayos es un método determinístico (o específico) que permite predecir los niveles de exposición al campo-E. El método de trazado de rayos se ha desarrollado en el lenguaje de programación JAVA, y se han 
Implementación del método de trazado de rayos en interiores

empleado diversas técnicas (expuestas en el capítulo anterior) para optimizar su ejecución, como son la teoría de las imágenes y el método 2.5D.

\subsection{Justificación de la aplicación del método de trazado de rayos en el modelo teórico}

Los modelos de propagación en entornos interiores presentan una serie de características diferentes a los modelos de propagación en entornos exteriores. Una característica relevante de los entornos interiores es la existencia de diferentes materiales con diferentes características eléctricas. Las señales transmitidas alcanzan el receptor a través de más de un camino, debido a las reflexiones, refracciones y difracciones que experimentan las ondas de radio como consecuencia de la existencia de diversos objetos tales como paredes, ventanas, puertas interiores, etc.

Los modelos de propagación específicos o deterministas están basados en la teoría de la propagación de ondas electromagnéticas. Al contrario que los modelos estadísticos, los modelos específicos no se basan en medidas exhaustivas, pero si en el conocimiento detallado del entorno, proporcionando predicciones precisas de la propagación de las señales.

En teoría, las características de propagación de las ondas electromagnéticas se pueden programar exactamente resolviendo las ecuaciones de Maxwell. Desafortunadamente, esta propuesta requiere operaciones matemáticas muy complejas y una potencia operacional considerable.

Uno de los modelos de propagación determinista es el trazado de rayos, basado en la GO y que puede ser fácilmente aplicado como un método de aproximación para la estimación de los niveles de los campos electromagnéticos de alta 
frecuencia. Según la GO se considera que la energía puede ser radiada a través de tubos infinitesimales, denominados rayos. Es una forma de prescindir de la naturaleza ondulatoria de los campos electromagnéticos, y de modelar la propagación de señales mediante la propagación de rayos. Estos rayos se propagan de forma perpendicular al frente de ondas y según la dirección de propagación, considerando que el índice de refracción del medio es constante. Por lo tanto, la propagación de la señal se puede modelar a través de la propagación de los rayos.

Bajo el concepto de trazado de rayos, los rayos son lanzados desde el transmisor, y la interacción de los rayos con el propio entorno se describe usando las teorías de la reflexión y de la difracción. En la GO sólo se consideran los rayos directos, reflejados y refractados, que se explicarán a continuación. La teoría geométrica de la difracción (Geometrical Theory of Difraction, GTD), y su extensión uniforme (UTD), complementan a la GO introduciendo los rayos difractados. Mediante la teoría de la difracción se pretende eliminar las discontinuidades que se pueden producir en el cálculo del campo eléctrico, e introducir las correcciones adecuadas, especialmente en las zonas que se predicen con ausencia de señal en la GO.

El principio de Fermat y el principio del campo local son dos conceptos básicos que se extienden al modelo de propagación de rayos. El principio de Fermat establece que un rayo sigue el camino más corto desde el origen hasta el destino, mientras que el principio de campo local establece que los rayos de alta frecuencia producen reflexiones y refracciones cuando inciden sobre una superficie.

El método de trazado de rayos está bastante extendido en la implementación de los modelos de propagación. Hay que tener en cuenta que es mucho más preciso 
Implementación del método de trazado de rayos en interiores

cuando el punto de observación se encuentra situado a una distancia muy superior a varias longitudes de onda respecto a la posición del elemento dispersor. Se asume que todos los elementos reflectantes y dispersores son grandes comparados con la longitud de onda.

En concreto se ha empleado el método de las imágenes, que consiste en la generación de imágenes de una fuente de radiación en todas las superficies que delimitan el entorno de estudio de forma recursiva.

La energía emitida por la fuente de radiación alcanza el destino a través de múltiples reflexiones y contribuye a la energía recibida. Una vez que se ha trazado el rayo con todas sus reflexiones desde el receptor hasta la fuente, se calcula la atenuación asociada a todas las reflexiones.

El valor del campo-E en cada punto de la ruta se ha calculado siguiendo la técnica del trazado de rayos considerando como entradas diversos parámetros del entorno como son la posición del transmisor y del receptor, así como las dimensiones y el tipo de materiales que forman el recinto interior.

La solución implementada se compone de una serie de clases programadas en el lenguaje de programación JAVA. En el desarrollo del modelo propuesto es importante tener en cuenta los siguientes aspectos:

- El número total de rayos que llegan a la posición del receptor depende del número de reflexiones que se consideran en cada una de las posibles superficies que componen el recinto, que también se han denominado facetas.

- La posición del transmisor se define como un punto de tres dimensiones, que se mantiene constante durante toda la ejecución del programa.

- La posición del receptor será, igualmente, un punto de tres dimensiones que va cambiando a lo largo de los puntos predefinidos de la ruta. 
- La obtención de los diferentes rayos se realizará teniendo en cuenta la teoría de las imágenes.

- Se considerará la topología particular del entorno en cada caso para implementar las difracciones de las esquinas.

\subsection{Cálculo teórico de los niveles de campo-E en interiores}

\subsubsection{Características generales}

La parte teórica de este trabajo consiste en contrastar las medidas realizadas en la parte experimental con los resultados obtenidos por un programa de simulación basado en la teoría de imágenes, implementado para tal propósito. El entorno interior considerado consiste en un recinto formado por varias facetas, en concreto, siete paredes, el techo y el suelo.

El modelo se ha desarrollado en diferentes pasos. Se ha implementado la técnica híbrida de la teoría de las imágenes según la cual la generación de imágenes $2 \mathrm{D}$ en los planos vertical y horizontal se combina para obtener caminos en 3D [Zho01].

Primero las paredes, el transmisor y el receptor (todo excepto el techo y el suelo) se proyectan verticalmente en el suelo, considerando como suelo el plano (x, y). Se emplea la técnica de trazado de rayos en 2D en el plano de proyección para obtener rayos 2D desde el transmisor hasta el receptor. En el plano horizontal, el número de rayos resultantes depende del número de reflexiones que se consideran en las paredes. 
Implementación del método de trazado de rayos en interiores

A continuación, por cada camino encontrado en el plano horizontal, se aplica la técnica del trazado de rayos en el plano vertical para obtener la posición de las reflexiones en el techo y en el suelo, y se calcula la altura de cada punto de reflexión para los rayos con reflexiones en superficies verticales. El número de rayos 3D resultantes depende del número de reflexiones consideradas en el techo y el suelo. Por ejemplo en la Figura 8, el transmisor lanza los rayos en diferentes direcciones según el diagrama de radiación de la antena. En el trazado de rayos horizontal se considera una sola reflexión en la pared, lo que se corresponderá con tres rayos en tres dimensiones si se considera el rayo directo, una reflexión en el suelo, y una reflexión en el techo, [Ath00].

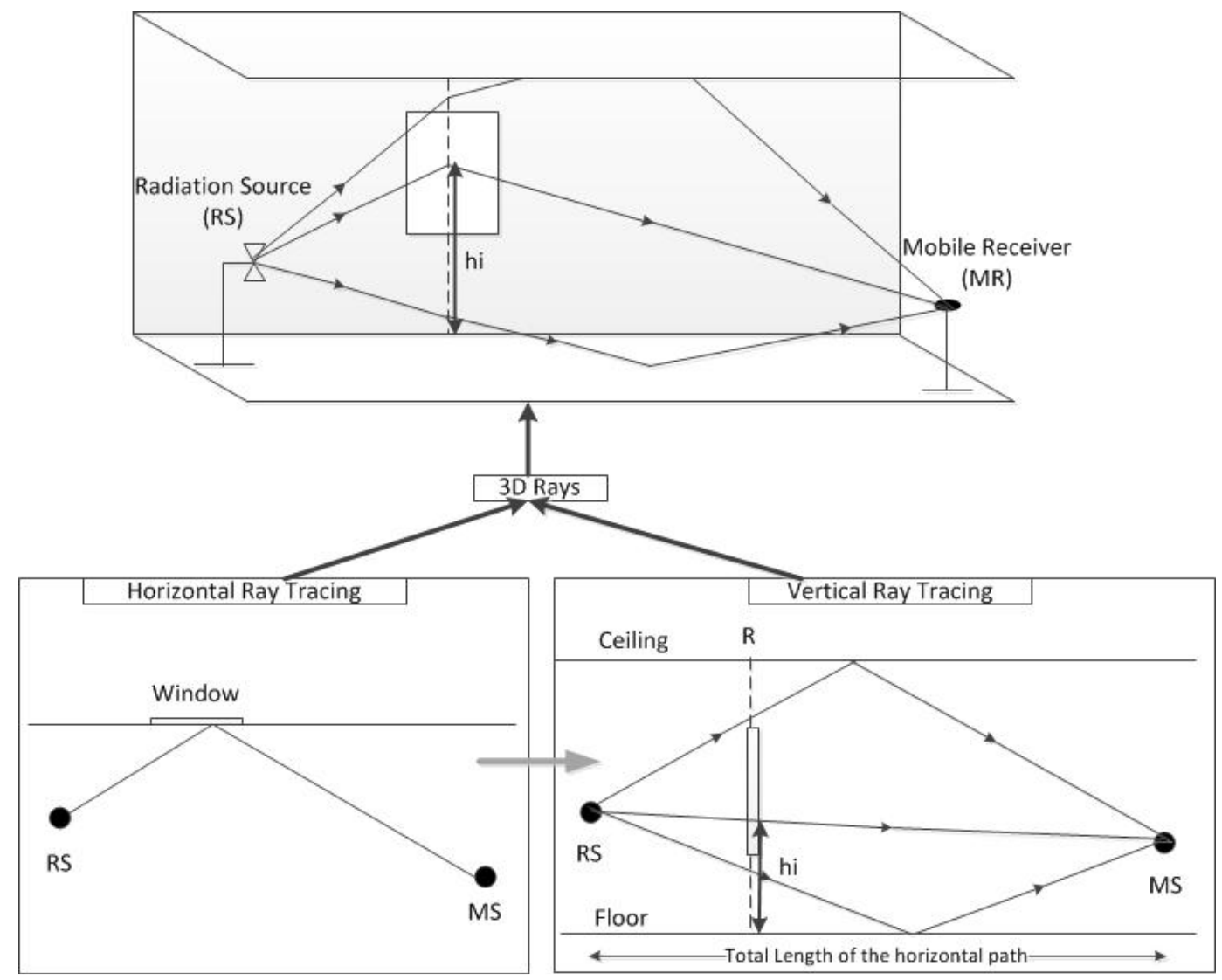

Figura 8.- Técnica híbrida 2D-3D en el trazado de rayos. 
A partir de la descripción del procedimiento del trazado de rayos en tres dimensiones se deduce que el número de reflexiones en cada una de las facetas del recinto es un parámetro de entrada. En este caso el número de reflexiones se ha fijado en 10, en cada una de las facetas que componen el recinto. El área del experimento es un recinto vacío. Generalmente en los modelos de propagación en interiores no se tienen en cuenta los obstáculos que interrumpen el camino directo de los rayos desde el transmisor al receptor [Cat98].

El programa de simulación dispone de varios parámetros topológicos y electromagnéticos, como son las dimensiones del recinto, la posición del transmisor y del receptor, así como las posiciones de la ruta predefinida en las que se ha de calcular el campo-E. Se han considerado las características electromagnéticas de los materiales del recinto, las cuales se indican en la siguiente tabla [Ath00].

Tabla 3. Parámetros electromagnéticos empleados en la simulación.

\begin{tabular}{|c|c|c|}
\hline & $\begin{array}{c}\text { Conductivity } \\
(\mathrm{S} / \mathrm{m})\end{array}$ & 2.5 \\
\hline $\begin{array}{c}\text { Ceiling - } \\
\text { chipboard }\end{array}$ & 0.001 & 7 \\
\hline Floor - Marble & 0.00022 & 3 \\
\hline Lateral walls & 0.005 & 3 \\
\hline Metal & 100 & 6 \\
\hline Glass & 0.0000000001 & 2 \\
\hline Wood & 0.0006 & 2.006 permittivity \\
\hline
\end{tabular}


Implementación del método de trazado de rayos en interiores

Para el modelado de la difracción se ha empleado una extensión de los coeficientes heurísticos de Holm propuestos por [Nec06], y que también han sido utilizados en otros estudios [Rod10].

\subsubsection{Descripción detallada del desarrollo del modelo}

A continuación se describirá el procedimiento que se ha seguido para la composición de los rayos entre el transmisor y el receptor mediante la teoría de las imágenes. Para ilustrar de forma óptima el procedimiento se ha optado por un recinto simple formado por cuatro paredes (superficies verticales), el techo y el suelo (superficies horizontales). La Figura 9 muestra la proyección en 2D de un recinto simple donde las cuatro paredes se han numerado del 1-4.

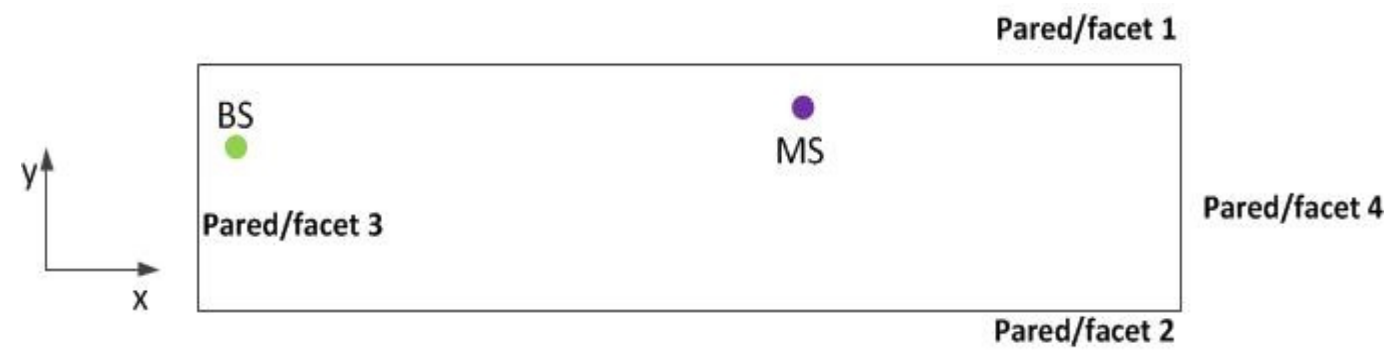

Figura 9.- Recinto en 2D, representado en el plano (X, Y), que se empleará para la obtención de los rayos entre el transmisor (BS) y el receptor (MS) mediante la teoría de las imágenes.

Para la obtención de los rayos en 3D será necesario numerar el techo y el suelo. Se ha considerado que el techo es la pared6 y el suelo es la pared7.

Para explicar el proceso de generación de rayos se ha considerado un rayo con dos puntos reflexión: uno en la pared1 (ver Figura 9) y otro en el techo, que es la pared6. Todo rayo se compone de una serie de puntos donde el primero y el último son el transmisor y el receptor respectivamente, siendo los puntos 
intermedios las localizaciones donde tienen lugar las reflexiones. El proceso de obtención de las coordenadas en 3D de los puntos de reflexión se compone de dos fases:

1.- Fase 2D: en esta fase se obtienen las coordenadas en 2D, o lo que es lo mismo en el plano (x, y), de los puntos de deflexión en las paredes. Por otra parte también permite obtener las coordenadas 2D de los puntos de reflexión en el techo o en el suelo, una vez conocida la distancia de estos puntos con el transmisor, que se calcula en la fase 3D.

2.- Fase 3D: se determina la altura, o coordenada $\mathrm{Z}$, de los puntos de reflexión en las paredes, cuyas coordenadas (x, y) se obtuvieron en la fase 2D. En esta fase también se obtiene la distancia entre el transmisor y los puntos de reflexión en el techo y en el suelo, a partir de la cual se obtienen las coordenadas (x, y) en el sistema de ejes $2 \mathrm{D}$ de la fase $2 \mathrm{D}$.

Se deduce que para determinar las coordenadas 3D de los puntos de reflexión en las paredes, o facetas horizontales, la secuencia de fases sería la siguiente: [fase2D] - [fase3D], mientras que el cálculo de las coordenadas de los puntos de reflexión en superficies verticales (techo y suelo) se compone de la siguiente secuencia de etapas o fases: [fase3D] - [fase2D]. La representación gráfica de la secuencia de fases indicada, en función de la superficie horizontal o vertical en la que tiene lugar las reflexiones, se indica en la Figura 10: 


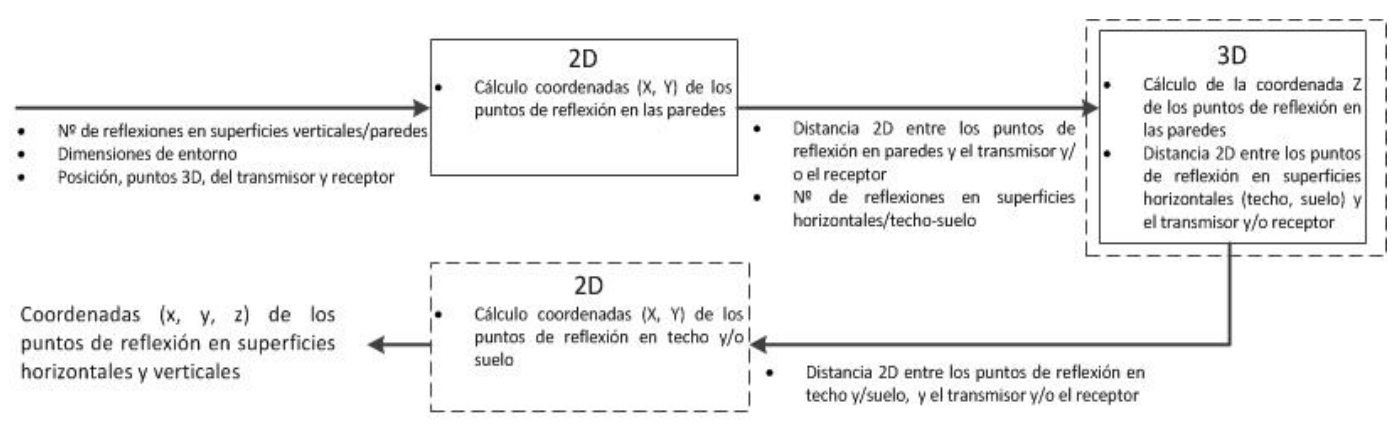

Cálculo de coordenadas de los puntos de reflexión en superficies verticales (paredes)

Cálculo de coordenadas de los puntos de reflexión en superficies horizontales (techo, suelo)

Figura 10.- Secuencia de fases de 2D y 3D necesarias para obtener las coordenadas de los puntos de reflexión en superficies verticales (paredes), y horizontales (techo y suelo).

\subsubsection{Fase en dos dimensiones, 2D}

En la primera fase, para el cálculo de los rayos en 2D, las paredes se proyectan sobre el suelo que es equivalente al plano (x, y). En el plano (x, y) se calculan los rayos entre el transmisor y el receptor según las siguientes propiedades [Ji01]:

1) Cuando un rayo se refleja en el suelo o en el techo, tanto el rayo incidente como el reflejado tienen el mismo azimut, concretamente, las proyecciones de ambos rayos en el plano (x, y) se encuentran en línea.

2) Cuando una pared vertical al suelo refleja un rayo, el ángulo de incidencia es igual al ángulo de reflexión respecto al plano perpendicular sobre el suelo.

3) El ángulo entre el rayo reflejado por una pared y el eje z es igual al existente entre el rayo incidente y el eje $\mathrm{z}$.

4) Los rayos que tienen el mismo ángulo de azimut en un espacio 3D tienen la misma proyección perpendicular sobre el suelo. 
En la Figura 11 el transmisor y el receptor están proyectados verticalmente en el suelo. Mediante el desarrollo del método de trazado de rayos en 2D en la proyección del plano $(\mathrm{x}, \mathrm{y})$, se van a calcular las coordenadas $(\mathrm{x}, \mathrm{y})$ de los puntos de reflexión en las paredes, o superficies verticales.

En esta fase se considerará un caso simple con una sola reflexión en la pared1, para determinar las coordenadas 2D del punto de reflexión se sigue el siguiente procedimiento:

- Primeramente se determina la posición de la imagen del transmisor que se produce por reflexión en dicha pared.

- La imagen obtenida se une mediante una línea recta con el receptor. Dicha línea ha de cortar únicamente a la pared o faceta que produjo la imagen. Si esta última consideración no se cumple, la imagen no está en línea de visión con el receptor, el rayo reflejado en esa pared no llega al receptor y no será tenido en cuenta para el cálculo del campo-E en el receptor.

- El punto de reflexión en la pared1 es el punto donde se cruzan el segmento que define la pared1 y el segmento que une la imagen con el receptor.

- $\quad$ Y por último se une el transmisor con el punto de reflexión en la pared1.

A continuación se compone el rayo, que estará formado por un número de "tramos" dependiente del número de reflexiones que se hayan considerado. En este caso el primer tramo es el segmento definido entre el transmisor y el punto de reflexión en la pared1 (RP1), y el segundo tramo es el segmento delimitado por el $R P 1$ y el receptor.

En la Figura 11 se visualiza el procedimiento descrito de cálculo del punto de reflexión en la pared1, que se resume de la siguiente manera: tras calcular la imagen del transmisor, el punto de reflexión será el punto de corte entre la pared que generó la imagen y el segmento que une la imagen con el receptor. 


\section{Reflexión en pared1}

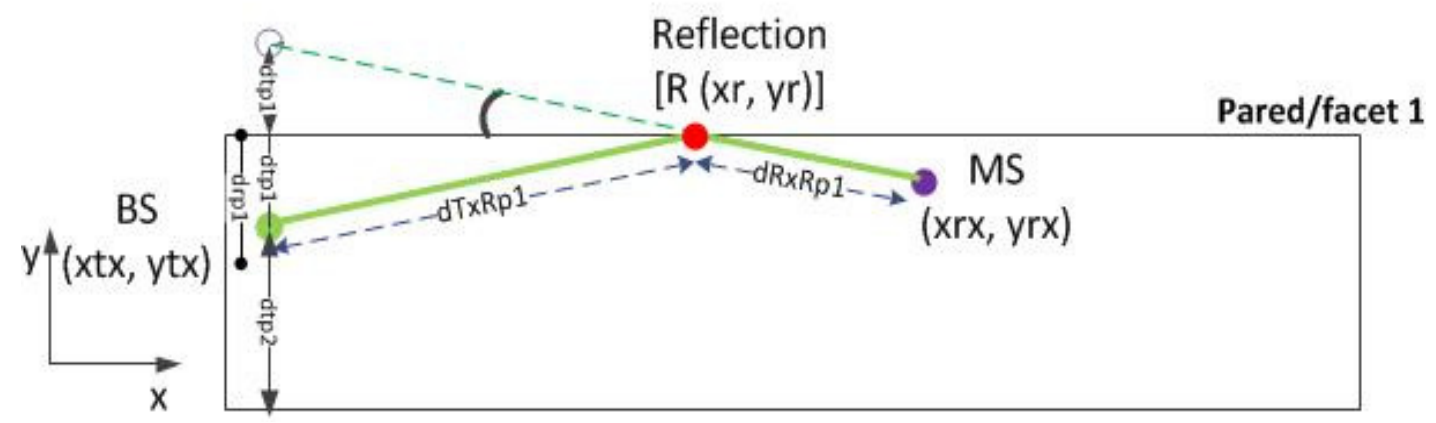

Figura 11.- Obtención en 2D de las coordenadas del punto de reflexión en una de las paredes.

Para el cálculo del camino de los rayos en 3D, y determinar la altura de los puntos de reflexión obtenidos, es necesario determinar la longitud del camino recorrido por el rayo en 2D, que se calcula según la siguiente expresión:

$$
\begin{aligned}
& \text { dtotal2D }=d T x R p 1+d R x R p 1 \\
& =\sqrt{\left(y_{r}-y_{t x}\right)^{2}+\left(x_{r}-x_{t x}\right)^{2}}+\sqrt{\left(y_{r}-y_{r x}\right)^{2}+\left(x_{r}-x_{r x}\right)^{2}}
\end{aligned}
$$

Siendo $d T x R p 1$ la distancia recorrida por el rayo entre el transmisor y el punto de reflexión, y $d R x R p 1$ la distancia recorrida entre el punto de reflexión y el receptor.

Es decir la longitud del rayo en 2D será igual a la suma de los dos tramos de los que se compone el rayo.

En el caso que existan más puntos de reflexión en las superficies verticales del recinto, será necesario generar las imágenes de forma recursiva. El último punto de reflexión será el punto de corte entre el segmento que une la última imagen con el receptor, y la faceta que generó dicha imagen. El resto de puntos de reflexión se van definiendo de forma recursiva como los puntos de corte entre las facetas que 
forman cada imagen y los segmentos definidos por dicha imagen y el punto de reflexión calculado inmediatamente antes.

\subsubsection{Fase en tres dimensiones, 3D}

En la fase 2D se ha definido una ruta en 2D formada por los siguientes puntos:

$$
|[T X]-[R P 1]-[R X]|_{2 D}
$$

Siendo $T X$ el transmisor, $R X$ el receptor, y $R P 1$ el punto de reflexión en la pared1.

Esta ruta en 2D se ha de pasar a 3D [DeA00], para lo que será necesario conocer la coordenada $\mathrm{Z}$ del punto $R P 1$. Al considerarse una reflexión en el techo, la ruta definida en $2 \mathrm{D}$ se traduce en 2 rutas en 3D, una de ellas consiste sólo en una reflexión en la pared1, y la otra consiste en dos reflexiones, una en la pared1 y otra en el techo (o también llamado pared6):

$$
\begin{aligned}
& \text { 1.- }|[T X]-[R P 1]-[R X]|_{3 D} \\
& \text { 2.- }|[T X]-[R P 6]-[R P 1]-[R X]|_{3 D}
\end{aligned}
$$

Se ha de tener siempre en cuenta que se denomina $R P 6$ al punto de reflexión el techo.

La fase 3D permite calcular las siguientes coordenadas de los puntos de reflexión:

- La coordenada Z del punto $R P 1$ cuyas coordenas (x, y) se obtuvieron en la fase $2 \mathrm{D}$.

- La distancia en 2D entre el punto de reflexión en el techo RP6, y el transmisor y/o el receptor. 
Implementación del método de trazado de rayos en interiores

Para realizar estos cálculos en la fase 3D se han de conocer los siguientes parámetros globales de configuración:

- Las alturas del transmisor y del receptor.

- Número de reflexiones en el techo y en suelo.

Las coordenadas $(\mathrm{x}, \mathrm{y})$ del punto $R P 6$ se obtendrán en el sistema de ejes de la fase $2 \mathrm{D}$, considerándose como una vuelta a la etapa anterior.

Es importante considerar en esta fase que el cálculo se realiza en el plano (line, $\mathrm{Z})$, siendo line el eje de abscisas, y definiéndose como la distancia recorrida por el rayo en 2D [DeA00].

A partir de la distancia total de la ruta en $2 \mathrm{D}$, dtotal2D, y las distancias entre el punto $R P 1$ y el transmisor y el receptor, la Figura 12 ilustra el cálculo de la coordenada $\mathrm{Z}$ del punto de reflexión en la pared1, $R P 1$.

\section{PLANO VERTICAL: pared1}

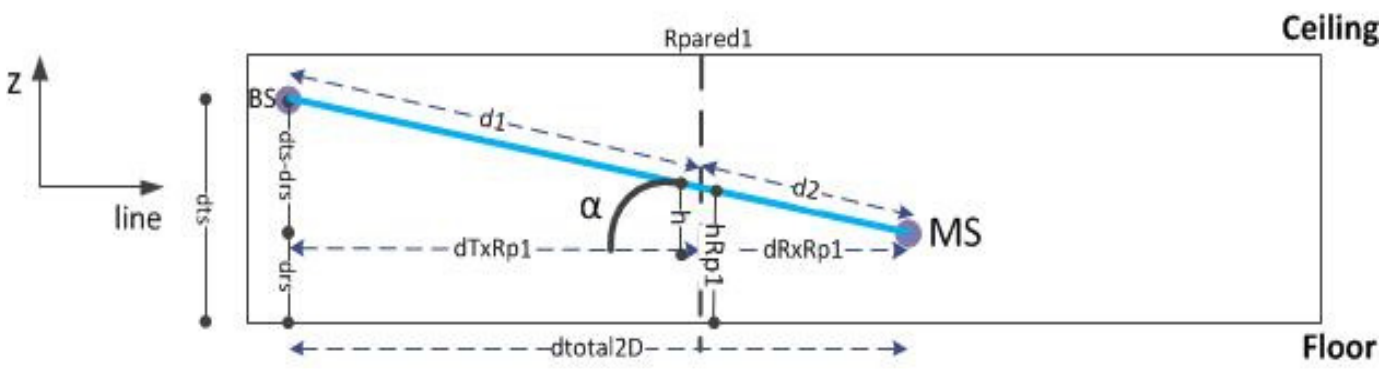

Figura 12.- Obtención en 3D de la coordenada $\mathrm{Z}$ del punto de reflexión en una de las paredes.

La altura del punto de reflexión en la pared1, $h$, se determinará según la siguiente expresión, haciendo uso de teorema de Pitágoras:

$$
\alpha=\arctan \frac{d t s-d r s}{d \operatorname{total} 2 D}=\arctan \frac{h}{d R x R p 1}
$$


Siendo: drs la altura del receptor (respecto del suelo), dts la altura del transmisor, dtotal2D distancia total en $2 \mathrm{D}, \mathrm{y} d R x R P 1$ la distancia entre el punto de reflexión y el receptor.

De la expresión anterior se extrae el valor de $h$, por lo que la altura de $R P 1$ se calcula según la siguiente expresión:

$$
h R p 1=h+d r s
$$

En el caso del rayo formado por las reflexiones en el techo (pared6) y en la pared1, la Figura 13 ilustra el cálculo de la nueva altura del punto de reflexión en la pared.

\section{PLANO VERTICAL: pared1}

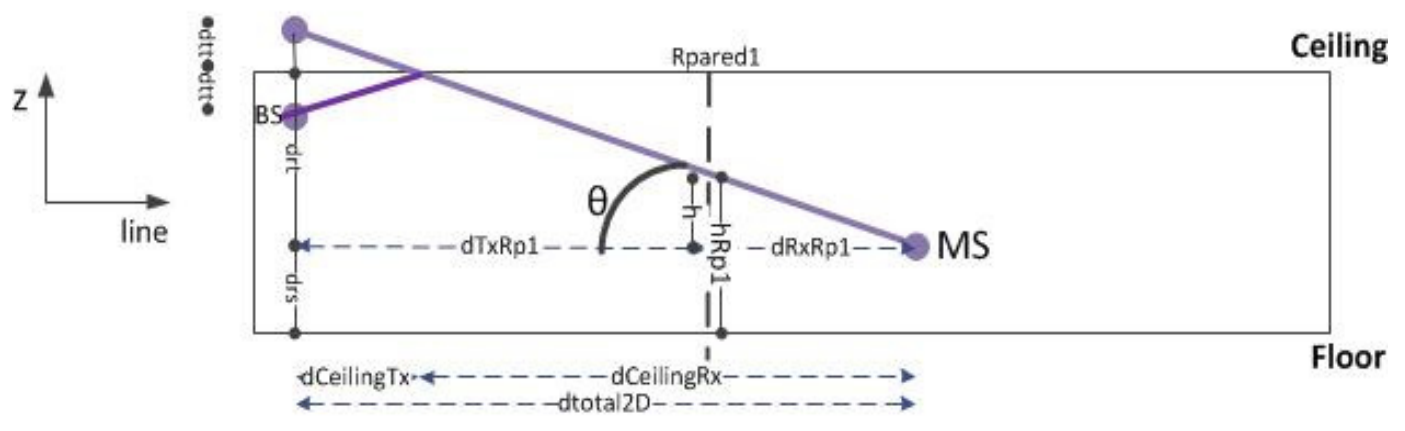

Figura 13.- Obtención en 3D de la distancia con respecto al transmisor del punto de reflexión en el techo.

Primeramente, igual que se ha hecho en la fase 2D, se determina la imagen del transmisor en el techo aplicando la teoría de las imágenes, y siguiendo el procedimiento ya explicado.

Se conocen las distancias entre el trasmisor y el punto de reflexión en la pared1 $R P 1$, que se han obtenido en la etapa anterior (2D). El esquema mostrado en la Figura 13 permite conocer la distancia entre el transmisor y el punto reflexión en 
Implementación del método de trazado de rayos en interiores

el techo. Con esta información se puede extraer el orden en el que tienen lugar las dos reflexiones, ordenándose estos puntos según su distancia desde el transmisor (o receptor).

Según la información aportada en la Figura 13 se calcula la altura, o la coordenada $\mathrm{Z}$, de $R P 1$. La siguiente expresión muestra el cálculo de h que es la altura del punto de reflexión en la pared respecto de la altura del receptor:

$$
\theta=\arctan \frac{d t t+d r t}{d \operatorname{total} 2 D}=\arctan \frac{h}{d R x R p 1}
$$

La expresión anterior permite obtener el valor de $h$. Ahora la altura del punto de reflexión en la pared, o la coordenada $\mathrm{Z}$ de $R P 1$, considerando que además hay un punto de reflexión en el techo, viene dada por la siguiente expresión:

$$
h R p 1=h+d r s
$$

Una vez que se conocen las coordenadas del punto $R P 1$, será necesario calcular las coordenadas del punto RP6. De momento sólo se conoce la coordenada $\mathrm{Z}$ del punto de reflexión en el techo, que es la altura máxima del recinto. A partir de la distancia entre el punto de reflexión en el techo y el transmisor se han de obtener las coordenadas $(\mathrm{X}, \mathrm{Y})$ de dicho punto en el esquema de 2D. Teniendo en cuenta el esquema representado en la Figura 13, la distancia entre el punto de reflexión en el techo y el transmisor, $d$ CeilingT $x$, se calcula según la siguiente expresión:

$$
\theta=\arctan \frac{d t t+d r t}{d \operatorname{total} 2 D}=\arctan \frac{d t t}{d \operatorname{CeilingTx}}
$$

Conociéndose dCeilingTx, la Figura 14 muestra el procedimiento de cálculo de las coordenadas (x y), del punto de reflexión en el techo. 


\section{Reflexión en pared1}

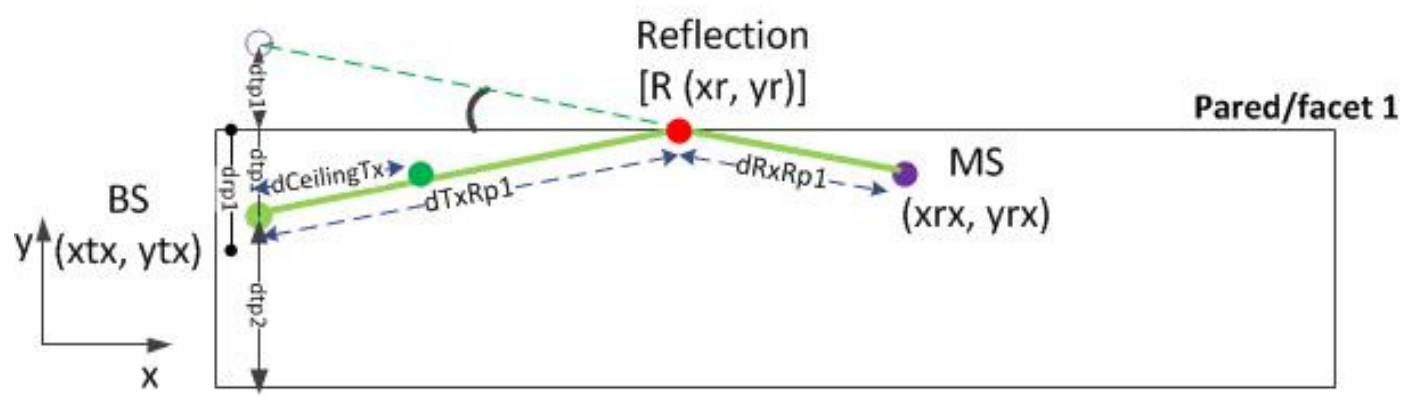

Figura 14.- Plano en 2D donde se indica las coordenadas (xr, yr) del punto de reflexión en una de las paredes. Se indica el punto de reflexión en el techo, cuya distancia respecto del transmisor es dCeilingTx.

El punto de reflexión en el techo tiene lugar entre el transmisor y el punto de reflexión en la pared. Para conocer las coordenadas del punto de reflexión en el techo $\left(\mathrm{x}_{\mathrm{T}}, \mathrm{y}_{\mathrm{T}}\right)$; se aplica de nuevo el teorema de Pitágoras y las reglas básicas de la geometría;

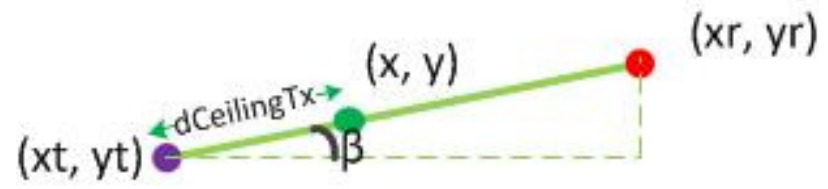

Figura 15.- Visualización del procedimiento de cálculo en las coordenadas del punto de reflexión en el techo, en el plano (x, y).

Las coordenadas buscadas serán ( $\mathrm{x}, \mathrm{y})$ considerando como origen de coordenadas las coordenadas del transmisor (xt, yt). Mediante las siguientes expresiones se calculan las coordenadas $(\mathrm{x}, \mathrm{y})$ teniendo en cuenta el teorema de Pitágoras y las reglas básicas de la geometría:

$$
\beta=\arctan \frac{x_{r}}{y_{r}}=\arctan \frac{x}{y}
$$


Implementación del método de trazado de rayos en interiores

$$
\text { dCeiling } x=\sqrt{x^{2}+y^{2}}
$$

Para obtener las coordenadas respecto del origen de coordenadas $(0,0)$ será necesario tener en cuenta las siguientes expresiones:

$$
\begin{aligned}
& x_{T}=x t+x \\
& y_{T}=y t+y
\end{aligned}
$$

Según el procedimiento descrito se van calculando los puntos de reflexión que componen el rayo. Los rayos quedan definidos como un array de puntos de tres dimensiones, incluyendo el transmisor y el receptor.

Para ilustrar el procedimiento de trazado de rayos se ha expuesto un ejemplo sencillo, donde solamente se han considerado dos reflexiones, una de ellas en una de las paredes verticales, y la otra en una superficie horizontal como es el techo. Si se tienen en cuenta todas las trayectorias del transmisor hasta el receptor se pueden realizar múltiples reflexiones, debido a la característica de recursividad propia de la teoría de las imágenes.

\subsubsection{Característica de recursividad}

Las imágenes del transmisor que se van generando en el proceso de composición de los rayos serán consideradas como fuentes secundarias. En el caso que existan $N$ planos de reflexión, habrá $N$ imágenes de primer orden debido a una sola reflexión; $N(N-1)$ imágenes debido a dos reflexiones, y $N(N-$ 1) $(N-1)$ imágenes si hay tres reflexiones en cada una de las superficies de reflexión, y así sucesivamente.

En la implementación de la simulación se han considerado un número de reflexiones igual a 10 en cada una de las facetas, aplicándose la característica de 
recursividad en el procedimiento de cálculo de los puntos que componen los diferentes rayos.

\subsubsection{Desarrollo del modelo en una fase en 3D}

El método de obtención de coordenadas de los puntos de reflexión que se ha indicado anteriormente está basado en dos fases, una fase en 2D donde se realiza una proyección del entorno global en el plano (x, y), y otra fase en 3D donde además se tiene en cuenta la coordenada $\mathrm{Z}$ de los puntos.

Existe otro método para el cálculo de los puntos de reflexión que se realiza completamente en $3 \mathrm{D}$, en este caso se ha de fijar en qué facetas se va a llevar a cabo la reflexión y el orden en que tienen lugar las reflexiones para obtener las imágenes secundarias. Para componer el rayo la última imagen se une mediante un segmento auxiliar con el receptor, si dicho segmento corta exclusivamente al plano en 3D que determina la faceta que generó la última imagen, ésta es visible desde el receptor. El punto de reflexión en dicha faceta será el punto de intersección entre el segmento auxiliar y dicha faceta. De forma recursiva se van obteniendo los puntos de reflexión que componen el rayo uniendo las imágenes secundarias con los puntos de reflexión que se van obteniendo.

\subsubsection{Concepto de matriz de imágenes}

De la explicación del método de obtención de rayos en 3D surge el concepto de matriz de imágenes que se forma alrededor del recinto de estudio. Cada una de las imágenes que pertenece a la matriz se puede referenciar de dos formas, indicando la secuencia de los identificadores de las facetas que originan dicha imagen por reflexión, o bien mediante tres coordenadas: $(a, b, c)$, cuyo valor depende del orden de reflexión de las facetas, siendo " $a$ " el orden de reflexión a lo largo del 
Implementación del método de trazado de rayos en interiores

eje X, " $b$ " el orden de reflexión a los largo del eje Y, y " $c$ " el orden de reflexión a los largo del eje Z. Se considera $(0,0,0)$ como la fuente transmisora principal.

Las imágenes se van formando por reflexión sucesiva en cada una de las facetas. Por ejemplo, considerando únicamente las reflexiones en el techo y en el suelo, las reflexiones se van produciendo de forma sucesiva en el techo-suelo-etc, hasta alcanzar el orden de recursividad deseado, es decir, si primero la imagen se refleja en el techo dicha imagen luego se reflejará en el suelo, y la imagen resultante otra vez en el techo, de esta forma se van formado imágenes que se van referenciando mediante el sistema de tres coordenadas. Para este caso, en el que las reflexiones tienen lugar en el techo y el suelo, las imágenes que se van formando se referencian mediante la coordenada " $c$ " de la forma que se indica a continuación:

- Reflexión en el techo: $(0,0,1)$

- Reflexión en el suelo: $(0,0,-1)$

- Reflexión en el techo-suelo: $(0,0,-2)$

- Reflexión en el suelo-techo: $(0,0,2)$

Es decir, las imágenes se van numerando según el orden en el que se van formando a lo largo del eje $\mathrm{Z}$ teniendo en cuenta la parte positiva y la parte negativa de dicho eje. Este procedimiento de numeración se indica en la Figura 16: 
Implementación del método de trazado de rayos en interiores

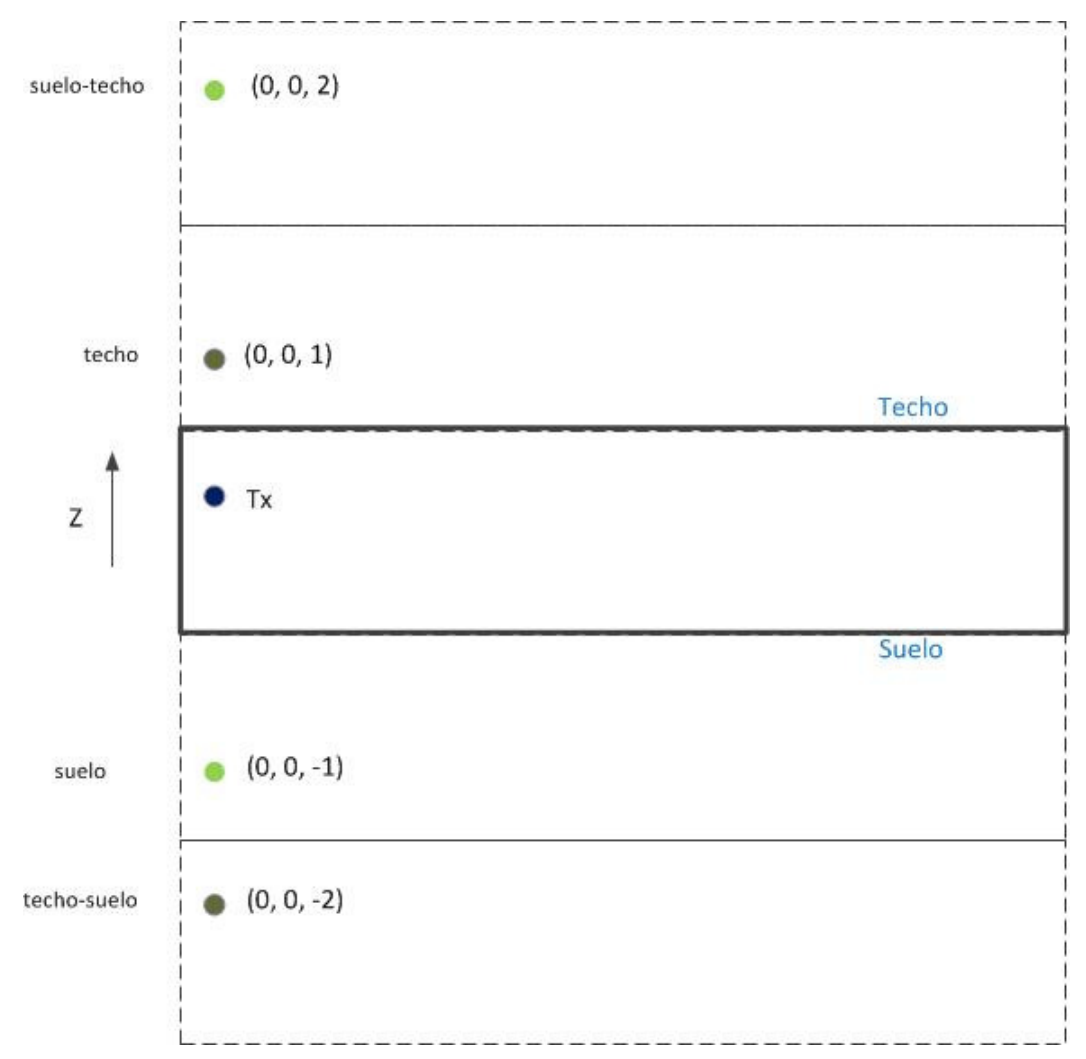

Figura 16.- Descripción del procedimiento de identificación de imágenes a lo largo del eje Z, según el formato $(x, y, z)$.

La Figura 17 muestra la matriz completa de imágenes alrededor del recinto simple, siendo el índice de recursividad igual a 2, donde se ha formado un rayo que sufre dos reflexiones: en la faceta vertical definida por $\mathrm{x}=0$, y otra reflexión en el techo (superficie horizontal). 


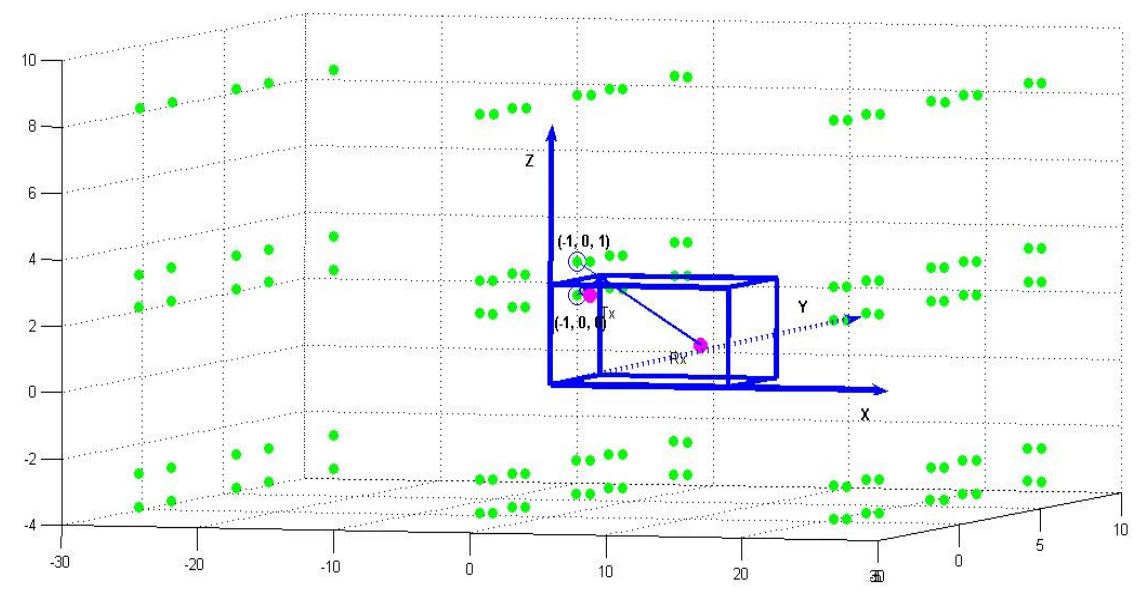

Figura 17.- Visualización del procedimiento de composición del rayo en un recinto de 3D, y la matriz completa de imágenes.

La primera imagen se corresponde con las coordenadas $(-1,0,0)$, se produce por reflexión en la faceta definida por el plano $\mathrm{x}=0$, siendo la primera imagen que se forma en la parte negativa del eje $\mathrm{x}$. La segunda imagen se forma por la reflexión de la anterior en el techo, por lo que la imagen final será $(-1,0,1)$. La coordenada $\mathrm{z}$ será 1 porque es la primera imagen que se forma por reflexión en el techo, quedando situada en la parte positiva del eje z. Para componer el rayo final se unen de forma recursiva las imágenes con los puntos de reflexión, tal como se ilustra en la Figura 18: 


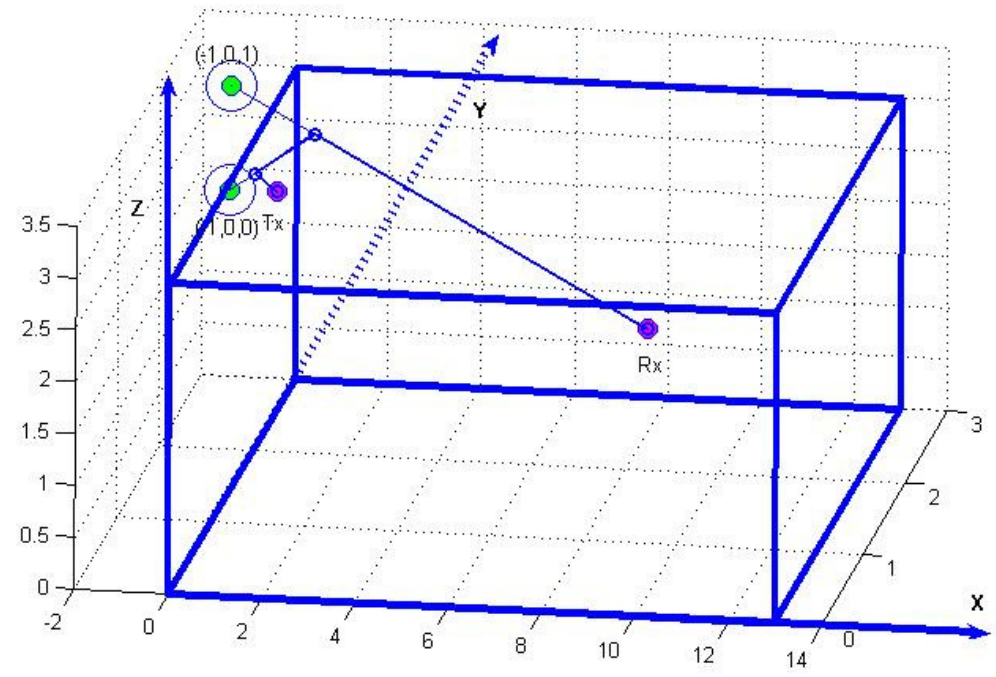

Figura 18.- Visualización del procedimiento de composición del rayo en un recinto de 3D.

En la Figura 19 se visualiza la composición de rayos más complejos indicándose las coordenadas de las imágenes que se van obteniendo hasta componer el rayo final, teniendo en cuenta las dos nomenclaturas. El orden de recursividad llega hasta 4 . La secuencia de facetas donde se producen reflexiones es: $5,2,6,1,2,5,1$, siendo la imagen final $(0,-4,3)$. 


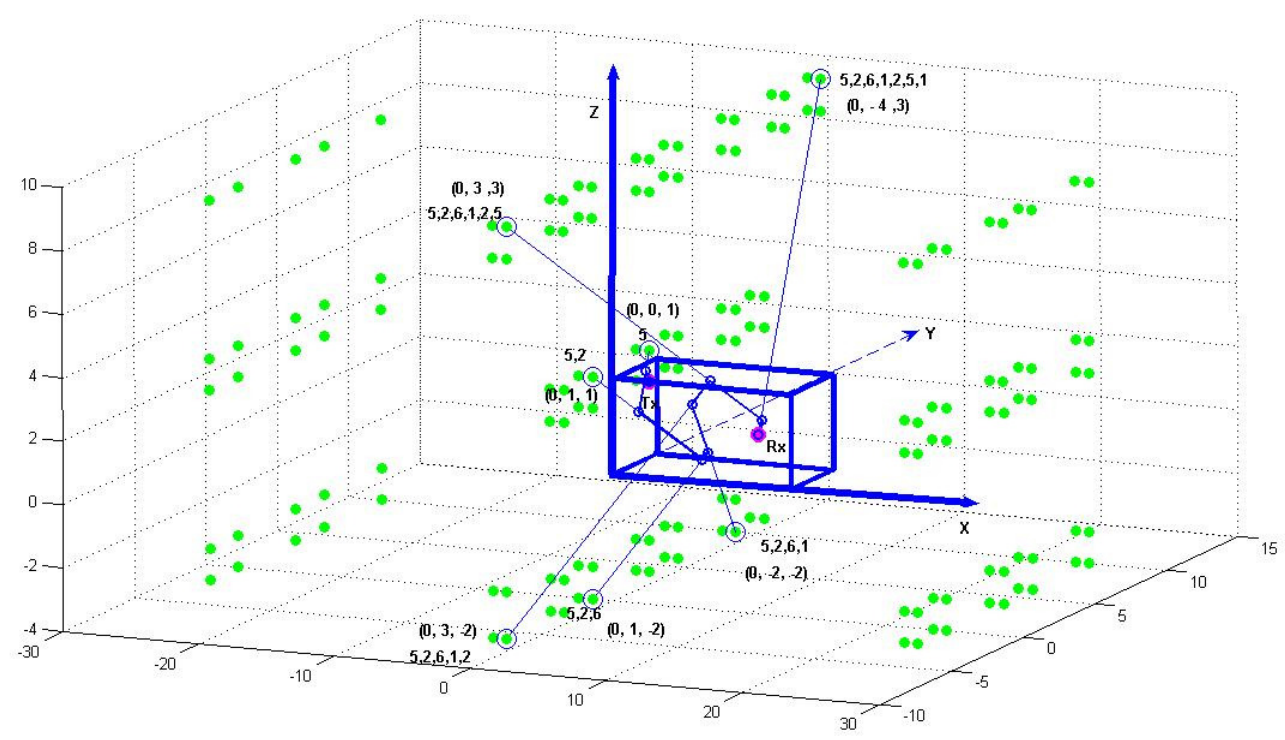

Figura 19.- Visualización en 3D en la composición de los rayos siendo la imagen final $(0,-4,3)$, junto con la matriz global de imágenes alrededor de recinto.

En la Figura 19 se ha empleado la doble nomenclatura para denominar las diferentes imágenes que se van formando. Teniendo en cuenta que la numeración de las paredes es 1-4, 5 el techo, y 6 el suelo, la Figura 20 ilustra de forma más concreta las imágenes que se van formado hasta la composición final del rayo. 


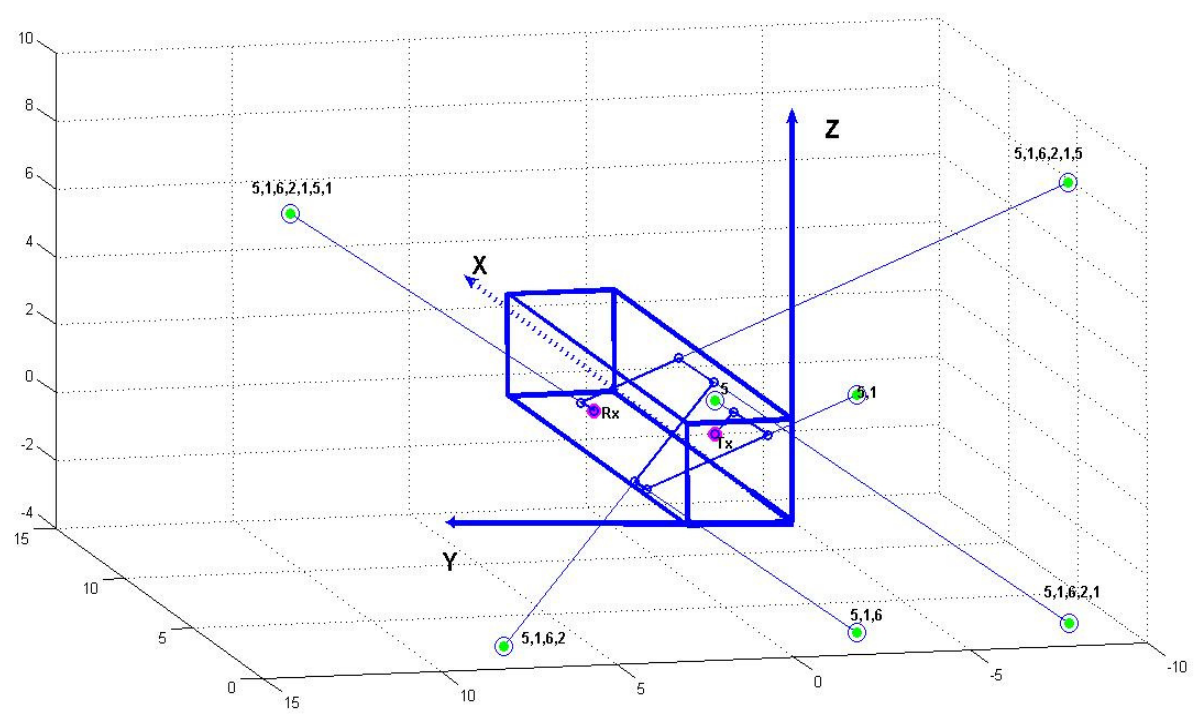

Figura 20.- Visualización en 3D en la composición de los rayos siendo la imagen final $(0,-4,3)$.

Una forma de comprobar si el rayo obtenido es correcto es contrastar la suma de la longitud de los diferentes tramos que componen el rayo con la distancia entre la última imagen y el receptor. En el caso que ambas longitudes coincidan, el rayo se ha obtenido de manera adecuada.

El proceso de trazado de rayos mediante la teoría de las imágenes se ha explicado teniendo en cuenta un recinto homogéneo cuyo volumen constituye un poliedro regular. En este caso cualquier imagen de la fuente en cualquiera de las facetas va a ser visible. La parte experimental se ha realizado en cuatro recintos, tres de ellos son homogéneos, como se ha ilustrado en los ejemplos anteriores, y uno es más irregular, tal como se indica en la Figura 21.

La Figura 21 muestra un plano a escala del primer recinto donde se ha llevado a cabo el primer experimento, que consta de siete paredes donde cada una de ellas se ha numerado del 1-7, siendo 6 y 7 el techo y el suelo respectivamente. 


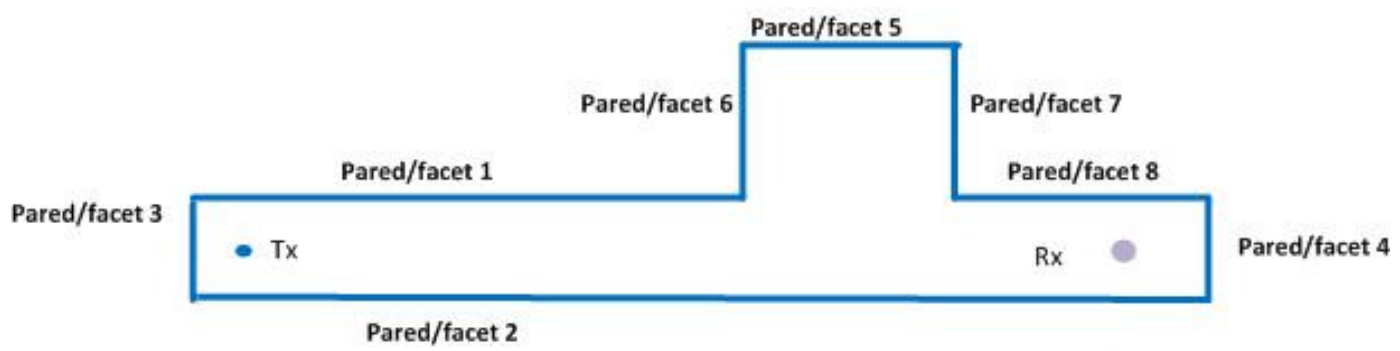

Figura 21.- Esquema del recinto en dos dimensiones donde se ha llevado el primer experimento.

\subsubsection{Aplicación de las áreas de visibilidad}

El método de las imágenes es eficiente en entornos simples. Muchos entornos de la vida diaria son irregulares, y el método convencional de las imágenes adquiere cierta complicación. Cómo ya se ha indicado, para determinar si una imagen de la fuente es visible desde un punto de destino, es necesario trazar un segmento auxiliar desde dicho punto hasta la imagen. Si el segmento auxiliar corta exclusivamente al plano que generó la imagen ésta es visible desde el receptor. Si el segmento auxiliar corta a otro plano o a más de uno, la imagen no es visible y por lo tanto el rayo reflejado no llegará al receptor.

Cada fuente principal o secundaria tiene asociada un área de visibilidad [OBr00]. El área de visibilidad de una imagen se define como la superficie del recinto donde cualquier receptor situado en esa área sería alcanzado por un rayo procedente de dicha imagen. Es necesario puntualizar que todo receptor, faceta, o parte de una faceta perteneciente a esta superficie está dentro de la línea de visión de dicha fuente. La definición de las áreas de visibilidad aporta cierta simplificación al proceso porque permite conocer qué rayos llegarán al receptor, y 
por lo tanto cuáles son los que hay que tener en cuenta para el cálculo del campoE.

Existen dos formas de determinar si un punto del recinto será alcanzado por una fuente, bien comprobando si pertenece al área de visibilidad de la fuente, o bien comprobando que el segmento auxiliar que une el receptor con la fuente corta exclusivamente al plano que generó la imagen.

A su vez una imagen principal o secundaria puede sufrir sucesivas reflexiones. El área de visibilidad además de indicar qué puntos del recinto pueden ser alcanzados por dicha imagen, también permite determinar en qué facetas o planos el rayo puede sufrir otra reflexión, es decir, una fuente (principal o secundaria) se puede reflejar en una faceta o en una parte de ella, siempre y cuando dicha faceta o la parte de ella, pertenezca al área de visibilidad de la imagen original.

Otros trabajos [DeA00] aplican otro criterio, que se indica en la siguiente ecuación donde se considera que una faceta es visible desde una fuente cuando se cumple la siguiente condición:

$$
\hat{n} \cdot \vec{r} \leq 0
$$

Siendo

$\hat{n} \quad$ vector normal a la faceta;

$\vec{r} \quad$ vector que une la fuente con uno de los vértices de la faceta. 


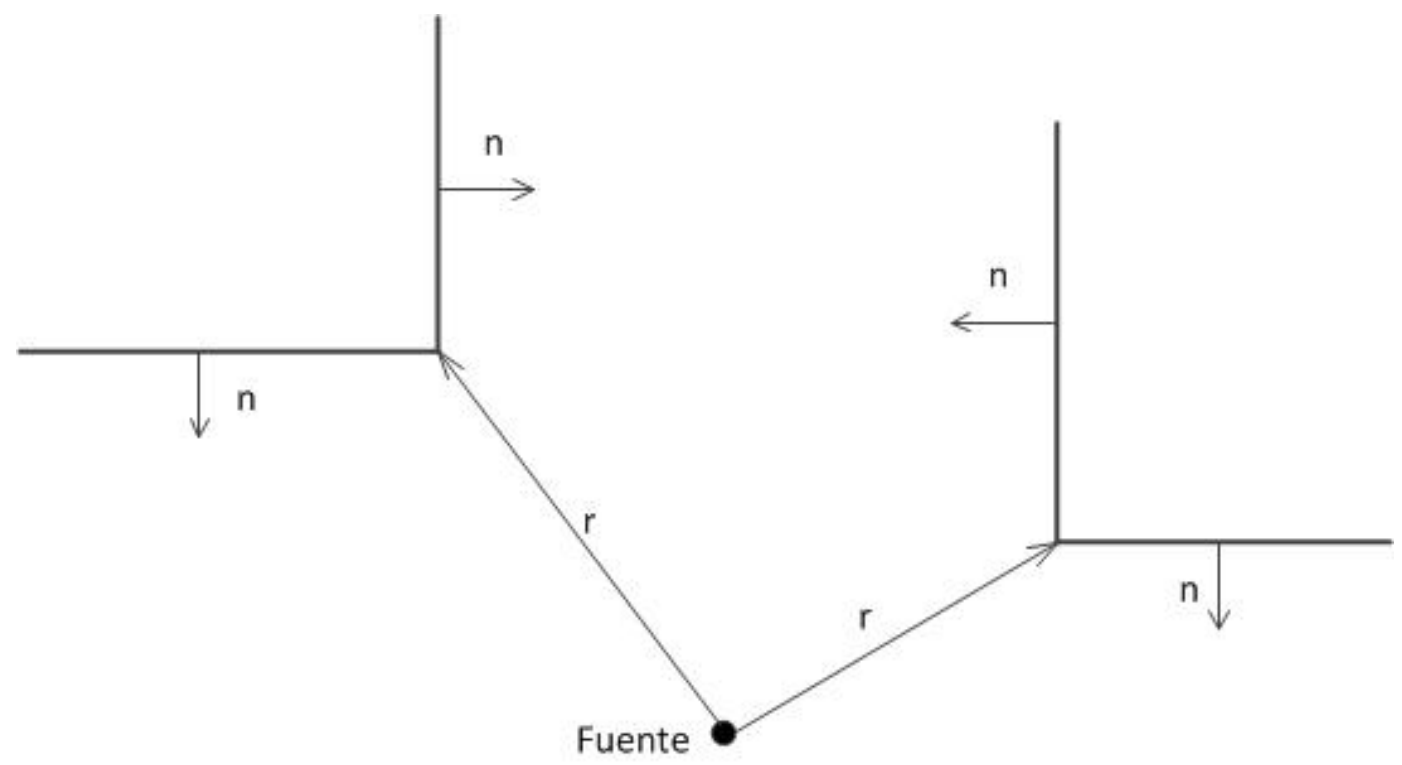

Figura 22.- Esquema gráfico de facetas que cumplen el criterio $\hat{n} \cdot \vec{r} \leq 0$.

En el caso que la imagen principal sufra varias reflexiones, cada nueva imagen tendrá su área de visibilidad en la que se definen en qué facetas se pueden producir reflexiones de orden superior. De esta forma se define el árbol de visibilidad (Visibility Tree, VT) como una estructura en la que de forma gráfica se visualizan cuáles son las facetas en las que una imagen generada puede sufrir otra reflexión. El VT es una consecuencia de la característica de recursividad de la teoría de imágenes. La raíz de VT es siempre la fuente principal, el proceso recursivo continúa hasta que el árbol alcanza la profundidad de $\mathrm{R}+1$, siendo $\mathrm{R}$ el orden de recursividad [Son99]. Teniendo en cuenta que el orden de recursividad se define como el número máximo de reflexiones en cada una de las facetas que experimentan los rayos antes de llegar al receptor.

La Figura 23 muestra la proyección en el plano (x, y) del recinto, en el que se ha indicado una zona de sombreado correspondiente al área de visibilidad de la 
fuente principal, así como la posición de algunas imágenes de primer y segundo orden.

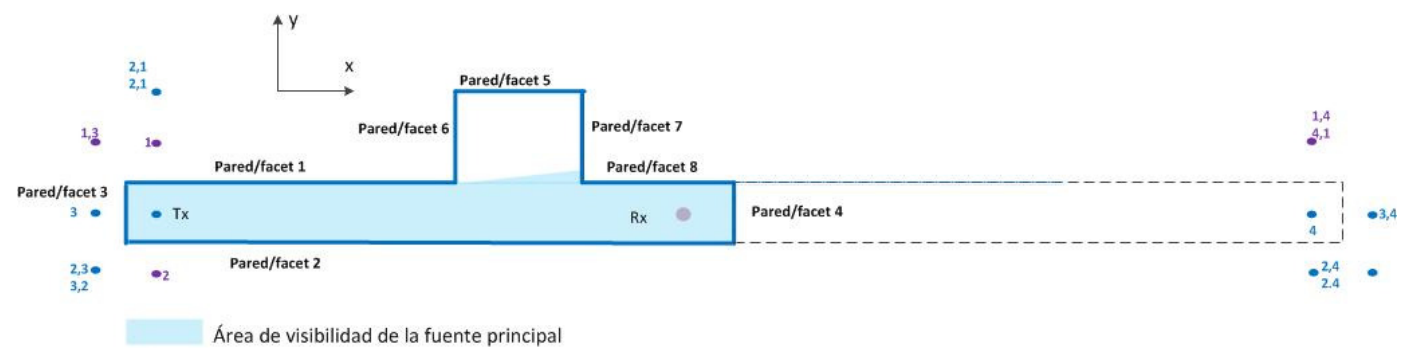

Figura 23.- Proyección en 2D del recinto donde se ha llevado a cabo el primer experimento. Área de visibilidad de la fuente principal. Imágenes secundarias con orden de recursividad igual a 2 .

La Figura 24 indica el área de visibilidad de la fuente secundaria de primer orden generada por reflexión en la pared1:

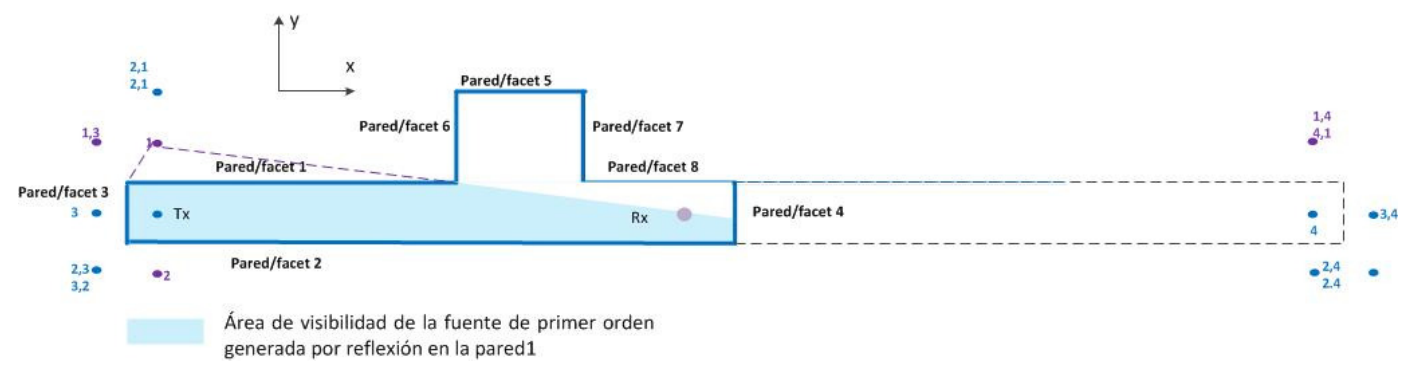

Figura 24.- Proyección en 2D del recinto donde se ha llevado a cabo el primer experimento. Área de visibilidad de la fuente secundaria generada por reflexión en la pared1. Se incluyen algunas imágenes secundarias con orden de recursividad igual a 2.

La Figura 25 muestra el VT del recinto donde se ha llevado a cabo el primer experimento, con un índice recursividad igual a 2. 


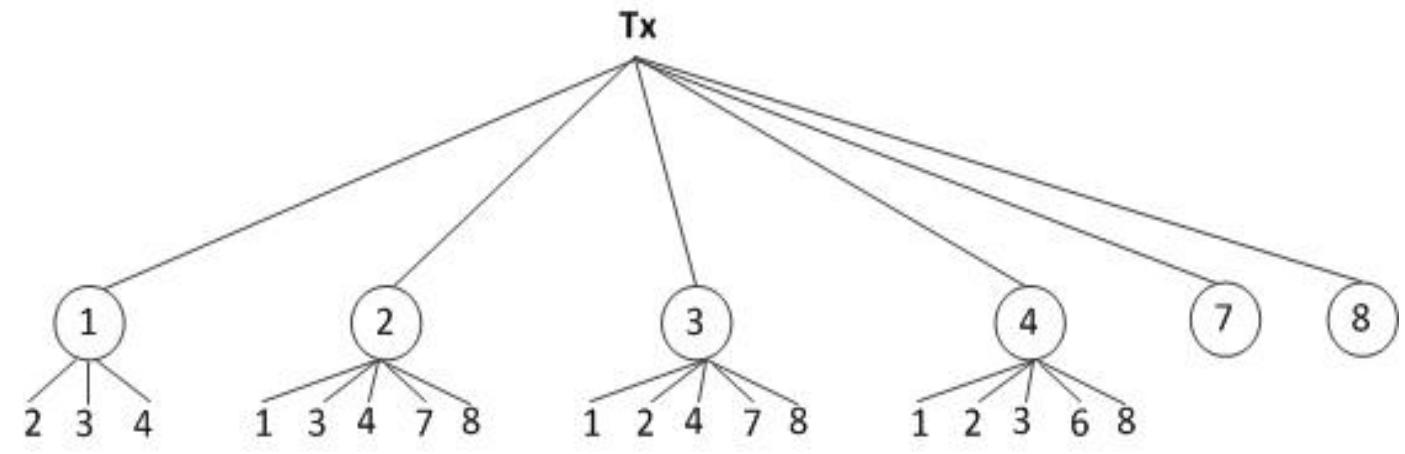

Figura 25.- Árbol de visibilidad del recinto del primer experimento con un índice de recursividad igual a 2 .

\subsubsection{Calculo de los rayos difractados}

Como ya se ha indicado en la descripción del procedimiento de trazado de rayos, para la resolución del problema de la difracción se ha hecho uso de la UTD. El fenómeno de la difracción tiene lugar cuando la onda incide sobre una discontinuidad del entorno. Se considera discontinuidad a cualquier irregularidad que obstaculiza el trayecto del rayo directo entre el transmisor y el receptor, exceptuando las paredes que limitan el entorno.

El recinto en el que se ha realizado el primer experimento consta de dos esquinas en las que se considera que tiene lugar el fenómeno de la difracción. Según el principio de Huygens las aristas actúan como un emisor de ondas secundario donde parte de la energía de la onda incidente radia hacia zonas que inicialmente son zonas de sombra.

Los rayos que sufren difracción se dividen claramente en dos tramos:

- El tramo comprendido entre el emisor principal y el secundario. 
- El tramo comprendido entre el emisor secundario y el receptor.

Estos tramos serán considerados en la composición de los puntos que componen el camino de los rayos desde el transmisor al receptor.

En la simulación sólo se considerarán como rayos difractados los que provienen directamente de la fuente principal, es decir, el rayo antes de difractarse su única trayectoria es el camino directo desde el transmisor hacia la esquina donde se produce la difracción con visión directa. Una vez que el rayo es difractado por cada una de las esquinas sufre diversas reflexiones. Se considera que llega al receptor tanto el rayo directo, procedente de la fuente secundaria, como los rayos debido a las sucesivas reflexiones que tienen lugar a lo largo del recorrido.

Durante la implementación de la solución, se han considerado las reflexiones del rayo antes de llegar a la fuente secundaria, pero la modificación en los resultados obtenidos no era lo suficientemente significativa si se consideraba únicamente el rayo directo entre el transmisor y la fuente secundaria. Según lo cual, para reducir la carga computacional, se optó por considerar únicamente los rayos directos entre la fuente principal y las fuentes secundarias que forman las esquinas.

Los rayos procedentes de la fuente secundaria serán tratados de la misma forma y sufrirán las mismas reflexiones que los rayos reflejados que viajan desde el transmisor principal hasta el receptor. La única diferencia es que hay que considerar que la fuente de transmisión es la esquina donde se produce la difración y no el transmisor principal. Tampoco hay que olvidar que en la composición de los rayos finales y en el cálculo de la coordenada $\mathrm{Z}$ de los puntos de reflexión, hay que considerar el tramo del rayos comprendido entre el transmisor y las fuentes secundarias. 
Implementación del método de trazado de rayos en interiores

En el cálculo de los puntos que componen los rayos difractados es relevante considerar algún aspecto particular del problema, por ejemplo, como la fuente secundaria es un punto de una esquina, dicho punto no se puede reflejar en las paredes que forman la esquina, es decir, esas paredes serán consideradas como no válidas a la hora de construir el VT. La Figura 26 indica las esquinas donde se produce el fenómeno de la difracción, que actúan como fuentes secundarias:

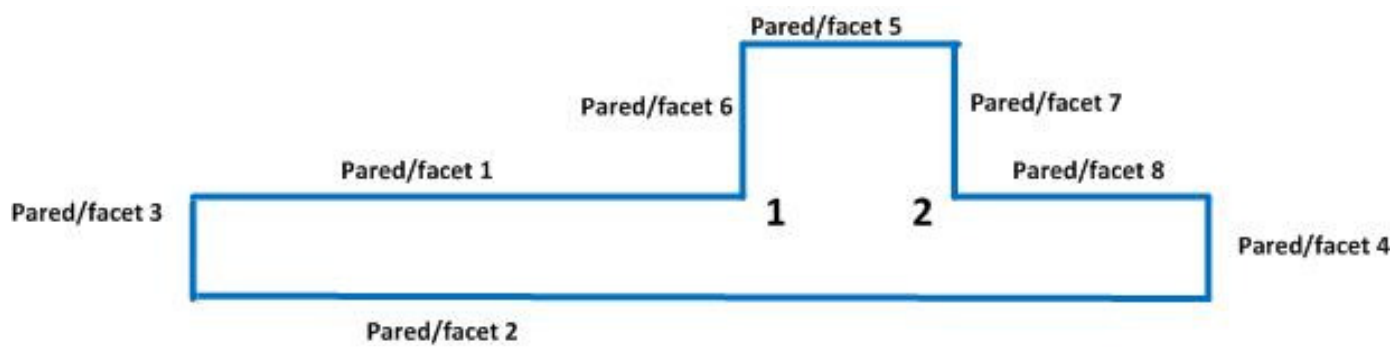

Figura 26.- Recinto experimental. Numeración de las esquinas donde se produce el fenómeno de la difracción que actúan como fuentes secundarias.

Para determinar en qué paredes se pueden reflejar las fuentes secundarias se hará uso de la ecuación ya indicada:

$$
\hat{n} \cdot \vec{r} \leq 0
$$

Siendo

$\hat{n} \quad$ vector normal a la faceta;

$\vec{r} \quad$ vector que une la fuente con uno de los vértices de la faceta.

De lo que se deduce que las fuentes de las esquinas no sufren reflexión en aquellas facetas que forman dichas esquinas. Teniendo en cuenta la numeración indicada en la Figura 26, la esquinal no se reflejará en las facetas 1 y 6 , y la esquina2 no se reflejará en las facetas 7 y 8. 
Las esquinas donde se produce la difracción, al ser consideradas como nuevas fuentes transmisoras, tendrán su propio árbol de visibilidad. El procedimiento de cálculo de los puntos que componen los rayos entre la esquina y el receptor, será el mismo que el aplicado en el cálculo de los rayos reflejados entre la fuente principal y el receptor.

\subsubsection{Concepto de ángulo de sombra}

Los ambientes interiores están caracterizados por reflexiones y difracciones que generan fuentes de radiación secundarias, y como consecuencia se obtienen mediciones de los niveles de campo-E de diferentes intensidades. En un escenario multitrayecto la exposición humana se caracteriza por un número de rayos de diferentes intensidades que inciden sobre el cuerpo humano con diferentes ángulos de llegada.

Es obvio que existe una región de sombra en el plano azimut respecto de la posición vertical del cuerpo humano. Esta región de sombra consiste en un sector angular dependiente del ángulo de llegada, AoA, de la principal contribución de RF y depende de la posición relativa del dosímetro respecto de la fuente principal de radiación y del cuerpo humano.

En lugar de calcular todas las posibles regiones de sombra al detalle, existen estudios que simplifican el problema asumiendo que los rayos pertenecientes a un cierto ángulo de llegada alrededor del cuerpo son bloqueados por el cuerpo humano, y por lo tanto alcanzan el dosímetro más atenuados que el resto de los rayos, como se muestra en la Figura 27. En este estudio se ha considerado que los rayos que son bloqueados por el cuerpo humano se atenúan $30 \mathrm{~dB}$ [Bla07]. Esta propuesta tiene la ventaja de proporcionar una regla simple de aceptar o descartar los rayos, independientemente de la posición de la fuente. 


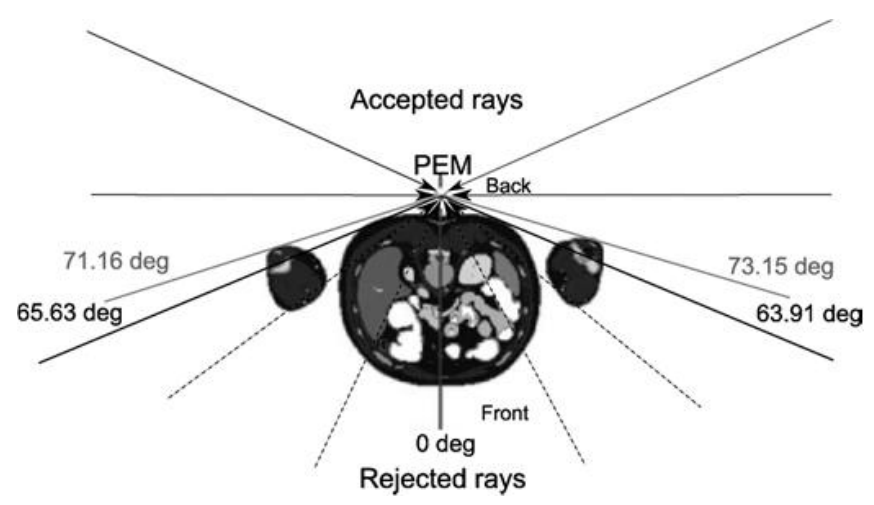

Figura 27.- Posición del dosímetro respecto del cuerpo humano. Sección del modelo del cuerpo humano a la altura de $1.45 \mathrm{~m}$ [Spi96].

A continuación se indicará como se ha introducido el ángulo de sombra en la implementación del modelo teórico.

\subsubsection{Simulación teórica del concepto de ángulo de sombra}

En los apartados anteriores se ha descrito el procedimiento de obtención de los rayos generados por reflexión, así como también los generados por el fenómeno de la difracción. La parte experimental del estudio se ha realizado en cuatro recintos sin considerar el fenómeno de la transmisión.

El objetivo de este trabajo es analizar el efecto sombra del cuerpo humano, siendo el único elemento considerado en los recintos de estudio. Para comprobar este efecto se han comparado los resultados obtenidos en presencia y en ausencia del cuerpo humano tanto en la parte experimental como en la parte teórica.

Los rayos durante su recorrido inciden en el cuerpo humano, siendo absorbidos, dispersados o refractados, como ya se ha descrito en el capítulo correspondiente. 
Se considera que los rayos que llegan al dosímetro, que es portado por el usuario, son atenuados siempre y cuando pertenezcan a un determinado ángulo de azimut. Se pretende demostrar que la atenuación que sufren estos rayos es $30 \mathrm{~dB}$ [Bla07]. Para ello, una vez que se ha calculado el rayo se calcula cuál es su ángulo de incidencia en el cuerpo humano, tal como se indica en la Figura 28. Si el ángulo resultante es menor que el ángulo definido como ángulo de sombra dicho rayo será atenuado $30 \mathrm{~dB}$, lo que equivale a multiplicar su amplitud por 0.03162 , por lo que la amplitud de dicho rayo se verá reducida considerablemente.

La Figura 28 ilustra el criterio considerado a la hora de decidir si los rayos incidentes en el dosímetro portado por el usuario se ven o no afectados por el efecto sombra del cuerpo humano.

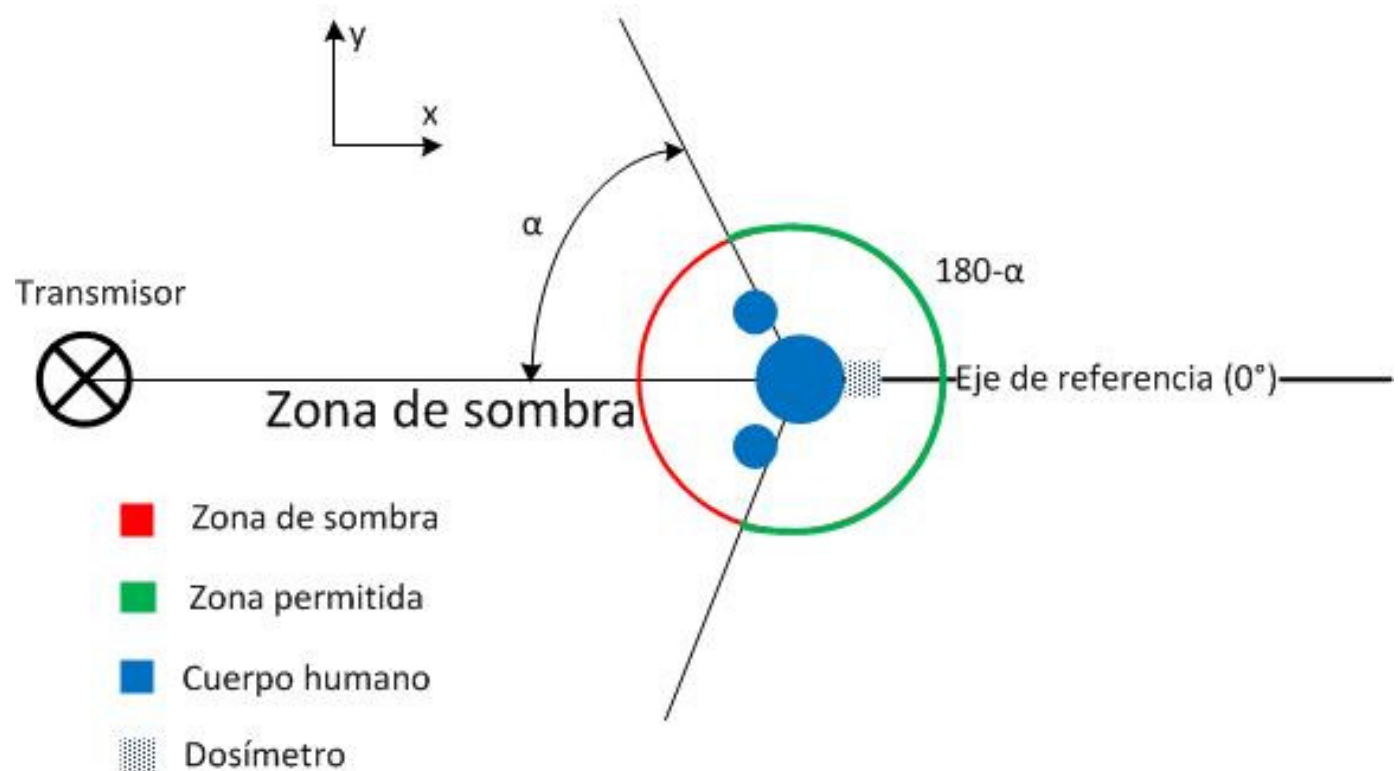

Figura 28.- Proyección en el plano (x, y) del cuerpo humano en el recinto de estudio. Se indica el ángulo de sombra para decidir si los rayos que llegan al receptor se van a ver afectados, o no, por el efecto sombra del cuerpo humano. 
Implementación del método de trazado de rayos en interiores

En la Figura 28 se ha denominado $\alpha$ al ángulo de sombra. Para cada rayo que llega al dosímetro se calcula el ángulo formado por el rayo incidente y el eje perpendicular a la máxima dimensión del cuerpo humano en su proyección sobre el plano (x, y), que se ha denominado eje de referencia en la Figura 28. Si el ángulo de incidencia calculado es menor que $180-\alpha$ se considera que dicho rayo no se ve afectado por el efecto sombra del cuerpo humano y por lo tanto no sufre atenuación alguna. En el caso que el ángulo sea mayor que 180- $\alpha$ se considera que el ángulo es atenuando por la presencia del cuerpo, tal que la amplitud del rayo será multiplicada por el factor de 0.03162 .

Para evaluar la presencia del cuerpo humano en los entornos interiores considerados, el campo-E se ha calculado dos veces, una teniendo en cuenta la atenuación de los $30 \mathrm{~dB}$ por la presencia del usuario, y otra sin considerar dicha influencia. En cada uno de los puntos de las trayectorias predefinidas se han obtenido los dos resultados, lo que va a permitir verificar si la consideración del ángulo de sombra es un buen modelo para caracterizar y cuantificar la influencia del cuerpo humano en las medidas dosimétricas.

Inicialmente se comenzó a trabajar con un ángulo de sombra de 48 grados que es el valor óptimo que se ha obtenido en estudios previos sobre el análisis del efecto sombra en entornos exteriores. Posteriormente se comprobó que introduciendo en el modelo valores del ángulo de sombra más bajos se obtenían mejores resultados. El análisis sobre el valor óptimo del ángulo de sombra se llevará a cabo en el capítulo de discusión de los resultados. 


\subsubsection{Simulación de las condiciones de medida del dosímetro}

Los dosímetros personales presentan unas características de funcionamiento que han de ser tenidas en cuenta en la simulación de las condiciones de medida. Los dosímetros empleados en este experimento tienen una sensibilidad de 0.05 $\mathrm{V} / \mathrm{m}$, por lo que los resultados de la simulación inferiores a este valor han sido sustituidos por el valor de $0.05 \mathrm{~V} / \mathrm{m}$ con el fin de simular las condiciones de funcionamiento del dispositivo de medida. Esta sustitución es una sobreestimación que ya ha sido considerada en estudios previos [Röö08]. En cualquier caso el porcentaje de non-detects obtenido en todas las medidas experimentales es más bajo que el $60 \%$, que es el límite para que la sustitución sea aceptable [Hel06].

De forma similar, los niveles de campo-E son cuantificados en intervalos de $0.01 \mathrm{~V} / \mathrm{m}$ con el propósito de simular la precisión máxima del dosímetro.

\subsubsection{Simulación de la fuente emisora}

Para el cálculo del campo eléctrico, se ha considerado la siguiente expresión referente al campo creado por una antena a una determinada distancia, $d$ :

$$
E=\frac{\sqrt{30 P_{0} A_{t t} A_{d} G}}{d}
$$

Siendo:

- $A_{t t}$ la atenuación del cable a la frecuencia de trabajo. Los datos de calibración facilitan la atenuación del cable en función de la frecuencia, ver Apéndice E. en este caso para una frecuencia de $2437 \mathrm{MHz}$ la atenuación del cable es $-1.4 \mathrm{~dB}, 0.7244$ en unidades naturales. 
Implementación del método de trazado de rayos en interiores

- $\quad P_{0}$ es la máxima potencia isótropa radiada equivalente según la normativa en la banda de frecuencia de $2.4 \mathrm{GHz}$.

- $G$ es la ganancia de la antena que se obtiene a partir de los datos de calibración y del factor de antena según la siguiente expresión:

$$
G=20 \log (F[M H z])-K[d B / m]-29.78[d B]
$$

- $\quad K$ es el factor de antena, que es igual a $43 \mathrm{~dB} / \mathrm{m}$ para la frecuencia de operación de $2437 \mathrm{MHz}$, según los datos indicados en el Apéndice F.

- $A_{d}$ es la atenuación introducida por el diagrama de radiación de la antena, que se explicará con más detalle en el apartado siguiente.

\subsubsection{Simulación de las condiciones de radiación de la antena}

En la implementación experimental, y tal como se ha indicado anteriormente, la antena empleada como fuente de radiación es una antena bicónica en polarización vertical. En la implementación del modelo teórico de trazado de rayos será importante considerar las condiciones de radiación de la antena que se indican mediante el diagrama de radiación.

La antena bicónica no radia de forma uniforme en todas las direcciones, lo hace teniendo en cuenta un patrón denominado diagrama de radiación. Para el caso de la antena bicónica el diagrama de radiación tiene forma de toroide siendo posible caracterizarlo fácilmente mediante las coordenadas esféricas

Lo más frecuente es representar los diagramas de radiación de las antenas en coordenadas esféricas (ver Apéndice G), mediante dos planos, uno de los planos será la variación en función de la componente $\theta$, que es la elevación, y el otro plano contiene la variación de la componente $\phi$, que es el azimut. Estos planos se denominan respectivamente plano de elevación y plano de azimut. Para el caso particular de la antena bicónica, como el diagrama de radiación es de tipo dipolo 
el plano de azimut, en función de la coordenada $\phi$, se considera constante, y el plano de elevación, en función de la coordenada $\theta$, se indica en la siguiente figura:

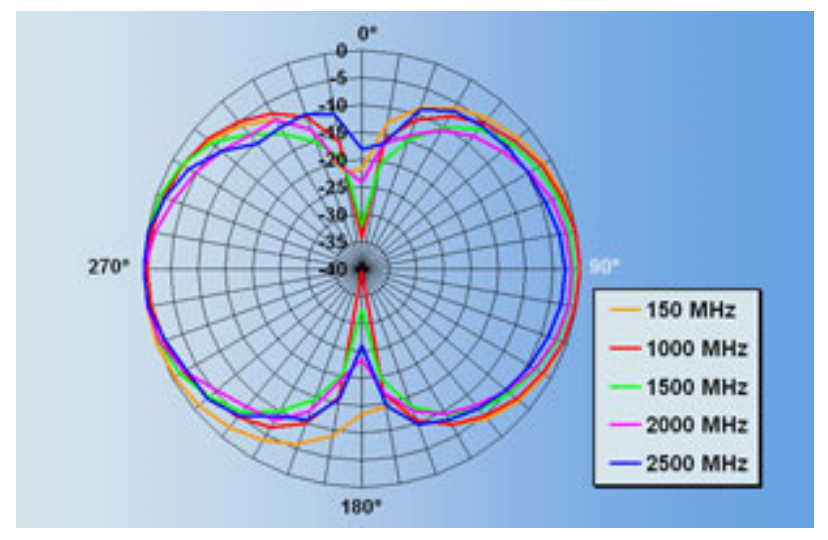

Figura 29.- Plano de la componente $\theta$ del diagrama de radiación de la antena bicónica PCD8250, para diferentes frecuencias.

La descripción de las principales características de los diagrama de radiación se recogen en el Apéndice C. Los valores numéricos del diagrama de radiación de la antena PCD 8250 se han indicado en el Apéndice D.

Como ya se ha indicado en la realización de las pruebas experimentales la antena se ha colocado en la posición correspondiente para que la polarización de las ondas emitidas sea vertical. En esta posición la atenuación que experimenta el campo debido al efecto sombra es más notable que en el caso de la polarización horizontal. La Figura 30 muestra la posición de la antena durante la realización del experimento en polarización vertical. 
Implementación del método de trazado de rayos en interiores

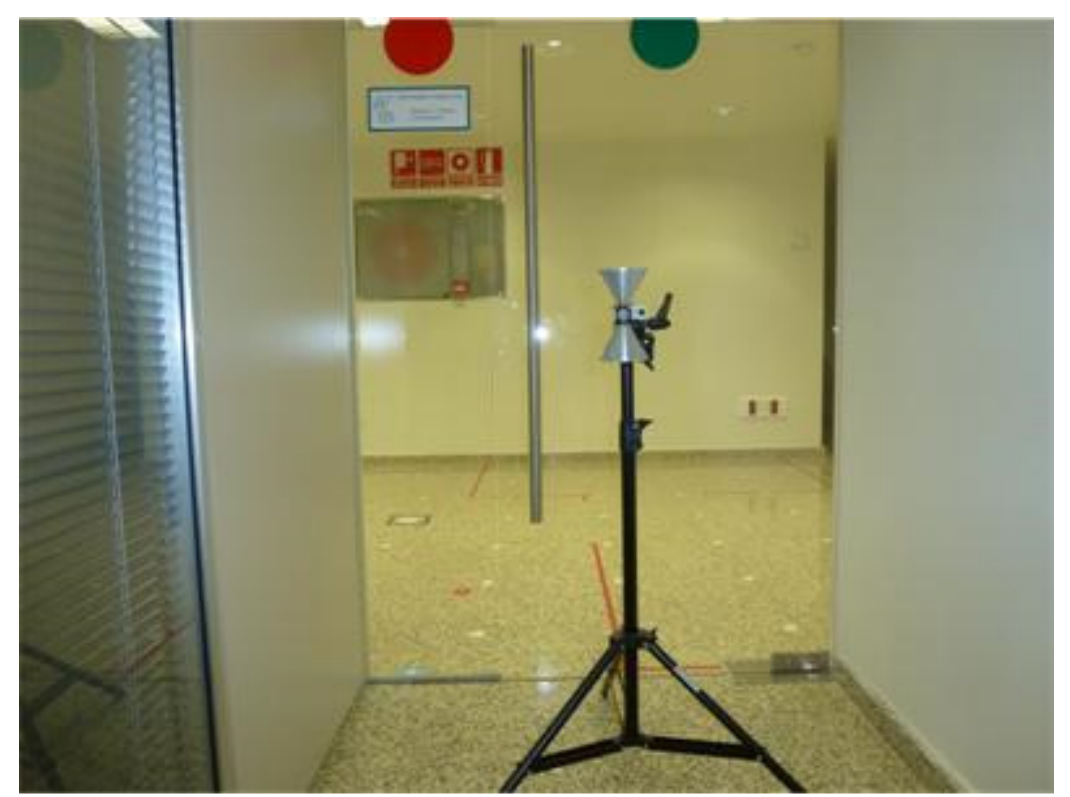

Figura 30.- Posición de la antena durante la realización del experimento en polarización vertical.

Al considerar la polarización vertical y teniendo en cuenta que el campo-E es perpendicular al frente de ondas se deduce que el campo-E sólo tiene componente $\theta$, considerando coordenadas esféricas, que se caracterizan por sus tres componentes: radial, acimutal y de elevación $(\mathrm{r}, \theta, \varphi)$.

Cada rayo consiste en una sucesión de puntos (en 3D, con tres componentes) siendo el primero y el último las coordenadas del transmisor y del receptor respectivamente. Para determinar la dirección con la que el rayo es emitido, y aplicar así el valor correspondiente del diagrama de radiación será necesario determinar el vector delimitado por el transmisor y el primer punto de reflexión. Dicho vector tiene unas coordenadas $(\theta, \varphi)$ a partir de las cuales se determinarán las componentes $\theta$ y $\varphi$ del campo-E $\left(\mathrm{E}_{\theta}\right.$ y $\left.\mathrm{E}_{\varphi}\right)$. Como la polarización es vertical sólo se tendrá en cuenta la componente $\mathrm{E}_{\theta}$ del vector del campo-E. 
Implementación del método de trazado de rayos en interiores

Una vez que se conoce la coordenada $\theta$ del vector que marca la dirección saliente de los rayos, se tomará el valor del diagrama de radiación para ese punto, dicho valor se denominará $\mathrm{A}_{\mathrm{d}}$, y se multiplicará por la ganancia de la antena. 



\section{CAPITULO 6}

\section{Protocolo de realización de las medidas experimentales}

\subsection{Introducción}

En este apartado se describe el protocolo que se ha seguido en la realización de las pruebas experimentales. Para aportar conclusiones fiables, la parte experimental del estudio se ha realizado en cuatro recintos, con el fin no sólo de confirmar las conclusiones que puedan ser extraídas, sino también de conocer como las diferentes características de los entornos influyen en los resultados obtenidos. 
Protocolo de realización de las medidas experimentales

Los niveles de exposición obtenidos en todos los escenarios han sido contrastados con los resultados del modelo teórico. En los siguientes capítulos se expondrán las conclusiones que se extraen de dicho análisis.

\subsection{Realización del primer experimento}

\subsubsection{Protocolo experimental}

El montaje experimental se ha realizado en el pasillo del pabellón 13 del Instituto de Salud Carlos III. Las dimensiones del pasillo son $12 \mathrm{~m} \times 1.26 \mathrm{~m} \times$ $2.45 \mathrm{~m}$.

El protocolo de las pruebas experimentales se ha diseñado con el fin de obtener datos comparables en presencia y ausencia del cuerpo humano. Para ello el usuario ha de portar dos dosímetros, uno LoS, y otro NLoS con respecto a la fuente de radiación.

El dosímetro fuera de la línea de visión será portado por el usuario pegado al cuerpo en la parte trasera, a la altura de las vértebras lumbares, de esta forma si el usuario camina hacia la fuente de radiación el dosímetro se encuentra completamente fuera de la línea de visión.

Con el propósito de evitar completamente la influencia del cuerpo humano y obtener las medidas en LoS será necesario que el usuario lleve el dosímetro alejado del cuerpo. Por esta razón, el segundo dosímetro se sitúa en el extremo de un tubo de cartón de un metro de longitud, que el usuario portará colgado del hombro durante la realización del experimento. Se ha considerado que la distancia a la que ha de estar el dosímetro respecto del usuario para evitar su influencia es 1 
m. Esta distancia ha sido ya considerada para el mismo propósito en trabajos anteriores [Rod10], [Urb14], [Bee13].

En la realización de la toma de medidas, el usuario portador de los dos dosímetros recorre el pasillo de un extremo a otro dirigiéndose hacia la fuente de radiación. Como ya se ha indicado uno de los dosímetros se encuentra completamente en línea de visión, y el otro se sitúa completamente fuera de la línea de visión. La ruta predefinida se muestra en la Figura 31:

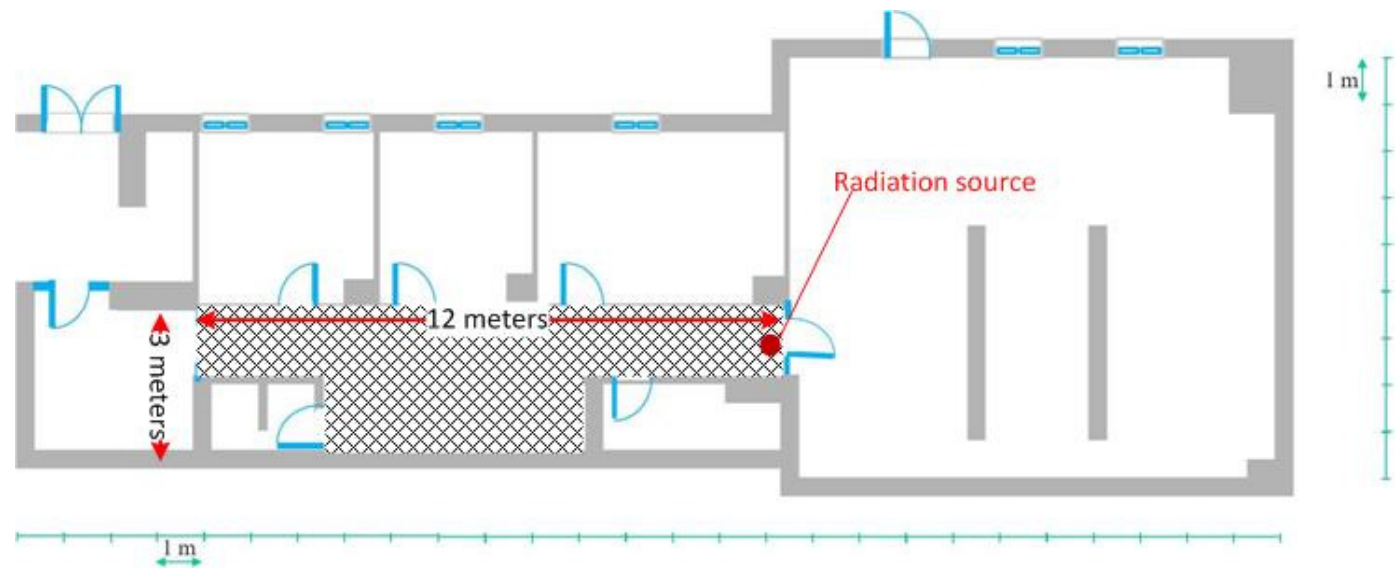

Experiment area

Figura 31.- Plano del pasillo donde se realizaron las primeras pruebas experimentales, incluyendo la posición de la fuente de radiación y la ruta predefinida.

A lo largo del trayecto el número de muestras obtenidas fue de 348 , y el tiempo empleado en la realización de la ruta fue de unos 25-30 minutos. 
Protocolo de realización de las medidas experimentales

\subsubsection{Descripción del material}

\subsubsection{Dispositivos de medida}

Como ya se ha indicado, el instrumento de medida empleado para detectar los niveles de campo-E en condiciones dinámicas es el dosímetro. Se han empleado dos tipos de dosímetros diferentes:

- El dosímetro afectado por el efecto sombra, situado NLoS respecto de la fuente de transmisión es: Antennessa EME SPY 120.

- El dosímetro situado en LoS con la fuente de radiación, y a 1 m de distancia del usuario, para no verse afectado por el efecto sombra del usuario es: Satimo EME SPY 121/100.

Ambos se han configurado con los mismos parámetros de operación, siendo la frecuencia de registro de una muestra cada $4 \mathrm{~s}$. El tiempo máximo de realización del trayecto no supera los 30 minutos, por lo que no se alcanza la máxima capacidad de almacenamiento del buffer del que están provistos los dosímetros.

\subsubsection{Fuente de radiación}

Después de llevar a cabo varias pruebas con un punto de acceso real operando a la frecuencia Wi-Fi de $2.4 \mathrm{GHz}$, se observó que el porcentaje de non-detects registrados por el dosímetro era demasiado elevado. Los non-detects son una consecuencia del rango de sensibilidad de los dosímetros, que en el primer capítulo se indicó como una de las causas de incertidumbre en la utilización de estos dispositivos. Si el nivel de señal que se detecta es inferior al límite inferior del rango de sensibilidad, en este caso $0.05 \mathrm{~V} / \mathrm{m}$, el valor registrado por el dosímetro es dicho límite $(0.05 \mathrm{~V} / \mathrm{m})$, lo que equivale a considerar que el valor real del campo-E no ha sido detectado. 
Se realizaron medidas con un analizador de espectro y tras analizar la potencia emitida se observó que hay períodos de tiempo durante los cuales el punto de acceso no transmite información, como ya se recoge en estudios previos [Fan10], [Pey11], [Kha11]. El concepto de factor de ocupación en una transmisión se define como la relación entre el tiempo durante el cual se transmite información de forma efectiva y la duración total de la transmisión:

$$
\text { factor de ocupación }=\frac{\text { tiempo efectivo de la transmisión }}{\text { duración total de la transmisión }}
$$

Esto implica dos cuestiones importantes: esta transmisión discontinua no ha sido considerada en la simulación desde el punto de vista teórico, y el hecho de considerar un factor de ocupación de $100 \%$ supone una sobrestimación del campo-E que no es real [Jos13]. Por esta razón se emplearon un generador de señal y una antena bicónica para obtener una señal continua dentro de la banda de frecuencia Wi-Fi.

Concretamente los modelos de los instrumentos empleados como fuente de radiación fueron: un generador de señal analógico Agilent N5181A MXG, una antena bicónica Seibersdorf Precision Conical Dipole (PCD) 8250, ambos conectados con un cable calibrado Rohde \& Schwarz (R\&S) LA-RG-214/U. La señal Wi-Fi generada ha sido configurada teniendo en cuenta los siguientes parámetros:

- Frecuencia: $2437 \mathrm{MHz}$.

- Potencia de salida: $20 \mathrm{dBm}(100 \mathrm{~mW})$.

- Modulación: sin modulación.

Según la normativa, la PIRE en la banda de frecuencia $2.4 \mathrm{GHz}$ no ha de superar los $100 \mathrm{~mW}$, por lo que la potencia de salida configurada en el generador 
Protocolo de realización de las medidas experimentales

de señal ha sido $20 \mathrm{dBm}(100 \mathrm{~mW})$. La frecuencia de la señal se configuró con un valor de $2437 \mathrm{MHz}$ por ser una de las frecuencias típicas empleadas en las comunicaciones Wi-Fi [Pey11].

La antena empleada fue una antena bicónica PCD 8250 de banda ancha, cuyo rango de frecuencia está comprendido entre $80 \mathrm{MHz}$ y $3 \mathrm{GHz}$. La longitud de la antena es $13 \mathrm{~cm}$, y permite llevar a cabo medidas según la normativa recomendada por IEEE C95.3 [IEE91].

La antena PCD 8250 es pequeña y ligera, y bastante portable. El diagrama de radiación es de tipo dipolo, siendo omnidireccional en el plano horizontal. Los datos de calibración, y el factor de antena, son proporcionados por el fabricante, y se indican en el Apéndice F. De igual forma los datos de calibración del cable (R\&S, LA-RG-214/U), que conecta la antena con el generador de señal, se incluyen en el Apéndice E.

\subsubsection{Descripción del entorno experimental electromagnético}

Con el fin de reproducir las medidas experimentales, es importante tener en cuenta que no es posible diferenciar las contribuciones procedentes de diferentes fuentes de radiación que operan en la misma banda de frecuencia.

Durante el tiempo de medida, se asume que no existen otros dispositivos Wi-Fi en las proximidades, y que el campo-E medido es debido únicamente a la señal generada. Antes de la realización de las medidas se han realizado varias pruebas de control con la fuente de radiación apagada con el fin de comprobar que no existen otros dispositivos Wi-Fi que estén operando en la frecuencia de trabajo y puedan distorsionar el experimento. El resultado de estas pruebas de control muestra que el nivel de intensidad del campo-E a la frecuencia Wi-Fi no supera el 
valor de $0.05 \mathrm{~V} / \mathrm{m}$, que es el nivel más bajo del rango de sensibilidad del dosímetro. Estas medidas de control aportan rigurosidad al experimento: se demuestra que no existen otras contribuciones en la frecuencia de trabajo que contaminen los datos obtenidos.

El experimento se ha repetido varios días con el fin de garantizar la repetitividad de los resultados. Los resultados obtenidos en los sucesivos experimentos no muestran variaciones relevantes que puedan estar asociadas con cambios en las condiciones de medida.

\subsection{Realización del segundo experimento}

Con el fin de comprobar los resultados obtenidos y proporcionar conclusiones más fiables, las medidas se han repetido en otro recinto interior de diferentes dimensiones.

Se eligió un segundo pasillo, cuyas dimensiones son aproximadamente: 27.15 $\mathrm{m} \times 0.93 \mathrm{~m} \times 3.1 \mathrm{~m}$. La Figura 32 muestra el esquema del recinto, indicándose la zona donde se han realizado las medidas: 
Protocolo de realización de las medidas experimentales

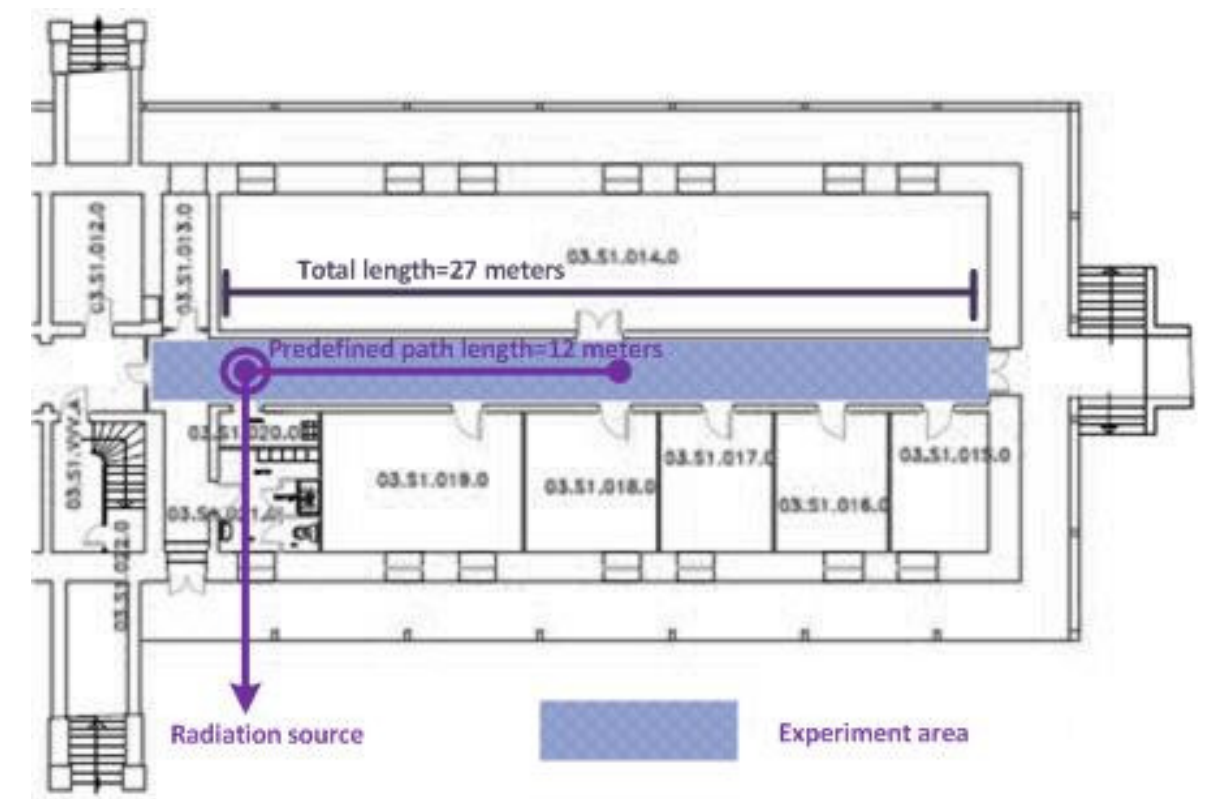

Figura 32.- Plano del recinto donde se realizaron las medidas del segundo experimento, incluyendo la posición de la fuente de radiación y la ruta predefinida.

Para generar una señal a la frecuencia Wi-Fi se emplearon los mismos instrumentos que en el experimento anterior, así como también el campo-E se midió utilizando los mismos dosímetros. Se comprobó que no existían otros dispositivos Wi-Fi transmitiendo a la misma frecuencia. El método empleado en la realización de las medidas fue el mismo que se definió en la sección anterior. En este caso la longitud de la ruta predefinida no es la longitud total del recinto. Con el fin de intentar replicar el protocolo de medida lo más fielmente posible, se estableció una ruta de $12 \mathrm{~m}$ dentro del recinto, para realizar un recorrido de la misma longitud que en el experimento previo.

Otra diferencia que surgió al intentar replicar el protocolo ya fijado, fue la potencia del generador. Inicialmente se estableció en $20 \mathrm{dBm}$, como en el primer experimento, pero los resultados no fueron suficientemente significativos debido 
al gran porcentaje de no-detects en las medidas obtenidas bajo la influencia del efecto sombra. En general los valores de campo-E obtenidos, en los casos de sombra y no-sombra, fueron más bajos que en el primer recinto. Por esta razón los datos aportados como resultados en el segundo experimento se realizaron con una PIRE de $25 \mathrm{dBm}$, el máximo valor permitido por el generador de señal.

\subsection{Realización de los experimentos de contraste}

Los experimentos previos se han realizado en entornos interiores cuyas dimensiones son muy diferentes, lo que va a permitir establecer una dependencia entre el valor del ángulo de sombra y el tamaño del recinto en el que se ha obtenido.

Para proporcionar una mayor generalidad a las conclusiones extraídas, el experimento se ha repetido en otros dos entornos, cuyas dimensiones son $9 \mathrm{~m} \times$ $2.56 \mathrm{~m} \times 2.47 \mathrm{~m}$ y $10 \mathrm{~m} \times 2.56 \mathrm{~m} \times 2.47 \mathrm{~m}$, siendo el volumen muy parecido al del primer entorno.

La Figura 33 muestra el plano de los recintos elegidos: 
Protocolo de realización de las medidas experimentales

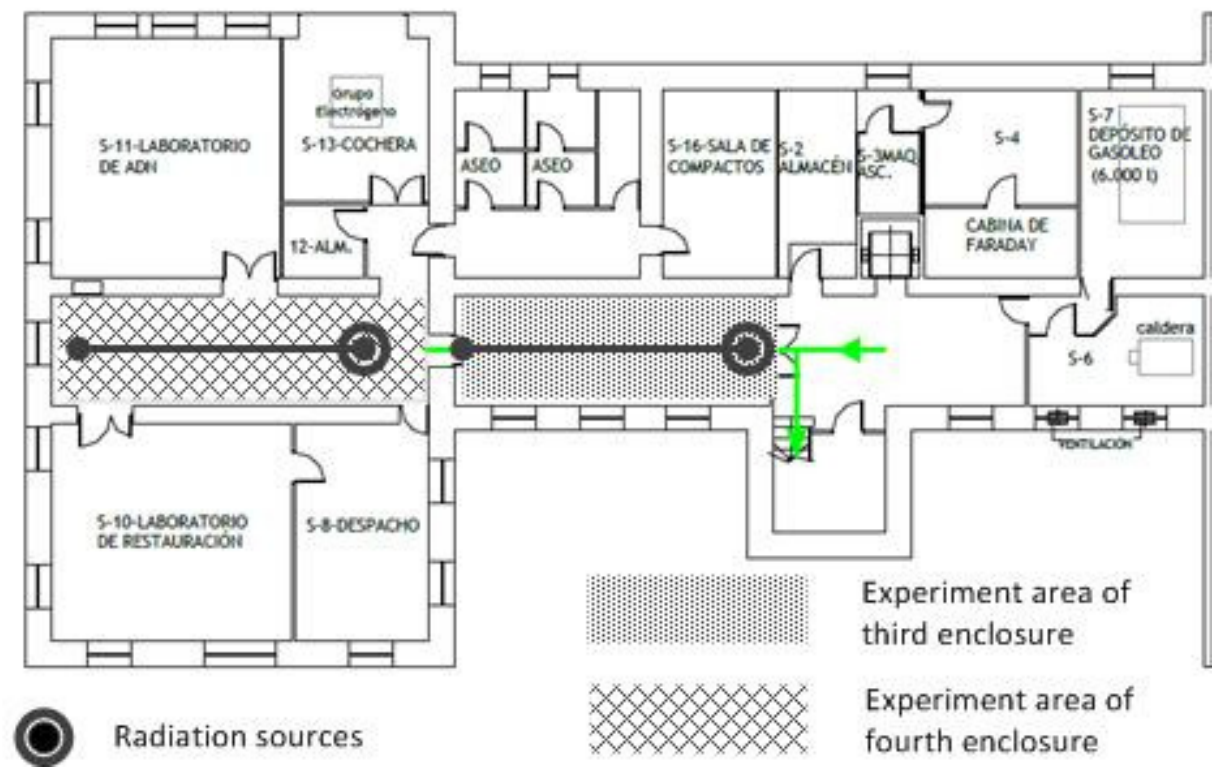

Figura 33.- Plano de los recintos donde se realizaron las mediciones de los experimentos tercero y cuarto. Se incluye la posición de la fuente de radiación y la ruta predefinida.

El protocolo de realización de las medidas es el mismo que se ha expuesto en los recintos anteriores. En ambos casos, la longitud de la ruta definida será acorde a la máxima dimensión de los recintos.

\subsection{Análisis de la posición del dosímetro en la zona de sombra}

El principal objetivo de este estudio es modelar la atenuación introducida en las medidas del campo-E por la presencia del usuario portador del dosímetro. Un aspecto muy importante del protocolo es conocer la posición en la que el usuario ha de llevar el dosímetro para que el efecto sombra sea máximo durante toda la realización del experimento. 
Existen trabajos previos donde se ha evaluado la atenuación ocasionada por el usuario, según la posición del dosímetro respecto de la fuente de radiación, para diferentes frecuencias en condiciones estáticas [Bol11]. En este apartado se expone el estudio experimental previo para verificar cuál es la posición óptima del dosímetro portado por el usuario para que el efecto sombra sea máximo, en condiciones dinámicas y considerando como frecuencia de trabajo la banda de 2.4 $\mathrm{GHz}$

Los rayos llegan al dosímetro que es portado por el usuario con un determinado ángulo de llegada, AoA. Si el AoA pertenece a un determinado sector angular en el plano de azimut del portador del dosímetro, dicho rayo experimenta una atenuación equivalente a $30 \mathrm{~dB}$. El valor del sector angular en el plano de azimut del usuario, respecto a la posición vertical, se ha definido como ángulo de sombra. Para aportar este concepto de una forma más sólida y obtener conclusiones fiables se han realizado varias pruebas experimentales, con el fin de demostrar que el efecto sombra es perfectamente modelable mediante la definición de dicho sector angular en la implementación del programa de trazado de rayos.

Como parte del protocolo experimental se incluye la utilización de dos dosímetros perfectamente sincronizados, uno de ellos afectado por el efecto sombra, NLoS respecto de la fuente de radiación, y otro no afectado por dicho efecto, y completamente LoS con la fuente de radiación, que es portado por el usuario y separado 1 metro de distancia. Se pretende establecer un protocolo de medida con unas condiciones que hagan posible detectar la máxima diferencia entre los resultados obtenidos con sombra y sin sombra.

A continuación se describen las pruebas iniciales que se han realizado con el fin de conseguir datos experimentales lo suficientemente significativos que 
Protocolo de realización de las medidas experimentales

permitirán reflejar la atenuación introducida por el cuerpo humano de forma notable en comparación con los datos que no se ven afectados por dicho efecto.

Para conseguir este propósito se realizaron pruebas preliminares en las que el usuario portaba simultáneamente tres dosímetros, ubicados en diferentes localizaciones del cuerpo humano:

- El primer dosímetro situado en la parte baja de la espalda a la altura de las vértebras lumbares: Satimo EME SPY 121/100.

- La posición del segundo dosímetro fue la parte delantera a la altura de la cintura: Antennessa EME SPY 120.

- Y un tercer dosímetro a un metro de distancia, y no afectado por el efecto sombra del cuerpo: Satimo EME SPY 121/100.

Teniendo en cuenta que el dosímetro es un dispositivo de medida portable, se pretende conocer cuál es la ubicación en la que los datos registrados experimentan una atenuación más notable por el efecto sombra del cuerpo humano. Las pruebas se realizaron en un entorno interior y con un punto de acceso real, Cisco Aironet 1130 Series. Este modelo está provisto de una antena integrada polarizada verticalmente [Cis14-2], lo que permitirá analizar el efecto sombra del cuerpo humano en condiciones de máxima atenuación [ICN98].

La Figura 34 es un esquema del recinto donde se han realizado las pruebas, también se indica la dirección del trayecto realizado, acercándose a la fuente de radiación: 


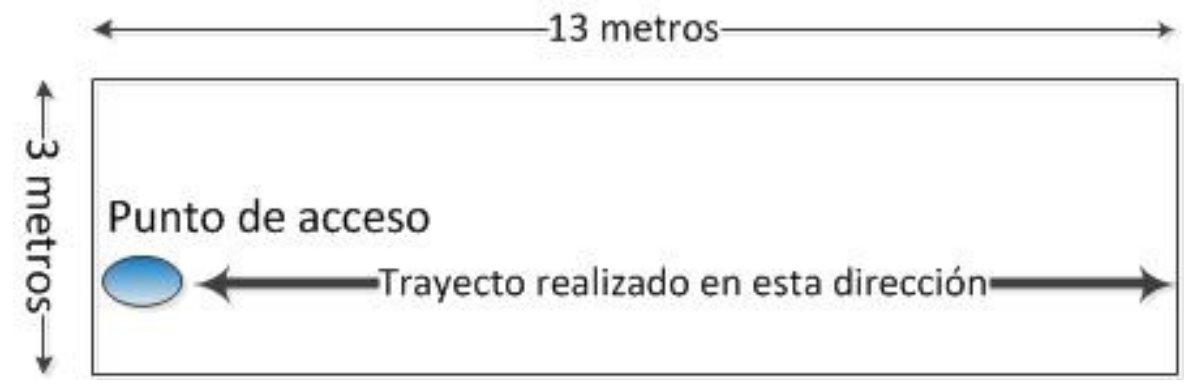

Figura 34.- Trayecto realizado en las pruebas experimentales iniciales.

Los resultados obtenidos en esta fase previa, se resumen en la Figura 35, donde se muestra las FDAs, obtenidas en la realización de experimento.

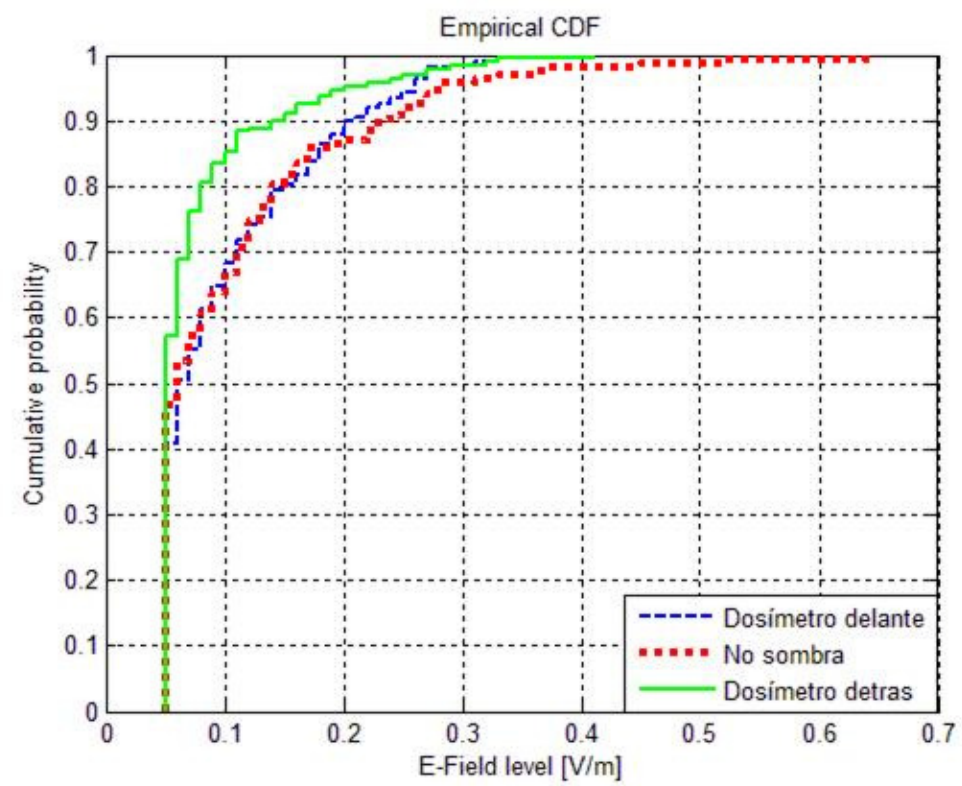

Figura 35.- FDAs de las pruebas experimentales realizadas con tres dosímetros: un dosímetro situado a un metro de distancia del cuerpo humano (caso de no sombra), otro colocado en la parte delantera del cuerpo, y por último otro dosímetro ubicado detrás del usuario (caso de sombra). 
Protocolo de realización de las medidas experimentales

Se observa que prácticamente los niveles obtenidos por el dosímetro situado delante del cuerpo son los mismos que los registrados por el dosímetro que se encuentra a un metro de distancia del cuerpo del usuario, ambos en línea de visión con la fuente de radiación. Aunque se aprecia que el dosímetro que está en contacto con el cuerpo registra valores un poco más bajos que el dosímetro que se encuentra a un metro de distancia. Observando la Figura 35 se deduce claramente que los datos recogidos por el dosímetro que se encuentra en la zona de sombra, fuera de la línea de visión de la fuente de radiación, son claramente inferiores que los datos recogidos por los dosímetros que se encuentran en línea de visión con la fuente de radiación. 


\section{CAPITULO 7}

\section{Análisis de los resultados}

\subsection{Introducción}

En este capítulo se exponen las conclusiones extraídas de la comparación entre los resultados teóricos y experimentales, así como las principales características de ámbito estadístico para ambos tipos de resultados.

Se calcula el valor del error cuadrático medio no solo para decidir la validez del modelo sino también como criterio en la elección del valor del ángulo de sombra.

Por último se presenta la técnica de los factores de corrección para resolver la subestimación ocasionada por el efecto sombra en las medidas realizadas, y su mayor o menor fiabilidad a partir de su aplicación en las FDAs de los resultados. 


\subsection{Resultados del primer experimento}

\subsubsection{Niveles de exposición del campo-E}

La parte experimental de este estudio pretende aportar validez al modelo teórico propuesto implementado mediante un programa de simulación.

Los niveles de exposición del campo-E se miden a lo largo de una ruta predefinida que es recorrida por el usuario desde uno de los extremos del recinto hasta la posición de la fuente de radiación. La duración de la ruta es de 25-30 minutos, tiempo durante el cual los dosímetros registran el valor del campo-E cada 4 s. El usuario se sitúa de frente a la fuente de radiación y lleva dos dosímetros, uno en la espalda, a la altura de la cintura, fuera de la línea de visión de la fuente de radiación y bajo el efecto sombra del cuerpo humano, y el otro a un metro de distancia fuera de la influencia del cuerpo humano y en LoS con la fuente de radiación.

Tal como se indicó en la sección anterior, cuando el cuerpo humano está en línea de visión con la fuente de radiación, existe una zona del cuerpo que no está iluminada directamente por dicha fuente, denominada zona de sombra. Los resultados de las pruebas experimentales demuestran que los valores del campo-E obtenidos por el dosímetro que se encuentra en la región de sombra son más bajos que los valores obtenidos por el dosímetro situado en línea de visión con la fuente de radiación, fuera de la influencia de la zona de sombra del usuario.

El efecto sombra es un fenómeno que conlleva la atenuación de los rayos que llegan al receptor con un determinado ángulo de incidencia. Con el fin de simular este efecto es necesario considerar un sector angular alrededor del cuerpo, asumiendo que la amplitud de los rayos que inciden en el receptor colocado en la 
zona de sombra, dentro de dicho sector angular, va a verse afectada por la subestimación.

Los valores del campo-E obtenidos en la simulación y en las pruebas experimentales, con y sin sombra, se muestran en la Figura 36. Los resultados que se presentan en esta sección se han obtenido considerando un ángulo de sombra de 13 grados. Contrastando resultados experimentales y simulados, en la Figura 36 se demuestra que en un recinto interior de las características consideradas, y bajo las condiciones consideradas, el efecto sombra del cuerpo humano puede ser modelado mediante un ángulo de sombra de 13 grados.

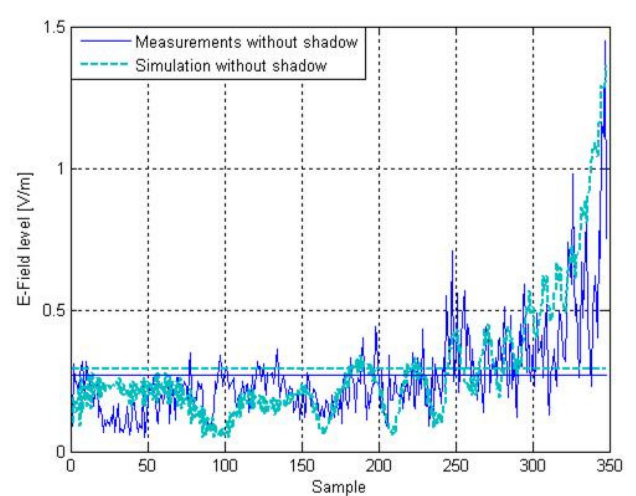

(a)

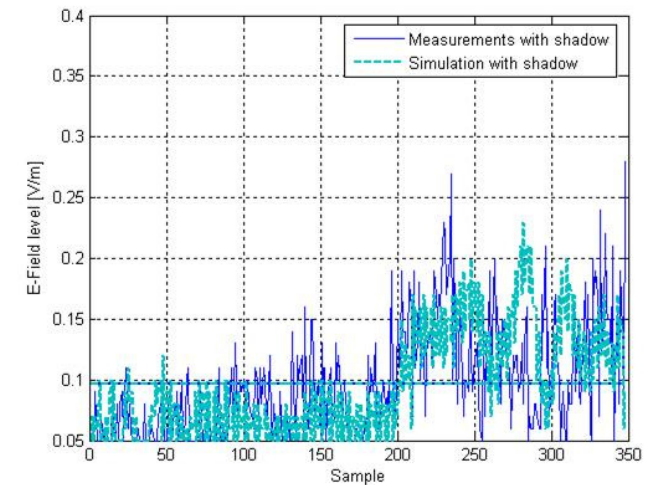

(b)

Figura 36.- Los datos experimentales y los resultados de la simulación para los casos de (a) nosombra y (b) sombra, del primer experimento. Los niveles medios de campo-E (V/m) se muestran mediante líneas horizontales.

La Figura 36 muestra como los resultados experimentales y simulados presentan la misma variabilidad para los casos de sombra y de no sombra, es decir, los valores de campo-E son bajos en las posiciones más alejadas del transmisor, alcanzándose valores más altos en las posiciones más próximas. Además, las medias de los resultados experimentales y simulados son muy similares para cada uno de los casos de sombra y de no sombra. 
La configuración del protocolo de realización de medidas tiene varias fuentes de incertidumbre, tales como: las oscilaciones de la posición de los dosímetros mientras que éstos son portados en la realización del experimento, aproximaciones del modelo de trazado de rayos, etc., que hacen casi imposible la coincidencia punto a punto de las medidas experimentales y los resultados de la simulación.

\subsubsection{Función de distribución acumulada}

La Figura 37 muestra la comparación entre las FDAs de las medidas experimentales y los resultados de la simulación. La prueba de KolmogorovSmirnov (KS) se empleó para la comparación de las FDAs de este estudio.

La prueba de KS trata de determinar si dos series de datos difieren significativamente. Se ha comparado la FDA de los datos estimados con la FDA de los datos experimentales, proporcionado la probabilidad de obtener la misma desviación máxima entre ambas funciones dado que proceden de la misma variable aleatoria. A partir del KS-test se obtiene el p-valor que es un indicador de la diferencia de las FDAs que se están evaluando. Cuanto mayor sea el p-valor, más cercana será la relación determinista entre los datos experimentales y los resultados de la simulación. 


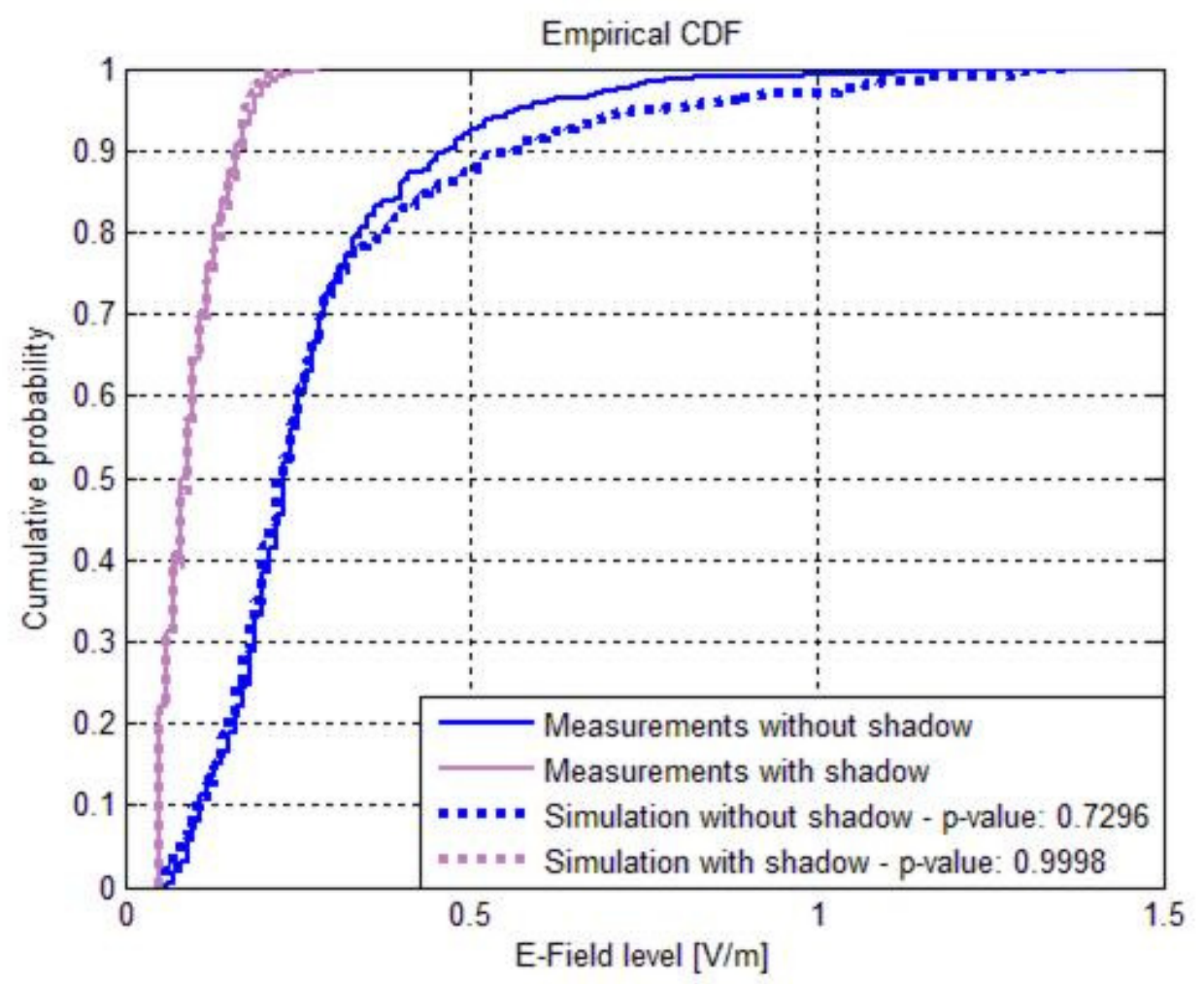

Figura 37.- FDA de los resultados simulados y las medidas experimentales del primer experimento.

El KS test muestra buenos resultados: el p-valor obtenido comparando los resultados experimentales y simulados que no se ven afectados por el efecto sombra es de 0.7296 , mientras que el p-valor obtenido a partir de los resultados considerando el efecto sombra es de 0.9998. En ambos casos el p-valor supera 0.05 , por lo que se consideran resultados aceptables.

La elección del valor del ángulo de sombra se ha realizado considerando el mejor p-valor del KS test obtenido en la comparación de los datos experimentales y los resultados de la simulación. Se darán más detalles en la siguiente sección. 


\subsection{3 Ángulo de sombra}

En la parte teórica, el ángulo de sombra es un factor clave: el cambio de valor de dicho ángulo hace variar los resultados para el caso de los niveles de campo-E medidos por el dosímetro afectado por el efecto sombra del usuario.

La elección del valor del ángulo de sombra en el modelado teórico se ha realizado teniendo en cuenta los resultados experimentales obtenidos por el dosímetro afectado por el efecto sombra. Se ha elegido el valor del ángulo de sombra óptimo en términos del KS test, con el fin de aproximar lo más posible la FDA de los resultados experimentales con la FDA de los resultados de la simulación.

La Figura 38 muestra el p-valor en función del valor del ángulo de sombra en los resultados del primer experimento. Para ángulos de azimut pequeños el p-valor es bastante aceptable. 


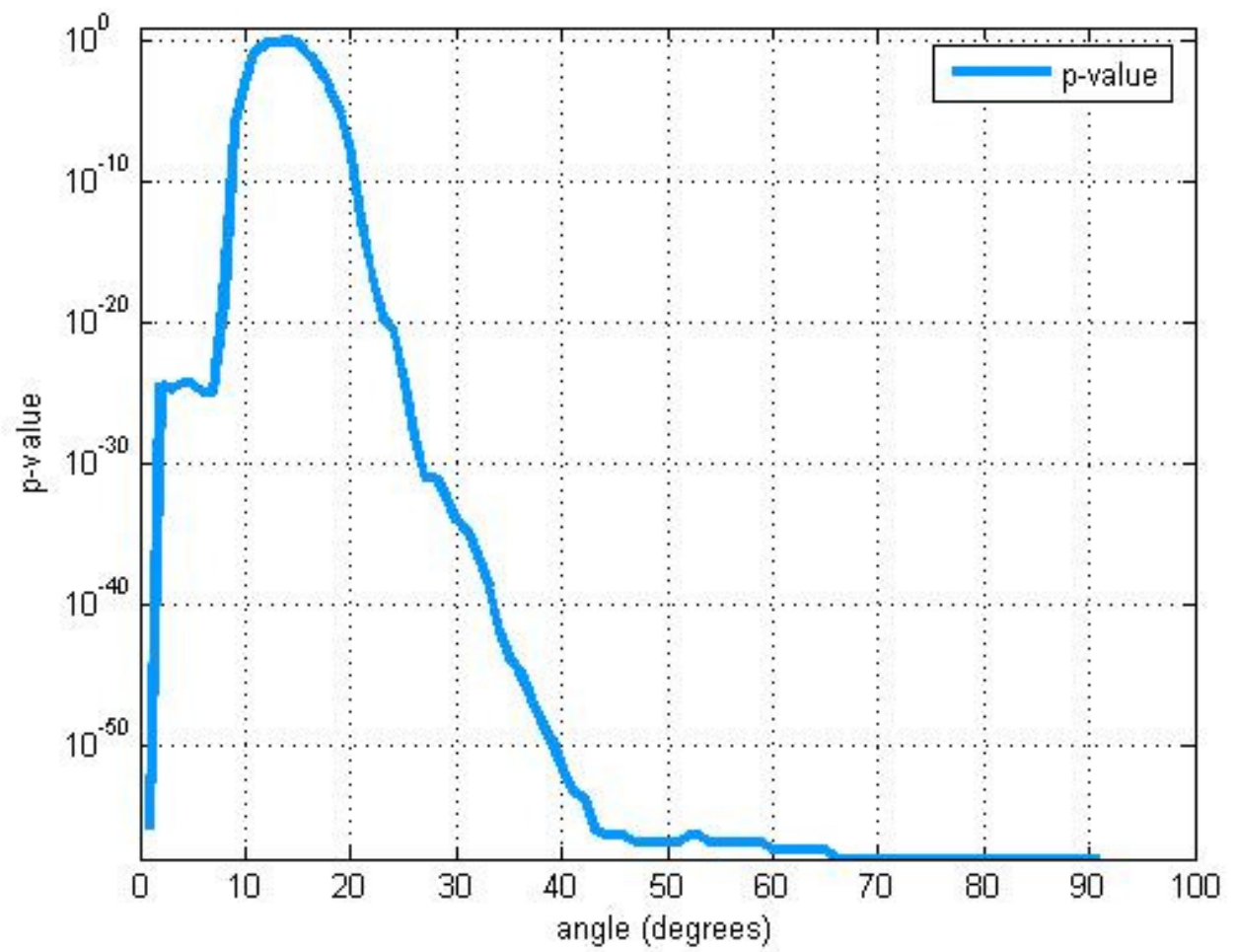

Figura 38.- Variación del p-valor en función del ángulo de azimut en el primer experimento.

El KS test presenta los mejores resultados para un ángulo de sombra de 13 grados. Este valor es notablemente menor que el obtenido para caracterizar el efecto sombra en espacios exteriores, 48 grados [Rod10].

\subsection{Resultados del segundo experimento}

En este apartado se presentan los resultados obtenidos tras la realización de las pruebas experimentales en el segundo recinto interior. Como ya se ha indicado, las diferentes características de ambos entornos han dado lugar a pequeñas variaciones en la aplicación del protocolo establecido. Y como se verá a 
continuación, las diferencias del recinto afectan a los resultados, permitiendo obtener conclusiones sobre la influencia de las características del entorno en los niveles de exposición registrados por los dosímetros.

\subsubsection{Niveles de exposición del campo-E}

La Figura 39 muestra los resultados obtenidos con y sin sombra para una potencia de transmisión de $20 \mathrm{dBm}$. A primera vista, es muy notable el elevado número de non-detects para el caso de sombra:

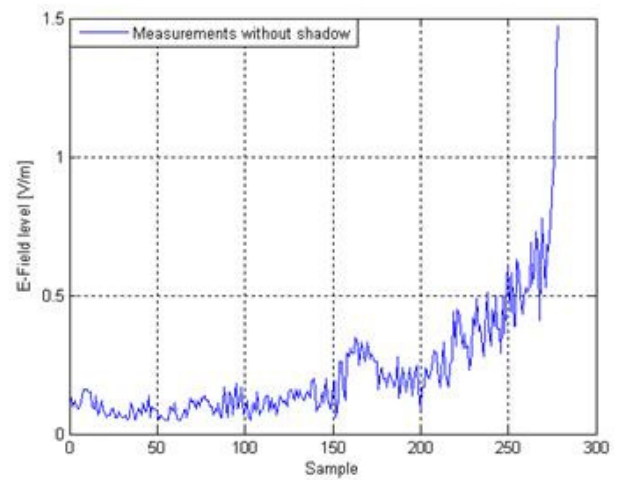

(a)

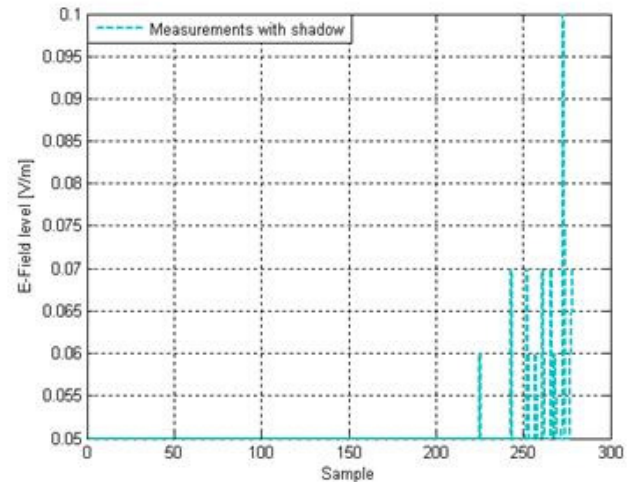

(b)

Figura 39.- Los datos experimentales y los resultados de la simulación para los casos de (a) nosombra y (b) sombra, para el segundo experimento siendo la potencia de transmisión $20 \mathrm{dBm}$.

Los resultados experimentales de la Figura 39 muestran que los niveles de campo-E medidos por los dosímetros a lo largo de la trayectoria predefinida presentan una clara tendencia a ser menores que en el primer experimento, con la excepción de los valores medidos en puntos de la ruta que están más cerca de la fuente de radiación. Se puede observar que la diferencia de los niveles de campo- 
E entre los casos de sombra y no sombra es más significativa que en el primer experimento.

Con el fin de obtener resultados significativos, se configuró el generador de señal con una potencia de salida de $25 \mathrm{dBm}$, que es el máximo valor permitido por el dispositivo.

La Figura 40 muestra las medidas del campo-E en los casos de sombra y de nosombra para una PIRE configurada en el generador de señal de $25 \mathrm{dBm}$. Además se muestran los resultados obtenidos por el programa de simulación, teniendo en cuenta las características del segundo entorno. Los resultados teóricos que se presentan en el caso de sombra, se han obtenido considerando un ángulo de sombra de 26 grados.

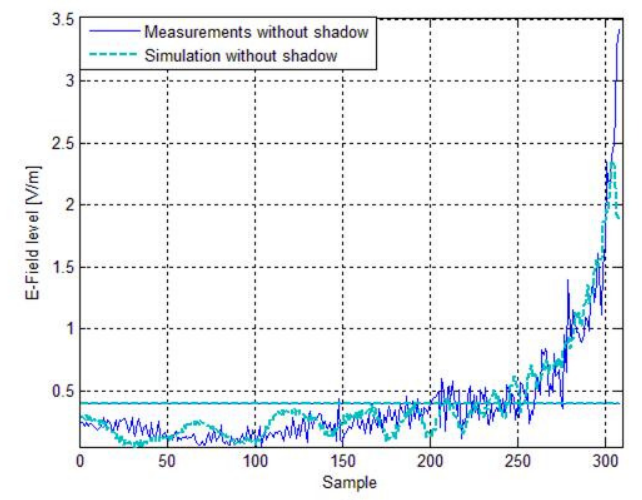

(a)

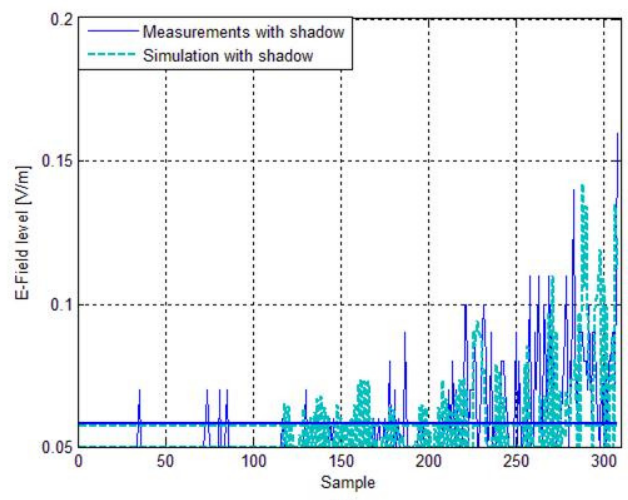

(b)

Figura 40.- Los datos experimentales y los resultados de la simulación para los casos de (a) nosombra y (b) sombra, para el segundo experimento siendo la potencia de transmisión $25 \mathrm{dBm}$. Los niveles medios de campo-E (V/m) se muestran mediante líneas horizontales.

La normativa europea fija la PIRE de los dispositivos que operan a la frecuencia Wi-Fi, en la banda de $2.4 \mathrm{GHz}$, en $20 \mathrm{dBm}$ (100 mW) [EU11], [EU13]. 
Ante la limitación del umbral inferior de sensibilidad del dispositivo de medida, en la realización de las pruebas experimentales en el segundo recinto, se ha superado la potencia indicada para obtener valores más significativos. Según el ICNIRP el mínimo umbral recomendado para garantizar la salud de las personas en el ámbito de la exposición a radiaciones no ionizantes a la frecuencia de 2.4 $\mathrm{GHz}$, es $61 \mathrm{~V} / \mathrm{m}$, para el caso de la población general [ICN98]. Según la información aportada por la Figura 40 los niveles de exposición que se han obtenido no alcanzan el umbral indicado, por lo que no se percibe ningún tipo de riesgo que permita obtener conclusiones lo suficiente relevantes que adviertan sobre peligro de sobreexposición.

En este recinto se ha de considerar un ángulo de 26 grados, para simular adecuadamente los niveles de campo-E en el caso de sombra. Por lo que el valor del ángulo de sombra que mejor ajusta las medidas a los resultados del modelo teórico es superior al valor obtenido en el primer recinto, pero inferior al obtenido en condiciones de espacio libre.

\subsubsection{Función de distribución acumulada}

Tras obtener los valores del campo-E, se han obtenido las FDAs junto con los resultados de la simulación. La Figura 41 muestra la FDA de las medidas en ambos casos. 


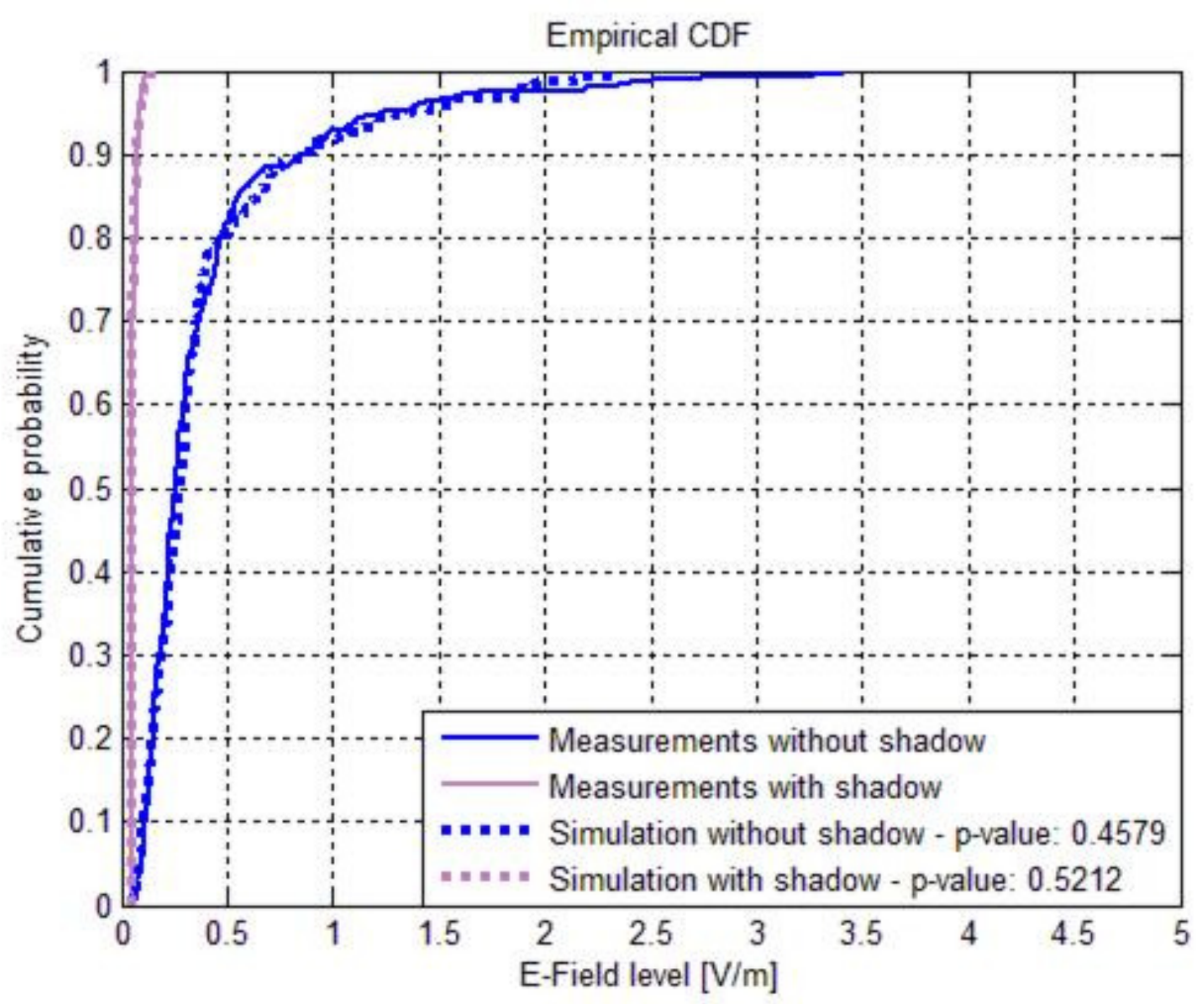

Figura 41.- FDAs de los resultados simulados y las medidas experimentales del segundo experimento.

La Figura 41 muestra que en los casos de sombra y no-sombra los resultados experimentales pueden ser simulados mediante el modelo teórico propuesto. Los p-valores obtenidos en la prueba de KS son 0.4579 , y 0.5212 , siendo superiores a 0.05 , que es el valor mínimo para considerar los resultados como aceptables.

Siguiendo con el protocolo establecido, en la simulación del caso de sombra se ha elegido el valor del ángulo de sombra que permita obtener el p-valor máximo a partir de KS test. En este caso los resultados de las medidas y de la simulación son acordes en términos del p-valor, si se considera un ángulo de 26 grados. En este caso el valor del ángulo de sombra óptimo es mayor que en el primer experimento 
Análisis de los resultados

donde el recinto es más estrecho y el volumen total también es menor. No obstante, en el segundo recinto, el valor del ángulo que permite modelar el efecto sombra es menor que los 48 grados obtenidos en condiciones de espacio libre.

La conclusión que se extrae a partir de la realización de las pruebas experimentales en ambos recintos, permite predecir que el valor del ángulo de sombra está relacionado con las dimensiones del recinto.

\subsection{3 Ángulo de sombra}

Siguiendo el protocolo establecido, la elección del valor del ángulo de sombra en el modelado teórico se ha realizado en términos del KS test, con el fin de aproximar lo más posible la FDA de los resultados experimentales con la FDA de los resultados de la simulación.

Para ilustrar la elección de un determinado valor del ángulo, la Figura 42 muestra el p-valor en función del valor del ángulo de sombra en los resultados del segundo experimento. Se observa que se obtienen valores aceptables para valores superiores a los obtenidos en el primer experimento. 


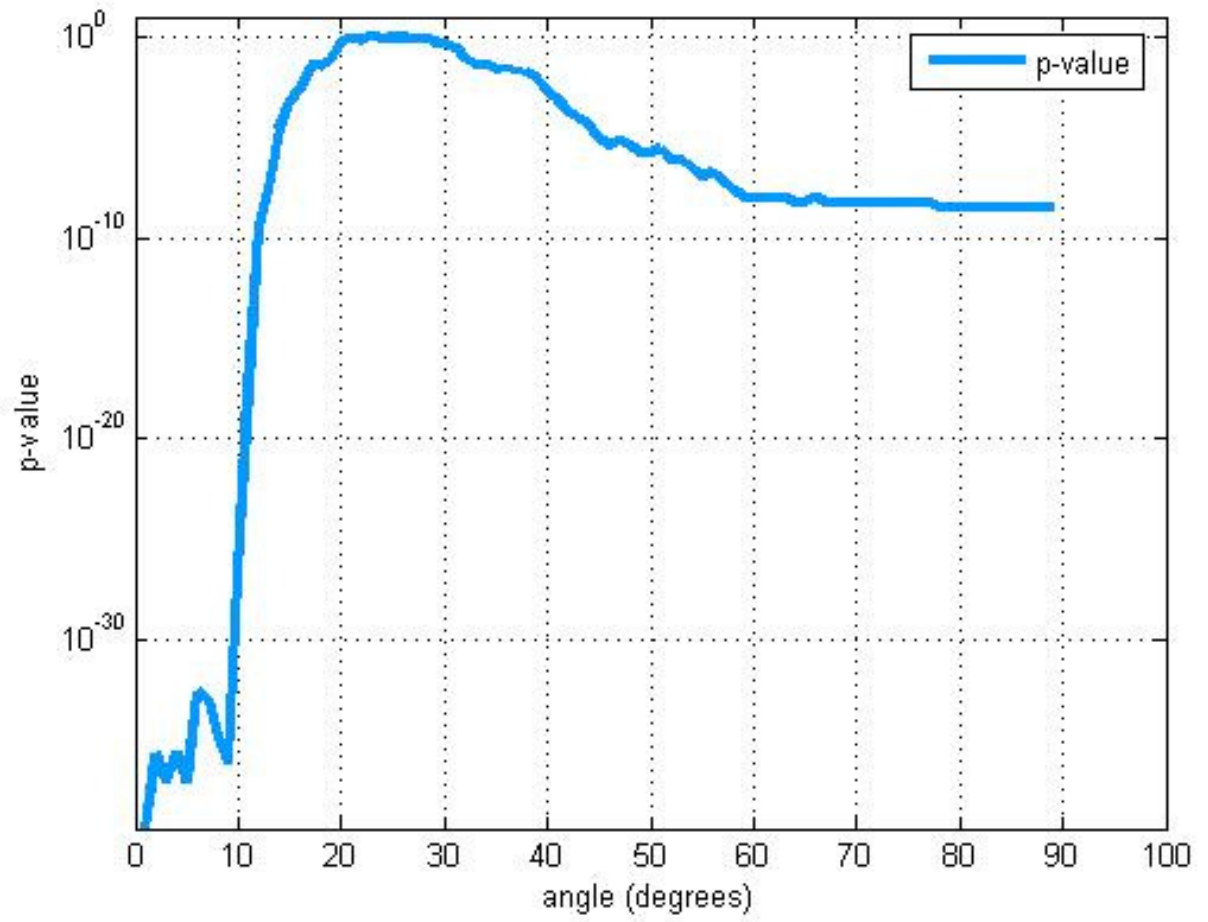

Figura 42.- Variación del p-valor en función del ángulo de azimut en el segundo experimento.

El KS test presenta el mejor resultado para un ángulo de sombra de 26 grados, que es menor que el obtenido en ambientes exteriores (48 grados), pero mayor que el dato obtenido en el primer experimento realizado en un recinto interior de menor volumen (13 grados).

\subsection{Resultados de los experimentos de contraste}

Con el fin de aportar una conclusión sólida referente a la relación entre el volumen de los recintos y el valor del ángulo de sombra, el experimento se ha 
Análisis de los resultados

repetido en otros dos entornos. Los resultados obtenidos se muestran a continuación.

\subsubsection{Niveles de exposición del campo-E}

La Figura 43 y la Figura 44 muestran las medidas del campo-E, en los recintos tercero y cuarto respectivamente, en los casos de sombra y de no-sombra para una PIRE configurada en el generador de señal de $25 \mathrm{dBm}$. Además se compararán con los resultados obtenidos por el programa de simulación, teniendo en cuenta las características de dichos entornos.

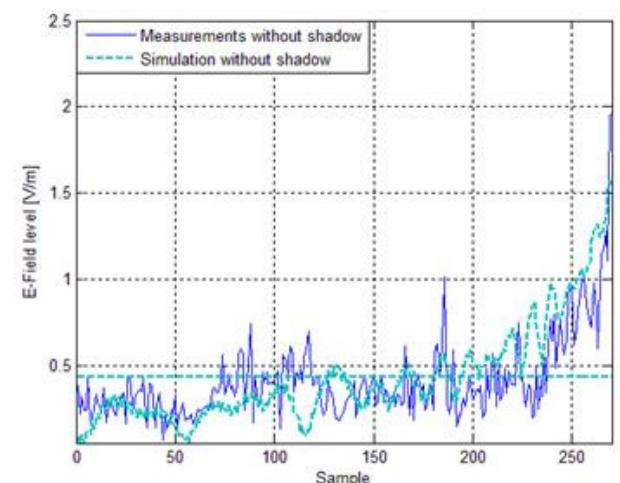

(a)

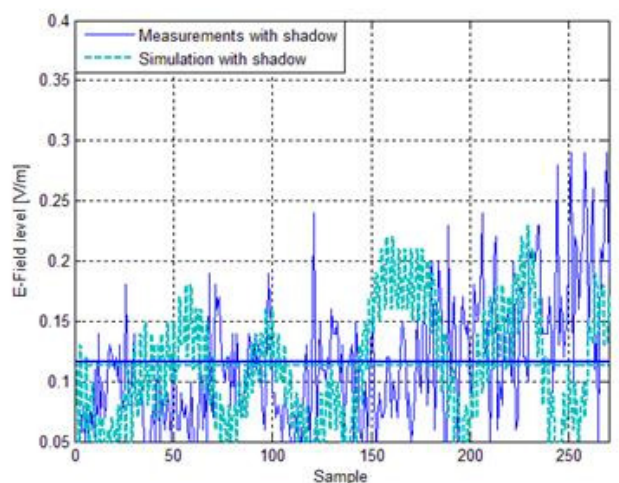

(b)

Figura 43.- Los datos experimentales y los resultados de la simulación para los casos de (a) nosombra y (b) sombra, para el tercer experimento siendo la potencia de transmisión 25 $\mathrm{dBm}$. Los niveles medios de campo-E (V/m) se muestran mediante líneas horizontales. 


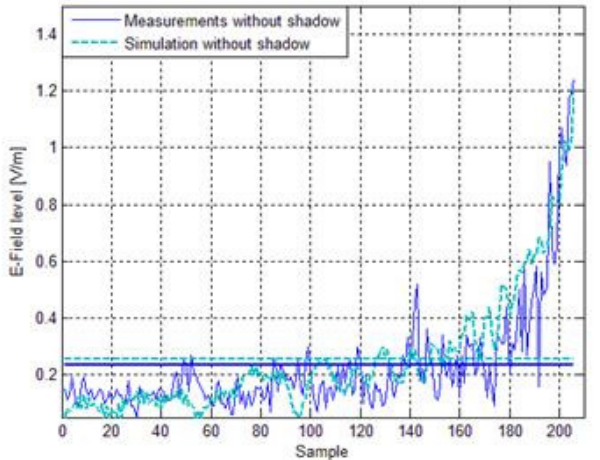

(a)

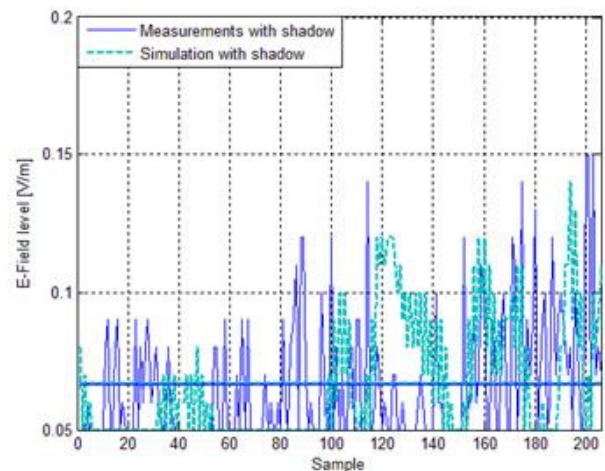

(b)

Figura 44.- Los datos experimentales y los resultados de la simulación para los casos de (a) nosombra y (b) sombra, para el cuarto experimento siendo la potencia de transmisión 25 $\mathrm{dBm}$. Los niveles medios de campo-E (V/m) se muestran mediante líneas horizontales.

\subsubsection{Función de distribución acumulada}

Tras obtener los valores experimentales del campo-E, se han obtenido las FDAs comparando con los resultados de la simulación. La Figura 45 muestra la FDA para el tercer recinto y la Figura 46 indica la FDA para el cuarto recinto. 


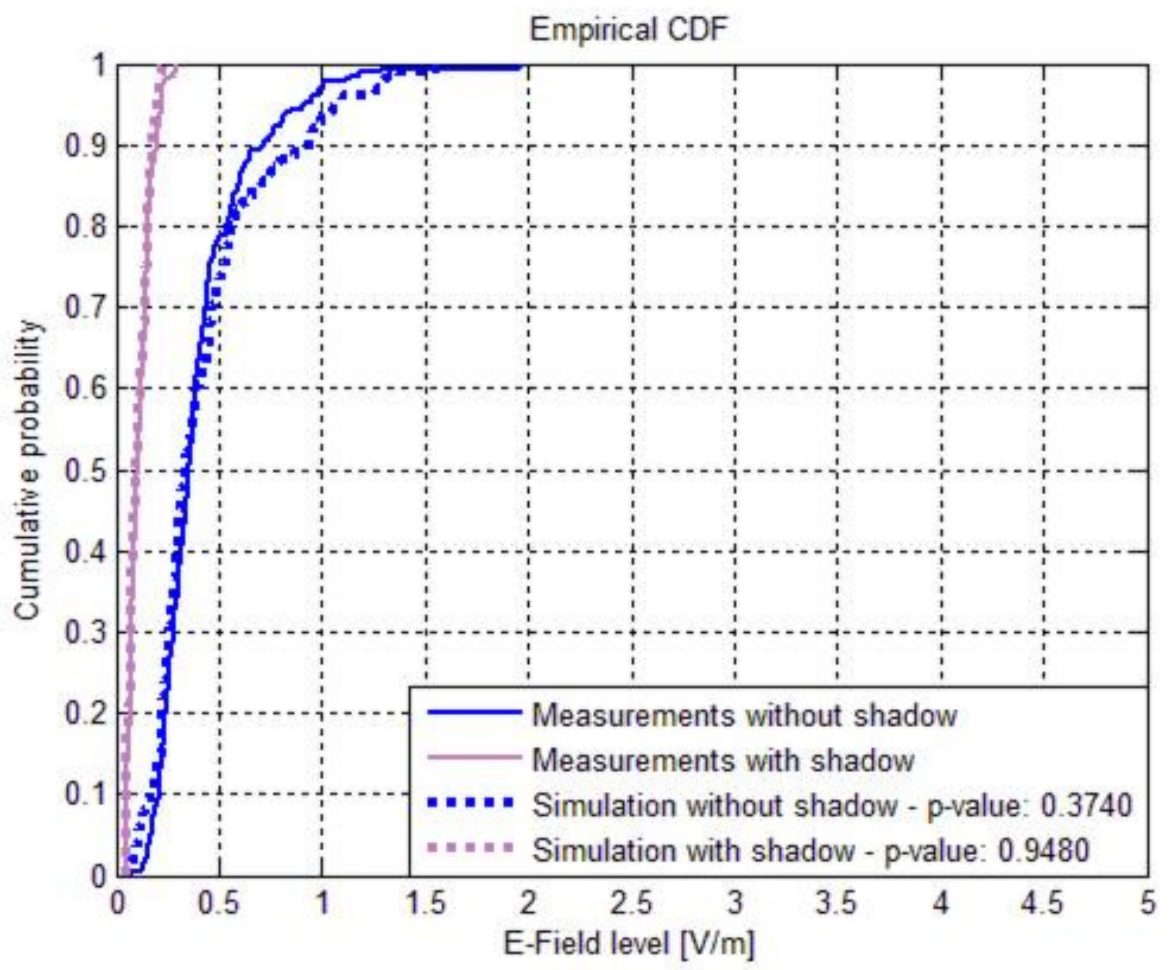

Figura 45.- FDAs de los resultados simulados y las medidas experimentales del tercer experimento. 


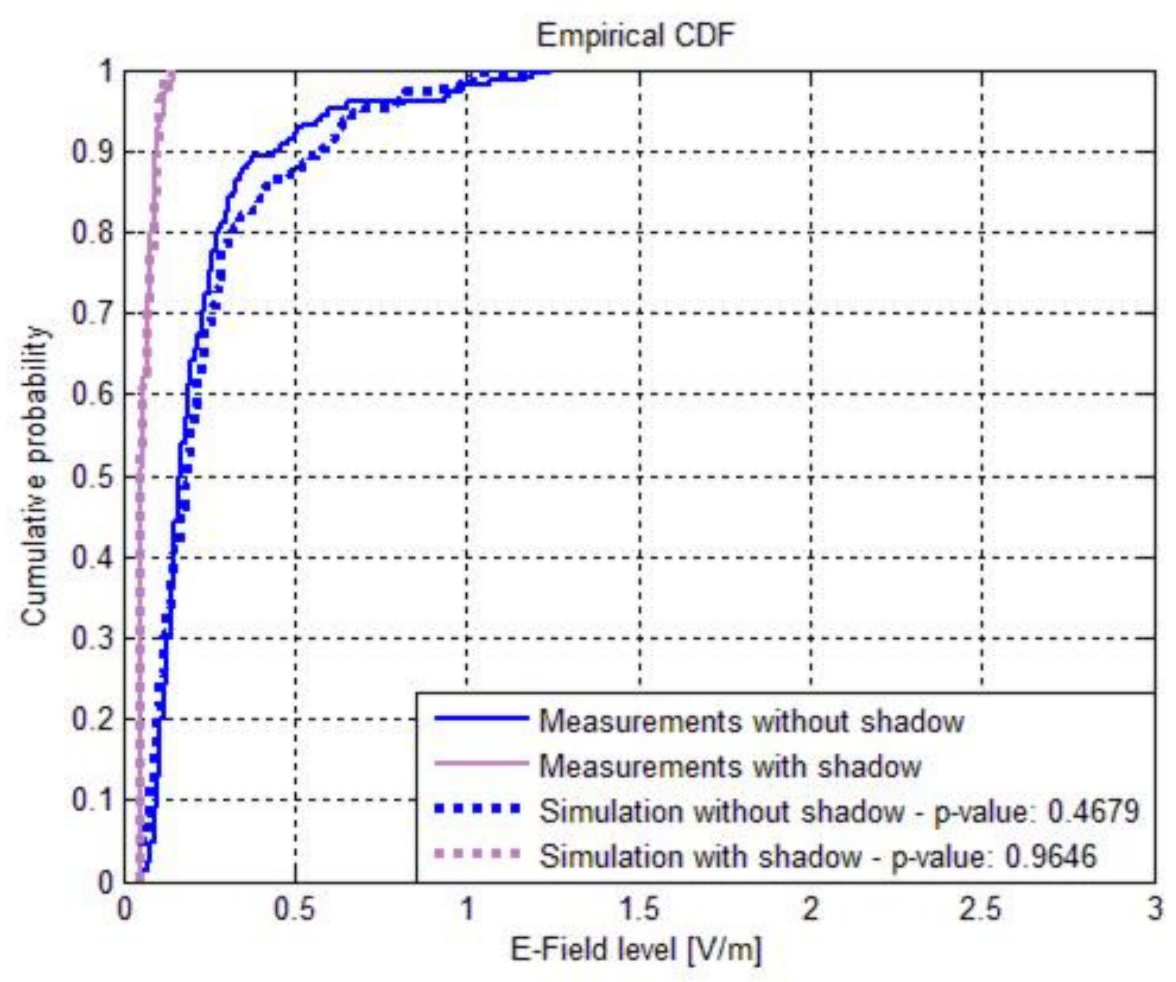

Figura 46.- FDAs de los resultados simulados y las medidas experimentales del cuarto experimento.

En el tercer recinto, el p-valor obtenido en el caso de no sombra es 0.3740 . Para el caso de la sombra, si se considera un ángulo de 12 grados el p-valor es óptimo siendo igual a 0.9480 .

En lo referente al cuarto recinto, el p-valor es 0.4679 en el caso de no sombra, y 0.9646 para el caso de sombra. El valor del ángulo de sombra es 13 grados, que es el mismo valor que el obtenido en el primer entorno.

En todos los casos el p-valor obtenido es superior a 0.05 , por lo que todos los resultados se pueden considerar como aceptables en términos del KS test. 


\subsection{3 Ángulo de sombra}

Siguiendo el protocolo establecido, la elección del valor del ángulo de sombra, en el modelado teórico, se ha realizado en términos del KS test, con el fin de aproximar lo más posible la FDA de los resultados experimentales con la FDA de los resultados de la simulación.

Para el tercer experimento el KS test presenta el mejor resultado para un ángulo de sombra de 12 grados, mientras que para el cuarto experimento el valor del ángulo de sombra óptimo es de 13, igual que el obtenido en el primer experimento. Cabe destacar además que los recintos primero, tercero y cuarto tienen un volumen bastante parecido, lo que permite confirmar la dependencia del valor del ángulo de sombra con las dimensiones del recinto.

\subsection{Discusión de los resultados}

\subsubsection{Influencia de la polarización del transmisor en el efecto sombra}

Como ya se ha indicado un factor que ocasiona incertidumbre en los datos registrados por los dosímetros es la polarización de la antena transmisora. Es importante destacar que la atenuación debida al efecto sombra del cuerpo humano es mayor cuando la polarización de la antena es vertical. Teóricamente las ondas polarizadas verticalmente están más atenuadas por el cuerpo humano que las ondas polarizadas horizontalmente, ya que el cuerpo erguido en su orientación vertical absorbe mejor las ondas polarizadas verticalmente [Bol11]. Cuando el eje mayor del cuerpo humano es paralelo al vector del campo eléctrico (lo que ocurre cuando la polarización de la antena bicónica es vertical), y bajo condiciones de 
exposición de onda plana (campo lejano), el SAR del cuerpo humano alcanza valores máximos [ICN98], lo que es equivalente a considerar que el cuerpo humano atenúa más las ondas. Según lo expuesto, la atenuación de las ondas como consecuencia de la presencia del cuerpo humano es más notable cuando la polarización es vertical, por esta razón se ha elegido esta polarización para modelar el efecto sombra del cuerpo humano.

Con el fin de analizar los niveles de campo-E en función de la polarización de la fuente emisora, se han realizado pruebas experimentales siendo la polarización de la antena transmisora horizontal en el segundo recinto. La Figura 47 muestra estos resultados:

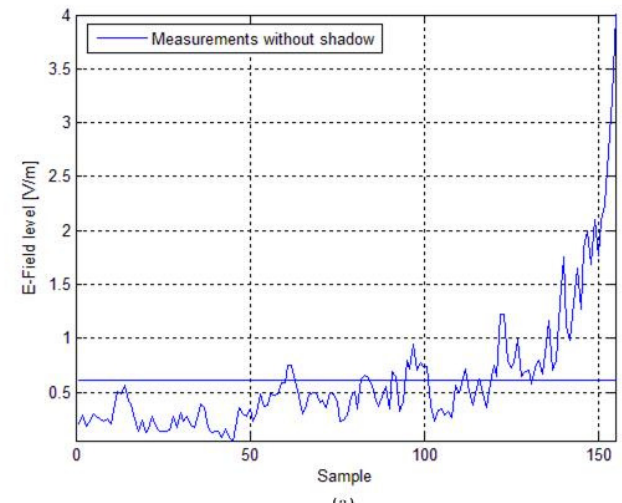

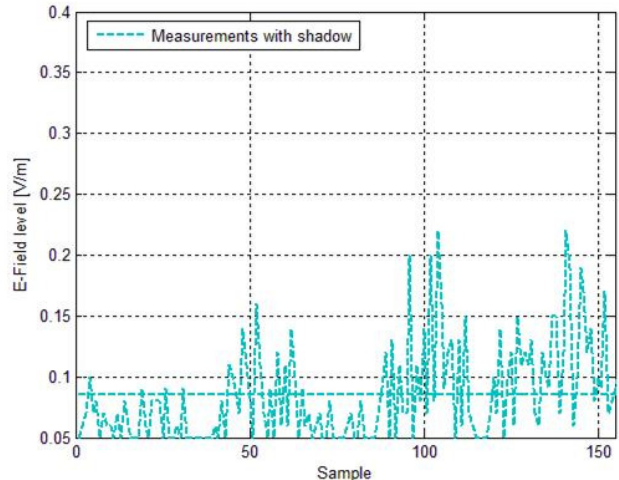

(b)

Figura 47.- Los datos experimentales para los casos de (a) no-sombra y (b) sombra, para el segundo experimento siendo la potencia de transmisión $25 \mathrm{dBm}$, y la polarización de la antena horizontal. Los niveles medios de campo-E (V/m) se muestran mediante líneas horizontales.

Si se comparan la Figura 40 y la Figura 47 se percibe que en los casos de sombra y polarización horizontal, la atenuación de los niveles de campo-E no es tan notable como en el caso de polarización vertical. 
Análisis de los resultados

También se realizaron medidas con la posición de la antena en polarización horizontal en el primer recinto, donde la influencia del cuerpo humano se caracteriza por un ángulo de sombra menor (13 grados). En este caso no hay diferencias lo suficientemente significativas entre la polarización vertical y horizontal.

De todas estas pruebas experimentales se concluye que en el segundo recinto, de mayores dimensiones, la atenuación por influencia del efecto sombra de los niveles de campo-E es más significativa si la polarización es vertical, siendo el ángulo de sombra 26 grados.

\subsubsection{Efecto de dispersión}

Después de analizar los resultados obtenidos, una cuestión importante es la conclusión referente a la menor subestimación de las medidas debido a la influencia del cuerpo humano en entornos interiores que en espacios exteriores.

Experimentos anteriores realizados en el espacio libre demuestran que es posible caracterizar el efecto sombra del cuerpo humano mediante un ángulo de sombra de 48 grados [Rod10], que es notablemente superior a los valores obtenidos en este estudio realizado en entornos interiores: 13 y 26 grados en función del volumen del recinto.

Las condiciones que existen en espacios abiertos y entornos interiores son diferentes. En condiciones de espacio libre el número de superficies susceptibles de ser causa de reflexiones y difracciones es notablemente inferior. Los entornos interiores se caracterizan por la propagación multitrayecto debido a las paredes, el techo, el suelo y la posible presencia de una gran variedad de objetos, (como son los muebles), lo que supone que las ondas que indicen simultáneamente sobre el dosímetro proceden de diferentes direcciones. Como consecuencia en entornos 
exteriores, existe un menor número de rayos que inciden sobre el dispositivo de medida.

Los modelos de trazado de rayos en entornos exteriores consideran sólo la contribución del rayo directo y de la reflexión en el suelo. Pueden existir también contribuciones debido a la presencia de elementos, como edificios, pero en cualquier caso la distancia entre los obstáculos y el dispositivo de medida en entornos exteriores siempre tiende a ser mayor que en entornos interiores, lo que hace que las contribuciones a los niveles de campo-E debido a las reflexiones en entornos exteriores sean menores que en interiores. Por otra parte cuanto mayor sea el recinto, los rayos recorren distancias mayores y sufren una mayor atenuación, por lo que los niveles de exposición detectados serán menores. Según lo indicado la propagación de rayos en entornos abiertos, en comparación con entornos interiores, se caracteriza por contribuciones de menor número de rayos y de menor intensidad.

En entornos interiores, una contribución importante del campo-E medido por el dosímetro situado en la zona de sombra del usuario, está estrechamente relacionada con el efecto de dispersión del cuerpo humano: los rayos que inciden en el cuerpo se dispersan, y después de ser reflejados, especialmente por las paredes más cercanas, llegan al dosímetro [Tof93], [Cot09], [Thi13]. Este efecto se traduce en un modelado del efecto sombra mediante un ángulo (13 grados), que es notablemente menor que en el espacio libre (48 grados), donde los rayos dispersados por el cuerpo del usuario se pueden considerar como una contribución perdida, al no existir una superficie reflectora cercana que permita que los rayos dispersados incidan en el dosímetro situado en la zona de sombra.

Según los resultados aportados, el valor del ángulo que modela el efecto sombra es mayor en espacios exteriores que en recintos interiores. La Figura 48(a) 
muestra la dispersión ocasionada por el usuario portador del dosímetro en un recinto interior. Los rayos dispersados llegan al dosímetro después de haber sido reflejados por las superficies reflectoras (paredes) más cercanas. En contraste, se muestra el mismo fenómeno en condiciones de espacio libre, Figura 48(b), donde las aportaciones de los rayos dispersados se pierden, no contribuyendo a los niveles de campo-E detectados por el dosímetro en la zona de sombra.

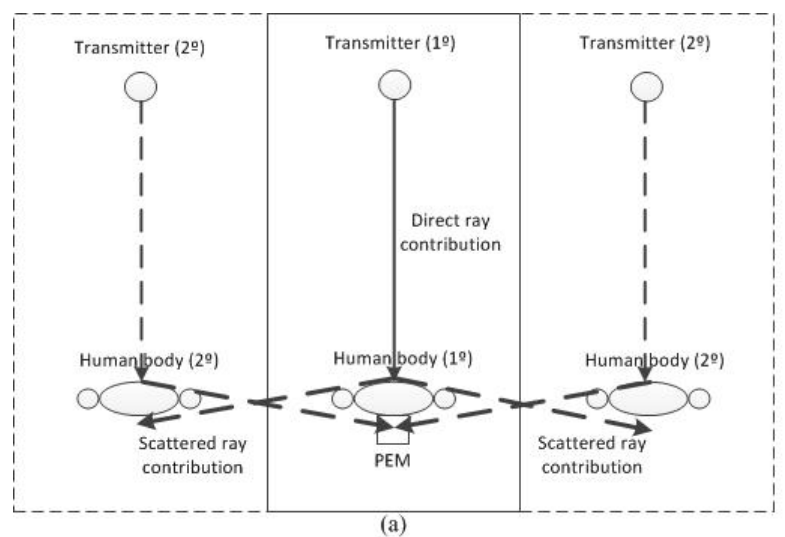

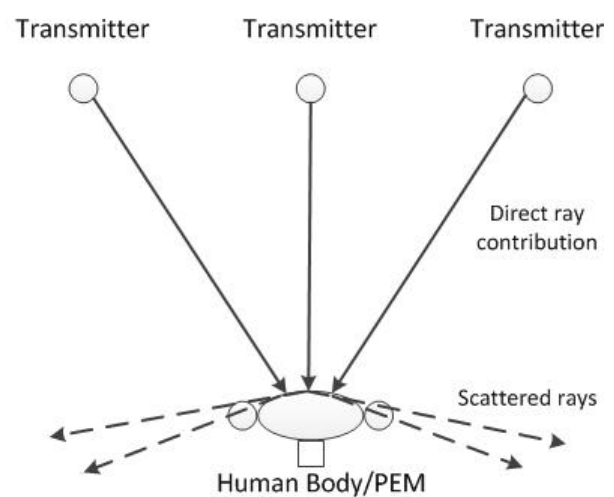

(b)

Figura 48.- (a) Reflexiones causadas por las fuentes secundarias del cuerpo humano, teniendo en cuenta el efecto de dispersión en recintos cerrados, (b) en contraposición se muestra lo que sucedería en el espacio libre donde las reflexiones de los rayos dispersados por el cuerpo humano no llegan al dosímetro ubicado en la región de sombra del usuario.

Esta pérdida de contribuciones en espacios abiertos puede ser modelada mediante un ángulo de sombra superior al considerado en recintos interiores.

En recintos de mayor volumen, los rayos están menos confinados y recorren distancias más grandes. Cuando los rayos llegan al receptor están más atenuados que si las distancias fueran más pequeñas. La Figura 36 y la Figura 39 muestran los resultados obtenidos en los recintos primero y segundo, respectivamente, para una misma potencia de transmisión: $20 \mathrm{dBm}$. Comparando la Figura 36 y la 
Figura 39, se deduce que los valores del campo-E medidos en un recinto de mayores dimensiones son menores que en recintos de menor volumen.

En particular, este mismo razonamiento también puede ser aplicado a los rayos que son dispersados por el cuerpo y que llegan al dosímetro después de ser reflejados: en el segundo experimento los rayos dispersados que llegan al dosímetro situado en la zona de sombra del usuario están más atenuados que en el recinto de menor volumen porque estos rayos también recorren distancias más grandes. Esto demuestra que si las dimensiones del recinto son mayores, las condiciones ambientales se parecen más a las del espacio libre y los resultados de las medidas realizadas se simulan mejor si se considera un ángulo de sombra mayor.

Después de analizar los resultados obtenidos se ratifica la conclusión referente a la menor subestimación de las medidas debido a la influencia del cuerpo humano en entornos cerrados que en espacios exteriores. Se demuestra que el valor del ángulo de sombra es dependiente de las condiciones del recinto y además cuanto mayor es el recinto las condiciones se aproximan más a las condiciones del espacio libre.

\subsubsection{Relación entre el ángulo de sombra y el tamaño del recinto}

Del estudio de los resultados experimentales y simulados de los dos primeros entornos se concluye que en los recintos más espaciosos la influencia del efecto sombra del cuerpo humano es más notable.

Para confirmar la relación entre el valor del ángulo de la sombra, y el tamaño del recinto interior, el experimento se repitió en otros dos entornos (tercero y cuarto) situados en el edificio 14 del Instituto de Salud Carlos III. El protocolo de 
realización de las pruebas experimentales fue el mismo que se describió en la sección anterior. Las medidas, en los casos de la sombra y no sombra, se contrastaron con los resultados de la simulación para determinar el valor del ángulo que mejor modela el efecto sombra del cuerpo humano en términos del KS test.

Teniendo en cuenta los recintos iniciales, cuyos resultados se han descrito anteriormente, en total el experimento se ha realizado en cuatro recintos. La Tabla 4 indica la relación entre las dimensiones, el volumen total de cada uno de los recintos, y los valores del ángulo de la sombra que se han obtenido en cada uno de ellos.

Tabla 4. Dimensiones, volumen total, y el valor del ángulo de sombra que mejor modela el efecto sombra en términos del KS test, para cada uno de los recintos interiores.

\begin{tabular}{|c|c|c|r|r|r|}
\hline Recinto & Anchura & Longitud & \multicolumn{1}{c|}{ Altura } & Volumen & Áng. sombra \\
\hline $\mathbf{1}$ & $1.26 / 3 \mathrm{~m}$ & $12 \mathrm{~m}$ & $2.45 \mathrm{~m}$ & $63 \mathrm{~m}^{3}$ & 13 grados \\
\hline $\mathbf{2}$ & $1.93 \mathrm{~m}$ & $27.15 \mathrm{~m}$ & $3.1 \mathrm{~m}$ & $162 \mathrm{~m}^{3}$ & 26 grados \\
\hline $\mathbf{3}$ & $2.56 \mathrm{~m}$ & $9 \mathrm{~m}$ & $2.47 \mathrm{~m}$ & $57 \mathrm{~m}^{3}$ & 12 grados \\
\hline $\mathbf{4}$ & $2.56 \mathrm{~m}$ & $10 \mathrm{~m}$ & $2.47 \mathrm{~m}$ & $63 \mathrm{~m}^{3}$ & 13 grados \\
\hline
\end{tabular}

Tal y como se muestra en la Figura 31, la anchura del primer recinto no es constante. Los diferentes valores de la anchura se indican en la Tabla 4. En el cálculo del volumen total se han considerado las áreas del recinto con diferente anchura.

En cuanto a los datos mostrados en la Tabla 4, los recintos 1, 3, y 4 son más pequeños que el segundo, y tienen un volumen total similar, siendo además el ángulo de sombra bastante parecido. En el caso del segundo recinto, el volumen 
total es considerablemente más grande, y el valor del ángulo es notablemente mayor que en los otros entornos (1, 3 y 4). Por lo tanto, del análisis de todos los resultados obtenidos se extrae que el efecto sombra del cuerpo humano es más notable en recintos grandes que en los que son más pequeños [Zir04], pudiéndose establecer una dependencia entre el valor del ángulo de sombra y las dimensiones del recinto.

\subsubsection{Concepto de variabilidad del diagrama de radiación}

A partir del análisis de los resultados obtenidos se ha deducido la relación existente entre las dimensiones del recinto y el ángulo de sombra. El valor del ángulo de sombra define el tamaño de un sector angular que puede considerarse como una alteración del diagrama de radiación del dispositivo receptor. En este apartado se presenta el concepto de variabilidad del diagrama de radiación como consecuencia de la presencia del usuario portador del dispositivo receptor.

Algunos autores [Che98], [Tof93] consideran que el diagrama de radiación de cualquier dispositivo receptor que es portado por el usuario (en este caso el dosímetro situado en la zona de sombra del usuario), puede verse afectado por la presencia del cuerpo humano. Según lo cual es posible afirmar que la variabilidad del diagrama de radiación es otra fuente de incertidumbre en la información proporcionada por los dosímetros personales.

El diagrama de radiación de los dosímetros receptores se considera isotrópico por aproximación teniendo en cuenta las características del fabricante [Spy14]. Los dosímetros se utilizan típicamente cerca del cuerpo del usuario. Bajo estas condiciones de proximidad, el patrón de radiación del dosímetro se distorsiona significativamente por acoplamiento con el cuerpo, lo que conlleva a una atenuación de la señal recibida. Estos efectos no sólo son dependientes de la 
Análisis de los resultados

frecuencia, pero variarán con el diseño del terminal, su antena, y el posicionamiento exacto respecto a la superficie del cuerpo [Sca01]. Cerca del cuerpo las antenas de los dispositivos llevables sufren una pérdida de su eficacia debido a la absorción electromagnética del tejido, la fragmentación del patrón de radiación, y las variaciones en el punto de alimentación de la impedancia. El concepto de efecto sombra no sólo se refiere a la obstrucción del cuerpo humano, sino que también incluye estas limitaciones. En este caso particular, en entornos interiores y en condiciones multitrayecto, la distorsión del diagrama de radiación de los dispositivos llevables se puede considerar como una forma de filtrado espacial [Sca01] que se modela mediante el ángulo de sombra, tal y como se muestra en este estudio.

Además como se ha indicado anteriormente, los efectos de dispersión y absorción que ocasiona el cuerpo humano, también se pueden modelar mediante la atenuación de los rayos que llegan al dosímetro pertenecientes a un determinado sector angular. La influencia de todos estos efectos en el diagrama de radiación se modela mediante el concepto de ángulo de sombra.

En la implementación del modelo teórico se considera que el dispositivo receptor, en este caso el dosímetro, es isotrópico: la intensidad con la que los rayos llegan al receptor es independiente del ángulo de incidencia, no sufriendo atenuación adicional alguna. Analizando las características técnicas de estos dispositivos, el hecho de considerar el diagrama de radiación como isotrópico puede ser una aproximación válida que se emplea a la hora de calcular los valores del campo-E que mide el dosímetro en el caso de no estar afectado por el efecto sombra. Por otra parte, la presencia del usuario altera la característica de isotropía del dosímetro, por lo que es necesario incluir esta influencia en el modelo teórico implementado. De esta forma el efecto del cuerpo humano en las proximidades 
del dosímetro se ha modelado mediante un sector angular cuyo valor es el ángulo de sombra, que se ha considerado como una variación del plano de azimut del diagrama de radiación del dosímetro.

\subsection{Error cuadrático medio}

Para verificar la precisión del modelado de la presencia del cuerpo humano mediante el efecto sombra se ha empleado el error cuadrático medio (ECM), que permite comparar los resultados simulados y experimentales punto por punto.

En estadística, el error cuadrático medio (ECM) es un indicador del promedio de los errores al cuadrado, en definitiva, de la diferencia entre la serie simulada y la serie real.

En función del valor del ángulo de sombra la estimación realizada puede sobrestimar o subestimar los datos reales. Si el valor del ángulo de sombra que se configura como parámetro en el simulador es inferior al ángulo óptimo se estarán sobrestimando los datos reales. Por el contrario si el valor del ángulo en la estimación es mayor que el ángulo óptimo se estarán subestimando los valores reales.

Para conocer el ECM en función del ángulo de sombra será necesario conocer para qué valores del ángulo de sombra la simulación sobrestima o subestima los valores reales. Para ello se emplea el mean bias error (MBE) que permite estimar la diferencia entre los valores simulados y los valores reales, y se define en porcentaje mediante la siguiente expresión:

$$
m b e=\frac{100}{\bar{X}}\left[\frac{\sum_{i=1}^{n}\left(Y_{i}-X_{i}\right)}{n}\right]
$$


Siendo $X$ la serie de datos experimentales, $\bar{X}$ es su media, e $Y$ es la serie estimada mediante la simulación.

Si el resultado del MBE es positivo, la simulación sobrestima los valores reales y en el caso que sea negativo subestimará los valores reales.

El cálculo del ECM se realiza según la siguiente fórmula como porcentaje:

$$
E C M=\frac{100}{\bar{X}}\left[\frac{\sum_{i=1}^{n}\left(Y_{i}-X_{i}\right)^{2}}{n}\right]^{\frac{1}{2}}
$$

Si para un determinado valor del ángulo de sombra el MBE es positivo, el ECM implica una sobrestimación de los valores reales y por lo tanto la incertidumbre introducida por la serie estimada se cuantifica mediante un factor que es superior a la unidad, siendo un valor positivo si se expresa en dB.

Si por el contrario el MBE es negativo la serie estimada subestima la real e introduce una incertidumbre que se expresa mediante un factor inferior a la unidad que en $\mathrm{dB}$ es un valor negativo.

Para cada posible valor del ángulo de sombra se ha obtenido el MBE y el ECM en \%. En función de si la serie simulada sobrestima o subestima los datos reales, se determina el factor de incertidumbre calculado en $\mathrm{dB}$, que será positivo para ángulos inferiores al ángulo de sombra óptimo, y negativo para los ángulos superiores al ángulo de sombra óptimo.

Si se obtiene el módulo de los factores de incertidumbre en función del valor del ángulo de sombra, el mínimo factor de incertidumbre ha de coincidir con el valor óptimo del ángulo de sombra 
La siguiente figura muestra el módulo de los factores de incertidumbre obtenidos a partir del ECM, junto con el MBE, para los resultados obtenidos en el primer experimento.

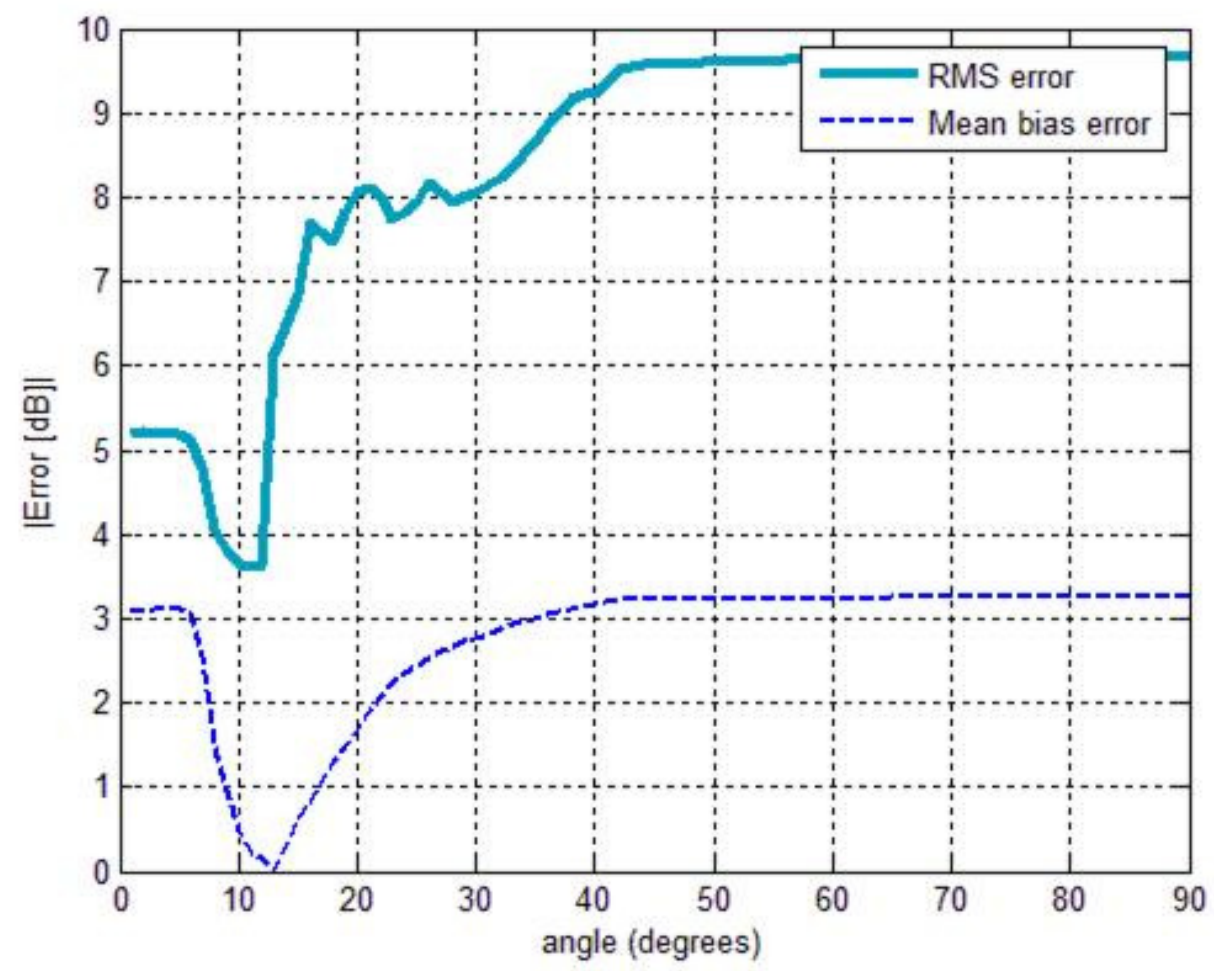

Figura 49.- Dependencia del ECM y MBE en función del valor del ángulo de sombra.

De la Figura 49 se deduce que el error de la simulación alcanza valores mínimos para ángulos comprendidos entre 10 y 15 grados, siendo el factor de incertidumbre igual a $3.6 \mathrm{~dB}$, equivalente a un valor de ECM de $51 \%$ en unidades de voltaje.

En el caso de no-sombra la simulación introduce una sobrestimación, ya que el ECM es del $58 \%$ lo que es equivalente a un factor de $4 \mathrm{~dB}$. 
Análisis de los resultados

Según la información aportada en la Figura 49 el modelo de simulación propuesto proporciona resultados aceptables en términos del ECM [Rod11]. Pero el valor óptimo del ángulo de sombra ha sido seleccionado teniendo en cuenta el resultado de KS test que es un mejor indicador para la evaluación de la precisión del modelo, ya que el ECM penaliza los pequeños desplazamientos relacionados con las incertidumbres de la longitud de la trayectoria eléctrica [Bla09].

\subsection{Análisis estadístico de los resultados}

Otra forma de modelar y caracterizar el efecto sombra es analizar las distribuciones estadísticas que siguen las FDAs de los resultados obtenidos, con el fin de establecer una vinculación de ámbito estadístico entre los resultados teóricos y los resultados experimentales.

Para aportar una mayor solidez al modelo teórico del efecto sombra, se comparan las FDAs de los resultados simulados y experimentales. Tras comprobar que las FDAs de ambos tipos de resultados son muy parecidas, se pretende verificar si los resultados teóricos presentan la misma distribución estadística que las medidas experimentales obtenidas en entornos reales.

Varios estudios definen las distribuciones Lognormal, Rician, Rayleigh, Weibull y Nakagami como las distribuciones típicas de ambientes interiores [Wyn09], [San10]. Otros estudios sugieren distribuciones específicas dependiendo de la frecuencia de trabajo y del entorno, por ejemplo la distribución Lognormal para ajustar los diferentes efectos de la sombra en redes personales basadas en la tecnología UWB [For06]. Otros resultados se basan en que la distribución para caracterizar las pérdidas de intensidad de los CEM a lo largo de un trayecto se puede caracterizar como Weibull o Nakagami en la mayoría de entornos. La semejanza entre todas estas distribuciones confirma que cualquiera de ellas puede 
caracterizar la propagación y el desvanecimiento implícito de los rayos en ambientes interiores [Bab00].

En cuanto a la distribución estadística que se ajusta mejor a los resultados del primer experimento, en ambos casos de sombra y no-sombra, las FDAs obtenidas siguen una distribución Lognormal. La Figura 50 y la Figura 51 muestran de forma gráfica la comparación entre las distribuciones más típicas de los ambientes interiores y las FDAs del campo-E tanto de las medidas experimentales como de los resultados de la simulación, respectivamente, para el primer experimento.

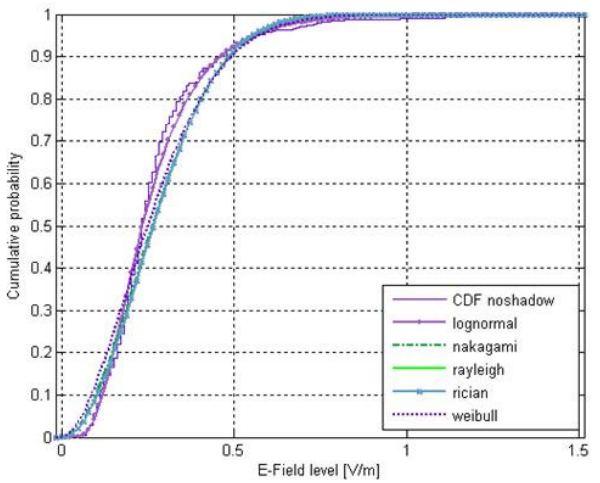

(a)

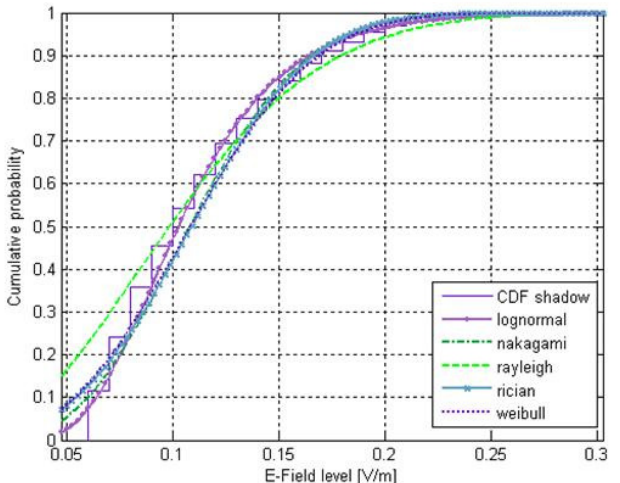

(b)

Figura 50.- Ajuste de los resultados experimentales para el primer experimento con las distribuciones estadísticas típicas en entornos interiores para los casos de: (a) nosombra, (b) sombra. 


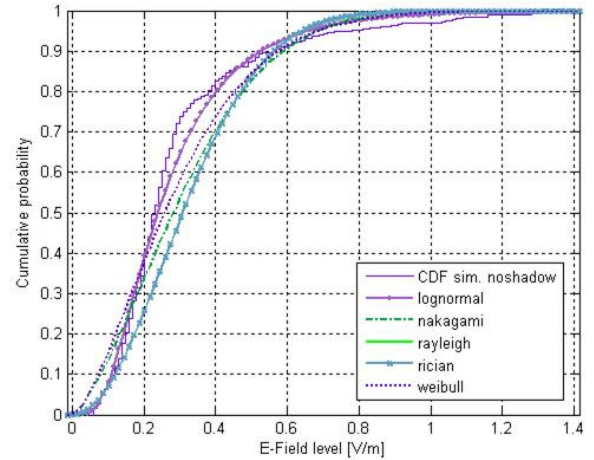

(a)

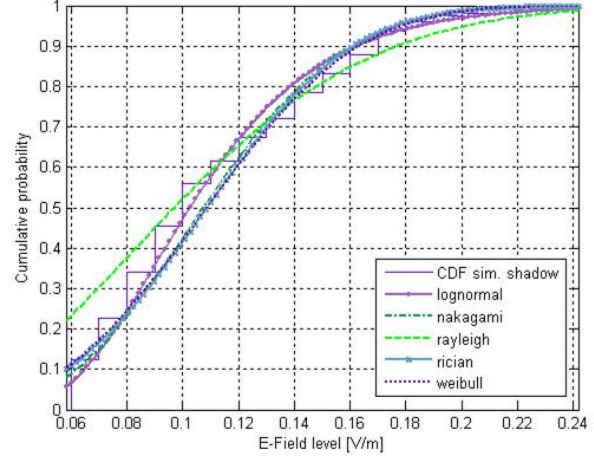

(b)

Figura 51.- Ajuste de los resultados de la simulación para el primer experimento con las distribuciones estadísticas típicas en entornos interiores para los casos de: (a) nosombra, (b) sombra.

La Tabla 5 indica los p-valores proporcionados por la prueba del KS entre las distribuciones estadísticas más típicas y las FDAs de las medidas y los resultados de la simulación que se han obtenido en el primer experimento. Se destaca que la distribución estadística que presenta el mayor p-valor es la distribución Lognormal en todos los casos.

Tabla 5. P-valores proporcionados por la prueba de KS entre las FDAs del campo-E obtenidas en el primer experimento, y las distribuciones estadísticas más típicas de los ambientes interiores.

\begin{tabular}{|c|c|c|c|c|}
\hline & Experimenta & & Simulación & \\
\hline & Sombra & No-sombra & Sombra & No-sombra \\
\hline Lognormal & 0.0026 & 0.0826 & 0.0099 & 0.0022 \\
\hline Nakagami & 0.0004 & 0.0000 & 0.0001 & 0.0000 \\
\hline Rayleigh & 0.0000 & 0.0000 & 0.0000 & 0.0000 \\
\hline Rician & 0.0003 & 0.0000 & 0.0000 & 0.0000 \\
\hline
\end{tabular}




$\begin{array}{lllll}\text { Weibull } & 0.0001 & 0.0000 & 0.0000 & 0.0000\end{array}$

Teniendo en cuenta la configuración experimental, se esperaba que las FDAs no siguieran una distribución Rayleigh, porque la intensidad de los rayos directos y reflejados disminuye con la propagación a lo largo de la trayectoria predefinida [Hor86]. Otros trabajos justifican que las variaciones de la intensidad detectada por los dosímetros portables debido al movimiento de los brazos se caracterizan mejor mediante las distribuciones Lognormal y Nakagami, en comparación con el modelo Rayleigh [For06].

Se ha demostrado que las FDAs de los datos medidos y los resultados de la simulación en el segundo recinto interior, también siguen una distribución Lognormal. Los p-valores obtenidos se muestran en la Tabla 6.

Tabla 6. P-valores proporcionados por la prueba de KS entre las FDAs del campo-E, obtenidas en el segundo experimento, y las distribuciones estadísticas más típicas de los ambientes interiores.

\begin{tabular}{|c|c|c|c|c|}
\hline & Experimental & & Simulación & \\
\hline & Sombra & No-sombra & Sombra & No-sombra \\
\hline Lognormal & 0.0041 & 0.0170 & 0.1313 & $0.4153 \times 10^{-3}$ \\
\hline Nakagami & 0.0015 & 0.0000 & 0.0134 & $10^{-3}$ \\
\hline Rayleigh & 0.0000 & 0.0000 & 0.0000 & $10^{-3}$ \\
\hline Rician & 0.0014 & 0.0000 & 0.0058 & $10^{-3}$ \\
\hline Weibull & 0.0003 & 0.0000 & 0.0043 & $10^{-3}$ \\
\hline
\end{tabular}


Los resultados de los experimentos tercero y cuarto también han sido analizados estadísticamente. De la misma forma que en los experimentos anteriores las FDAs que se han obtenido a partir de los resultados experimentales y simulados, para los casos de sombra y no-sombra, también siguen una distribución Lognormal, tal como se muestra en las Tablas 7 y 8.

La única excepción son los resultados de la simulación para el caso de sombra del cuarto experimento, donde la FDA se ajusta a una distribución de tipo Weibull. No obstante este caso es una excepción que no ha de considerarse como relevante, teniendo en cuenta que la distribución Weibull es muy semejante a la Lognormal, y como ya se indicado, cualquiera de ellas puede caracterizar de forma óptima el desvanecimiento de una señal de RF en recintos cerrados [Bab00], además, tal como se indica en la Tabla 8, los p-valor obtenidos para ambas distribuciones, Lognormal y Weibull, son muy semejantes.

Tabla 7. P-valores proporcionados por la prueba de KS entre las FDAs del campo-E, obtenidas en el tercer experimento, y las distribuciones estadísticas más típicas de los ambientes interiores.

\begin{tabular}{|c|c|c|c|c|}
\hline & Experimenta & & Simulación & \\
\hline & Sombra & No-sombra & Sombra & No-sombra \\
\hline Lognormal & 0.0952 & 0.0551 & 0.0225 & 0.1513 \\
\hline Nakagami & 0.0092 & 0.0000 & 0.0162 & 0.0001 \\
\hline Rayleigh & 0.0000 & 0.0000 & 0.0000 & 0.0000 \\
\hline Rician & 0.0169 & 0.0000 & 0.0043 & 0.0000 \\
\hline Weibull & 0.0272 & 0.0000 & 0.0061 & 0.0078 \\
\hline
\end{tabular}


Tabla 8. P-valores proporcionados por la prueba de KS entre las FDAs del campo-E, obtenidas en el cuarto experimento, y las distribuciones estadísticas más típicas de los ambientes interiores.

\begin{tabular}{|c|c|c|c|c|}
\hline & Experimental & & Simulación & \\
\hline & Sombra & No-sombra & Sombra & No-sombra \\
\hline Lognormal & 0.0203 & 0.0185 & 0.0138 & 0.3503 \\
\hline Nakagami & 0.0113 & 0.0000 & 0.0085 & 0.0000 \\
\hline Rayleigh & 0.0000 & 0.0000 & 0.0000 & 0.0000 \\
\hline Rician & 0.0044 & 0.0000 & 0.0079 & 0.0000 \\
\hline Weibull & 0.0015 & 0.0001 & 0.0186 & 0.0017 \\
\hline
\end{tabular}

\subsection{Factores de corrección}

Estudios previos abordan diferentes formas de obtener factores de corrección para corregir la subestimación debida a la presencia del cuerpo humano en las medidas registradas por los dosímetros personales [Neu10], [Bol11]. A continuación, se definirá un método de cálculo de factores de corrección para este propósito y se comprobará si la subestimación ocasionada como consecuencia del efecto sombra del cuerpo humano puede ser corregida.

Dadas dos series de datos, una de ellas consta de los valores registrados en presencia del cuerpo humano $\left(\mathrm{S}_{\text {sombra }}\right.$ ), mientras que la otra serie contiene los niveles de exposición sin que se vean afectados por la presencia del cuerpo 
humano $\left(\mathrm{S}_{\text {nosombra }}\right)$, el factor de corrección se define como la relación entre los valores medios de ambas series:

$$
\text { factor de correción }=\frac{\text { mean }\left(S_{\text {nosombra }}\right)}{\operatorname{mean}\left(S_{\text {sombra }}\right)}
$$

El factor de corrección referente a la relación entre los valores medios de las medidas experimentales con el efecto sombra y los resultados de la simulación en ausencia del cuerpo es un factor de 3, equivalente a $9.3 \mathrm{~dB}$. Si este factor se aplica a las medidas obtenidas considerando el efecto sombra, el p-valor muestra un valor del orden de $10^{-6}$ en comparación con los resultados de la simulación sin dicho efecto. Las FDAs para las medidas con sombra, los resultados de la simulación sin sombra, y la corrección de la subestimación mediante el factor de corrección se muestra en la Figura 52. 


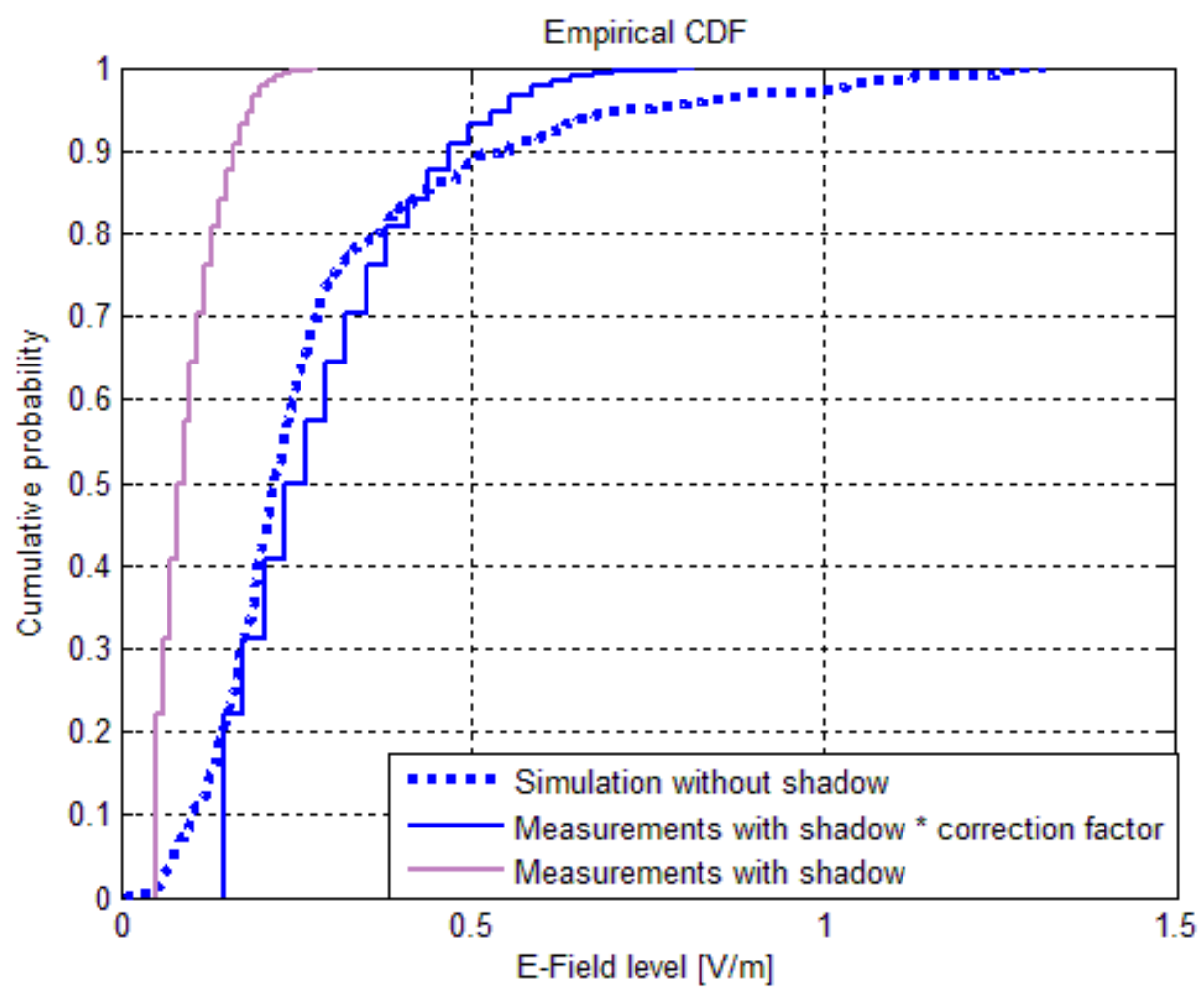

Figura 52.- Comparación entre las medidas experimentales con sombra, los resultados de la simulación sin sombra, y la corrección de la incertidumbre de la sombra mediante el factor de corrección.

A partir de la Figura 52 se deduce que existen diferencias entre las FDAs de los resultados de la simulación sin sombra y la corrección de las medidas con sombra mediante el factor de corrección. Tanto las medidas corregidas, como la simulación sin el efecto sombra presentan los mismos valores medios, entre 0.2 y $0.4 \mathrm{~V} / \mathrm{m}$, pero al aplicar el factor de corrección se subestiman los valores máximos. Además, esta corrección genera una sobreestimación de los valores detectados que son menores que $0.05 \mathrm{~V} / \mathrm{m}$, que es el límite más bajo de la 
sensibilidad del dosímetro. Por las razones indicadas la corrección de la subestimación se penaliza con un p-valor de $10^{-6}$.

A continuación se comparan las resultados de las medidas del dosímetro con y sin el efecto sombra. El factor de corrección es aproximado al anterior: 2.8 (9 dB): La Figura 53 muestra la comparación de las FDAs. El resultado es muy similar al anterior, pero el p-valor es algo superior, $10^{-5}$. En este caso aunque los valores medios son incluso más aproximados, el p-valor es bajo debido principalmente a la sobrestimación de los niveles más bajos del campo-E y a la no coincidencia de los valores máximos.

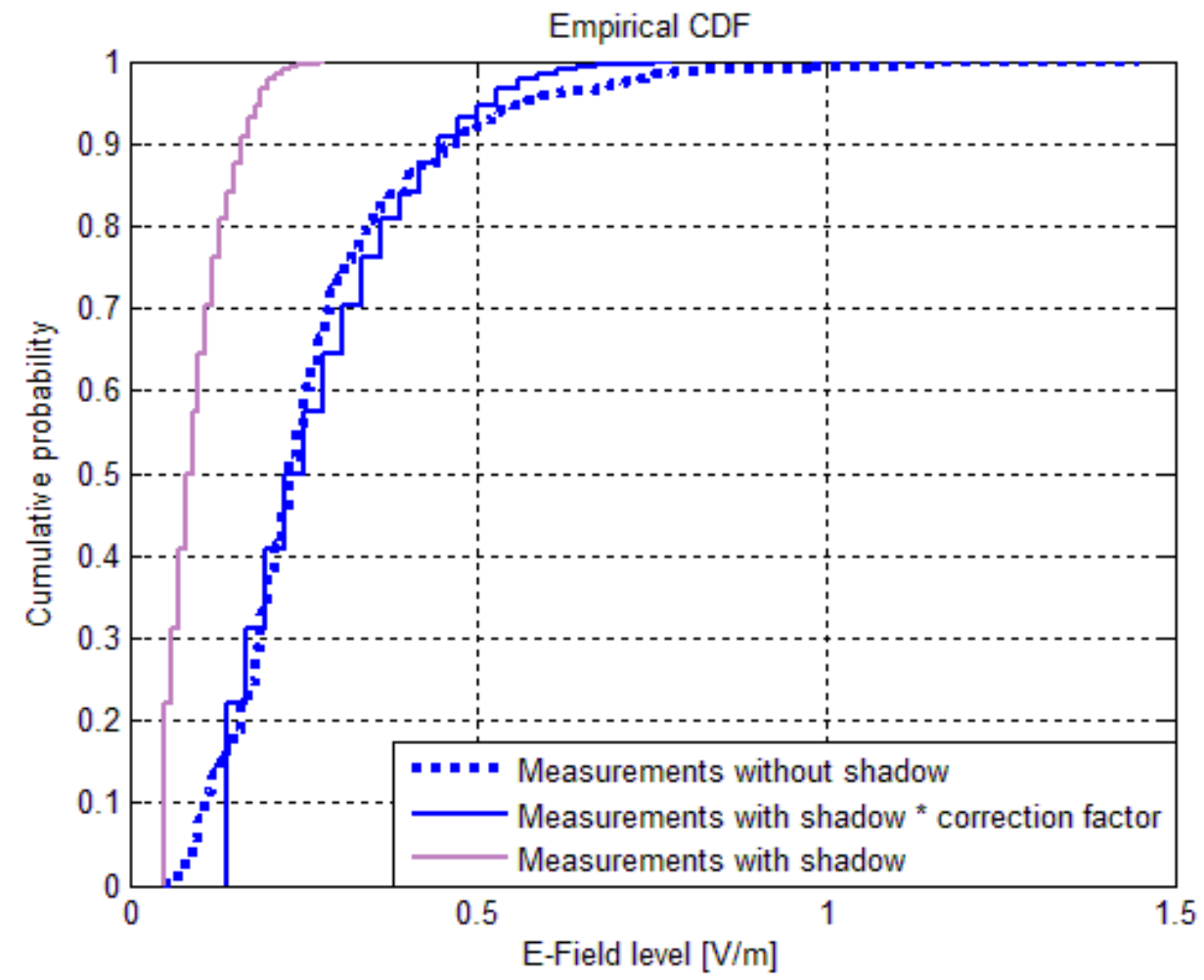

Figura 53.- Comparación entre los resultados experimentales sin sombra y con sombra aplicando factores de corrección. 
Mediante los factores de corrección promediados se puede corregir la subestimación debida a la presencia del cuerpo humano, tal y como reflejan las FDAs, pero no es posible incluir todas las implicaciones del efecto sombra, lo que permitiría obtener un ajuste estadístico más preciso.

Además la realización del KS-test aporta una justificación más precisa: los pvalor obtenidos no superan el valor de 0.05 , por lo que los factores de corrección no serían un método del todo válido para compensar la subestimación en los niveles de exposición a los CEM como consecuencia de la presencia del cuerpo humano.

El método de los factores de corrección promediados es una buena solución para corregir los valores medios, pero subestima los niveles máximos del campoE, y en el caso de los valores mínimos, el rango de sensibilidad introduce una sobreestimación que no es una consecuencia directa de la aplicación de los factores de corrección.

La sobrestimación de los valores mínimos se puede evitar con el uso de un modelo de dosímetro más moderno como es EME SPY 140 o EME SPY 200, cuyo límite inferior del rango de sensibilidad es 0.005. Estos dosímetros proporcionan valores medidos más fiables porque los valores comprendidos entre 0.005 y 0.05 se medirán realmente, y no van a ser sustituidos por 0.05 , que es una sobrestimación que no es causada directamente por el efecto sombra, pero se mantiene cuando se aplica el factor de corrección.

Para proporcionar una conclusión más fiable sobre la subestimación de los valores máximos, el método de los factores de corrección se ha aplicado a los resultados de los tres experimentos. En todos los casos se subestimaron los valores máximos, por lo que este efecto puede ser considerado como una consecuencia directa de la aplicación de este método. 
Análisis de los resultados

En conclusión, la aplicación de factores de corrección promediados no incluye todas las implicaciones del efecto sombra. Los problemas asociados con la presencia del usuario podrían aminorase al tratar de colocar el dosímetro en la línea de visión con la fuente de radiación durante la realización de la campaña de medidas. Otra posible solución es el uso de dispositivos de medida que estén provistos de varias sondas, colocadas intencionadamente para que no se vean afectadas simultáneamente por la sombra del usuario. 


\section{CAPITULO 8}

\section{Conclusiones}

\subsection{Conclusiones}

Los dosímetros son instrumentos muy extendidos destinados a la medición de los niveles de exposición a emisiones radioeléctricas, que se emplean especialmente para la obtención de datos variables en el tiempo y en varias localizaciones geográficas. La motivación de este trabajo es el modelado y caracterización de uno de los errores implícitos que es causa de incertidumbre en los datos registrados por los dosímetros: el efecto sombra del cuerpo humano.

Una de las partes de este estudio se ha centrado en la realización de las medidas experimentales, que ha permitido definir la dependencia entre el modelado del efecto sombra del usuario portador del dosímetro, y las características del recinto interior donde se han realizado las medidas. 
Se ha diseñado e implementado un modelo de propagación en interiores mediante la técnica de las imágenes y del trazado de rayos que ha permitido demostrar la validez del modelo propuesto.

Con ello se ha profundizado en la interpretación de la información aportada por los procedimientos de medición de la exposición humana a radiaciones no ionizantes. La presencia del usuario en las proximidades del dosímetro ocasiona una subestimación de los datos obtenidos que no refleja las condiciones reales de la exposición, mientras que la ausencia de dicha influencia implica mayores niveles de exposición que realmente no están siendo detectados.

A continuación se expondrán de forma resumida los resultados más importantes de este trabajo, enfocando estos resultados en el ámbito del estado actual del conocimiento acerca del tema tratado. Finalmente se indicarán una serie de líneas futuras de investigación que permiten profundizar en diversos aspectos que han sido presentados y que complementan el trabajo realizado.

\subsubsection{Mejora de los procedimientos de medición de dosímetros personales}

El problema que se pretende resolver surge de los factores de incertidumbre conocidos y asociados a los procedimientos de medición de los niveles de la exposición humana a las radiaciones no ionizantes. El escenario experimental es un recinto interior donde el usuario portador del dosímetro está expuesto a la radiación radioeléctrica procedente de una fuente transmisora que radia a la frecuencia de $2.4 \mathrm{GHz}$. El usuario camina de frente hacia el transmisor, portando un dosímetro que se encuentra colocado en la parte baja de la espalda a la altura de la cintura. Idealmente el dosímetro debería registrar los valores que serían medidos si no estuviera presente el usuario que lleva el dispositivo de medida. La 
normativa vigente en muchos países, y que es recomendada por varias organizaciones internacionales, regula los valores de la onda incidente, que son los que han de ser objeto de comparación con los niveles y umbrales propuestos.

El objetivo de este trabajo es analizar la subestimación ocasionada por la influencia del cuerpo del sujeto que está portando un medidor personal. Se pretende modelar este efecto mediante la implementación de un programa de trazado de rayos donde se consideran de manera especial los rayos que se ven afectados por el efecto sombra del cuerpo humano.

Para aportar resultados fiables en el diseño del protocolo experimental se ha incluido un segundo dosímetro que se encuentra fuera de la zona de sombra del sujeto, y que al igual que el otro dosímetro registra los valores de exposición. Es decir, el segundo dosímetro se encuentra completamente en línea de visión con la fuente emisora y no afectado por la influencia del efecto sombra, mientras el otro dosímetro se encuentra completamente fuera de la zona de iluminación del transmisor. Se pretende encontrar la mayor diferencia posible entre las medidas registradas por los dos dosímetros para modelar el efecto sombra. Esto es especialmente relevante en el caso de querer conocer si los valores de los campos electromagnéticos se están aproximando o superan los valores límites establecidos en la legislación. Los errores de medida ocasionan que el dispositivo no alerte sobre situaciones de alarma en los casos en los que fuera necesario.

\subsubsection{Modelado del efecto sombra del cuerpo humano y sus implicaciones estadísticas}

Con el objetivo de modelar el efecto sombra del cuerpo humano en condiciones de movimiento, en recintos interiores las pruebas experimentales se han llevado a 
cabo en cuatro recintos experimentales. Con ello se ha pretendido aportar una mayor fiabilidad a las conclusiones finales.

Este estudio compara los resultados experimentales con los resultados teóricos. Los resultados teóricos han sido aportados mediante la implementación de un programa de simulación de trazado de rayos en interiores en el que se ha tenido en cuenta la subestimación de los resultados del campo-E como consecuencia de la presencia del usuario portador del dosímetro. La frecuencia de trabajo ha sido la banda de frecuencia Wi-Fi de $2.4 \mathrm{GHz}$, siendo hoy en día la banda más utilizada por las comunicaciones personales en entornos interiores.

La comparación de las medidas de los dos dosímetros empleados en la parte experimental, permite afirmar que, bajo los condiciones indicadas, el efecto sombra del cuerpo introduce una subestimación media de los niveles del campo-E de $9 \mathrm{~dB}$ considerando el caso más desfavorable, en el que el dosímetro situado fuera de la línea de visión, NLoS, está siendo afectado por el efecto sombra durante todo el experimento.

En la implementación del modelo teórico se ha propuesto una forma de identificar y de cuantificar qué rayos son los que se ven afectados por el efecto sombra. Se ha considerado que los rayos que inciden en el receptor con un determinado ángulo respecto a la posición del usuario son atenuados. Este ángulo de sombra se ha introducido como un parámetro del modelo para decidir si un rayo en concreto está siendo atenuado o no. El cálculo del valor óptimo del ángulo de sombra se ha llevado a cabo mediante la comparación de las medidas experimentales y los resultados de la simulación en términos del KS test. Esta técnica muestra una buena correlación con las medidas registradas en la parte experimental en relación con los resultados obtenidos y en términos de precisión estadística. Además, el cálculo del ECM ha permitido comprobar para qué valores 
del ángulo de sombra los resultados de la simulación se aproximan más a las condiciones reales de exposición a los CEM.

La investigación llevada a cabo en este estudio está motivada por trabajos previos sobre la cuantificación del ángulo de sombra en espacios abiertos. Se ha tomado como punto de partida el valor del ángulo de sombra óptimo obtenido en trabajos destinados al estudio de este efecto en espacios abiertos. Se demuestra que es posible cuantificar el efecto sombra del cuerpo humano en entornos interiores como un ángulo de sombra cuyo valor es menor que en entornos exteriores.

Además, la conclusión que se obtiene referente a la forma de modelar el ángulo de sombra se ha contrastado con la realización del experimento en otros tres recintos interiores, lo que ha permitido afirmar que el ángulo de sombra en entornos interiores depende de las dimensiones del área del recinto sometida al experimento. El efecto sombra es más significativo en recintos espaciosos que en los que son más pequeños. En el caso de recintos cerrados y pequeños, los rayos que son dispersados por el cuerpo humano llegan al dosímetro de la zona de sombra después de haber sido reflejados por las paredes más cercanas sin ser atenuados excesivamente. En contraste, en recintos que son más anchos, y de volumen mayor, los rayos dispersados recorren distancias mayores y llegan al dosímetro más atenuados.

Este trabajo también proporciona una visión útil sobre las características estadísticas asociadas a la influencia del cuerpo humano en los niveles del campoE medidos por los dosímetros. Los experimentos y los resultados de la simulación muestran que los niveles de los CEM en ausencia del cuerpo humano se ajustan a una distribución Lognormal, una de las distribuciones estadísticas más típicas en recintos interiores para modelar los niveles de exposición. Los resultados 
obtenidos con el dosímetro que está siendo afectado por efecto sombra, situado completamente NLoS, también siguen el mismo tipo de distribución. Sin embargo la subestimación debida al efecto sombra no puede ser corregida con exactitud mediante el uso de factores de corrección, aunque este enfoque ofrece una solución más o menos aproximada. El análisis de las FDAs permite afirmar que los factores de corrección proporcionan una solución aceptable al problema de la incertidumbre del efecto sombra en lo referente a los valores medios, pero su aplicación no permite reflejar en su totalidad la variabilidad de los niveles de exposición introducida por el efecto sombra en condiciones dinámicas y en entornos interiores.

Este estudio demuestra que el hecho de prescindir del efecto sombra es un error sistemático que conlleva la subestimación de los niveles de exposición reales a las radiaciones no ionizantes en entornos interiores. Este trabajo proporciona una metodología útil para entender las consecuencias desde el punto de vista estadístico del efecto sombra.

\subsection{Listado de publicaciones}

A continuación se indican las publicaciones derivadas del trabajo realizado en la Tesis:

S. de Miguel-Bilbao, J. García, V. Ramos, J. Blas. "Assessment of human body influence in exposure measurements of electric field in indoor enclosures," aceptado para publicación en Bioelectromagnetics. 2014.

S. de Miguel-Bilbao, J. Fernández, J. Roldán, J. García, O.J. Suárez, V. Ramos, "Assessment of exposure of Wi-Fi devices," 2014 IEEE International Symposium 
on Medical Measurements and Applications (MeMeA), Lisboa (Portugal), pp: 14, 11-12 junio, 2014. DOI: 10.1109/MeMeA.2014.6860147.

S. de Miguel-Bilbao, M.A. Martín, A. del Pozo, V. Febles, J.A. Hernández, J.C. Fernández de Aldecoa, V. Ramos, "Analysis of exposure to electromagnetic fields in a healthcare environment: simulation and experimental study," Health Physics, 105(5):S209-S222, 2013. DOI: 10.1097/HP.0b013e31828e5c15.

S. de Miguel-Bilbao, J. García, M. D. Marcos, V. Ramos. 2013. "Short range technologies for ambient assisted living systems in telemedicine: New healthcare environments". Chap.8. In Telemedicine, Madhavan, R. and Khalid, S. (eds). Intech. ISBN 978-953-51-1211-2.

S. de Miguel-Bilbao1, F. Solano, J. García, O. J. Suárez, D. Rubio, V. Ramos, "Analysis of exposure of social alarm devices in near field conditions," 13th Mediterranean Conference on Medical and Biological Engineering (MEDICON 2013), pp: 1155-1158, Sevilla (España), 25-28 septiembre, 2013. DOI: 10.1007/978-3-319-00846-2_286.

S. de Miguel-Bilbao, J. García, E. Aguirre, L. Azpilicueta, F. Falcone, V. Ramos, "Assessment of statistical distribution of exposure to electromagnetic fields from social alarm devices," 13th Mediterranean Conference on Medical and Biological Engineering (MEDICON 2013), pp: 1159-1162, Sevilla (España), 25-28 septiembre, 2013. DOI: 10.1007/978-3-319-00846-2_286.

S. de Miguel, J. del Pozo, V. Ramos, V. Febles, M.A. Martín, J.C. Fernández de Aldecoa. "Electromagnetic compatibility in hospitals for electromedical equipment and personal communication systems," Advanced Electromagnetics Symposium (AES), pp: 185-189, París (Francia), 16-19 abril, 2012. 
Conclusiones

S. de Miguel, J. García, V. Ramos, D. Rubio, O. Suarez, "Analysis of Electromagnetic Compatibility of Wireless Ambient Assisted Living Devices," 32nd Progress In Electromagnetics Research Symposium (PIERS), Moscú (Rusia), pp: 746-749, 19-23 agosto, 2012. ISBN: 978-1-934142-22-6.

S. de Miguel, J. García, A. del Pozo, F. Falcone, V. Ramos. "Study of EMF exposure for personal Communications in an outdoor environment," $4^{\text {th }}$ International Conference on Electromagnetic Fields, Health and Environment (EHE), Coimbra (Portugal), pp: 94-98, 25-29 mayo, 2011. ISBN: 978-972-822$22-4$. 


\section{CAPITULO 9}

\section{Nuevas propuestas de investigación}

El cálculo de los niveles de exposición a radiaciones no ionizantes en los diferentes ámbitos de la vida diaria es un problema difícil de abordar con la precisión requerida debido a varios factores de incertidumbre.

En concreto este trabajo se ha centrado en modelar la subestimación de los niveles de exposición registrados por los dosímetros como consecuencia de la presencia del usuario que está portando el dispositivo de medida.

A partir del trabajo realizado se han detectado una serie de aspectos en los que se debería profundizar en el futuro: 
Nuevas propuestas de investigación

- Estudio de la distancia efectiva a partir de la cual el dosímetro no se encuentra sometido a la influencia del cuerpo humano, comprobándose si existen diferencias entre ambientes interiores y ambientes exteriores.

- Posibilidad de emplear un dispositivo automático capaz de desplazar el dosímetro a la velocidad requerida, sin que el usuario tenga que llevarlo consigo, para evitar lo más posible la influencia del cuerpo humano.

- Establecer una dependencia matemática entre el valor del ángulo de sombra y las dimensiones del recinto.

- Analizar y modelar la dependencia del valor del ángulo de sombra con la complexión del usuario portador del dosímetro y de su postura (sentado o levantado, etc.).

- Estudio de la atenuación en el caso que el dosímetro no se encuentre completamente fuera de la línea de visión con la fuente de radiación, por ejemplo en el caso que sea portado por el usuario lateralmente y sujeto a la altura de la cadera.

- Modelado del efecto sombra no sólo teniendo en cuenta el ángulo de azimut con el que los rayos alcanzan al dosímetro en la zona de sombra, sino también mediante la definición de la variabilidad del ángulo de elevación.

- Posible caracterización de la presencia de varias personas en el mismo recinto interior que está siendo estudiado.

- Caracterizar el efecto sombra si el trayecto recorrido por el usuario es transversal a la dirección del rayo directo entre el transmisor y el receptor. Considerar también las implicaciones en las FDAs obtenidas en estos casos, destacando sobre todo las posibles diferencias que se pueden encontrar en el caso de considerar los trayectos transversales y longitudinales respecto al rayo directo entre el transmisor y el receptor. 
- Realizar el estudio con un dosímetro más moderno, por ejemplo, EME SPY 140, o EME SPY 200, lo que permitiría analizar la influencia del efecto sombra en otras frecuencias de trabajo, como puede ser la banda de $5 \mathrm{GHz}$, que es empleada en otros protocolos como son 802.11a, y 802.11 n.

Otra mejora que incorporan los dosímetros EME SPY 140, y EME SPY 200, es referente al rango de sensibilidad, que está comprendido entre $0.005 \mathrm{~V} / \mathrm{m}$ y $6 \mathrm{~V} / \mathrm{m}$ para la banda de frecuencia de $2.4 \mathrm{GHz}$. Esta característica permite obtener datos experimentales más fiables sobre todo en el caso de sombra en recintos más espaciosos donde la subestimación ocasionada por la presencia del cuerpo humano es más notable.

Comprobar la influencia del efecto sombra en condiciones de espacio libre con los resultados obtenidos en un espacio anecoico. En entornos exteriores las únicas contribuciones son el rayo directo y el rayo que se refleja en el suelo. Se puede reproducir el mismo escenario en una cámara semianecoica donde sólo se produciría una reflexión en el suelo, por lo que los niveles de campo-E que se registran en los dosímetros son debidos exclusivamente al rayo directo y al rayo reflejado en el suelo. 



\section{Apéndice A}

\section{A.1 Óptica Geométrica}

El trazado de rayos es un método determinista, o específico, que se emplea para determinar la respuesta del canal de radiocomunicaciones. El método del trazado de rayos se basa en la Óptica Geométrica, GO, y la Teoría Uniforme de la Difracción, UTD.

La propagación de las ondas electromagnéticas se puede seguir igual que el camino que recorre un rayo óptico, simplificando enormemente el análisis.

Reflexión, difracción y dispersión son los tres mecanismos básicos de propagación de los sistemas de comunicaciones móviles inalámbricos [Sar03]:

- La reflexión es el cambio de dirección que experimenta una onda electromagnética cuando incide sobre un objeto cuyas dimensiones son superiores a la longitud de onda. Según la GO el problema de la reflexión se resuelve mediante la ley de Snell. Cuando una onda es reflejada, también puede ser parcialmente refractada

- La difracción es la desviación que sufre un rayo al atravesar una rendija, o bien, al incidir sobre una superficie con irregularidades abruptas, como son las aristas de las paredes o determinados objetos. Según el principio de Huygens el rayo al incidir en una arista genera ondas secundarias que se resolverán mediante la UTD.

- En física se denomina dispersión al fenómeno de separación de las ondas de distinta frecuencia al atravesar un material. La dispersión tiene lugar 
cuando una onda viaja por un medio con objetos de dimensiones similares a la longitud de onda, o cuando el número de objetos por unidad de volumen es alto. El fenómeno de la dispersión es producido por superficies rugosas, objetos pequeños, u otras irregularidades que están presentes en el entorno.

El procedimiento de trazado de rayos está basado en la teoría de la propagación de ondas electromagnéticas. En teoría, las características de propagación de las ondas electromagnéticas se pueden calcular mediante la programación exacta de las ecuaciones de Maxwell. Desafortunadamente, esta propuesta requiere de operaciones matemáticas muy complejas y requiere una considerable carga computacional.

La GO contempla las contribuciones que se describen en los siguientes apartados.

\section{A.1.1 Rayo Directo}

Se considera que los rayos se propagan en medios homogéneos con un índice de refracción constante dentro de un mismo medio. El rayo directo sigue un camino recto entre el transmisor y el receptor, sin obstáculos, considerándose que hay visión directa entre el transmisor y el receptor. Esta situación se considera en línea de visión con la fuente de radiación, LoS. El campo electromagnético definido por el rayo directo es:

$$
E_{D I R}=E_{0} \frac{e^{-j k r}}{r}
$$

Donde:

- $E_{0}$ depende de las características de la fuente emisora,

- $\quad r$ es la distancia entre el transmisor y el receptor, 
- $\quad k$ es el número de onda, $k=\frac{2 \pi}{\lambda}$.

La expresión se corresponde con el campo de una onda esférica, el cual se atenúa inversamente con la distancia. El término exponencial indica la fase de la onda, que depende de la distancia recorrida.

\section{A.1.2 Rayo Reflejado}

La reflexión se produce cuando una onda incide sobre un objeto de dimensiones más grandes en comparación con la longitud de onda. Parte de la onda incidente es reflejada, y parte es refractada. Mediante la GO se calcula el valor del campo reflejado y refractado, basándose en las leyes de Snell para la reflexión.

Para ello se define un coeficiente de reflexión, $R$, que relaciona la onda incidente y la onda reflejada, y que depende de las características eléctricas de la superficie de reflexión (permitividad y conductividad), de la polarización de la onda incidente, del ángulo de incidencia y de la frecuencia de la onda.

Las propiedades electromagnéticas de una superficie cualquiera se caracterizan mediante una constante dieléctrica compleja relativa:

$$
\varepsilon^{\prime}=\frac{\varepsilon}{\varepsilon_{0}}=\varepsilon_{r}-\frac{\sigma}{\omega \varepsilon_{0}} j
$$

Donde:

- $\quad \varepsilon^{\prime}$ es la permitividad relativa compleja del medio sobre el que incide la onda,

- $\sigma$ es la conductividad del medio, que se expresa en unidades de conductancia por unidad de longitud $(\mathrm{S} / \mathrm{m})$, 
- $\omega$ es la frecuencia angular, que se expresa en unidades de radianes por unidad de tiempo, $\mathrm{rad} / \mathrm{s}$,

- $\varepsilon_{0}$ es la permitividad en el vacío, que se expresa en unidades de capacidad por unidad de longitud, F/m.

\section{A.1.2.1 Polarización Soft}

Se denomina polarización horizontal, y se caracteriza porque el vector del campo eléctrico de la onda incidente es perpendicular al plano de incidencia (ver Figura 54). El plano de incidencia contiene el rayo incidente y reflejado, según las ley de Snell. Al considerase campo lejano, el campo magnético es perpendicular al campo eléctrico por lo que estará contenido en el mismo plano.

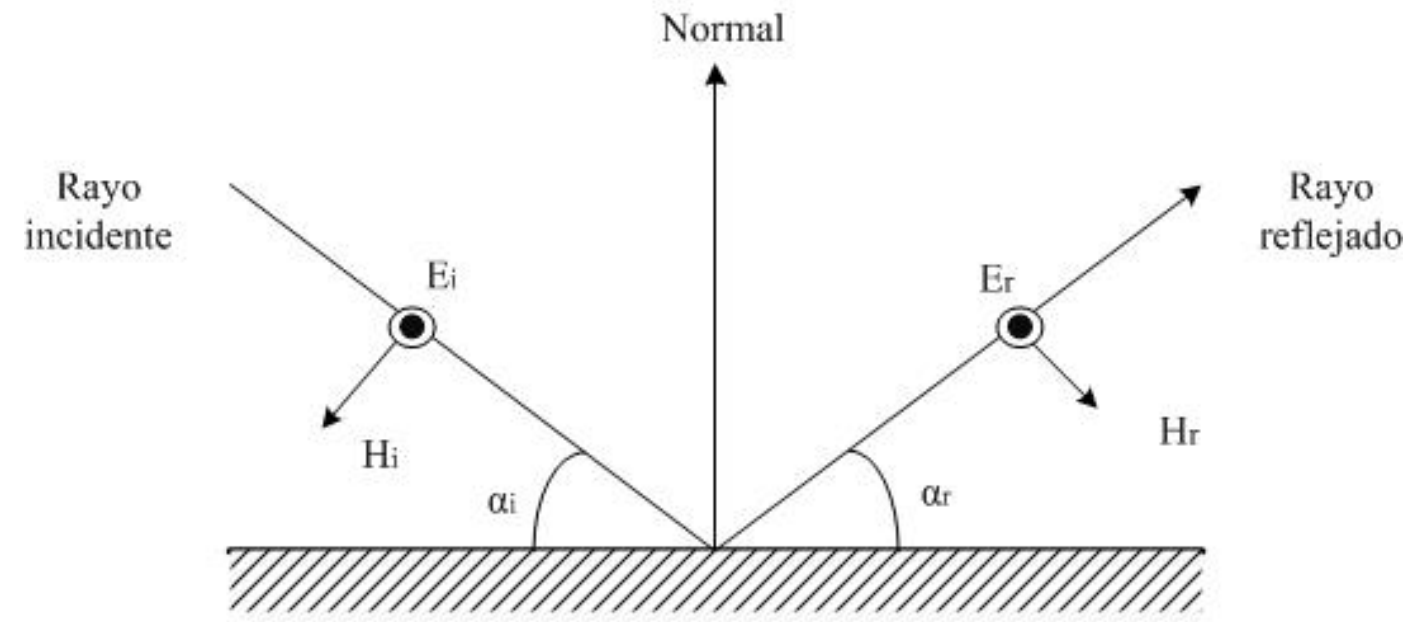

Superficie de reflexión

Figura 54.- Polarización horizontal, o soft. Corte por el plano de incidencia.

Según la ley de Snell el ángulo de incidencia ha de ser igual que el ángulo de reflexión: $\alpha_{i}=\alpha_{r}=\alpha$. 
El coeficiente de reflexión cuando la polarización es horizontal (o soft), es el siguiente:

$$
R_{\perp}=\frac{\operatorname{sen} \alpha-\sqrt{\varepsilon^{\prime}-\cos ^{2} \alpha}}{\operatorname{sen} \alpha+\sqrt{\varepsilon^{\prime}-\cos ^{2} \alpha}}
$$

\section{A.1.2.2 Polarización Hard}

Se caracteriza porque el vector de campo eléctrico de la onda incidente está contenido en el plano de incidencia (Figura 55). El campo magnético será, pues, perpendicular al mismo. A esta polarización también se le denomina polarización vertical.

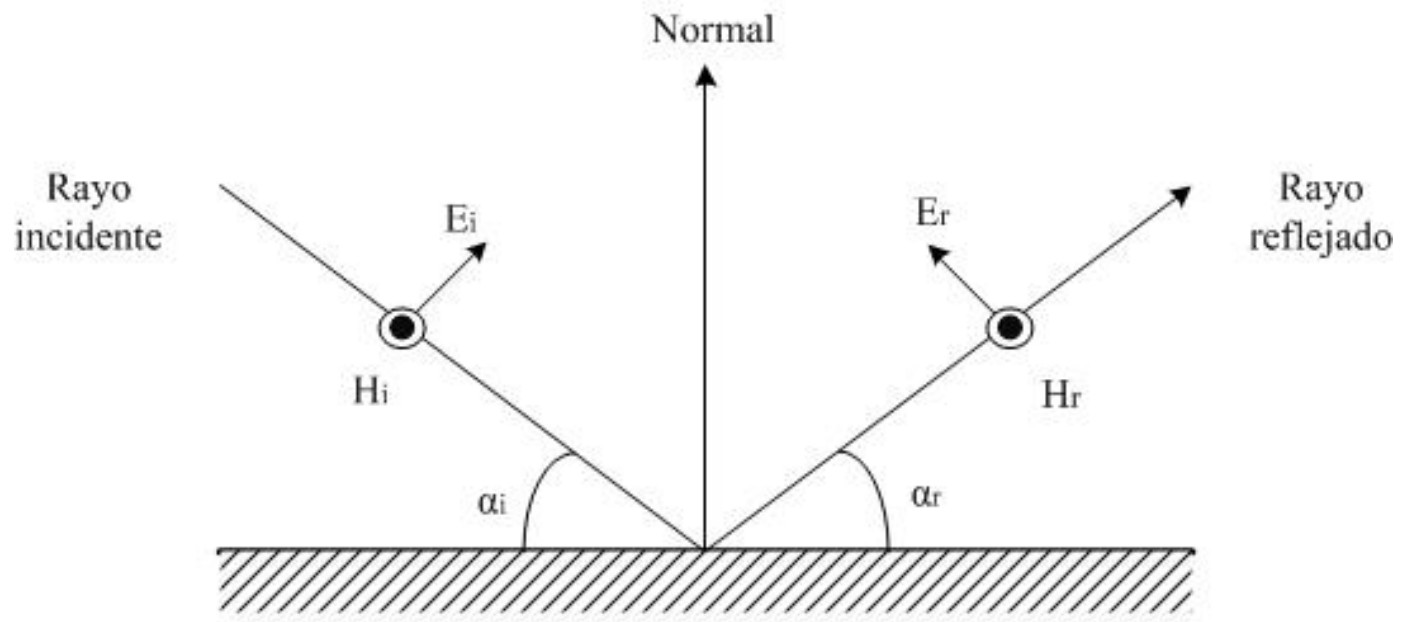

Superficie de reflexión

Figura 55.- Polarización vertical, o hard. Corte por el plano de incidencia.

El coeficiente de reflexión para una polarización hard es:

$$
R_{\|}=\frac{\varepsilon^{\prime} \operatorname{sen} \alpha-\sqrt{\varepsilon^{\prime}-\cos ^{2} \alpha}}{\varepsilon^{\prime} \operatorname{sen} \alpha+\sqrt{\varepsilon^{\prime}-\cos ^{2} \alpha}}
$$




\section{A.1.2.3 Campo eléctrico definido por un rayo reflejado}

En el caso de la polarización mixta, bastará con descomponer el campo incidente en una componente soft y otra hard, y aplicar los coeficientes $R_{\perp}$ y $R_{\|}$ por separado. Se han de sumar vectorialmente las dos soluciones ortogonales obtenidas. La expresión del campo electromagnético asociado a la contribución de una onda reflejada (o rayo reflejado, en GO) es la siguiente:

$$
E_{R}(r)=E_{0} R \frac{e^{-j k r}}{r}
$$

Donde:

- $\quad E_{0}$ es un factor que depende del transmisor,

- $\quad k$ es el número de onda,

- $\quad r$ es la distancia total recorrida por el rayo reflejado,

- $\quad R$ es el coeficiente de reflexión, que será igual a $R_{\perp}$ o $R_{\|}$, dependiendo de si la polarización del campo incidente es soft o hard. Si se produjesen múltiples reflexiones para una misma onda, el valor de $\mathrm{R}$ sería el producto acumulado de cada valor $\mathrm{Ri}$ correspondiente a la reflexión i-ésima:

$$
R=\Pi_{i} R_{i}
$$




\section{Apéndice B}

\section{B.1 Teoría geométrica de la difracción (GTD)}

La teoría geométrica de la difracción, GTD, es una extensión de la GO para predecir el campo difractado por las esquinas en entornos interiores [Zho01].

Para el cálculo de los rayos difractados se ha de aplicar el coeficiente de difracción que se define según la siguiente expresión [Hol00]:

$$
D=D\left(L, n ; \phi, \phi^{\prime}\right)=D^{(1)}+D^{(2)}+R_{0} D^{(3)}+R_{n} D^{(4)}
$$

Donde: $R_{0}$ y $R_{n}$ son los coeficientes de reflexión para las facetas 0 y $\mathrm{n}$ (ver Figura 56). Los componentes $D^{(l)}(l=1,2,3,4)$ indicados en el coeficiente de difracción se indican mediante la siguiente ecuación:

$$
D=D\left(L, n ; \phi, \phi^{\prime}\right)=\frac{-e^{-j \pi / 4}}{2 n \sqrt{2 \pi k}} \cot \gamma^{(l)} F_{0}\left(2 k L n^{2} \operatorname{sen}^{2} \gamma^{(l)}\right)
$$

Siendo:

- $\quad k$, el número de onda,

- $\quad L=\frac{s^{\prime} s}{s^{\prime}+s}$ para una onda esférica, s para una onda plana,

- $n \pi$ el ángulo exterior del borde,

- $F_{0}$ es la función de transición que consiste en la integral de Fresnel [Kou74],

- $\gamma^{(l)}=\frac{\pi \pm \beta}{2 n}$

$-\beta=\phi \pm \phi^{\prime}$. 
Apéndice B

La Figura 56 muestra la representación geométrica del problema de la difracción por un borde exterior con un ángulo interior igual a $(2-n) \pi$. La fuente está localizada en el punto del transmisor, $T X$, y el campo difractado se mide en el punto de observación recepción, $R X$. El ángulo de incidencia $\phi^{\prime}$, y el ángulo de difracción $\phi$ se miden arbitrariamente en la cara $\mathrm{n}$ de la esquina [1] [Nech06].

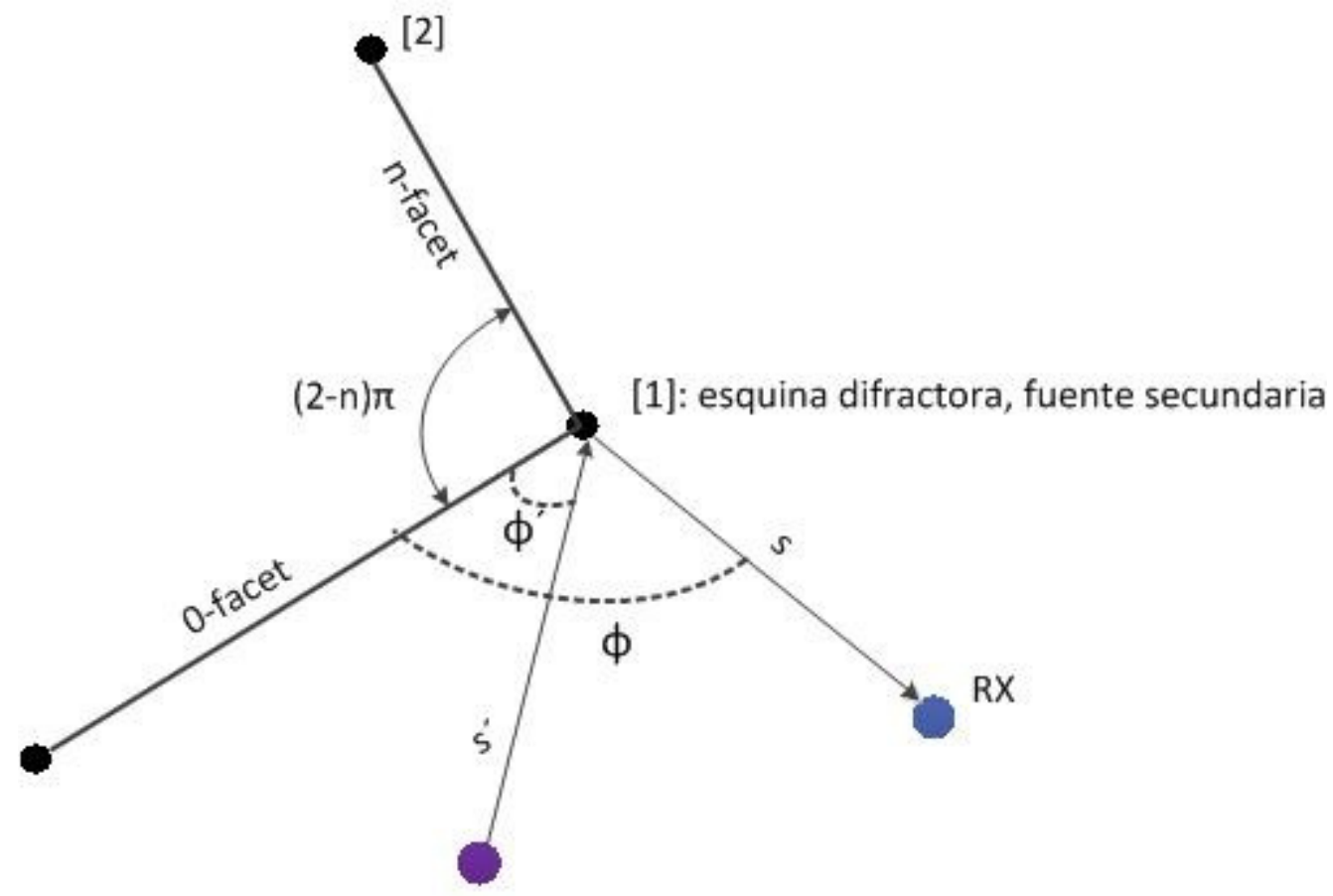

TX: fuente principal

Figura 56.- Geometría del rayo incidente y difractado por una esquina.

La función $\mathrm{F}(\mathrm{x})$ recibe el nombre de Función de Transición de Fresnel y se define en términos de una integral de Fresnel:

$$
F(x)=2 j \sqrt{x} e^{j x} \int_{\sqrt{x}}^{\infty} e^{-j \tau^{2}} d \tau
$$


La función $\mathrm{F}(\mathrm{x})$ puede calcularse a partir de las integrales del seno y el coseno

$$
\begin{aligned}
& S(x)=\int_{0}^{x} \operatorname{sen}\left(\frac{\pi}{2} \tau^{2}\right) d \tau \\
& C(x)=\int_{0}^{x} \cos \left(\frac{\pi}{2} \tau^{2}\right) d \tau
\end{aligned}
$$

De la siguiente manera:

$$
F(x)=j \sqrt{2 \pi} \sqrt{x} e^{j x}\left\{\left[\frac{1}{2}-C\left(\sqrt{\frac{2}{\pi}} \sqrt{x}\right)\right]-j\left[\frac{1}{2}-S\left(\sqrt{\frac{2}{\pi}} \sqrt{x}\right)\right]\right\}
$$

Esta función también se puede resolver mediante una serie de potencias que convergen para todo $\mathrm{x}$ según las siguientes expresiones que se indican a continuación. Para valores grandes de $\mathrm{x}, \mathrm{F}(\mathrm{x})$ se puede aproximar mediante:

$$
F(x) \approx 1+j \frac{1}{2 x}-\frac{3}{4} \frac{1}{x^{2}}-j \frac{15}{8} \frac{1}{x^{3}}+\frac{75}{16} \frac{1}{x^{4}}
$$

Y para pequeños valores de $\mathrm{x}$ :

$$
F(x) \approx\left[\sqrt{\pi x}-2 x e^{j \frac{\pi}{4}}-\frac{2}{3} x^{2} e^{-j \frac{\pi}{4}}\right] e^{j\left(\frac{\pi}{4}+x\right)}
$$

La integral se ha resuelto según la solución propuesta en [Fal14].

\section{B.2 Campo Eléctrico Definido por un Rayo Difractado.}

El objetivo de la UTD es que los rayos difractados puedan ser tratados de la misma manera que los rayos reflejados definidos en la GO.

El campo definido por un rayo difractado que alcanza el receptor y que no ha sido afectado por otro mecanismo de propagación se puede expresar según la siguiente expresión [Hol00]: 


$$
E^{d}=E^{i} D \sqrt{\frac{s^{\prime}}{s\left(s^{\prime}+s\right)}} e^{\prime j k s}=\frac{E_{0}}{s^{\prime}} D A\left(s, s^{\prime}\right) e^{-j k\left(s^{\prime}+s\right)}
$$

Donde:

- $\quad E_{0}$ es la amplitud de la onda incidente,

- $s^{\prime}$ es la distancia recorrida por el rayo incidente,

- $S$ es la distancia recorrida por el rayo difractado,

- $\quad D$ es el coeficiente de difracción cuya expresión ya se ha indicado anteriormente,

- $A\left(s, s^{\prime}\right)$ es un parámetro de atenuación referente a la variación de la intensidad del campo atendiendo al recorrido del rayo difractado. Para ondas esféricas se define según la siguiente expresión:

$$
A\left(s, s^{\prime}\right)=\sqrt{\frac{s^{\prime}}{s\left(s+s^{\prime}\right)}}
$$

Este factor representa la atenuación del campo difractado con la distancia. Se le denomina Spreading Factor. Para ondas planas se considera igual a $1 / \sqrt{s}$.

De la expresión anterior del campo difractado $E^{d}$, se deduce el campo incidente en la esquina donde se produce la difracción, según la siguiente expresión:

$$
E^{i}=\frac{E_{0} e^{-j k s^{\prime}}}{s^{\prime}}
$$

En cuanto al campo generado por una antena $E_{0}$, se calcula atendiendo a la siguiente fórmula:

$$
E_{0}=\sqrt{30 P I R E}=\sqrt{30 P_{T} G A_{d}}
$$


Siendo PIRE, la potencia isótropa radiada equivalente, que se define a continuación:

$$
P I R E=P_{T} G A_{d}
$$

Donde:

- $\quad P_{T}$ es la potencia emitida por la antena,

- $G$ es la ganancia de la antena,

- $A_{d}$ es la atenuación debida al diagrama de radiación.

Por lo tanto, el campo incidente se puede calcular según la siguiente expresión:

$$
E^{i}=\frac{E_{0} e^{-j k s^{\prime}}}{s^{\prime}}=\frac{\sqrt{30 P_{T} G A_{d}}}{s^{\prime}} e^{-j k s^{\prime}}=\frac{\sqrt{30 P_{T} G A_{d}}}{s^{\prime}}\left(\cos \left(k s^{\prime}\right)-j \operatorname{sen}\left(k s^{\prime}\right)\right)
$$

Los mecanismos básicos de propagación son la reflexión, la difracción y la dispersión. Considerando que el entorno del experimento es un entorno vacío se puede prescindir de la dispersión, tal y como se indica en algunos estudios [Cat98], donde no se tienen en cuenta los obstáculos que interrumpen el camino de los rayos entre el transmisor al receptor. La solución implementada permite calcular la intensidad del campo eléctrico considerando las contribuciones debidas a los rayos incidente, reflejado y difractado [Kou74], [Nec06].

$$
E=E^{i}+E^{r}+E^{d}
$$





\section{Apéndice C}

\section{C.1 Diagrama de radiación de las antenas}

En este apartado se exponen los principios que gobiernan los sistemas irradiantes para la transmisión y recepción de ondas electromagnéticas. Las antenas como elementos irradiantes de energía electromagnética tienen su principal aplicación en la construcción de sistemas inalámbricos de comunicaciones. La energía radiada por la fuente no varía cuando una parte de la misma es absorbida por un dispositivo receptor en el espacio libre. Este efecto es contrario a lo que ocurre en el transporte de energía por conducción.

Se aportarán las definiciones básicas de los parámetros empleados en la descripción del funcionamiento de las antenas [Cis14-1]. También se discutirá sobre los tipos de antenas más comunes y sus propiedades, incluyéndose la descripción de los diferentes tipos de diagramas de radiación.

Las antenas utilizadas en los sistemas WLAN son dipolos, antenas omnidireccionales, parches y Yagis. Aunque puedan existir algunas diferencias dependiendo del fabricante, las características principales son comunes de unos tipos a otros. Las principales características de cada tipo de antena se explican en detalle en este apartado.

\section{C.2 Definiciones básicas}

A menudo se define el concepto de antena en términos de antena transmisora, pero todos los conceptos se pueden aplicar también a las antenas receptoras. De 
Apéndice $\mathrm{C}$

hecho las propiedades de las antenas son las mismas en cada modo de operación. Todas las características y definiciones que se indican a continuación se pueden aplicar tanto a las antenas transmisoras como a las antenas receptoras.

Los parámetros de una antena son parámetros susceptibles de ser medidos. Se definen parámetros de tipo circuital y de tipo direccional. La mayoría de estos parámetros se definen en transmisión, pero son válidos también en recepción.

Los principales parámetros de las antenas son:

- Directividad

- Diagrama de radiación

- Lóbulos

- Nivel de lóbulos secundarios

- Ancho del haz principal a -3 dB

- Ancho del haz principal entre nulos

- Relación delante-atrás

- Radiador isotrópico

- Ganancia

- Polarización

- Resistencia de radiación

- Relación de onda estacionaria

- Ancho de banda de la antena

- Intensidad de Campo

\section{C.2.1 Antena}

Una antena es un dispositivo metálico capaz de radiar y recibir ondas electromagnéticas del espacio. En los circuitos transmisores y receptores de radio, se producen corrientes y tensiones eléctricas de altas frecuencias y asociadas a 
ellas se encuentran las ondas electromagnéticas. Las señales eléctricas se han de acoplar al espacio para propagarse. Esta es la función de la antena: adaptar los CEM entre distintos medios de conducción. Por ello concebimos una antena, como un dispositivo encargado de convertir ondas electromagnéticas "conducidas" por una línea de transmisión o guía de ondas, en ondas que pueden propagarse libremente en el espacio. Una antena es una interfaz entre el espacio libre y la línea de transmisión. Mientras la línea no irradia energía al espacio, la antena si lo hace. Según la aplicación de la antena, el tamaño de la misma estará relacionado con la banda de frecuencias que se quiere captar o transmitir.

Cuando la antena es utilizada para radiar ondas electromagnéticas al espacio, cumple el papel de antena emisora o transmisora y cuando se emplea para interceptar o capturar ondas que se propagan en el espacio y convertirlas en energía útil, aprovechable por un receptor, cumple la función de antena receptora. En otras palabras, es un adaptador entre la fuente de energía y el espacio libre (antena transmisora) y también un adaptador entre el espacio libre y el sumidero de energía (antena receptora).

Físicamente una antena es un trozo de material conductor, al cual se le aplica una señal, y ésta es radiada a través del espacio libre. Opera igualmente en sentido inverso, capturando la señal de radiofrecuencia del aire y entregándola posteriormente al dispositivo receptor.

\section{C.2.2 Directividad}

La directividad es la propiedad que tiene una antena de transmitir o recibir energía irradiada en una determinada dirección. Esta propiedad de las antenas cobra especial relevancia en un enlace inalámbrico que utiliza antenas fijas en 
ambos extremos, utilizándose la directividad para concentrar la radiación en la dirección deseada.

En cambio, para una estación móvil y otra fija o ambas móviles, donde no se puede predecir donde va a estar una de ellas, la antena deberá radiar en todas las direcciones del plano horizontal y para ello se utiliza una antena omnidireccional (que se definirá más adelante).

\section{C.2.3 Diagrama de radiación}

El diagrama de radiación es la representación gráfica de las propiedades de radiación de una antena en función del espacio. Es decir, el diagrama de radiación describe cómo la antena radia energía en el espacio (o cómo recibe energía). Es importante exponer que una antena, en cierta medida, radia energía en todas las direcciones, por lo que realmente el diagrama de radiación de una antena es tridimensional, definiéndose mediante dos planos en 2D. Estos planos se obtienen haciendo dos cortes al diagrama en 3D por sus valores máximos, o directamente mediante la calibración de la antena.

La caracterización de la antena mediante su diagrama de radiación es adecuada siempre y cuando la forma en la que la antena radia quede perfectamente definida mediante los dos planos en 2D, sin que esto suponga la pérdida de información.

Los diagramas de radiación de las antenas se indican siempre en coordenadas esféricas. Uno de los planos será la variación en función de la componente $\theta$, que es la elevación, y el otro plano contiene la variación de la componente $\phi$, que es el azimut. Estos planos se denominan respectivamente plano de elevación y plano de azimut. En ocasiones el término azimut se refiere a "la horizontal", y el término elevación a "la vertical". A la hora de caracterizar la antena mediante los planos 
de azimut y de elevación se considera siempre que la antena está colocada según la orientación en la que va a ser usada.

En la Figura 57 se muestra el sistema de coordenadas esféricas, donde el plano XY $(\theta=90)$ es el plano de azimut, y el plano YZ $(\phi=90)$ es el plano de elevación. La obtención de plano de azimut del diagrama de radiación se realiza mediante medidas en todo el plano XY alrededor de la antena objeto de estudio. El plano de elevación es el plano perpendicular al plano XY, es el plano YZ $(\phi=90)$. El plano de elevación del diagrama de radiación se obtiene realizando medidas en todo el plano YZ alrededor de la antena objeto de estudio.

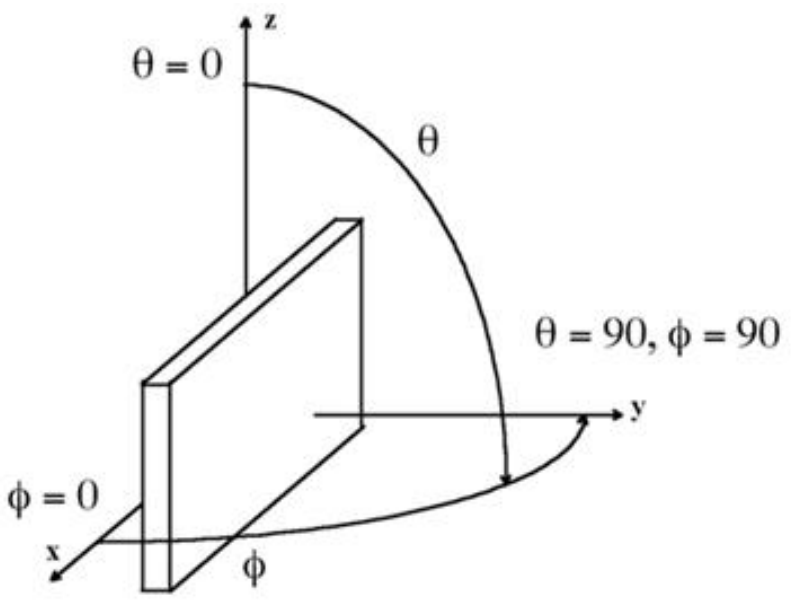

Figura 57.- Sistema de coordenadas esféricas de referencia para una antena

En ocasiones los diagramas de radiación también se representan mediante coordenadas polares, aportando un mayor realismo en la visualización de las características de radiación de la antena. En ocasiones puede ser útil representar el diagrama de radiación en coordenadas cartesianas (o rectangulares), especialmente cuando hay lóbulos secundarios. 


\section{C.2.4 Lóbulos}

Se define un lóbulo de radiación como la porción del diagrama delimitada por regiones de menor radiación (nulos). Los distintos tipos de lóbulos se indican a continuación:

- Lóbulo principal: aquél que contiene la dirección de máxima radiación.

- Lóbulos secundarios: todos aquellos distintos al principal.

- Lóbulos laterales: los adyacentes al principal, que generalmente son los más altos de todos los secundarios.

- Lóbulo posterior: el que se encuentra en la dirección opuesta a la principal.

- Nulos: en los diagramas de radiación de una antena, una zona nula es aquella en la cual hay un mínimo de potencia radiada efectiva. Un nulo a menudo tiene un ángulo de directividad estrecho en comparación con el haz principal. Los nulos son útiles para varios propósitos tales como la supresión de señales interferentes en una dirección dada.

La Figura 58 proporciona un diagrama de radiación en el que se indican los diferentes tipos de lóbulos incluyendo los nulos. 


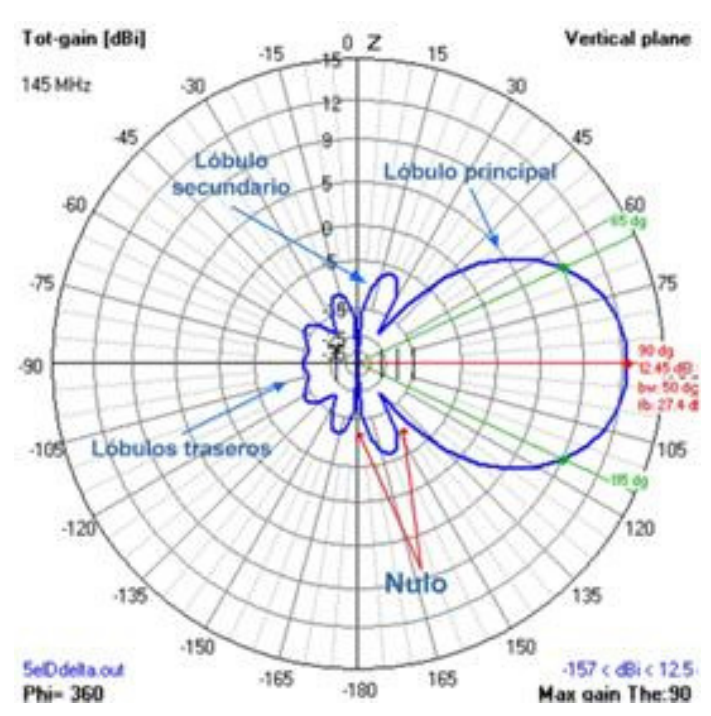

Figura 58.- Diagrama de radiación. Se indican los nulos y los diferentes tipos de lóbulos.

Una vez que se identifican los lóbulos es posible definir una serie de parámetros que se indican a continuación.

\section{C.2.5 Nivel de lóbulos secundarios}

Es el nivel del mayor lóbulo secundario respecto al principal. A veces se utiliza la relación del lóbulo principal a lóbulo secundario, que coincide con el negativo del lóbulo posterior (en dB). Los lóbulos secundarios radian potencia indeseada en direcciones no controladas, que pueden dar lugar a interferencias en sistemas de comunicaciones.

\section{C.2.6 Ancho del haz principal a $-3 \mathrm{~dB}$}

El ancho del haz de una antena se entiende como el ancho del haz a mitad de potencia. A partir del pico donde la intensidad de radiación es máxima, se localizan los puntos a ambos lados del pico que representan la mitad de la 
Apéndice $\mathrm{C}$

potencia de intensidad del pico. La distancia angular entre los puntos de mitad de potencia se define como el ancho del haz. La mitad de la potencia expresada en decibelios es de $-3 \mathrm{~dB}$, por lo tanto algunas veces el ancho del haz a mitad de potencia es referido como el ancho del haz a $-3 \mathrm{~dB}$.

\section{C.2.7 Ancho del haz principal entre nulos}

Es el ancho del lóbulo principal completo. Para el mismo plano, la relación entre este parámetro y el anterior está comprendida entre 2 y 3 , dependiendo de la distribución de corriente o de campo sobre la antena. A nivel práctico este parámetro se suele definir mediante la siguiente expresión:

$$
B W_{n} \approx 2.25 B W_{-3 d B}
$$

\section{C.2.8 Relación delante-atrás}

Es la relación entre el lóbulo principal y el lóbulo posterior. La radiación posterior puede ser causa de interferencias en radioenlaces, ya que muchas veces, debido a la simetría de los reflectores parabólicos, la radiación posterior asociada a la difracción en los bordes de éstos es elevada.

\section{C.2.9 Radiador isotrópico}

Un radiador isotrópico es una hipotética antena sin pérdidas que radia energía de forma equitativa en todas las direcciones. Esta antena imaginaria dispone de un diagrama de radiación esférico (tal como se indica en la Figura 59) y los cortes en los planos principales son círculos, de hecho los cortes en cualquier plano serían círculos. 


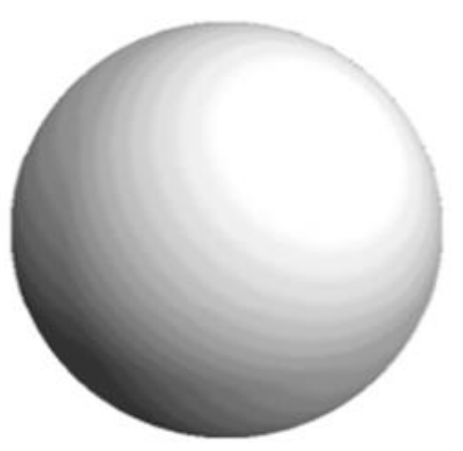

Figura 59.- Diagrama de radiación de una antena isotrópica.

\section{C.2.10 Ganancia}

La ganancia de una antena (en cualquier dirección dada) se define como la relación entre la ganancia de potencia en una dirección dada y la ganancia de potencia de una antena de referencia en la misma dirección. Por ejemplo, para el caso de un radiador isotrópico, que radia la misma energía en todas las direcciones, la ganancia es $\mathrm{G}=1$ (o $0 \mathrm{~dB}$ ). Es habitual emplear la unidad de $\mathrm{dBi}$ (decibelios relativos a un radiador isotrópico) para la ganancia con respecto a un radiador isotrópico. La ganancia expresada en dBi se calcula según la siguiente fórmula:

$$
G(d B i)=10 \log (\text { GAntena } / \text { GIsotropica })=10 \log (\text { GAntena })
$$

La ganancia se puede expresar en unidades de $\mathrm{dBi}$, denotando así ganancia respecto a la antena isótropica, pero se puede expresar en relación a otra antena de referencia, para ello basta restar el valor de la ganancia de la antena de referencia respecto a la antena isótropa. Veamos el caso en el que la antena de referencia es el dipolo $\lambda / 2$ :

$G(d B d)=G(d B i)-G_{d i p}(d B i)=G(d B i)-2.15$ 
Señalar que cuando la ganancia de una antena se indica mediante un solo dato se refiere a la ganancia en la máxima dirección de radiación.

\section{C.2.11 Polarización}

Una antena generará una onda electromagnética que varía en el tiempo a lo largo de su propagación por el espacio. La polarización de una antena se refiere a la dirección de propagación del vector de campo-E que es radiado por dicha antena. Una antena puede polarizarse en forma lineal (por lo general, polarización horizontal o vertical), en forma elíptica o circular.

Si una antena irradia una onda electromagnética polarizada verticalmente, es decir, si el vector de radiación del campo-E oscila en el plano vertical ("de arriba a abajo"), la antena se define como polarizada verticalmente. Si la antena irradia una onda electromagnética polarizada horizontalmente, se dice que la antena está polarizada horizontalmente; si el campo eléctrico radiado gira en un patrón elíptico, está polarizada elípticamente; y si el campo eléctrico gira en un patrón circular, está polarizada circularmente. Esto implica que determinados tipos de antenas sean sensibles a un tipo particular de ondas electromagnéticas. La implicación práctica inmediata de este concepto es que las antenas transmisoras y receptoras con la misma polarización proporcionan un mejor trayecto de propagación de la onda.

Si una antena polarizada linealmente lanza una onda electromagnética linealmente polarizada, el mejor receptor de dicha onda será otra antena con la misma polarización lineal.

La polarización lineal también incluye la posibilidad de que las ondas electromagnéticas que viajan de "arriba a abajo" (polarización vertical) pasen a viajar de "derecha a izquierda" (polarización horizontal). A menudo, las antenas 
pueden girarse físicamente para pasar de polarización horizontal a vertical o viceversa, aunque en ocasiones esta no es la mejor opción.

Las antenas de polarización circular pueden emitir ondas electromagnéticas que giran en el sentido de las agujas del reloj o en sentido contrario dependiendo de la estructura. Esta dirección de giro se denomina polarización circular a izquierdas o polarización circular a derechas.

\section{C.2.12 Impedancia de entrada}

Es el cociente entre el voltaje aplicado a los terminales de entrada de la antena y la corriente resultante. En general tiene una componente resistiva y una reactiva, sin embargo, si el punto de alimentación de la antena está en un máximo de corriente, la componente reactiva resulta despreciable, por tanto la impedancia de entrada es igual a la suma de la resistencia de radiación más la resistencia de pérdidas. Si la impedancia no presenta una parte reactiva (puramente resistiva) a una frecuencia determinada se dice que es una antena resonante.

\section{C.2.13 Resistencia de radiación}

La resistencia de radiación es un valor asignado a una resistencia ficticia cuyo valor es el que tendría una resistencia que disipa la misma potencia eléctrica entregada por la antena con la misma potencia radiada por la antena. En la práctica no toda la potencia entregada por la antena es radiada totalmente al espacio que la rodea, parte se disipa en forma de calor a causa de las pérdidas resistivas provocadas por los conductores, aisladores de soporte, etc. 


\section{C.2.14 Relación de onda estacionaria}

La relación de onda estacionaria (ROE) se define como la relación entre el máximo voltaje y el mínimo voltaje en un patrón de onda estacionaria. Una onda estacionaria se desarrolla cuando la energía es reflejada en una carga. ROE relaciona la energía que se entrega a un dispositivo en contraposición con la cantidad de energía que es reflejada. Si la fuente y la impedancia de carga son los mismos, el ROE es 1:1, no hay potencia reflejada.

\section{C.2.15 Ancho de banda de la antena}

Es el intervalo de frecuencias en el cual debe funcionar satisfactoriamente la antena, dentro de las normas técnicas vigentes a su aplicación. El ancho de banda se puede indicar en términos de porcentaje respecto a la frecuencia central de la banda:

$$
\text { Ancho de banda }(\%)=100 \frac{f_{H}-f_{L}}{f_{C}}
$$

$f_{H}$ es la frecuencia más alta de la banda, $f_{L}$ es la frecuencia más baja, y $f_{C}$ es la frecuencia central. De esta forma, el ancho de banda porcentual es constante respecto a la frecuencia central. Los diferentes tipos de antenas tienen diferentes limitaciones en cuanto al ancho de banda.

\section{C.2.16 Intensidad de Campo}

La intensidad de campo esperada en el espacio libre a una distancia $d$ de una antena transmisora se expresa en unidades de diferencia de potencial por unidad de longitud $(\mathrm{V} / \mathrm{m})$, y se expresa según la siguiente fórmula: 


$$
E=\frac{\sqrt{30 G_{t} P_{t}}}{d}
$$

Donde:

- $\quad d$ es la distancia entre el transmisor y el punto de observación,

- $G_{t}$ es la ganancia de la antena transmisora respecto a una antena isotrópica,

- $\quad P_{t}$ es la potencia radiada de la antena transmisora, que se define en $\mathrm{W}$.

El campo recibido también se puede expresar en términos de la densidad de potencia, lo cual es muy común, sobre todo a frecuencias superiores de $300 \mathrm{MHz}$ $(\lambda<1$ metro). La conversión de campo eléctrico a densidad de potencia se efectúa según la siguiente fórmula:

$$
P=\frac{E^{2}}{120 \pi}
$$

Donde:

- $E$ es la intensidad de campo indicada en unidades de diferencia de potencial por unidad de longitud, V/m.

- $\quad P$ es la densidad de potencia de campo, que se expresa en unidades de potencia por unidad de superficie, $\mathrm{W} / \mathrm{m}^{2}$.

$120 \pi$ es la impedancia intrínseca del espacio libre, cuyo valor es aproximadamente igual a $377 \mathrm{Ohms}$, representa la oposición al flujo de energía electromagnética en el espacio libre, y se puede obtener según la siguiente expresión:

$$
Z_{0}=\sqrt{\frac{\mu_{0}}{\varepsilon_{0}}}
$$


Siendo:

- $\quad \mu_{0}$ la permeabilidad absoluta expresada en unidades de inductancia por unidad de longitud $(\mathrm{H} / \mathrm{m})$, y

- $\quad \varepsilon_{0}$ la permitividad absoluta que se expresa en unidades de capacidad por unidad de longitud (F/m), del espacio libre respectivamente.

\section{C.3 TIPOS DE ANTENAS}

En esta sección se describen los tipos de antenas más comunes incluyéndose detalles sobre los diagramas de radiación. Existen diferentes tipos de antenas para la banda de $2.4 \mathrm{GHz}$, cada una de las cuales tiene una aplicación y entorno de uso específico, ofreciendo una capacidad de cobertura determinada. Cada tipo de antena está caracterizada por un patrón de radiación específico que define las características de radiación.

\section{C.3.1 Antenas Omnidireccionales}

Una antena omnidireccional es aquella diseñada para proveer un patrón de radiación de 360 grados (Figura 60). Propagan la señal de RF en todas las direcciones en el plano horizontal aunque tienen un rango limitado en el plano vertical. Son las más empleadas en las infraestructuras de comunicaciones inalámbricas de corto alcance, y se utilizan cuando se requiere dotar de cobertura en todas las direcciones, proporcionando la cobertura más amplia dentro de edificios al formarse celdas circulares mínimamente solapadas. La mayoría de los puntos de acceso estándar disponen de una antena omnidireccional de baja ganancia. 


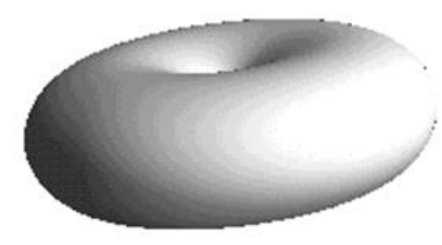

Figura 60.- Diagrama de radiación de una antena omnidireccional

\section{C.3.2 Antenas Direccionales}

Las antenas direccionales transmiten y reciben energía RF en una determinada dirección. Este patrón de radiación es similar a la luz producida por un flash o un foco. La antena no añade potencia a la señal sino que simplemente redirige la energía entregada por el transmisor en una determinada dirección. Al distribuir más energía en una dirección y menos en el resto, la ganancia de las antenas direccionales se incrementa y su ángulo de radiación generalmente decrece, proporcionando una mayor distancia de cobertura pero reduciéndose el ángulo de cobertura. Las antenas dotan a la onda radiada de directividad, es decir, deben acentuar una sola dirección, y anular o mermar las demás, en el caso que sólo interese radiar hacia una dirección determinada, tal como indica la Figura 61. Existen diferentes tipos de antena direccionales, cada una con una forma y estilo determinado, incluyendo yagis, antenas parche y parabólicas. 
Apéndice C

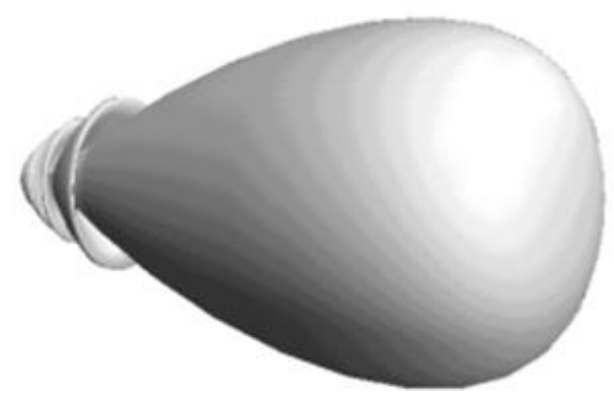

Figura 61.- Diagrama de radiación de una antena direccional 


\section{Apéndice D}

\section{D.1 Valores del diagrama de radiación}

La siguiente tabla (Tabla 9) muestra los valores de componte $\theta$, o de elevación de la antena bicónica [PCD14].

Tabla 9. Valores del diagrama de radiación de la antena bicónica PCD 8250 en función de la componente de elevación, $\theta$.

\begin{tabular}{|r|r|r|r|r|r|}
\hline $\boldsymbol{\theta}$ & \multicolumn{1}{|c|}{$\mathbf{R D}$} & $\boldsymbol{\theta}$ & $\mathbf{R D}$ & $\boldsymbol{\theta}$ & \multicolumn{1}{|c|}{ RD } \\
\hline 1 & -17.3 & 26 & -10 & 51 & -6.6 \\
\hline 2 & -16.6 & 27 & -10 & 52 & -6.2 \\
\hline 3 & -15.9 & 28 & -10 & 53 & -5.8 \\
\hline 4 & -15.2 & 29 & -10 & 54 & -5.4 \\
\hline 5 & -14.5 & 30 & -10 & 55 & -5 \\
\hline 6 & -13.8 & 31 & -10 & 56 & -4.6 \\
\hline 7 & -13.1 & 32 & -10 & 57 & -4.2 \\
\hline 8 & -12.4 & 33 & -10 & 58 & -3.8 \\
\hline 9 & -11.7 & 34 & -10 & 59 & -3.4 \\
\hline 10 & -11 & 35 & -10 & 60 & -3 \\
\hline 11 & -10.9 & 36 & -10 & 61 & -2.9 \\
\hline 12 & -10.8 & 37 & -10 & 62 & -2.8 \\
\hline 13 & -10.7 & 38 & -10 & 63 & -2.7 \\
\hline 14 & -10.6 & 39 & -10 & 64 & -2.6 \\
\hline 15 & -10.5 & 40 & -10 & 65 & -2.5 \\
\hline 16 & -10.4 & 41 & -9.7 & 66 & -2.4 \\
\hline 17 & -10.3 & 42 & -9.4 & 67 & -2.3 \\
\hline 18 & -10.2 & 43 & -9.1 & 68 & -2.2 \\
\hline 19 & -10.1 & 44 & -8.8 & 69 & -2.1 \\
\hline 20 & -10 & 45 & -8.5 & 70 & -2 \\
\hline 21 & -10 & 46 & -8.2 & 71 & -1.9 \\
\hline 22 & -10 & 47 & -7.9 & 72 & -1.8 \\
\hline 23 & -10 & 48 & -7.6 & 73 & -1.7 \\
\hline 24 & -10 & 49 & -7.3 & 74 & -1.6 \\
\hline 25 & -10 & 50 & -7 & 75 & -1.5 \\
\hline
\end{tabular}


Apéndice D

\begin{tabular}{|c|c|c|c|c|c|}
\hline$\theta$ & RD & $\theta$ & RD & $\theta$ & RD \\
\hline 76 & $\begin{array}{l}-1.4 \\
\end{array}$ & 111 & -2.1 & 146 & $\begin{array}{l}-7.4 \\
\end{array}$ \\
\hline 77 & -1.3 & 112 & -2.2 & 147 & -7.8 \\
\hline 78 & -1.2 & 113 & -2.3 & 148 & -8.2 \\
\hline 79 & -1.1 & 114 & -2.4 & 149 & -8.6 \\
\hline 80 & -1 & 115 & -2.5 & 150 & -9 \\
\hline 81 & -0.9 & 116 & -2.6 & 151 & -9.1 \\
\hline 82 & -0.8 & 117 & -2.7 & 152 & -9.2 \\
\hline 83 & -0.7 & 118 & -2.8 & 153 & -9.3 \\
\hline 84 & -0.6 & 119 & -2.9 & 154 & $\begin{array}{l}-9.4 \\
\end{array}$ \\
\hline 85 & -0.5 & 120 & -3 & 155 & -9.5 \\
\hline 86 & -0.4 & 121 & -3.1 & 156 & -9.6 \\
\hline 87 & -0.3 & 122 & $\begin{array}{l}-3.2 \\
\end{array}$ & 157 & -9.7 \\
\hline 88 & -0.2 & 123 & -3.3 & 158 & -9.8 \\
\hline 89 & -0.1 & 124 & -3.4 & 159 & -9.9 \\
\hline 90 & 0 & 125 & -3.5 & 160 & -10 \\
\hline 91 & 0 & 126 & -3.6 & 161 & -10.5 \\
\hline 92 & 0 & 127 & -3.7 & 162 & -11 \\
\hline 93 & 0 & 128 & -3.8 & 163 & -11.5 \\
\hline 94 & 0 & 129 & -3.9 & 164 & -12 \\
\hline 95 & 0 & 130 & -4 & 165 & -12.5 \\
\hline 96 & 0 & 131 & -4.1 & 166 & -13 \\
\hline 97 & 0 & 132 & -4.2 & 167 & -13.5 \\
\hline 98 & 0 & 133 & -4.3 & 168 & -14 \\
\hline 99 & 0 & 134 & -4.4 & 169 & -14.5 \\
\hline 100 & 0 & 135 & -4.5 & 170 & -15 \\
\hline 101 & -0.8 & 136 & -4.6 & 171 & -16 \\
\hline 102 & $\begin{array}{l}-1.6 \\
\end{array}$ & 137 & -4.7 & 172 & -17 \\
\hline 103 & -2.4 & 138 & -4.8 & 173 & -18 \\
\hline 104 & -3.2 & 139 & -4.9 & 174 & -19 \\
\hline 105 & -4 & 140 & -5 & 175 & -20 \\
\hline 106 & -4.8 & 141 & -5.4 & 176 & -21 \\
\hline 107 & -5.6 & 142 & -5.8 & 177 & -22 \\
\hline 108 & -6.4 & 143 & -6.2 & 178 & -23 \\
\hline 109 & -7.2 & 144 & -6.6 & 179 & -24 \\
\hline 110 & -2 & 145 & -7 & 180 & -25 \\
\hline
\end{tabular}


Apéndice D

\begin{tabular}{|r|r|r|r|r|r|}
\hline $\boldsymbol{\theta}$ & RD & $\boldsymbol{\theta}$ & $\mathbf{R D}$ & $\boldsymbol{\theta}$ & \multicolumn{1}{|c|}{ RD } \\
\hline 181 & -24 & 211 & -7.8 & 241 & -4.9 \\
\hline 182 & -23 & 212 & -7.6 & 242 & -4.8 \\
\hline 183 & -22 & 213 & -7.4 & 243 & -4.7 \\
\hline 184 & -21 & 214 & -7.2 & 244 & -4.6 \\
\hline 185 & -20 & 215 & -7 & 245 & -4.5 \\
\hline 186 & -19 & 216 & -6.8 & 246 & -4.4 \\
\hline 187 & -18 & 217 & -6.6 & 247 & -4.3 \\
\hline 188 & -17 & 218 & -6.4 & 248 & -4.2 \\
\hline 189 & -16 & 219 & -6.2 & 249 & -4.1 \\
\hline 190 & -15 & 220 & -6 & 250 & -4 \\
\hline 191 & -14.5 & 221 & -5.9 & 251 & -3.9 \\
\hline 192 & -14 & 222 & -5.8 & 252 & -3.8 \\
\hline 193 & -13.5 & 223 & -5.7 & 253 & -3.7 \\
\hline 194 & -13 & 224 & -5.6 & 254 & -3.6 \\
\hline 195 & -12.5 & 225 & -5.5 & 255 & -3.5 \\
\hline 196 & -12 & 226 & -5.4 & 256 & -3.4 \\
\hline 197 & -11.5 & 227 & -5.3 & 257 & -3.3 \\
\hline 198 & -11 & 228 & -5.2 & 258 & -3.2 \\
\hline 199 & -10.5 & 229 & -5.1 & 259 & -3.1 \\
\hline 200 & -10 & 230 & -5 & 260 & -3 \\
\hline 201 & -9.8 & 231 & -5 & 261 & -2.95 \\
\hline 202 & -9.6 & 232 & -5 & 262 & -2.9 \\
\hline 203 & -9.4 & 233 & -5 & 263 & -2.85 \\
\hline 204 & -9.2 & 234 & -5 & 264 & -2.8 \\
\hline 205 & -9 & 235 & -5 & 265 & -2.75 \\
\hline 206 & -8.8 & 236 & -5 & 266 & -2.7 \\
\hline 207 & -8.6 & 237 & -5 & 267 & -2.65 \\
\hline 208 & -8.4 & 238 & -5 & 268 & -2.6 \\
\hline 209 & -8.2 & 239 & -5 & 269 & -2.55 \\
\hline 210 & -8 & 240 & -5 & 270 & -2.5 \\
\hline & & & & & \\
\hline
\end{tabular}


Apéndice D

\begin{tabular}{|l|r|r|r|r|r|}
\hline $\boldsymbol{\theta}$ & $\mathbf{R D}$ & $\boldsymbol{\theta}$ & $\mathbf{R D}$ & $\boldsymbol{\theta}$ & \multicolumn{1}{|c|}{ RD } \\
\hline 271 & -2.55 & 301 & -5 & 331 & -6.3 \\
\hline 272 & -2.6 & 302 & -5 & 332 & -6.6 \\
\hline 273 & -2.65 & 303 & -5 & 333 & -6.9 \\
\hline 274 & -2.7 & 304 & -5 & 334 & -7.2 \\
\hline 275 & -2.75 & 305 & -5 & 335 & -7.5 \\
\hline 276 & -2.8 & 306 & -5 & 336 & -7.8 \\
\hline 277 & -2.85 & 307 & -5 & 337 & -8.1 \\
\hline 278 & -2.9 & 308 & -5 & 338 & -8.4 \\
\hline 279 & -2.95 & 309 & -5 & 339 & -8.7 \\
\hline 280 & -3 & 310 & -5 & 340 & -9 \\
\hline 281 & -3.1 & 311 & -5.1 & 341 & -9.8 \\
\hline 282 & -3.2 & 312 & -5.2 & 342 & -10.6 \\
\hline 283 & -3.3 & 313 & -5.3 & 343 & -11.4 \\
\hline 284 & -3.4 & 314 & -5.4 & 344 & -12.2 \\
\hline 285 & -3.5 & 315 & -5.5 & 345 & -13 \\
\hline 286 & -3.6 & 316 & -5.6 & 346 & -13.8 \\
\hline 287 & -3.7 & 317 & -5.7 & 347 & -14.6 \\
\hline 288 & -3.8 & 318 & -5.8 & 348 & -15.4 \\
\hline 289 & -3.9 & 319 & -5.9 & 349 & -16.2 \\
\hline 290 & -4 & 320 & -6 & 350 & -17 \\
\hline 291 & -4.1 & 321 & -6 & 351 & -17.1 \\
\hline 292 & -4.2 & 322 & -6 & 352 & -17.2 \\
\hline 293 & -4.3 & 323 & -6 & 353 & -17.3 \\
\hline 294 & -4.4 & 324 & -6 & 354 & -17.4 \\
\hline 295 & -4.5 & 325 & -6 & 355 & -17.5 \\
\hline 296 & -4.6 & 326 & -6 & 356 & -17.6 \\
\hline 297 & -4.7 & 327 & -6 & 357 & -17.7 \\
\hline 298 & -4.8 & 328 & -6 & 358 & -17.8 \\
\hline 299 & -4.9 & 329 & -6 & 359 & -17.9 \\
\hline 300 & -5 & 330 & -6 & 360 & -18 \\
\hline & & & & & \\
\hline
\end{tabular}




\section{Apéndice $E$}

\section{E.1 Valores de calibración del cable Rohde \& Schwarz LA-}

\section{RG-214/U}

Tabla 10. Valores de la atenuación del cable R\&D LA-RG-214/U, en función de la frecuencia.

\begin{tabular}{|c|c|}
\hline FRECUENCIA & ATENUACIÓN \\
\hline $0,05 \mathrm{GHz}$ & $0,60 \mathrm{~dB}$ \\
\hline $1,0 \mathrm{GHz}$ & $0,93 \mathrm{~dB}$ \\
\hline $2,0 \mathrm{GHz}$ & $0,99 \mathrm{~dB}$ \\
\hline $3,0 \mathrm{GHz}$ & $1,86 \mathrm{~dB}$ \\
\hline $4,0 \mathrm{GHz}$ & $2,34 \mathrm{~dB}$ \\
\hline $5,0 \mathrm{GHz}$ & $3,09 \mathrm{~dB}$ \\
\hline $6,0 \mathrm{GHz}$ & $3,30 \mathrm{~dB}$ \\
\hline $7,0 \mathrm{GHz}$ & $4,36 \mathrm{~dB}$ \\
\hline $8,0 \mathrm{GHz}$ & $5,73 \mathrm{~dB}$ \\
\hline $9,0 \mathrm{GHz}$ & $7,37 \mathrm{~dB}$ \\
\hline $10,0 \mathrm{GHz}$ & $7,93 \mathrm{~dB}$ \\
\hline $11,0 \mathrm{GHz}$ & $9,94 \mathrm{~dB}$ \\
\hline $12,0 \mathrm{GHz}$ & $11,29 \mathrm{~dB}$ \\
\hline $13,0 \mathrm{GHz}$ & $12,63 \mathrm{~dB}$ \\
\hline $14,0 \mathrm{GHz}$ & $14,34 \mathrm{~dB}$ \\
\hline $15,0 \mathrm{GHz}$ & $15,77 \mathrm{~dB}$ \\
\hline $16,0 \mathrm{GHz}$ & $18,13 \mathrm{~dB}$ \\
\hline $17,0 \mathrm{GHz}$ & $19,63 \mathrm{~dB}$ \\
\hline $18,0 \mathrm{GHz}$ & $22,02 \mathrm{~dB}$ \\
\hline
\end{tabular}





\section{Apéndice F}

\section{F.1 Resultados de calibración de la antena bicónica PCD}

\section{0}

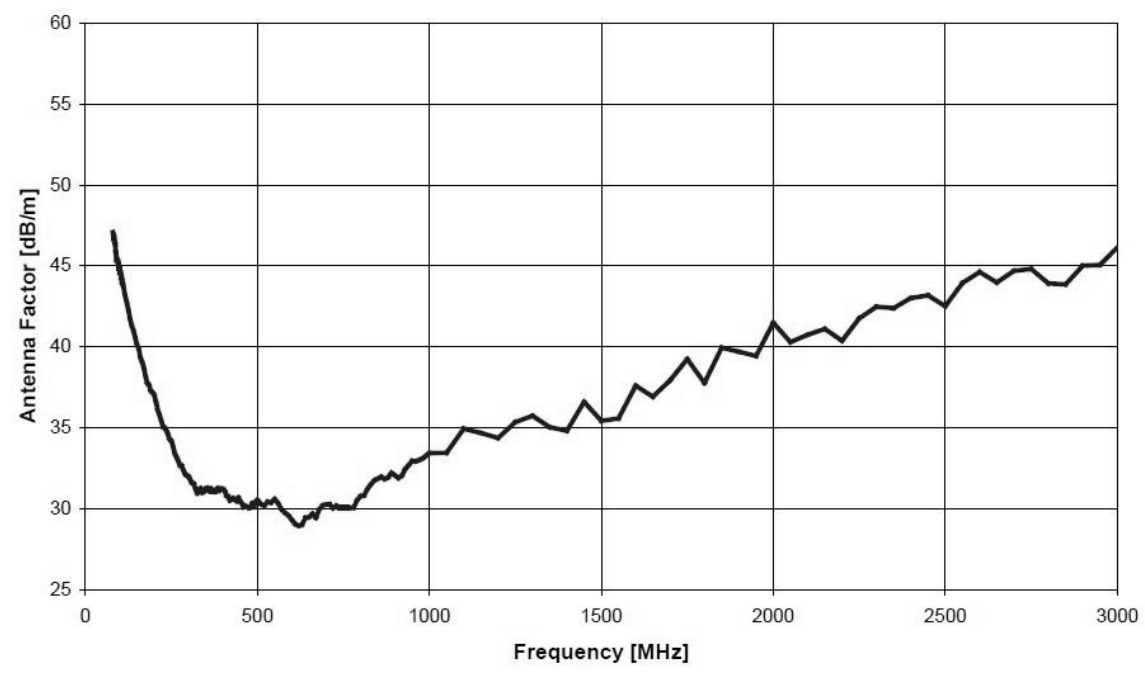

Figura 62.- Factor de antena para la antena bicónica PCD 8250 en función de la frecuencia. 
Apéndice F

Tabla 11. Valores del factor de antena para la antena bicónica PCD 8250, en función de la frecuencia.

\begin{tabular}{|c|c|c|c|c|c|}
\hline $\mathrm{f}[\mathrm{MHz}]$ & $A F[d B / m]$ & $\mathrm{f}[\mathrm{MHz}]$ & $A F[d B / m]$ & $\mathrm{f}[\mathrm{MHz}]$ & $\mathrm{AF}[\mathrm{dB} / \mathrm{m}]$ \\
\hline 80 & 47.09 & 140 & 40.98 & 320 & 31.22 \\
\hline 81 & 46.97 & 145 & 40.58 & 325 & 30.95 \\
\hline 82 & 46.70 & 150 & 40.13 & 330 & 31.17 \\
\hline 83 & 46.85 & 155 & 39.89 & 335 & 31.25 \\
\hline 84 & 46.66 & 160 & 39.34 & 340 & 30.98 \\
\hline 85 & 46.45 & 165 & 39.04 & 345 & 31.07 \\
\hline 86 & 46.46 & 170 & 38.67 & 350 & 31.24 \\
\hline 87 & 46.29 & 175 & 38.16 & 355 & 31.27 \\
\hline 88 & 45.88 & 180 & 37.77 & 360 & 31.10 \\
\hline 89 & 45.80 & 185 & 37.64 & 365 & 31.23 \\
\hline 90 & 45.62 & 190 & 37.29 & 370 & 31.07 \\
\hline 91 & 45.37 & 195 & 37.18 & 375 & 31.06 \\
\hline 92 & 45.31 & 200 & 37.03 & 380 & 31.17 \\
\hline 93 & 45.36 & 205 & 36.62 & 385 & 31.25 \\
\hline 94 & 45.29 & 210 & 36.11 & 390 & 31.12 \\
\hline 95 & 45.26 & 215 & 35.81 & 395 & 31.22 \\
\hline 96 & 45.15 & 220 & 35.44 & 400 & 31.20 \\
\hline 97 & 45.01 & 225 & 35.06 & 405 & 31.08 \\
\hline 98 & 44.84 & 230 & 35.01 & 410 & 30.80 \\
\hline 99 & 44.84 & 235 & 34.84 & 415 & 30.75 \\
\hline 100 & 44.58 & 240 & 34.60 & 420 & 30.51 \\
\hline 101 & 44.65 & 245 & 34.29 & 425 & 30.57 \\
\hline 102 & 44.57 & 250 & 34.18 & 430 & 30.63 \\
\hline 103 & 44.49 & 255 & 33.82 & 435 & 30.56 \\
\hline 104 & 44.44 & 260 & 33.39 & 440 & 30.47 \\
\hline 105 & 44.19 & 265 & 33.17 & 445 & 30.68 \\
\hline 106 & 44.18 & 270 & 32.94 & 450 & 30.46 \\
\hline 107 & 43.97 & 275 & 32.68 & 455 & 30.30 \\
\hline 108 & 43.95 & 280 & 32.65 & 460 & 30.10 \\
\hline 109 & 43.88 & 285 & 32.39 & 465 & 30.15 \\
\hline 110 & 43.75 & 290 & 32.15 & 470 & 30.10 \\
\hline 115 & 43.21 & 295 & 32.04 & 475 & 30.05 \\
\hline 120 & 42.77 & 300 & 31.99 & 480 & 30.08 \\
\hline 125 & 42.25 & 305 & 31.78 & 485 & 30.31 \\
\hline 130 & 41.72 & 310 & 31.60 & 490 & 30.11 \\
\hline 135 & 41.32 & 315 & 31.54 & 495 & 30.41 \\
\hline
\end{tabular}


Apéndice F

\begin{tabular}{|r|r|r|r|r|r|}
\hline $\mathbf{f}[\mathbf{M H z}]$ & $\mathbf{A F}[\mathbf{d B} / \mathbf{m}]$ & \multicolumn{1}{|c|}{$\mathbf{f}[\mathbf{M H z}]$} & \multicolumn{1}{|c|}{$\mathbf{A F}[\mathbf{d B} / \mathbf{m}]$} & $\mathbf{f}[\mathbf{M H z}]$ & $\mathbf{A F}[\mathbf{d B} / \mathbf{m}]$ \\
\hline 500 & 30.54 & 840 & 31.73 & 1900 & 39.70 \\
\hline 510 & 30.29 & 850 & 31.84 & 1950 & 39.43 \\
\hline 520 & 30.16 & 860 & 31.95 & 2050 & 40.29 \\
\hline 550 & 30.58 & 870 & 31.83 & 2100 & 40.75 \\
\hline 560 & 30.33 & 880 & 31.93 & 2150 & 41.10 \\
\hline 570 & 29.96 & 890 & 32.20 & 2200 & 40.38 \\
\hline 580 & 29.75 & 900 & 32.05 & 2250 & 41.76 \\
\hline 590 & 29.58 & 910 & 31.90 & 2300 & 42.48 \\
\hline 600 & 29.30 & 920 & 32.04 & 2350 & 42.40 \\
\hline 610 & 29.05 & 930 & 32.43 & 2400 & 43.02 \\
\hline 620 & 28.95 & 940 & 32.68 & 2450 & 43.18 \\
\hline 630 & 29.01 & 950 & 32.95 & 2500 & 42.52 \\
\hline 640 & 29.42 & 960 & 32.92 & 2550 & 43.95 \\
\hline 650 & 29.48 & 990 & 33.25 & 2600 & 44.62 \\
\hline 660 & 29.68 & 1000 & 33.43 & 2650 & 43.98 \\
\hline 670 & 29.44 & 1050 & 33.44 & 2700 & 44.69 \\
\hline 680 & 29.94 & 1100 & 34.94 & 2750 & 44.82 \\
\hline 690 & 30.19 & 1150 & 34.68 & 2800 & 43.92 \\
\hline 700 & 30.24 & 1200 & 34.36 & 2850 & 43.86 \\
\hline 710 & 30.26 & 1250 & 35.35 & 2900 & 45.01 \\
\hline 720 & 30.04 & 1300 & 35.74 & 2950 & 45.06 \\
\hline 730 & 30.17 & 1350 & 35.03 & 3000 & 46.13 \\
\hline 740 & 30.06 & 1400 & 34.80 & 2300 & 42.48 \\
\hline 750 & 30.07 & 1450 & 36.60 & 2350 & 42.40 \\
\hline 760 & 30.07 & 1500 & 35.42 & 2400 & 43.02 \\
\hline 770 & 30.04 & 1550 & 35.57 & 2450 & 43.18 \\
\hline 780 & 30.06 & 1600 & 37.60 & 2500 & 42.52 \\
\hline 790 & 30.52 & 1650 & 36.92 & 2300 & 42.48 \\
\hline 800 & 30.76 & 1700 & 37.93 & 2350 & 42.40 \\
\hline 810 & 30.81 & 1750 & 39.24 & 2400 & 43.02 \\
\hline 820 & 31.21 & 1800 & 37.76 & 2450 & 43.18 \\
\hline 830 & 31.49 & 1850 & 39.95 & 2500 & 42.52 \\
\hline & & & & & \\
\hline
\end{tabular}





\section{Apéndice G}

\section{G.1 Sistema de coordenadas esféricas, convenio}

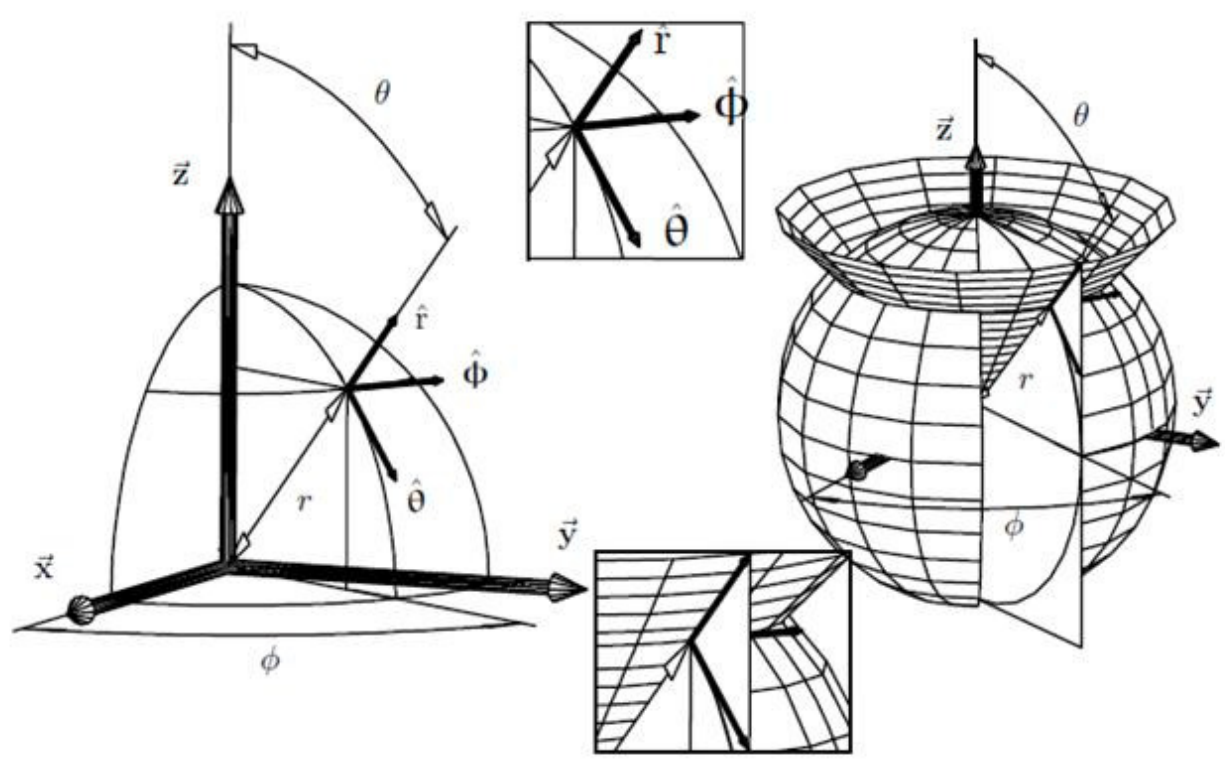

Figura 63.- Coordenadas esféricas, vectores unitarios. 
Apéndice G

Tabla 12. Descripción de los vectores unitarios en coordenadas esféricas.

\begin{tabular}{|c||c|c|}
\hline Unitarios & Perpendicular a & Tangente a \\
\hline \multirow{\theta}{\theta}{} & Conos: superficie $\theta=$ cte & Meridianos: $r=c t e_{1}, \phi=c t e_{2}$ \\
\hline$\hat{\phi}$ & Semiplanos: superficie $\phi=$ & Paralelos: $r=c t e_{1}, \theta=c t e_{2}$ \\
& cte & \\
\hline$\hat{r}$ & Esferas: superficie $r=c t e$ & $\begin{array}{c}\text { Generatriz cono: } \theta=c t e_{1}, \phi= \\
\text { cte } e_{2}\end{array}$ \\
\hline
\end{tabular}

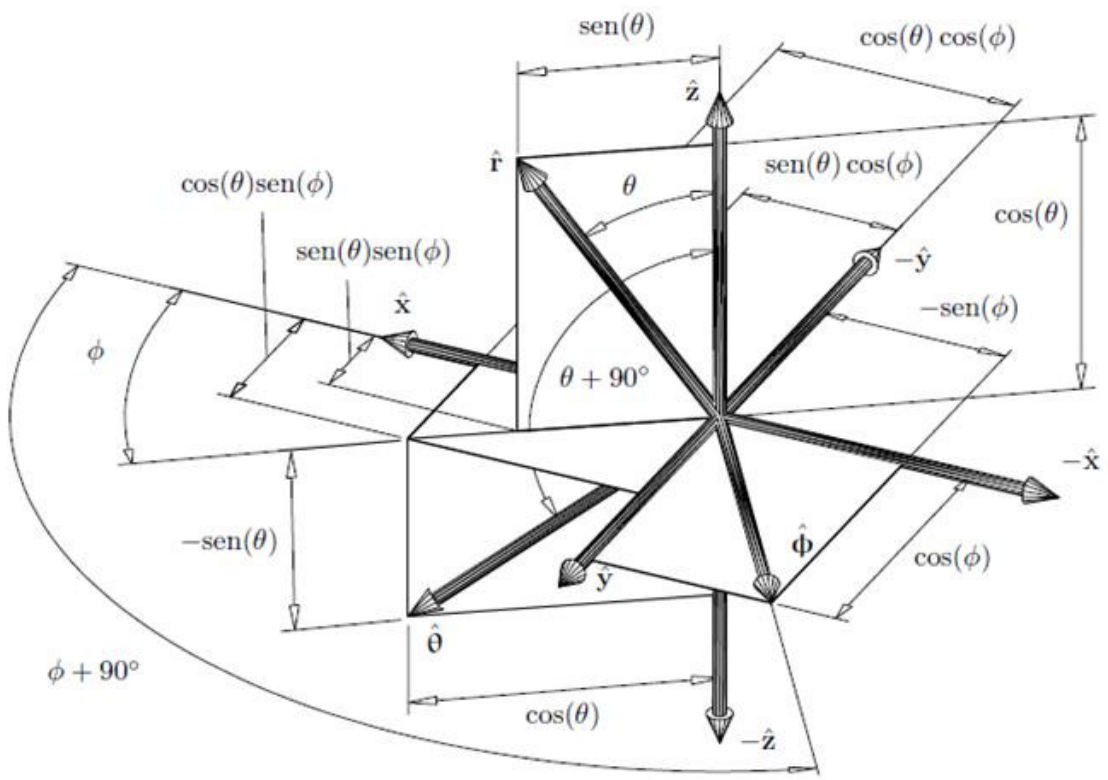

Figura 64.- Descripción gráfica del cambio de coordenadas esféricas-cartesianas. 
La expresión matricial del cambio de coordenadas de esféricas a cartesianas (ver Figura 64) que se indica a continuación:

$$
\left[\begin{array}{l}
\hat{r} \\
\hat{\theta} \\
\hat{\phi}
\end{array}\right]=\left[\begin{array}{ccc}
\operatorname{sen}(\theta) \cos (\phi) & \operatorname{sen}(\theta) \operatorname{sen}(\phi) & \cos (\theta) \\
\cos (\theta) \cos (\phi) & \cos (\theta) \operatorname{sen}(\phi) & -\operatorname{sen}(\theta) \\
-\operatorname{sen}(\phi) & \cos (\phi) & 0
\end{array}\right]\left[\begin{array}{l}
\hat{x} \\
\hat{y} \\
\hat{z}
\end{array}\right]
$$
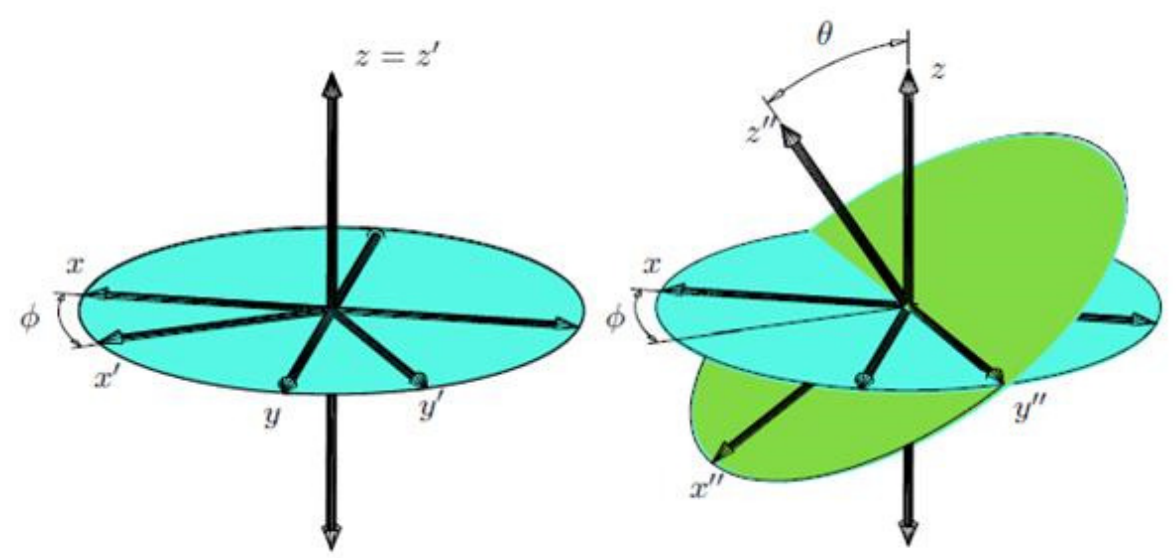

Figura 65.- Cambio de coordenada como rotación doble

La matriz indicada en la expresión anterior es una matriz ortogonal por lo que el cambio inverso se realiza mediante la matriz transpuesta:

$$
\left[\begin{array}{l}
\hat{x} \\
\hat{y} \\
\hat{z}
\end{array}\right]=\left[\begin{array}{ccc}
\operatorname{sen}(\theta) \cos (\phi) & \cos (\theta) \cos (\phi) & -\operatorname{sen}(\phi) \\
\operatorname{sen}(\theta) \operatorname{sen}(\phi) & \cos (\theta) \operatorname{sen}(\phi) & \cos (\phi) \\
\cos (\theta) & -\operatorname{sen}(\theta) & 0
\end{array}\right]\left[\begin{array}{c}
\hat{r} \\
\hat{\theta} \\
\hat{\phi}
\end{array}\right]
$$

El cambio de la base vectorial de cartesianas a esféricas se puede ver como una rotación doble del sistema de coordenadas local, tal y como se representa gráficamente en la Figura 65. 


$$
\left[\begin{array}{l}
\hat{r} \\
\hat{\theta} \\
\hat{\phi}
\end{array}\right]=\left[\begin{array}{ccc}
\operatorname{sen}(\theta) & 0 & \cos (\theta) \\
\cos (\theta) & 0 & -\operatorname{sen}(\theta) \\
0 & 1 & 0
\end{array}\right]\left[\begin{array}{ccc}
\cos (\phi) & \operatorname{sen}(\phi) & 0 \\
-\operatorname{sen}(\phi) & \cos (\phi) & 0 \\
0 & 0 & 1
\end{array}\right]\left[\begin{array}{c}
\hat{x} \\
\hat{y} \\
\hat{z}
\end{array}\right]
$$

La relación con las coordenadas cartesianas y esféricas se indica a continuación:

$$
\begin{gathered}
r=\sqrt{x^{2}+y^{2}+z^{2}} \\
\theta=\left\{\begin{array}{cc}
\arctan \frac{\sqrt{x^{2}+y^{2}}}{z} & z>0 \\
\frac{\pi}{2} & z=0 \\
\pi+\arctan \frac{\sqrt{x^{2}+y^{2}}}{z} & z<0
\end{array}\right. \\
\phi=\left\{\begin{array}{cc}
\arctan \frac{y}{x} & x>0, y>0 \\
2 \pi+\arctan \frac{y}{x} & x>0, y<0 \\
\frac{\pi}{2} \operatorname{sgn}(y) & x=0 \\
\pi+\arctan \frac{y}{x} & y<0
\end{array}\right.
\end{gathered}
$$

Las relaciones inversas se indican a continuación:

$$
\begin{gathered}
x=r \operatorname{sen} \theta \cos \phi \\
y=r \operatorname{sen} \theta \operatorname{sen} \phi \\
z=r \cos \phi
\end{gathered}
$$


Apéndice G 



\section{Referencias}

[AEN08] AENOR. UNE - EN 60601-1-2 Equipos electromédicos. Parte 1-2: requisitos generales para la seguridad básica y funcionamiento esencial. Norma colateral: Compatibilidad electromagnética. Requisitos y ensayos.

[Aer13] Aerts S, Deschrijver D, Joseph w, Verloock L, Goeminne F, Martens L, Dhaene T. Exposure Assessment of Mobile Phone Base Station Radiation in an Outdoor Environment Using Sequential Surrogate Modeling. Bioelectromagnetics 34(4):300-311, 2013.

[AGN12] AGNIR: Advisory Group on Non-ionizing Radiation. 2012. Health Effects from Radiofrequency Electromagnetic Fields. Report of the Advisory Group on Non-ionizing Radiation. Document of the Health Protection Agency. http://www.hpa.org.uk/webc/hpawebfile/hpaweb_c/13171338 27077. Ultimo acceso: julio de 2014.

[And10] Andersen JB, Mogensen PE, Pedersen GF. Power variations of wireless communication systems. Bioelectromagnetics, 31(4):302-310, 2010.

[Ath00] Athanasiadou GE, Nix AR. A novel 3-D indoor ray-tracing propagation model: The path generator and evaluation of narrow-band and wide-band predictions. IEEE Transactions 
on Vehicular Technology, 49(4):1152-1168, 2000.

[Bab00] Babich F, Lombardi G. Statistical analysis and characterization of the indoor propagation channel. IEEE Transactions on Communications, 48(3):455-464, 2000.

[Bah08] Bahillo A, Blas J, Fernández P, Lorenzo RM, Mazuelas S, Abril EJ. E-field assessment errors associated with RF dosemeters for different angles of arrival. Radiation Protection Dosimetry, 132(1):51-56, 2008.

[Bak10] Bakker JF, Paulides MM, Christ A, Kuster N, van Rhoon GC. Assessment of induced SAR in children exposed to electromagnetic plane waves between $10 \mathrm{MHz}$ and 5.6 GHz. Physics in Medicine and Biology, 55(11):3115-3130, 2010.

[Bar11] Barbiroli M, Carciofi C, Guiducci D. Assessment of Population and Occupational Exposure to Wi-Fi Systems: Measurements and Simulations. IEEE Transactions on Electromagnetic Compatibility, 53(1):219-228, 2011.

[Bec12] Bechet P, Miclaus S, Bechet AC. Improving the Accuracy of Exposure Assessment to Stochastic-like Radiofrequency Signals. IEEE Transactions on Electromagnetic Compatibility, 54(5):1169-1177, 2012.

[Bee13] Beekhuizen J, Vermeulen R, Kromhout H, Bürgi A, Huss A. Geospatial modelling of electromagnetic fields from mobile phone base stations. Science of Total Environment, 445446:202-209, 2013. 
[Bla07] Blas J, Lago FA, Fernandez P, Lorenzo RM, Abril EJ. Potential exposure assessment errors associated with bodyworn RF dosimeters. Bioelectromagnetics, 28(7):573-576, 2007.

[Bol11] Bolte JFB, van der Zande G, Kamer J. Calibration and uncertainties in personal exposure measurements of radiofrequency electromagnetic fields. Bioelectromagnetics, 32(8):652-663, 2011.

[Car11] Carranza N, Febles V, Hernández JA, Bardasano JL, Monteagudo JL, Fernández de Aldecoa JC, Ramos V. Patient safety and electromagnetic protection: A review. Health Physics, 100(5):530-541, 2011,

[Cat98] Catedra MF, Pérez J, Sáez de Adana F, Gutiérrez O. Efficient ray-tracing techniques for three-dimensional analyses of propagation in mobile communications: application to picocell and microcell scenarios. IEEE Antennas and Propagation Magazine, 40(2):15-28, 1998.

[CE99] 1999/519/CE. Recomendación del Consejo de 12 de julio de 1999, relativa a la limitación de exposición del público en general a campos electromagnéticos $(0 \mathrm{~Hz}$ a $300 \mathrm{GHz})$. Diario Oficial de las Comunidades Europeas 30.7.1999, pp L $199 / 59$

[Cis14-1] Cisco Aironet Antennas and Accessories. White Papers: Antenna Patterns and Their Meaning. Último acceso: febrero de 2014. 
http://www.cisco.com/c/en/us/products/collateral/wireless/airo net-antennasaccessories/prod_white_paper0900aecd806a1a3e.pdf

[Cis14-2] Cisco Aironet Antennas and Accessories Reference Guide. Product Data Sheet. Último acceso: marzo de 2014. http://www.cisco.com/c/en/us/products/collateral/wireless/airo net-antennasaccessories/product_data_sheet09186a008008883b.pdf

[Che98] Chen WT, Chuang HR. Numerical computation of human interaction with arbitrarily oriented superquadric loop antennas in personal communications. IEEE Transactions on Antennas and Propagation, 46(6):821-828, 1998.

[Cot07] Cotton SL, Scanlon WG. Characterization and Modeling of the Indoor Radio Channel at $868 \mathrm{MHz}$ for a Mobile Bodyworn Wireless Personal Area Network. IEEE Antennas and Wireless Propagation Letters 6:51-55, 2007.

[Cot09] Cotton S, Scanlon WG. An Experimental Investigation into the Influence of User State and Environment on Fading Characteristics in Wireless Body Area Networks at $2.45 \mathrm{GHz}$. IEEE Transactions on Wireless Communications, 8(1):6-12, 2009.

[DeA00] De Adana FS, Gutiérrez Blanco O, Diego IG, Pérez Arriaga J, Cátedra MF. Propagation model based on ray tracing for the design of personal communication systems in indoor environments. IEEE Transactions on Vehicular Technology, 
49(6):2105-2112, 2000.

[DeM13] De Miguel-Bilbao S, Martín MA, Pozo A, Febles V, Hernández JA, Fernández de Aldecoa JC, Ramos V. Analysis of exposure to electromagnetic fields in a healthcare environment: simulation and experimental study. Health Physics, 105(5):S209-S222, 2013.

[Dir04] Directiva 2004/40/CE del Parlamento Europeo y del Consejo, de 29 de abril de 2004 , sobre las disposiciones mínimas de seguridad y de salud relativas a la exposición de los trabajadores a los riesgos derivados de los agentes físicos (campos electromagnéticos)

[Dir08] Directiva 2008/46/CE del Parlamento Europeo y del Consejo, de 23 de abril de 2008 , por la que se modifica la Directiva 2004/40/CE sobre las disposiciones mínimas de seguridad y de salud relativas a la exposición de los trabajadores a los riesgos derivados de los agentes físicos (campos electromagnéticos).

[Dir12] Directiva 2012/11/UE del Parlamento Europeo y del Consejo, de 19 de abril de 2012, por la que se modifica la Directiva 2004/40/CE, sobre las disposiciones mínimas de seguridad y de salud relativas a la exposición de los trabajadores a los riesgos derivados de los agentes físicos (campos electromagnéticos)

[Dir13] Directiva 2013/35/UE del Parlamento Europeo y del Consejo, de 26 de junio de 2013, sobre las disposiciones mínimas de 
salud y seguridad relativas a la exposición de los trabajadores a los riesgos derivados de agentes físicos (campos electromagnéticos), y por la que se deroga la Directiva 2004/40/CE.

[ElH10] El Habachi A, Conil E, Hadjem A, Vazquez E, Wong MF, Gati A, Fleury G, Wiart J. Statistical analysis of whole-body absorption depending on anatomical human characteristics at a frequency of $2.1 \mathrm{GHz}$. Physics in Medicine and Biology, 55(7):1875-1887, 2010.

[Est14] Estenberg J, Augustsson t. Extensive frequency selective measurements of radiofrequency fields in outdoor environments performed with a novel mobile monitoring system, 35(3):227-230, 2014.

[EU11] 2011/829/EU. Commission Implementing Decision of 8 December 2011 amending Decision 2006/771/EC on harmonisation of the radio spectrum for use by short-range devices.

[EU13] 2013/752/UE: Decisión de Ejecución de la Comisión, de 11 de diciembre de 2013 , por la que se modifica la Decisión 2006/771/CE sobre la armonización del espectro radioeléctrico para su uso por dispositivos de corto alcance y se deroga la Decisión 2005/928/CE

[Fal14] Solución de la ecuación de Fresnel. Último acceso: julio de 2014. http://www.falstad.com.

[Fan10] Fang M, Malone D. Experimental verification of a 
radiofrequency power model for Wi-Fi technology. Health Physics, 98(4):574-583, 2010.

[Fin10] Findlay R, Dimbylow PJ. SAR in a child voxel phantom from exposure to wireless computer networks networks (Wi-Fi). Physics in Medicine and Biology, 55(15):N405-N411, 2010.

[For06] Fort A, Desset C, De Doncker P, Wambacq P, Van Biesen L. An ultra-wideband body area propagation channel model From statistics to implementation. IEEE Transactions on Microwave Theory and Techniques, 54(4):1820-1826, 2006.

[Fos96] Foschini GJ. Layered space-time architecture for wireless communication in a fading environment when using multielement antennas. Bell Labs Technical Journal, 1(2):41-59, 1996

[Fos13-1] Foster KR. A world awash with wireless devices: Radiofrequency exposure issues. IEEE Microwave Magazine, 14(2):73-84, 2013.

[Fos13-2] Foster KR, Moulder JE. Wi-fi and health: review of current status of research. Health Physics, 105(6):561-575, 2013.

[Gaj02] Gajsek P, Pakhomov AG, Klauenberg BJ. Electromagnetic field standards in central and eastern european countries: current state and stipulations for international harmonization. Health Physics, 82(4):473-483, 2002.

[Gha04] Ghaddar M, Talbi L, Denidni TA. Human body modellingmodeling for prediction of effect of people on indoor propagation channel. IEEE Electronics Letters, 
40(25):1592-1594, 2004.

[Gha07] Ghaddar M, Talbi L, Denidni TA, Sebak A. A conducting cylinder for modeling human body presence in indoor propagation channel. IEEE Transactions on Antennas Propagation, 55(11):3099-3103, 2007.

[Gra09] Grandolfo M. Worldwide standards on exposure to electromagnetic fields: an overview. Environmentalist, 29(2):109-117, 2009.

[Har99] Har D, Watson AM, Chadney AG. Comment on diffraction loss of rooftop-to-street in COST 231-Walfisch-Ikegami model. IEEE Transactions on Vehicular Technology, 48(5):1451-1452, 1999.

[Hat80] Hata M. Empirical formula for propagation loss in land mobile radio services. . IEEE Transactions on Vehicular Technology, 29(3):317-325, 1980.

[Hel06] Helsel DR. Fabricating data: How substituting values for nondetects can ruin results and what can be done about it. Chemosphere, 65(11):2434-2439, 2006.

[Hol00] Holm PD. A new heuristic UTD diffraction coefficient for nonperfectly conducting wedges. IEEE Transactions on Antennas and Propagation, 48(8):1211-1219, 2000.

[Hor86] Horikoshi J, Tanaka K, Morinaga T. $1.2 \mathrm{GHz}$ Band Wave Propagation Measurements in Concrete Building for Indoor Radio Communications. IEEE Transactions on Vehicular 
Technology, 35(4):146-152, 1986.

[Hua06] Huang Y, Talbi L, Charbonneau A, Denidni TA. Effect of Human Body Upon Line Of Sight Indoor Radio Propagation. Canadian Conference on Electrical and Computer Engineering, (CCECE), 1775-1778, 2006.

[ICN98] International Commission on Non-Ionizing Radiation Protection (ICNIRP). Guidelines for limiting exposure to time-varying electric, magnetic, and electromagnetic fields (up to $300 \mathrm{GHz}$ ). Health Physics, 74(4):494-522, 1998.

[IEE91] IEEE, Institute of Electronics and Electrical Engineers. 1991. IEEE recommended practice for the measurement of potentially hazardous electromagnetic fields- $\mathrm{RF}$ and microwave. Piscataway, NJ: IEEE Standard Association; IEEE C95.3, 1991.

[IEE99] IEEE, Institute of Electronics and Electrical Engineers. 1999. IEEE standard for safety levels with respect to human exposure to radio frequency electromagnetic fields, $3 \mathrm{kHz}$ to 300 GHz, IEEE Std C95.1-1991 (1999 Edition).

[Isk02] Iskander MF, Yun Z. Propagation Prediction Models for Wireless Communication Systems. IEEE Transactions on Microwave Theory and Techniques, 50(3):662:673, 2002.

[Isk10] Iskra S, McKenzie R, Cosic I. Factors influencing uncertainty in measurement of electric fields close to the body in personal RF dosimetry. Radiation Protection Dosimetry, 140(1):25-33, 2010 . 
[Ji01] Ji Z, Li B, Wang H, Chen H, Sarkar TK. Efficient ray-tracing methods for propagation prediction for indoor wireless communications. IEEE Antennas and Propagation Magazine, 43(2):41-49, 2001.

[Jos13] Joseph W, Pareit D, Vermeeren G, Naudts D, Verloock L, Martens L, Moerman I. Determination of the duty cycle of WLAN for realistic radio frequency electromagnetic field exposure assessment. Progress in Biophysics and Molecular Biology, 111(1):30-36, 2013.

[Kha11] Khalid M, Mee T, Peyman A, Addison D, Calderon C, Maslanyj M, Man S. Exposure to radio frequency electromagnetic fields from wireless computer networks: duty factors of Wi-Fi devices operating in schools. Progress in Biophysics and Molecular Biology, 107(3):412-420, 2011.

[Kna08] Knafl U, Lehmann H, Riederer M. Electromagnetic field measurements using personal exposimeters. Bioelectromagnetics, 29(2):160-162, 2008.

[Kou74] Kouyoumjian RG, Pathak PH. 1974. A uniform geometrical theory of diffraction for an edge in a perfectly conducting surface. Proceedings of the IEEE, 62(11):1448-1461, 1974.

[Küh09] Kühn S, Jennings W, Christ A, Kuster N. Assessment of induced radio-frequency electromagnetic fields in various anatomical human body models. Physics in Medicine and Biology, 54(4):875-890, 2009. 
[Lau12] Lauer O, Neubauer G, Röösli M, Riederer M, Frei P, Mohler E, Fröhlich J. Measurement setup and protocol for characterizing and testing radio frequency personal exposure meters. Bioelectromagnetics, 33(1):75-85, 2012.

[Lia98] Liang G, Bertoni HL. A new approach to 3-D ray tracing for propagation prediction in cities, IEEE Transactions on Antennas and Propagation, 46(6):853-863, 1998.

[Nec06] Nechayev YI, Constantinou CC. Improved heuristic diffraction coefficients for an impedance wedge at normal incidence. Microwaves, Antennas and Propagation, IEEE Proceedings, 153(2):125-132, 2006.

[Neu09] Neubauer G, Preiner P, Cecil S, Mitrevski N, Gorter J, Garn $\mathrm{H}$. The relation between the specific absorption rate and electromagnetic field intensity for heterogeneous exposure conditions at mobile communications frequencies. Bioelectromagnetics, 30(8):651-662, 2009.

[Neu10] Neubauer G, Cecil S, GicziW, Petric B, Preiner P, Fröhlich J, Röösli M. The association between exposure determined by radiofrequency personal exposimeters and human exposure: A simulation study. Bioelectromagnetics, 31(7):535-545, 2010.

[Oba98] Obayashi S, Zander J. A body shadowing model for indoor radio communication environments. IEEE Transactions on Antennas and Propagation, 46(6):920 927, 1998. 
[OBr00] O'Brien WM, Kenny EM, Cullen PJ. An efficient implementation of a three-dimensional microcell propagation tool for indoor and outdoor urban environments. IEEE Transactions on Vehicular Technology, 49(2):622-630, 2000.

[Oku68] Okumura Y, Ohmori E, Kawano T, Fukuda K. Field strength variability in VHF and UHF land mobile service. Review Electrical Communication. Laboratory, 16(9-10):825-873, 1968.

[Ose03] Osepchuk JM, Petersen RC. Historical review of RF exposure standards and the International Committee on Electromagnetic Safety (ICES). Bioelectromagnetics, Suppl 6:S7-S16, 2003.

[PCD14] PCD8250: Feature sheet of Biconical Antenna 8250 PCD. Ultimo acceso: julio de 2014. http://www.seibersdorflaboratories.at/fileadmin/uploads/PB_EH_PCD_31052012_en _FINAL_web.pdf.

[Pey11] Peyman A, Khalid M, Calderon C, Addison D, Mee T, Maslanyj M, Mann S. Assessment of exposure to electromagnetic fields from wireless computer networks (WiFi) in schools; results of laboratory measurements. Health Physics, 100(6):594-612, 2011.

[RD01] Real Decreto 1066/2001, de 28 de septiembre, por el que se aprueba el Reglamento que establece condiciones de protección del dominio público radioeléctrico, restricciones a las emisiones radioeléctricas y medidas de protección sanitaria frente a emisiones radioeléctricas. 
[Rep12] Repacholi M, Grigoriev Y, Bushmann J, Pioli C. Scientific basis for the soviet and russinan radiofrequency standards for the general public. Bioeletromagnetics, 33(8):623-633, 2012.

[Rod10] Rodríguez B, Blas J, Lorenzo RM, Fernández P, Abril EJ. Statistical perturbations in personal exposure meters caused by the human body in dynamic outdoor environments. Bioelectromagnetics, 32(3):209-217, 2010.

[Röö08] Röösli M, Frei P, Mohler E, Braun-Fahrländer C, Burgi A, Frohlich J, Neubauer G, Theis G, Egger M. Statistical analysis of personal radiofrequency electromagnetic field measurements with nondetects. Bioelectromagnetics, 29(6): 471-478, 2008.

[Röö10] Röösli M, Frei P, Bolte J, Neubauer G, Cardis E, Feychting M, Gajsek P, Heinrich S, Joseph W, Mann S, Martens L, Mohler E, Parslow RC, Poulsen AH, Radon K, Schüz J, Thuroczy G, Viel JF, Vrijheid M. Conduct of a personal radiofrequency electromagnetic field measurement study: proposed study protocol. Environmental Health, 9:23, 2010.

[Roy07] Roy CR, Martin LJ. A comparison of important international and national standards for limiting exposure to EMF including the scientific rational. Health Physics, 92(6):635-41, 2007.

[Sag09] Sage C, Carpenter DO. Public health implications of wireless technologies. Pathophysiology, 19:233-246, 2009. 
[San10] Sani A, Alomainy A, Palikaras G, Nechayev Y, Yang Hao, Parini C, Hall PS. Experimental characterization of UWB onbody radio channel in indoor environment considering different antennas. IEEE Transactions on Antennas Propagation, 58(1):238-241, 2010.

[Sar03] Sarkar TK, Zhong J, Kyungjung Kim, Medouri A, SalazarPalma M. A survey of various propagation models for mobile communication. IEEE Antennas and Propagation Magazine, 45(3):51-82, 2003.

[Sca01] Scanlon WG, Evans NE. Numerical analysis of bodyworn UHF antenna systems. Electronics \& Communication Engineering Journal, 13(2):53-64, 2001.

[Sei94] Seidel SY, Rappaport TS. Site-specific propagation prediction for wireless in-building personal communication system design. IEEE Transactions on Vehicular Technology, 43(4):879-891. 1994.

[Son99] Son H, Myung N. A deterministic ray tube method for microcellular wave propagation prediction model. IEEE Transactions on Antennas Propagation, 47(8):1344-1350, 1999.

[Spi96] Spitzer V, Ackerman MJ, Scherzinger AL, Whitlock D. The visible human male: A technical report. Journal of the American Medical Informatics Association, 3(2):118-130, 1996. 
[Spy14] EME Spy 121/100. Data sheet. Último acceso: marzo 2014. http://www.satimo.com/sites/www.satimo.com/files/EMF_E ME\%20Spy\%20121_2010_0.pdf.

[Tan96] Tan SY, Tan HS. A microcellular communications propagation model based on the uniform theory of diffraction and multiple image theory. IEEE Transactions on Antennas Propagation, 44(10):1317-1326, 1996.

[Tan09] Tang C, Chan K, Fung L, Leung S. Electromagnetic interference immunity testing of medical equipment to second and third generation mobile phones. IEEE Transactions on Electromagnetic Compatibility, 51(3):659-664, 2009.

[Tar98] Tarokh V, Seshadri N, Calderbank AR. Space-time codes for high data rate wireless communication: Performance criterion and code construction. IEEE Transactions on Information Theory, 44(2):744-765, 1998

[Thi13] Thielens A, De Clercq H, Agneessens S, Lecoutere J, Verloock L, Declercq F, Vermeeren G, Tanghe E, Rogier H, Puers R, Martens L, Joseph W. 2013. Personal distributed exposimeter for radio frequency exposure assessment in real environments. Bioelectromagnetics, 34(7):563-567, 2013.

[Thi14] Thielens A, Agneessens S, Verloock L, Tanghe E, Rogier H, Martens L, Joseph W. On-body calibration and processing for a combination of two radio-frequency personal exposimeters. Radiation Protection Dosimetry, 1-12, 2014. 
[Tof93] Toftgard J, Hornsleth SN, Andersen JB. Effects on portable antennas of the presence of a person. IEEE Transactions on Antennas and Propagation, 41(6):739, 1993.

[Tri04] Tri JL, Trusty JM, Hayes DL. Potential for Personal Digital Assistant interference with implantable cardiac devices. Mayo Clinic Proceedings, 79(12):1527-1530, 2004.

[Urb14] Urbinello D, Huss A, Beekhuizen J, Vermeulen R, Röösli M. Use of portable exposure meters for comparing mobile phone base station radiation in different types of areas in the cities of Basel and Amsterdam. Science of the Total Environment, 468-469C:1028-1033, 2014.

[Urd07] Urdiales-García C, García-Sigler F, Domínguez- Durán M, de-la-Torre J, Coslado-Aristizabal F, Pérez-Parras S, TraperoMiralles R, Sandoval-Hernández F. On practical issues about interference in telecare applications based on different wireless technologies. Telemedicine and e-Health, 13(5):519$533,2007$.

[Wal88] Walfisch J, Bertoni HL. A theoretical model of UHF propagation in urban environments. IEEE Transactions on Antennas and Propagation, 36(12):1788-1796, 1988.

[Wat08] Watanabe K, Hari S, Ohno K, Ikegami T. Experiments on Shadow Effects of Body and Effective Paths for UWB Transmission in BAN. International Symposium on Communications and Information Technologies (ISCIT), 232237, 2008 . 
[Wyn09] Wyne S, Singh PA, Tufvesson F. A Statistical Model for Indoor Office Wireless Sensor Channels. IEEE Transactions on Wireless Communication, 8(8):4154-4164, 2009.

[Zha09] Zhang R, Cai L, He S, Dong X, Pan J. Modeling, validation and performance evaluation of body shadowing effect in ultrawideband networks. Physical Communication, 2(4):237-247, 2009.

[Zho01] Zhong J, Bin-Hong L, Hao-Xing W, Hsing-Yi C, Tapan S. Efficient ray-tracing methods for propagation prediction for indoor wireless propagation. IEEE Transactions on Antennas and Propagation, 43(2):41-49, 2001.

[Zir04] Ziri-Castro KI, Scanlon WG, Evans NE. Indoor radio channel characterization and modeling for a $5.2-\mathrm{GHz}$ body worn receiver. IEEE Antennas and Wireless Propagation Letters, 3:219-222, 2004. 



\section{Índice de figuras}

Figura 1.- $\quad$ Niveles de referencia del ICNIRP para la exposición del público general y ocupacional. Se han indicado los niveles de referencia para la frecuencia particular de estudio: $2.4 \mathrm{GHz}$.

Figura 2.- Umbral de campo-E establecidos por el IEEE para ambientes controlados. Se han indicado los niveles de referencia para la frecuencia particular de estudio: $2.4 \mathrm{GHz}$.

Figura 3.- Umbral de campo-E establecidos por el IEEE para ambientes no controlados. Se han indicado los niveles de referencia para la frecuencia particular de estudio: $2.4 \mathrm{GHz}$. 32

Figura 4.- Cono de rayos y tubo de rayos. (a) Cono de rayos. (b) Tubo de rayos. 60

Figura 5.- Gráfico ilustrativo del método de las imágenes. 62

Figura 6.- Concepto básico de generación de imágenes y trazado de trayectos usando zonas de iluminación de las imágenes.

Figura 7.- Determinación del borde sobre el que incidirá el rayo en el método de división triangular .68

Figura 8.- $\quad$ Técnica híbrida 2D-3D en el trazado de rayos. .84

Figura 9.- $\quad$ Recinto en 2D, representado en el plano $(\mathrm{X}, \mathrm{Y})$, que se empleará para la obtención de los rayos entre el transmisor (BS) y el receptor (MS) mediante la teoría de las imágenes. .86 
Índice de figuras

Figura 10.- Secuencia de fases de 2D y 3D necesarias para obtener las coordenadas de los puntos de reflexión en superficies verticales (paredes), y horizontales (techo y suelo). 88

Figura 11.- Obtención en 2D de las coordenadas del punto de reflexión en una de las paredes. 90

Figura 12.- $\quad$ Obtención en 3D de la coordenada $\mathrm{Z}$ del punto de reflexión en una de las paredes. 92

Figura 13.- Obtención en 3D de la distancia con respecto al transmisor del punto de reflexión en el techo. 93

Figura 14.- Plano en 2D donde se indica las coordenadas (xr, yr) del punto de reflexión en una de las paredes. Se indica el punto de reflexión en el techo, cuya distancia respecto del transmisor es dCeilingTx.95

Figura 15.- Visualización del procedimiento de cálculo en las coordenadas del punto de reflexión en el techo, en el plano $(\mathrm{x}, \mathrm{y})$ 95

Figura 16.- Descripción del procedimiento de identificación de imágenes a lo largo del eje Z, según el formato $(\mathrm{x}, \mathrm{y}, \mathrm{z})$. 99

Figura 17.- Visualización del procedimiento de composición del rayo en un recinto de $3 \mathrm{D}$, y la matriz completa de imágenes. 100

Figura 18.- Visualización del procedimiento de composición del rayo en un recinto de $3 \mathrm{D}$ 101

Figura 19.- Visualización en 3D en la composición de los rayos siendo la imagen final $(0,-4,3)$, junto con la matriz global de imágenes alrededor de recinto 102 
Figura 20.- Visualización en 3D en la composición de los rayos siendo la imagen final $(0,-4,3)$. 103

Figura 21.- Esquema del recinto en dos dimensiones donde se ha llevado el primer experimento. 104

Figura 22.- $\quad$ Esquema gráfico de facetas que cumplen el criterio $n \cdot r \leq 0.106$

Figura 23.- $\quad$ Proyección en 2D del recinto donde se ha llevado a cabo el primer experimento. Área de visibilidad de la fuente principal. Imágenes secundarias con orden de recursividad igual a 2. 107

Figura 24.- Proyección en 2D del recinto donde se ha llevado a cabo el primer experimento. Área de visibilidad de la fuente secundaria generada por reflexión en la pared1. Se incluyen algunas imágenes secundarias con orden de recursividad igual a 2 . 107

Figura 25.- Árbol de visibilidad del recinto del primer experimento con un índice de recursividad igual a 2 . 108

Figura 26.- Recinto experimental. Numeración de las esquinas donde se produce el fenómeno de la difracción que actúan como fuentes secundarias.

Figura 27.- Posición del dosímetro respecto del cuerpo humano. Sección del modelo del cuerpo humano a la altura de $1.45 \mathrm{~m}$ [Spi96]

Figura 28.- $\quad$ Proyección en el plano $(\mathrm{x}, \mathrm{y})$ del cuerpo humano en el recinto de estudio. Se indica el ángulo de sombra para decidir si los rayos que llegan al receptor se van a ver afectados, o no, por el efecto sombra del cuerpo humano. 
Índice de figuras

Figura 29.- $\quad$ Plano de la componente $\theta$ del diagrama de radiación de la antena bicónica PCD8250, para diferentes frecuencias. 117

Figura 30.- Posición de la antena durante la realización del experimento en polarización vertical. 118

Figura 31.- Plano del pasillo donde se realizaron las primeras pruebas experimentales, incluyendo la posición de la fuente de radiación y la ruta predefinida. 123

Figura 32.- Plano del recinto donde se realizaron las medidas del segundo experimento, incluyendo la posición de la fuente de radiación y la ruta predefinida. 128

Figura 33.- Plano de los recintos donde se realizaron las mediciones de los experimentos tercero y cuarto. Se incluye la posición de la fuente de radiación y la ruta predefinida 130

Figura 34.- $\quad$ Trayecto realizado en las pruebas experimentales iniciales.... 133

Figura 35.- $\quad$ FDAs de las pruebas experimentales realizadas con tres dosímetros: un dosímetro situado a un metro de distancia del cuerpo humano (caso de no sombra), otro colocado en la parte delantera del cuerpo, y por último otro dosímetro ubicado detrás del usuario (caso de sombra). 133

Figura 36.- $\quad$ Los datos experimentales y los resultados de la simulación para los casos de (a) no-sombra y (b) sombra, del primer experimento. Los niveles medios de campo-E $(\mathrm{V} / \mathrm{m})$ se muestran mediante líneas horizontales. 137 
Figura 37.- $\quad$ FDA de los resultados simulados y las medidas experimentales del primer experimento. 139

Figura 38.- Variación del p-valor en función del ángulo de azimut en el primer experimento.

Figura 39.- $\quad$ Los datos experimentales y los resultados de la simulación para los casos de (a) no-sombra y (b) sombra, para el segundo experimento siendo la potencia de transmisión $20 \mathrm{dBm}$.

Figura 40.- $\quad$ Los datos experimentales y los resultados de la simulación para los casos de (a) no-sombra y (b) sombra, para el segundo experimento siendo la potencia de transmisión $25 \mathrm{dBm}$. Los niveles medios de campo-E (V/m) se muestran mediante líneas horizontales. .... 143

Figura 41.- $\quad$ FDAs de los resultados simulados y las medidas experimentales del segundo experimento. 145

Figura 42.- Variación del p-valor en función del ángulo de azimut en el segundo experimento.

Figura 43.- Los datos experimentales y los resultados de la simulación para los casos de (a) no-sombra y (b) sombra, para el tercer experimento siendo la potencia de transmisión $25 \mathrm{dBm}$. Los niveles medios de campo-E (V/m) se muestran mediante líneas horizontales. .... 148

Figura 44.- $\quad$ Los datos experimentales y los resultados de la simulación para los casos de (a) no-sombra y (b) sombra, para el cuarto experimento siendo la potencia de transmisión $25 \mathrm{dBm}$. Los niveles medios de campo-E $(\mathrm{V} / \mathrm{m})$ se muestran mediante líneas horizontales. .... 149

Figura 45.- $\quad$ FDAs de los resultados simulados y las medidas experimentales del tercer experimento. 150 
Índice de figuras

Figura 46.- $\quad$ FDAs de los resultados simulados y las medidas experimentales del cuarto experimento 151

Figura 47.- Los datos experimentales para los casos de (a) no-sombra y (b) sombra, para el segundo experimento siendo la potencia de transmisión $25 \mathrm{dBm}$, y la polarización de la antena horizontal. Los niveles medios de campo-E $(\mathrm{V} / \mathrm{m})$ se muestran mediante líneas horizontales.

Figura 48.- (a) Reflexiones causadas por las fuentes secundarias del cuerpo humano, teniendo en cuenta el efecto de dispersión en recintos cerrados, (b) en contraposición se muestra lo que sucedería en el espacio libre donde las reflexiones de los rayos dispersados por el cuerpo humano no llegan al dosímetro ubicado en la región de sombra del usuario. 156

Figura 49.- Dependencia del ECM y MBE en función del valor del ángulo de sombra 163

Figura 50.- $\quad$ Ajuste de los resultados experimentales para el primer experimento con las distribuciones estadísticas típicas en entornos interiores para los casos de: (a) no-sombra, (b) sombra. 165

Figura 51.- Ajuste de los resultados de la simulación para el primer experimento con las distribuciones estadísticas típicas en entornos interiores para los casos de: (a) no-sombra, (b) sombra. 166

Figura 52.- Comparación entre las medidas experimentales con sombra, los resultados de la simulación sin sombra, y la corrección de la incertidumbre de la sombra mediante el factor de corrección. 171 
Índice de figuras

Figura 53.- Comparación entre los resultados experimentales sin sombra y con sombra aplicando factores de corrección. 172

Figura 54.- $\quad$ Polarización horizontal, o soft. Corte por el plano de incidencia.190

Figura 55.- $\quad$ Polarización vertical, o hard. Corte por el plano de incidencia.191

Figura 56.- Geometría del rayo incidente y difractado por una esquina.... 194

Figura 57.- $\quad$ Sistema de coordenadas esféricas de referencia para una antena203

Figura 58.- Diagrama de radiación. Se indican los nulos y los diferentes tipos de lóbulos. .205

Figura 59.- $\quad$ Diagrama de radiación de una antena isotrópica.....................207

Figura 60.- $\quad$ Diagrama de radiación de una antena omnidireccional...........213

Figura 61.- $\quad$ Diagrama de radiación de una antena direccional ...................214

Figura 62.- $\quad$ Factor de antena para la antena bicónica PCD 8250 en función de la frecuencia. ..................................................................... 221

Figura 63.- Coordenadas esféricas, vectores unitarios............................225

Figura 64.- Descripción gráfica del cambio de coordenadas esféricas-

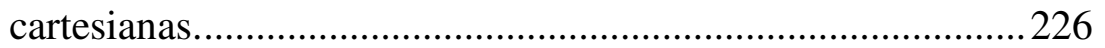

Figura 65.- Cambio de coordenada como rotación doble ..........................2227 

Índice de tablas

\section{Índice de tablas}

Tabla 1. Límites de exposición establecidos por el ICNIRP y el IEEE para la frecuencia Wi-Fi de $2.4 \mathrm{GHz}$ 32

Tabla 2. Comparación de los principales modelos de pérdidas de propagación. .75

Tabla 3. Parámetros electromagnéticos empleados en la simulación.......85

Tabla 4. Dimensiones, volumen total, y el valor del ángulo de sombra que mejor modela el efecto sombra en términos del KS test, para cada uno de los recintos interiores. 158

Tabla 5. P-valores proporcionados por la prueba de KS entre las FDAs del campo-E obtenidas en el primer experimento, y las distribuciones estadísticas más típicas de los ambientes interiores. 166

Tabla 6. P-valores proporcionados por la prueba de KS entre las FDAs del campo-E, obtenidas en el segundo experimento, y las distribuciones estadísticas más típicas de los ambientes interiores. 167

Tabla 7. P-valores proporcionados por la prueba de KS entre las FDAs del campo-E, obtenidas en el tercer experimento, y las distribuciones estadísticas más típicas de los ambientes interiores. 168

Tabla 8. P-valores proporcionados por la prueba de KS entre las FDAs del campo-E, obtenidas en el cuarto experimento, y las distribuciones estadísticas más típicas de los ambientes interiores. 169 
Índice de tablas

Tabla 9. Valores del diagrama de radiación de la antena bicónica PCD 8250 en función de la componente de elevación, $\theta$. 215

Tabla 10. Valores de la atenuación del cable R\&D LA-RG-214/U, en función de la frecuencia. 219

Tabla 11. Valores del factor de antena para la antena bicónica PCD 8250, en función de la frecuencia. 222

Tabla 12. Descripción de los vectores unitarios en coordenadas esféricas.226 


\section{Acrónimos y abreviaturas}

2D

3D

AoA

ARPANSA

Campo-E

CDF

CEM

DSSS

ECM

EE

EEUU

EMC

EMF

EMI

FCC

FDA
Dos Dimensiones

Tres Dimensiones

Angle of Arrival

Australian Radiation Protection and Nuclear Safety

Agency

Campo Eléctrico

Cumulative Distribution Function

Campos Electromagnéticos

Direct-Sequence Spread Spectrum

Error Cuadrático Medio

Europa del Este

Estados Unidos

Electromagnetic Compatibility

Electromagnetic Field

Electromagnetic Interference

Federal Communications Commission

Función de Distribución Acumulada 
FDTD

FHSS

FM

GO

GSM

GTD

IARC

ICNIRP

IEEE

ISM

KS

LoS

MBE

MIMO

MoM

NLoS

OFDM

OMS

PCD

PIRE
Finite-Difference Time-Domain

Frequency Hopping Spread Spectrum

Frecuencia Modulada

Geometrical Optics

Global System for Mobile Communications

Geometrical Theory of Difraction

International Agency for Research on Cancer

International Commission on Non-ionizing

Radiation Protection

Institute of Electrical and Electronics Engineers

Industrial-Scientific-Medical

Kolmogorov-Smirnov

Line of Sight

Mean Bias Error

Multiple-Input Multiple-Output

Method of Moments

Non line of sight

Orthogonal Frequency Division Multiplexing

Organización Mundial de la Salud

Precision Conical Dipole

Potencia Isótropa Radiada Equivalente 


$\begin{array}{ll}\text { QoS } & \text { Quality of Service } \\ \text { RBF } & \text { Radial Base Function } \\ \text { RF } & \text { Radiofrecuencia } \\ \text { RNAs } & \text { Redes Neuronales Artificiales } \\ \text { ROE } & \text { Relación de Onda Estacionaria } \\ \text { SAR } & \text { Specific Absorption Rate } \\ \text { UMTS } & \text { Universal Mobile Telecommunications System } \\ \text { UTD } & \text { Uniform Theory of Difraction } \\ \text { VT } & \text { Visibility Tree } \\ \text { WHO } & \text { World Health Organization } \\ \text { WLAN } & \text { Wireless Local Area Networks }\end{array}$

